\title{
THE ACQUISITION OF QUESTIONS BY INDONESIAN ADULT LEARNERS OF ENGLISH AS A FOREIGN LANGUAGE
}

\author{
By \\ M. ZAIM \\ Drs (IKIP Padang) \\ MHum (University of Indonesia, Jakarta)
}

A dissertation submitted to the Faculty of Education University of Tasmania at Launceston in partial fulfilment of the requirements for the degree of Doctor of Education $(E d D)$ in Educational Linguistics

\author{
FACULTY OF EDUCATION \\ UNIVERSITY OF TASMANIA AT LAUNCESTON
}

October 1998 
We learn by asking questions.

We learn better by asking better questions.

We learn more by having opportunities to ask more questions.

(Morgan \& Saxton, 1991) 
v.

This dissertation is dedicated to:

my wife, Yartis

my son, Rifqi Aulia Zaim

my son, Ryanda Luthfi Zaim

and

my parents, brothers, and sisters who always pray for my success. 


\section{TABLE OF CONTENTS}

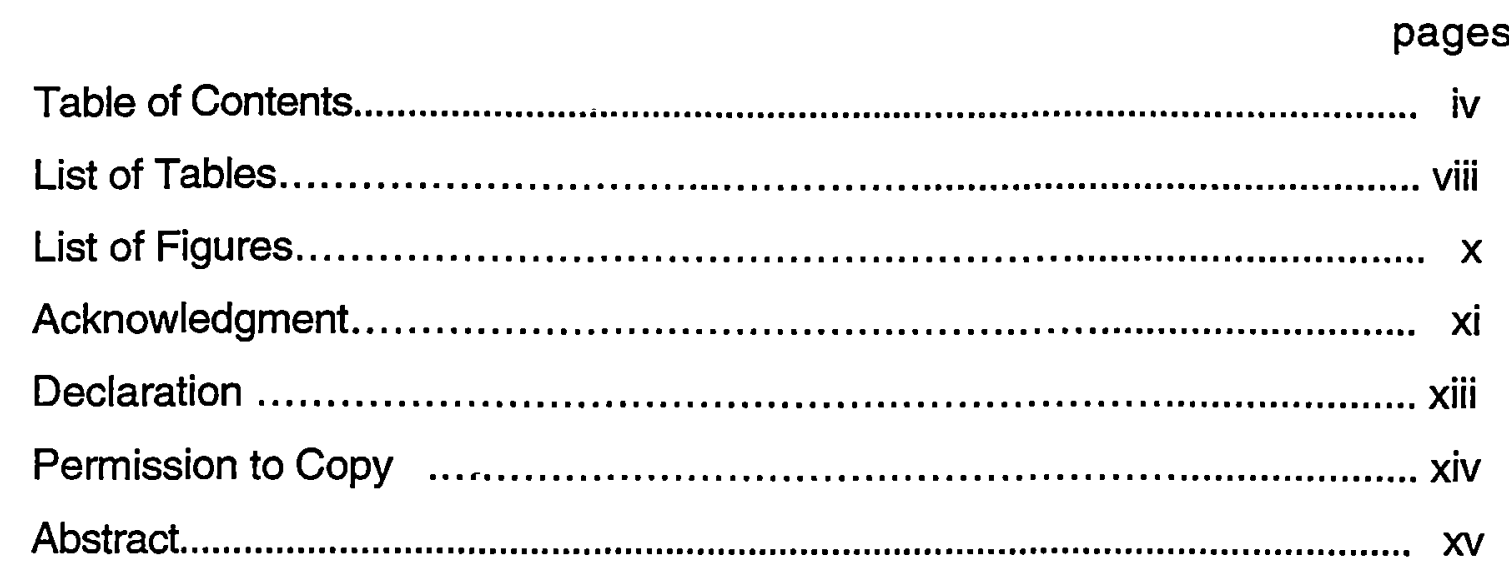

\section{CHAPTER 1 INTRODUCTION}

1.1 Nature, scope, and background of this study .................................. 1

1.1.1 Teaching English as a foreign language in Indonesia ............. 2

1.1.2 Questioning as a part of the teaching-learning process ........... 4

1.1.3 Interlanguage development in the classroom environment ..... 7

1.2 The Purpose and Significance of this Study........................ 9

1.3 Questions to be Answered ........................................... 10

1.4 Definitions of Key Terms ..................................................................... 11

1.5 Chapter Outlines ..............................................................................12

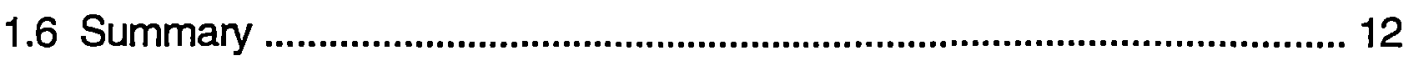

\section{CHAPTER 2 LITERATURE REVIEW}

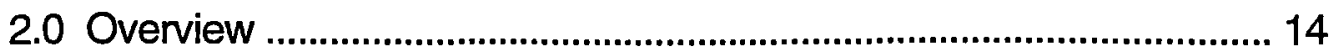

2.1 Language acquisition....................................... 14

2.1.1 Theories of language acquisition .................................... 14

2.1.2 Adult language acquisition and learning .......................... $16^{-}$

2.2. The Acquisition of Questions in the Classroom Environment .... 17

2.2.1 Conditions that enable learners to acquire a language ... 17

2.2.2 Teaching strategies...................................... 19 
2.2.2.2 Communicative language teaching .......................... 22

2.3 Types of Questions ...................................................................... 24

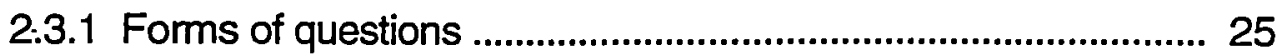

2.3.2 Contents of Questions ................................................ 25

2.3.3 Functions of Questions .......................................................... 26

2.4 Stages of the acquisition of question forms in English ................. 29

2.5 Types of errors ....................................................... 32

2.6 Teachers' responses........................................... 36

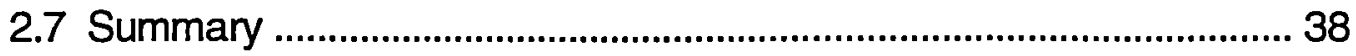

\section{CHAPTER 3 QUESTIONS IN ENGLISH AND INDONESIAN}

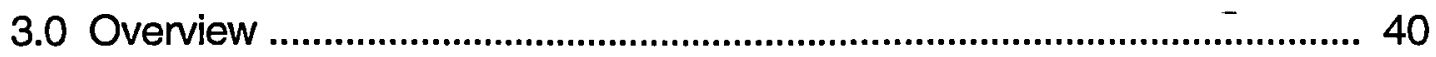

3.1 English Question Formation .................................................................... 40

3.2 Indonesian Question Formation ............................................................ 42

3.2.1 Five ways of question formation in Indonesian .......................... 43

3.2.2 Types of question forms in Indonesian ........................................ 46

3.3 Contrastive Analysis of English and Indonesian Question

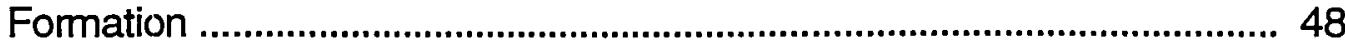

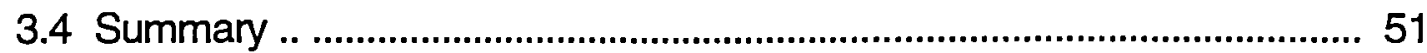

\section{CHAPTER 4 METHODOLOGY}

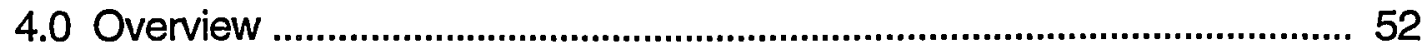

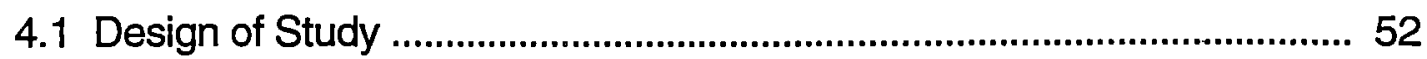

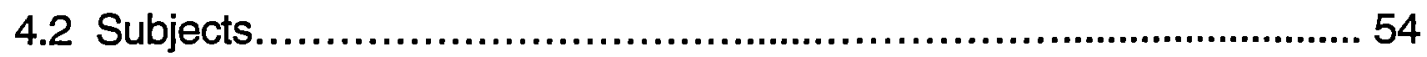

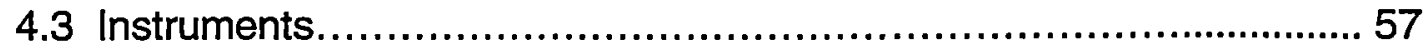

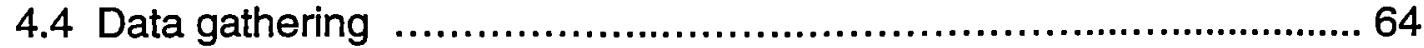

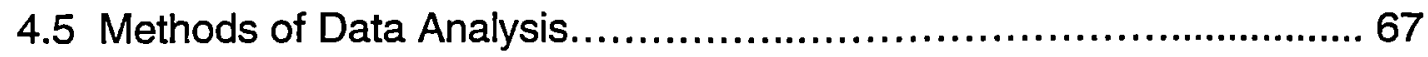

4.6 Summary ................................................................................................ 71 


\section{CHAPTER 5 DATA ANALYSIS AND RESULTS}

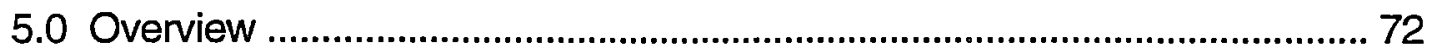

5.1 The acquisition of question forms in classroom interaction ...............72

5.1.1 The conditions that enable learners to acquire questions in classroom interaction .......................................................... 73

5.1.2 Teaching strategies used by teachers to enable learners to ask questions in English .................................... 89

5.1.3 Teaching strategies for encouraging learners to ask

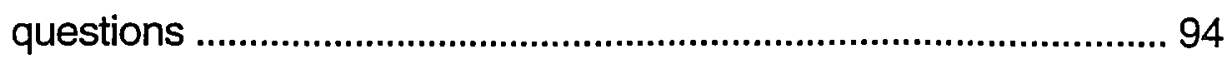

5.1.4 The frequency of questions in classroom interaction .............. 95

5.2 Types of questions most frequently used in teaching-learning process

5.2.1 Types of forms of questions most frequently used in

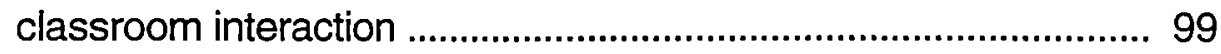

5.2.2 Types of contents of questions most frequently used in classroom interaction 101

5.2.3 Types of functions of questions most frequently used in classroom interaction ............................................................. 104

5.3 Types of errors ...................................................... 107

5.3.1 Types of errors usually made by Indonesian adult learners in forming questions in English ................................ 107

5.3.2 The cause of error occurrences .............................. 120

5.4 Teachers' Responses ................................................ 126

5.4.1 Teachers' responses to learners' questions .......................126

5.4.2 Types of responses to the questions made by learners .......... 128

5.5 The development of question forms .................................... 132

5.5.1 The sequential stages of the question forms of Indonesian adult learners 132

5.5.2 The interpretation of the results in relation to a universal pattern of development of question forms 156 


\section{CHAPTER 6 DISCUSSION}

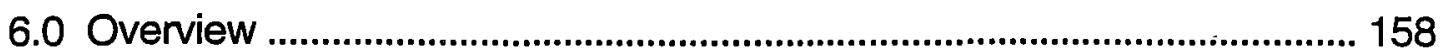

6.1 The acquisition of question forms in classroom interactions ...............158

6.1.1 The conditions that enable learners to acquire questions .......158

6.1.2 Questions in classroom interactions ...........................................163

6.2 The development of question forms of Indonesian adult learners ......171

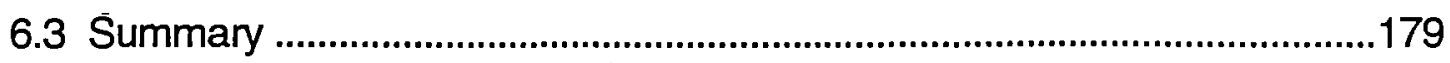

\section{CHAPTER 7 CONCLUSIONS}

7.1 The Research Study and Results .........................................180

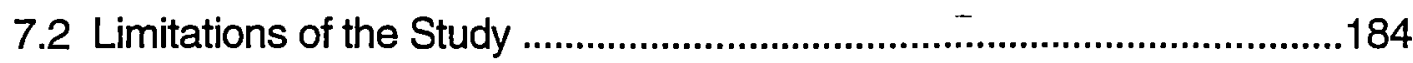

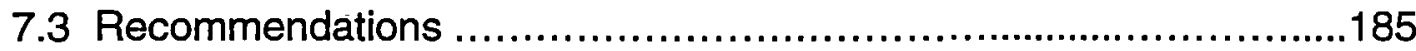

7.4 Avenue for Further Research ............................................................... 186

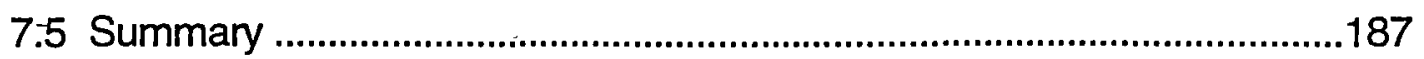

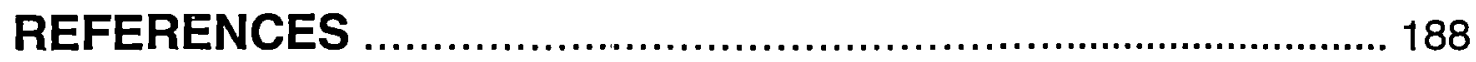

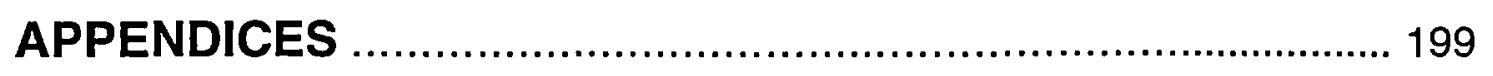

A. Leamers' Questionnaire ......................................................................... 200

B. Teachers' Questionnaire ..................................................................... 204

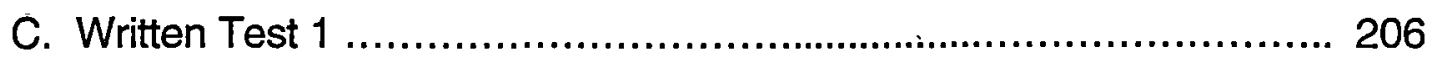

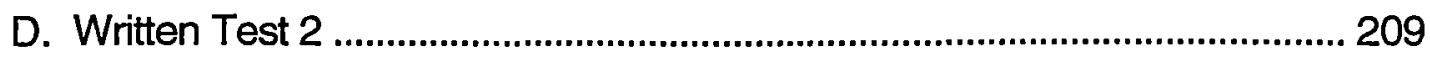

E. Written Test 3 ....................................................................................... 211

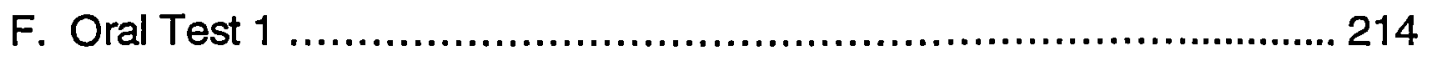

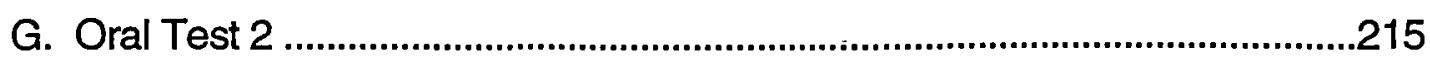

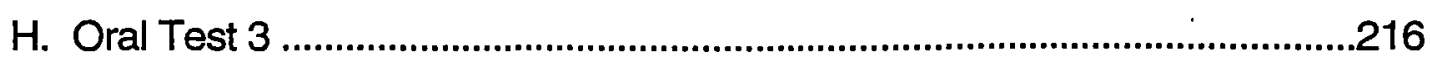

1. Guiding Questions for Interviewing Teachers ..........................................217

J. Guiding Questions for interviewing Learners ..............................218 


\section{LIST OF TABLES}

\section{Table}

$1 \quad$ Similarities and differences in forming questions in English and Indonesian 50

2 Distribution of subjects observed in classroom interaction .............. 55

3 Subjects studied longitudinally ...................................................... 56

4 Description of each indicator into question items ............................. 59

5 The mean scores of teacher questionnaires .................................... 75

6 The mean scores of learner questionnaires ...................................... 79

7 The frequency of questions produced by learners in classroom

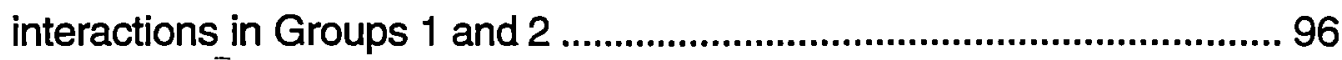

8 The frequency of questions produced by learners in classroom interactions in Group 1 .................................................................... 96

9 The frequency of questions produced by learners in classroom interactions in Group 2

10 Types of question forms frequently used by learners in classroom interactions in Groups 1 and 2

11 Types of question forms frequently used by learners in classroom interactions in Group 1

12 Types of question forms frequently used by learners in classroom interactions in Group 2 100

13 Types of questions frequently used in classroom interactions based on hierarchical structure of thinking in Groups 1 and 2

14 Types of questions frequently used in classroom interactions based on hierarchical structure of thinking in Group 1

15 Types of questions frequently used in classroōm interactions based on hierarchical structure of thinking in Group 2 103

16 Functions of questions frequently used by the learners in Groups 1 and 2 
17 Function of questions frequently used by learners in Group 1 .......... 106

18 Function of questions frequently used by learners in Group 2 .......... 106

19 Correct and incorrect questions produced by learners in classroom

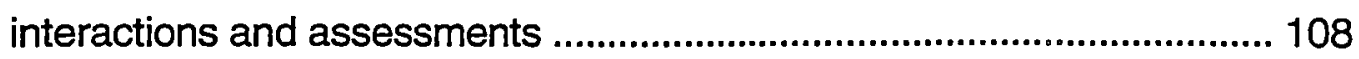

20 Types of errors made by learners in forming questions in English ... 109

21 The development of questions by Group 1 of Indonesian adult leamers of $E F L$ in percentage (\%) 133

22 The development of questions by Group 2 of Indonesian adult leamers of $\mathrm{EFL}$ in percentage (\%) 134 


\section{LIST OF FIGURES}

Figure

page

1 Classroom conditions according to teachers of groups 1 and $2 \ldots \ldots \ldots . .76$

2 Classroom conditions according to teachers per questionnaire item .. 77

3 Classroom conditions according to learners in each class for groups 1 and 2

4 Classroom conditions according to learners of group 1 by questionnaire item

5 Classroom conditions according to learners of group 2 by questionnaire item 83

6 Question Development of L1 137

7 Question Development of $L 2$. 138

8 Question Development of L3 140

9 Question Development of L4 ............................................................... 141

10 Question Development of L5 ............................................................ 142

11 Question Development of L6 ............................................................. 143

12 Question Development of L7 ............................................................ 145

13 Question Development of L8 ……....................................................... 146

14 Question Development of S1 ............................................................. 147

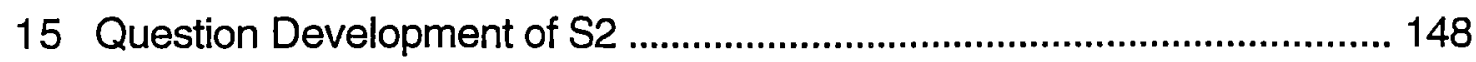

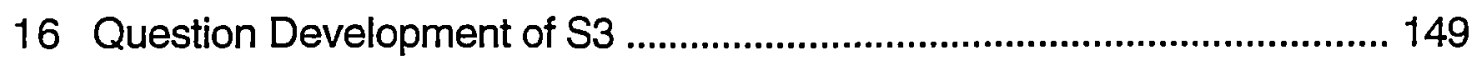

17 Question Development of S4 ……………............................................... 151

18 Question Development of S5 ............................................................... 152

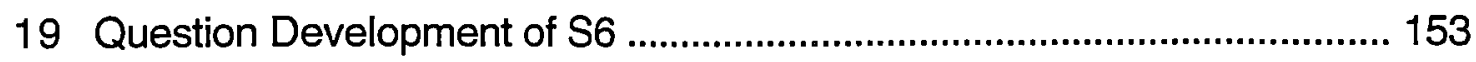

20 Question Development of S7 .............................................................. 154

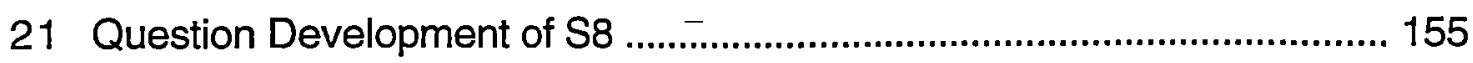




\section{ACKNOWLEDGMENTS}

Many individuals and institutions have helped me during the completion of this dissertation. I should like to acknowledge and thank them all.

I wish to express my whole-hearted thanks and gratitude to:

- My supervisors, Dr. Thao Le and Dr. Marion Myhill, whose assistance, guidance and constructive criticism has proved invaluable during the preparation of this dissertation.

- Prof John Williamson, the coordinator of EdD program, who has provided me with all facilities in the Faculty of Education, University of Tasmania that enabled me to fulfil the course work requirements and finish this dissertation.

- Rector of IKIP Padang, Drs. Mohd. Ansyar, Ph.D, the Vice Rector of Academic Studies, Drs. Azmi, M.A., Ph.D, and the Head of BOKS, Drs. Zainil, MA, Ph.D, who gave me the opportunity to study at the University of Tasmania at Launceston by providing me with a scholarship.

- Dr. Agustiar Syah Nur, M.A., the former dean of FPBS IKIP Padang, and Drs. Zainuddin Amir, the former chairman of the English Department of IKIP Padang and the present dean of FPBS IKIP Padang who have always encouraged me to continue my education with the doctorate program and gave me permission to take leave from my teaching job.

- Drs. Zainil, M.A., Ph.D and Dr. Anas Yasin, M.A., my advisers while conducting research in Padang, who have given assistance and guidance in conducting this research in the field.

- Learners of both groups at the English Department of IKIP Padang and English Training Centre of IAIN, without whose help this study could not have been made. 
- Loren Douglas, Jeffry Tapp, Dra. Hermawati Syarif, Dra. Rahmah Apen, Dra. Yenni Rozimella, M.Ed., and Drs. Rusdi Thaib, M.A. who gave me permission to observe in their classes both in IKIP and IAIN, and to use their students as the subjects of this research.

- Dr. Ismet Fanany and Dr. Rabecca Fanany whose help and support have proved invaluable during course work study and preparation of the earliest version of this dissertation.

- Megan Lee for the major role she had in spending many hours reading the draft of this dissertation and advising me on the finer points of the English language.

- My colleagues Nizwardi Jalinus, Nusirjan, Chalid Marzuki, Marjohan, and Azwar Ananda, the first group of the EdD program at the University of Tasmania, who offered comments, and support during course work study in the EdD program and preparation of this dissertation.

- My father, the late Drs. R. M. Zuhdan, who always supported my academic endeavours, my mother, Anidar, who played a important role in guiding, encouraging and helping me to achieve my professional goals, and my brothers and sisters for their encouragement, and constant support.

- My wife, Yartis, S.Pd, and my sons Rifqi Aulia Zaim, and Ryanda Luthfi Zaim for their help, support, patience, and constant encouragement offered during the many hours of working to prepare and produce this dissertation. 


\section{DECLARATION}

I declare that this dissertation does not contain material which has been accepted for the award of any other degree or diploma in any university; nor does it contain material previously published or written by any other person, except where due reference is made in the text of the dissertation.

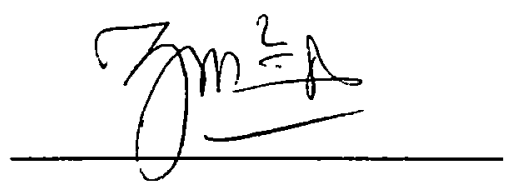

M. Zaim 


\section{PERMISSION TO COPY}

I hereby give permission to the staff of the University library and to the staff and students of the Faculty of Education within the University of Tasmania to copy this dissertation in whole or in part without reference to me. This permission covers only single copies made for study purposes, subject to the normal conditions of acknowledgment.

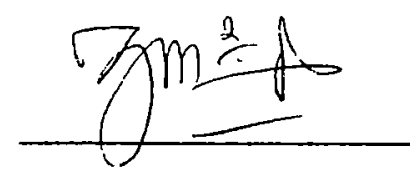

M. Zaim 


\section{ABSTRACT}

Questions, as a sentence form that functions to elicit information, are important to examine both semantically and syntactically. Semantically, a single question form may have different functions in communication which may create problems if the question is not appropriately used. Syntactically, problems can arise in forming questions, not only for a second language learner but also for a child learning its first language. The development of learner's questions can be identified from the types of errors made in forming questions,.

This study investigated the development of questions by Indonesian adult learners English as a foreign language (EFL). The linguistic problems they faced and their relation to teachers' responses and teaching strategies in the classroom were examined. This study was a process-product research study: the 'process' of interaction between learners and their classroom environment was observed, and the 'product' of the utterances that the learners actually produced was analysed. This allowed the identification of the conditions that enable learners to acquire language and the stages of their question development.

Two groups of adult learners were observed. In each group, eight learners were randomly selected and their language development was observed over one semester. Data from classroom interaction were collected by a multi-person multi-method procedure, that is by gaining information of the process of classroom interaction from both teachers and learners, and observing, audio recording, interviewing, and administering questionnaires. A cross-sectional study and a longitudinal study were undertaken by observing the process of learning of the 16 learners and assessing both their oral and written question forms to ascertain their question formation development.

By analysing the quantitative data from the questionnaires, and the qualitative data from the interviews and observations, it was found that teachers in Group 1 created more activities that enabled learners to speak freely in class. That is why more questions were asked by the learners of this group in classroom interaction compared to Group 2. It was also found that meaningful communicative activities in small group work and pair work encouraged learners to ask and answer questions spontaneously in their own words, so that the process of language acquisition functioned well in these activities.

From this investigation of the linguistic problems the learners faced in forming questions, it was found that most of the errors made by the learners were developmental errors. The dominant errors made were in fronting. 
Interlingual errors occurred in using question words, non-verb sentences, and yes-no questions in wh-question forms. The decrease in generating non-grammatical questions and the increase in producing grammatical questions indicated that the learners showed a developmental progress in their formation of questions in English. Some learners improved from stage 3 (fronting) of question development to stage 4 (Inversion in yes-no questions) and 5 (inversion in wh-questions), while two learners remained in stage 3 (fronting) of their question development.

These findings suggest that meaningful communicative activities in English as a foreign language classroom interaction encourage learners to communicate in the language being learned without having pressure, for instance being afraid of making mistakes. The investigation of linguistic problems revealed that errors in the higher stage of question development reflected the types of errors made in the previous stages.

For further research, it is suggested that the nature of the relationship between teaching strategies used by teachers and the development of questions by EFL learners be more fully established by correlational or experimental studies. Similarly, it would be useful to study the relationship between teaching strategies and EFL learner development of English question forms by controlling age ranges of students studied and by replicating the study with beginner and advanced EFL learners as well as intermediate learners. 


\section{CHAPTER 1}

\section{INTRODUCTION}

\subsection{Nature, Scope, and Background of this Study}

The need to learn a foreign language is essential for every one in this era of globalisation. With the emergence of communication technology, such as the internet, people can easily communicate with each other over long distances, with others of different races and cultures. In this situation, the ability to communicate in an international language that can link a person in one country to another person in another country is a must to ensure successful interaction. English is learned in most developing countries, since it is a language of international communication for business, politics and education. Most books and news are written and broadcast in English. Therefore, people in business, politics, and education are motivated to learn this language to enable them to communicate with people in other countries.

One of the aims of learning a foreign language is to enable learners to get information directly from foreign countries. Information is often attained by asking questions. Thus, skill in asking questions is necessary to enable learners to form and ask the right questions appropriately. Morgan and Saxton (1991) considered the classroom to be the place to develop knowledge and skills in asking productive questions, because teachers can help students to improve their questioning skills.

This study is an attempt to investigate classroom conditions that enable learners to acquire question forms in English as a Foreign Language (EFL). To convey an understanding of the nature, scope, and background of this study, 
teaching EFL in Indonesia, questioning as a part of the teaching-learning process, and interlanguage development in the classroom environment will be discussed to draw attention to the problems to be investigated.

\subsubsection{Teaching English as a Foreign Language in Indonesia}

Mastery of the English language has been a topic of importance both in Indonesian academic institutions and outside. In both business and academic contexts, professionals and practitioners must be able to read and speak English in order to further their careers and to enhance their status. English Training Centres exist everywhere to cater for this need. They all claim that their programs will enable learners to master English in a short time.

In light of the increasing importance of English teaching in Indonesian education, EFL teachers have tried to improve techniques and practical materials in order to make their teaching more effective and more efficient. A major change in their teaching approaches has been a shift from the grammarbased approach, with its emphasis on teaching knowledge about the language, to the communicative approach, with its focus on teaching language as a means of communication.

Although there have been some attempts to improve the teaching-learning process, English achievement in formal education is still viewed with scepticism by the community. Most secondary graduates are still unable to understand everyday spoken and written English, much less to read an English text (Tomlinson, 1990:26). The same problem occurs among university graduates of whom only a few are able to speak English well (Alwasilah, 1991). For this reason, many adults, including university students and university graduates, are returning to English Training Centres to study English from a basic level, in order to enable them to communicate in English. 
Despite the fact that there have been some minor changes in teaching methodology, from grammar-based methods to communicative-based methods, the main approach used by EFL teachers in Indonesia is still the grammar-based methods (Yang, 1988; Alwasilah, 1991). This method stresses grammatical principles and translation from English into Indonesian. The grammar-based method is characterised by an emphasis on accuracy and the written form of language. It assumes that to enable learners to achieve proficiency in the target language, the learners need to master the grammar of the language, that language is a grammatical system and that learning a language consists basically of learning that system (Cook, 1991). Through mastery of the grammar of the language, the aim is to train learners to write the language accurately. This aim is achieved through elaborate grammatical explanations and demonstrations in the native language, followed by practice of the rules the learners have just learned and translation of foreign texts into the native language. Communicative based methods on the other hand focus on what Hymes (1972) termed 'communicative competence' which refers to the ability to communicate. For Hymes, the ability to speak competently not only entails knowing the grammatical rules of a language, but also knowing what to say to whom in what circumstances and how to say it. Grammar rules still have a place in communicative methods, because there must be rules of use, without which the rules of grammar would be useless (Scarcella, Andersen \&Krashen, 1990).

Although the communicative approach has been attempted in language classes, especially in EFL classes in Indonesia, a good result has not yet been achieved (Alwasilah, 1994). To enhance the communicative competence of the students, there are many factors to be considered, one of which is the classroom environment (Ellis, 1984). Different models of classroom interaction result in the improvement of different skills. One way to develop the communicative competence of the students in the classroom is by questioning (Morgan \& Saxton, 1991). 
Generally, questioning is an effort to gain information during classroom interaction (River, 1989). Questioning is also considered to be a learning strategy in the classroom (Oxford \& Crookall, 1988). This idea is supported by Chaudron (1988), and Nio (1993) who stated that questioning is one of the learning strategies that needs to be developed. Moreover, Nio (1993) suggested that questioning is a good learning activity not only in the English language class, but also in the non-language classes. By questioning, students actively engage in interaction, and develop their language skills (Pica, 1994). It is important, therefore, to recognise that questioning is a part of culture of the college classroom (Shaw \& Bailey, 1990). In addition, questioning is not simply teacher behaviour but mutual constructions of language by teachers and students (Carlsen, 1991).

\subsubsection{Questioning as a Part of the Teaching-Learning Process}

Questioning is one of the activities that occurs in the teaching-learning process which indicates that an interaction is taking place between the teacher and students, and which signifies that there is an active engagement by teacher and students with the subject being discussed. Questioning as a part of the teaching-learning process can be recognised in four ways: a teaching strategy, a learning strategy, a form of communication, and a language skill. As a teaching strategy, questioning is a device of the teacher to foster and maintain student involvement in learning (Morgan \& Saxton, 1991). As a learning strategy, questioning is a means to gain knowledge and skills effectively. It is a behaviour of successful language learners (Nunan, 1989a). As a form of communication, questioning is a discourse pattern or turn taking (Hasan, 1991). As a language skill, questioning is the skill of forming and using questions appropriately to elicit information (Quirk et al, 1985; Crystal, 1991). This study will investigate questioning as a language skill by examining classroom interaction. Questioning as a learning strategy and a form of communication is 
also recognised in analysing questions produced by students in classroom interaction, but questioning as a teaching strategy will not be discussed here.

Questioning as a learning strategy is considered to be important in gaining knowledge and skills effectively (Oxford \& Crookall, 1988; Nunan, 1989b). The initiative of making and asking questions may come from both teachers and students, but research indicates that the initiative mostly comes from teachers (Morgan \& Saxton, 1991:3). Students can only take the initiative if they are able to be actively involved in classroom interaction. It is believed that questions from both teachers and students stimulate ideas and encourage both teachers and students to enjoy "a shared, creative learning experience" (Morgan \& Saxton, 1991:7). Moreover, Seliger (1983) states that learners who initiate and participate in interaction will make more rapid progress in language learning than those who interact little. Spada (1986) also claim that classroom interaction will happen if teachers give students the chance to speak and the students feel free to take risks in the language being learned.

A question proposed by a student is an element in classroom interaction. It indicates that there is an effort to get involved, to ask for an explanation about something, to ask for clarification or to check whether something is correct or incorrect. It reveals that the student has been given the opportunity to practise the language being learned. Teaching is not communicative if there is no interaction in class, or no occasion for the students to ask and to use the language being learned (Rivers, 1987)

Research by Shaw and Bailey (1990) and Alwasilah (1991) in questionasking in classrooms indicates that non-native speakers of English in American university classrooms lack access to the discussion process in classroom interaction. This is because it is not the custom in the home culture of many international students to ask questions of the professor during class 
(Shaw \& Bailey, 1990). Students' inability to be involved in discussion may also occur because of a lack of ability to communicate, especially to form and ask questions (Alwasilah, 1991). Thus, it is suggested by Shaw and Bailey (1990) that international students should be prepared by their English language program to ask questions clearly and appropriately.

In a second or foreign language class, asking questions is a skill which is taught to students to allow them to make contact in the process of communication. A second or foreign language learner must be able to form and use questions accurately to seek information or to clarify ideas in the language being learned. For learners whose native language (L1) system is different from the target language being learned (L2), it may be difficult for them to form questions in L2 since they must use L2 rules which are not the same as those in their L1.

For Indonesian-speaking learners of English, forming and asking questions in English is a persistent problem. The question structure in English cannot be mastered in a short time since their L1 has a different system of question formation. The systems differ in word order, inversion rules, agreement, the use of question words and tenses. That is probably why Indonesian adult advanced learners, as well as those who are beginning to study English, still make errors in forming questions in English. The errors they make can be observed in the process of communication that occurs in classroom interaction and in situations outside the classroom.

It appears that there has been little research on the acquisition of questions in English by Indonesian-speaking adult leamers. A study made by GrowMaienza (1991) focused on teachers' questions and students' response patterns in secondary schools in Indonesia. Using classifications adapted from Bloom's Taxonomy of educational objectives in the cognitive domain, it was 
found that teachers were able to involve students in higher order thinking by asking higher order questions. Grow-Maienza's study investigated questioning as a teaching strategy, while the present study focused on questioning as a language skill.

\subsubsection{Interlanguage Development in the Classroom Environment}

The language used by a foreign language learner in uttering the language being learned is called interlanguage. The term "interlanguage" was proposed firstly by Selinker (1972) to indicate the speech which is produced by second/foreign language learners before their speech achieves fluency. Changes in interlanguage are due to interaction and influences of the first language and the characteristics of the second language (Stevens, 1984:4).

How a second or foreign language is acquired in the classroom and in the natural environment is still a contentious issue. Most people assume that second and foreign language students who receive formal instruction assistance in learning English do better than those who go through no program (Nelson, Lomax \& Perlman, 1984). Researchers in interlanguage development still argue about the effects of form-focused instruction on language acquisition. Schwartz (1986) points out that most rules teachers actually teach in a class do not correspond to the reality of the target language. Learners who are taught and drilled the patterns of language in the classroom tend to use certain structures for a period of time, then drop them when they realise that other forms are more comfortable for communication (Spada \& Lightbown, 1993). However, instruction does have a positive effect. Krashen (1982) argues that learners in the classroom environment have greater access to 'comprehensible input' than those left to acquire the language naturally. When learners are exposed to ${ }^{-}$comprehensible input, their language acquisition progresses at a faster rate. Thus, formal instruction has positive 
effects particularly in settings where learners have little opportunity to use the language outside their language class (Spada \& Lightbown, 1993).

Research by Day and Shapson (1991) in French language acquisition indicates that form-focused instruction makes an impact on the interlanguage development of students who have had several years of experience with communicative language use. In addition, research by Spada and Lightbown (1993) in Canada indicated that form-focused instruction within the context of communicative. interaction contributes positively to second language development. Moreover, White (1990) in relation to these two findings also suggests that although the language being taught in second and foreign language classes is based on information about what is grammatical in English (positive evidence), learners may also insist upon information about what is not grammatical (negative evidence). In the case where their native language structure differs from the target language, assistance to find grammatical and ungrammatical structures in the target language is necessary for learners. A study by Hammerly (1987) indicates that learners exposed to natural language acquisition will produce error-filled speech long after learners who have had more form-focused instruction overcome the same error types.

The forms of utterances in the target language can be marked by one of three signals; (1) borrowing mother tongue patterns (language transfer), (2) expanding the patterns of target language, and (3) expressing meaning by using words and grammatical rules of target language (communication strategy) (Faerch \& Kasper, 1984).

The present study investigated the problems faced by Indonesian adult learners in Indonesia in acquiring question forms in English. In order to achieve this, the acquisition of questions by Indonesian adult learners of 
English was described and analysed and the difficulties faced by them in forming questions in English were examined. In the classroom context, problems can be identified in classroom interaction in terms of types of errors made by Indonesian adult learners of English, responses of teachers to the errors, and teaching strategies used by teachers to encourage learners to form questions accurately. These three aspects were the focus of this study.

\subsection{The Purpose and Significance of this Study}

The main purpose of this study was to investigate linguistic problems faced by Indonesian adult learners in acquiring questions in English as an important feature of their interlanguage development, and to analyse their relation to teachers' responses and teaching strategies in the classroom. The specific aims of this study were:

- to identify the types of questions frequently used by Indonesian adult learners of English

- to investigate the errors made in forming questions in English

- to investigate the teachers' responses to errors made by the learners

- to analyse the teaching strategies used by teachers to encourage learners to accurately form questions in English

- to identify the sequential stages of the acquisition of question forms by the learners

It is anticipated that this study will be useful for developing greater understanding of the problems in teaching English for Indonesian adult learners. It is also anticipated that it will be a useful linguistic study of second and foreign language acquisition. Pedagogically, the findings from this study will provide English teachers in Indonesia and elsewhere with information on acquisition of English questions by Indonesian adult learners, which may be used to improve foreign language teaching in Indonesia. Theoretically, the 
findings from this study will contribute to the development of research on second and foreign language acquisition, especially in questioning.

\subsection{Questions to be Answered}

The issues considered in this study give rise to questions, which will be addressed in this study.

\section{The Acquisition of Question Forms in Classroom Interaction}

a) What are the conditions that enable learners to acquire question forms in classroom interaction?

b) What are the teaching strategies used by teachers to enable learners to ask questions in English?

c) Which teaching strategies are more effective in encouraging learners to ask questions accurately?

d) What is the frequency of questions asked by Indonesian adult learners in each teaching-learning interaction in the classroom?

2. The Types of questions most frequently used in classroom interaction

a) What types of question forms are most frequently used by Indonesian adult learners in the teaching-learning process of EFL?

b) What types of question contents are most frequently used by Indonesian adult learners in the teaching-learning process of EFL?

c) What types of question functions are most frequently used by Indonesian adult learners in the teaching-learning process of EFL?

3. Types of Errors

a) What types of errors are usually made by Indonesian adult learners in forming questions in English? 
b) Why do these errors occur?

\section{Teachers' Responses}

a) How do teachers respond to questions made by learners?

b) What types of responses are made by teachers?

\section{The Development of Question Structure}

a) What are the sequential stages of the acquisition of question forms by Indonesian adult learners of English?

b) To what extent do the sequential stages of the acquisition of questions forms by the Indonesian adult learners follow a universal pattern of the development of English question forms?

These questions will be answered and analysed on the basis of theories related to these problems. Specifically, they will be answered on the basis of data collected through assessments, questionnaires, interviews, and the observation and audio recordings of classroom interactions.

\subsection{Definitions of Key Terms}

The following definitions will be used through out this dissertation:

Acquisition: The process of learning a language in an environment where the language is frequently spoken.

Question: The interrogative expression used to elicit an information or a response

Foreign Language: A setting where the language plays no major rule in the community and is primarily learned only in the classroom. 


\subsection{Chapter Outlines}

There are seven chapters in this dissertation. Chapter 1 is concerned with the nature, scope and background of the study, its purpose and significance and the questions to be answered in this study. The description of these components is intended to give a general overview of what is to be discussed in the following chapters. Chapter 2 presents a literature review of current theory and research on language acquisition, the acquisition of questions in classroom environment, types of questions, stages of the acquisition of question forms in English, types of errors and teachers' responses. Chapter 3 provides a contrastive analysis of questions in English and Indonesian. Chapter 4 presents the design of the study, subjects, instruments, data gathering and methods of data analysis. Chapter 5 presents data and analysis the results. The data were analysed in terms of the five major problems of this study: (1) the acquisition of question forms in classroom interaction, (2) types of questions most frequently used in teaching-learning process, (3) types of errors made by the learners, (4) teachers' responses to the questions made by learners, and the development of question forms. Chapter 6 is the interpretation and discussion of the study. This chapter primarily examines the results described in Chapter 5. Two main topics are discussed: the acquisition of question forms in classroom interaction and the question development of the 16 Indonesian adult learners. Chapter 7 presents the conclusion of this study. This chapter presents the research study and results, limitations of the study, and recommendations.

\subsection{Summary}

Questioning is an important activity in the classroom and reflects active engagement between students and teacher, and students with other students. It has been indicated by some researchers that forming questions is still a 
problem for most Indonesian learners of EFL, since the systems of forming questions in English and Indonesian are different. Not only children but also adult learners have problems in producing questions in English. This study was carried out to investigate these problems in classroom interaction to find the types of questions most frequently used in classroom interaction, and to find errors that are usually made by learners. This study will finally identify the sequential stages of the acquisition of English questions forms by Indonesian adult learners. 


\section{CHAPTER 2}

\section{LITERATURE REVIEW}

\subsection{Overview}

To attain an understanding of the acquisition of questions, a review of related literature is presented below. The literature review presents current theory and research on language acquisition and language learning in relation to the acquisition of question forms. The following is a brief review of theories of language acquisition, the acquisition of questions in the classroom environment, teaching strategies, types of questions, stages of the acquisition of questions, types of errors, and teachers' responses to the questions made by learners.

\subsection{Language Acquisition}

Language acquisition can be defined as a process by which an individual learns a language (Tardif, 1989:190) or creates a new language system (Gass \& Selinker, 1994:1). This definition is supported by Dulay, Burt, and Krashen (1982:10) who include language acquisition in the situation of learning a new language in a foreign language context as well as learning a new language in the host language environment. Ringbom (1987:26) and Schwartz (1993) support the above idea by indicating that language acquisition not only covers second language acquisition in an environment where the language is frequently spoken, but learning in the classroom situation as well.

\subsubsection{Theories of Language Acquisition}

There are three main theories of language acquisition; nativist theory (Chomsky, 1965), environmental theory (Schuman, 197.5) and interactionist 
theory (Givon, 1979). Nativist theories suggest that every human being has an innate language learning ability. Children are able to acquire a language because they possess this innate language acquisition device (LAD). Someone who has acquired a first language is able to acquire his second language because he has such a device. In other words, a second language can be acquired because each individual has an innate knowledge of the grammar of a possible language (Chomsky, 1965).

In contrast, according to environmental theories, children acquire language through the imitation of adult speech and reinforcement. In the process of acquiring a language, children are conditioned to speak correctly through positive reinforcement for 'correct' utterances and negative reinforcement for 'error' usage (Fromkin, 1984). This view holds that children learn the language of their environment (Burns \& Broman, 1983:31). Experience is an important factor to develop a language, it is more important than its nature or innate contribution (Larsen-Freeman \& Long, 1991). That is why Schuman (1975) states second language acquisition is a product of acculturation.

Interactionist theory claims that language is a production of face to face interaction which moves from a pragmatic mode of communication, a discourse-based mode, to a more syntactic mode (Givon, 1979). The language development of learners is considered the result of their interaction with their environment with a complementary interaction between their developing cognitive capacities and their linguistic experience (Brown, 1994). Hence, interactionist theory calls upon both innate and environmental factors to explain language learning (Larsen-Freeman \& Long, 1991). It is not only the 'product' of utterances that must be analysed, but also the 'process' of acquisition/learning. By studying the learning process, researchers can explain second or foreign language acquisition and understand how it happens. 
A number of approaches have been developed by interactionists. Givon (1979) developed an approach called 'functional-typological syntactic analysis'. He claims that syntactic change in the speech production is caused by the advancement in applying pragmatic principles in face to face communication. On the other hand, Clahsen, Meisel, and Pienemann (1983), McLaughin (1987), and Pienemann and Johnston (1987) were inspired by the works in experimental psycholinguistics and cognitive psychology. The explanation on the multidimentional model of ZISA's groups, for instance, is cognitive. They stated that speech processing is constrained by the set of strategies available to the learner at any one time. The strategies available to the learner determine what they are currently capable of processing (LarsenFreemen \& Long, 1991).

This study uses interactionist theory to analyse the acquisition of questions of Indonesian adult learners of English as a foreign language, since the process of interaction in class will be considered in analysing the questions produced by learners both in classroom interaction and assessments given. In addition, interactionist theory is more powerful than single factor solution, as in innatist and behaviourist theories, because it examines two or more variables and relationship among variables (Long, 1990b).

\subsubsection{Adult Language Acquisition and Learning}

The process of acquiring a second or foreign language is actually different from that of acquiring the first language. In acquiring a second or foreign language, learners can be assisted by a formal knowledge of the grammar of the target language (Gass \& Selinker, 1994) and a dictionary. This can help learners speed up the process of acquiring the language. In acquiring a first language, children acquire the language solely through a process of interaction with other human beings. No one teaches children the grammar of 
the language, they just pick it up. The grammar of the language is acquired in the process of communication.

Adult learners have two distinctive ways of developing competencies in a second or foreign language. One is acquisition, that is acquiring language in a process of natural communication. The other is learning, that is acquiring language through a process of formal learning (Krashen, 1981). For Krashen (1985), 'acquisition' is considered to be a subconscious process identical in all important ways to the process children utilise in acquiring their first language, while 'learning' is a conscious process that results in "knowing about" language. Language learning relies on memorisation and problem solving and leads to explicit, conscious knowledge about the second language (Zobl, 1995:35). However, Terrel (1977) claimed that although the emphasis of second language is learning, since no one has ever completely described the grammar of a language much less taught it to anyone, the development in second language must also involve acquisition.

The language teaching program must have these two components, acquisition and learning, if it can create materials and context that provide intake (Krashen, 1981:101). Intake is available when meaningful and communicative activities are supplied by the teacher. The Total Physical Response (Asher, 1969), Communicative Approach (Hymes, 1972) and theNatural Approach (Terrel, 1977), are some methods which may fit the requirement for intake in language teaching programs.

\subsection{The Acquisition of Questions in the Classroom Environment}

\subsubsection{Conditions that enable learners to acquire a language}

The classroom is the main language environment for learners who study English as a foreign language. Conditions in the classroom determine the 
development of learners' lânguage. Dulay, Burt, and Krashen (1982) claim that the language environment provides everything the learner hears and sees in the new language. So, the most beneficial language environment is one where language is used naturally for communication. The more a learner hears a structure, the sooner it will be acquired.

Methods used by teachers influence the skills of the language learners. A study by Spada (1987) indicated that learners who received communicative based interaction scored higher on an oral communication test than learners who received structure based interaction. This study reveals that since the aim of teaching a language is to enable the learners to communicate in the language being learned, the approach used by the teachers must be one which allows the learners to practise in the language being learned as much as possible. In other words, the methods used must enhance communicative ability. Lynch (1996) suggests that in communicative language learning teachers should create opportunities for interaction that allow freer language use. There must be no psychological burden to speak in the language being learned in the classroom. However, learners must have many opportunities to use the language in class, especially speaking it in and outside the classroom (Nunan, 1989a).

Lynch (1996) mentions two ways in which learners may be involved in classroom interaction: (1) through teacher-learner interaction, and (2) through learner-learner interaction. In general, there is some interaction between teacher and learners but only in the sense that each speaking turn from the teacher is followed by either an individual or choral response. In other words, this is one way communication. There is only a little communication. Communication will be enhanced if learners are really involved in negotiating meaning with the teacher or other learners (Doughty \& Pica, 1986). In this way, the learner may take initiative in asking questions. Therefore, the learners do 
best if they are allowed to ask about language they do not understand (Pica, 1994).

There are a number of ways of letting learners take initiative in negotiating meaning with the teacher or with other learners. Speaking tasks in pairs and small groups maximise each learner's opportunity to speak. In addition, practising language in small groups reduces the psychological burden of public performance (Lynch, 1996:10). It has also been indicated that group work is more likely to lead to negotiation of meaning than interaction with the teacher (Doughty \& Pica, 1986; Hasan, 1991). In group work, learners express a wider range of language functions (Long, Adams, Mclean \& Castanos, 1976; Long, 1990b).

\subsubsection{Teaching Strategies}

The concept of teaching strategies has been expressed differently by several experts. Joni (1980) and Le and McCausland (1986) define teaching strategies as the general forms of the teachers' activities in teaching. Likewise, Depdikbud (1981:106) states that a teaching strategy is the activity which is chosen by teachers in the learning and teaching process to facilitate students' learning. Furthermore, Gerlach and Ely (1978:174) and Eggen (1979:8) consider that a teaching strategy is made up of approach, method and techniques or procedures which will ensure that the learners reach the objective.

Two approaches are widely used in the teaching of English as a foreign language; the grammar-based approach and the communicative-based approach. The grammar-based approach aims at achieving proficiency in a language through elaborate grammatical explanations and demonstrations in the native language of the learners, followed by practice of the rules the learners have just learned. Using the grammar-based approach, students are 
expected to master the grammar of the language and learn to write the language accurately (Allen, 1980). The communicative approach on the other hand was developed as a reaction to the grammar-based approaches. The major difference is a shift from teaching knowledge about a language to teaching language as communication. In the communicative approach, students in the classroom use language to communicate ideas, not just to practise language forms (Harmer, 1987:5). The teacher acts as a facilitator and organisator. As a facilitator, a teacher should organise students' activities into class work activity, group work activity, and pair work activity. These activities can optimise the students' chances to speak and interact with each other in the classroom (Cazden, 1987).

In terms of teaching styles, Ramirez and Stromquist (1978) point out two general styles which are evident in ESL/EFL classes: the mechanical and the communicative. The mechanical style is closely associated with the behaviourist tradition. It involves repetition through language drills, correction of errors in pronunciation, and little emphasis on informal dialogue between teachers and learners (Nelson, Lomax \& Perlman, 1984). The communicative style emphasises communicative activities in the classroom. The communicative style is also referred to as the integrative method. This style involves eliciting responses from learners through questioning, and correction of grammatical rather than pronunciation errors (Ramirez \& Stromquist, 1978).

Recent research on second language acquisition indicates that form-focused instruction provided within the context of communicative interaction contributes to higher levels of linguistic knowledge and performance (Spada, 1986; Lightbown \& Spada, 1990; Fotos \& Ellis, 1991; Spada \& Lightbown, 1993). In addition, accuracy, fluency, and overall communicative skills are best developed through instruction that is primarily meaning based (Spada, 1987; Lightbown \& Spada, 1990; Carrol \& Swain, 1993). Thus, teaching strategies 
which enhance communicative competence should be in the form of meaning based activities.

Two components are usually discussed in terms of teaching strategies in language learning: communicative competence and communicative language teaching. Communicative competence is the outcome aimed for in language learning/teaching. Communicative language teaching is the means to achieve this communicative competence. In other words, communicative language teaching is the process that is designed to enable students to communicate in the language being learned. In the following section, these two concepts will be discussed.

\subsubsection{Communicative Competence}

The concept of communicative competence has been developed by a number of linguists, including Chomsky (1965), Hymes (1972), and Savignon (1982). In general, communicative competence is considered to be the ability to use the language as a tool of communication. It includes the ability to use appropriate speech for certain circumstances. Chomsky (1965) regards communicative competence as the ability to communicate based on speakers' knowledge of the grammar of their language. Hymes (1972) coined the term communicative competence by focusing on the sociolinguistic function of language as well as the linguistic forms. Communicative competence is achieved when someone learns to speak not only grammatically but also appropriately. Therefore, in the process of communication, the speaker must learn a variety of sociolinguistic and social interactional rules that govern appropriate language use (Andersen, 1990). Moreover, Savignon (1982) indicates that communicative competence is achieved when the speaker can adjust the language forms in the context of the speaking process. 
Although Chomsky (1965), Hymes (1972), and Savignon (1982) have different perspectives of communicative competence, they support each other. While Chomsky (1965) considered grammar as the basis of communicative competence, Hymes (1972) added that someone must know more than grammatical rules and vocabulary alone, he must be able to use the language appropriately in the social context. This idea is also supported by Savignon (1983) who indicated that communication happens in specific ways and this needs adjustment of the language used, since the same surface structure can carry different social meanings.

Richard, Platt and Weber (1985) propose four characteristics of communicative competence. They are the knowledge about the grammatical rules and vocabulary of a languiage, the knowledge of how to speak, the knowledge of how to use and respond to a speech act, and the knowledge to use a language correctly and appropriately. Andersen (1990), more specifically, indicates communicative competence as knowing the social rules of language use, since the meaning of an interaction is easily misinterpreted if the speakers do not share the same set of rules. In addition, Garcia (1994) states that communicative competence is the knowledge that allows individuals to understand and act in concert with the expectations of other participants. Thus, communicative competence reflects what is appropriate in one speech community.

\subsubsection{Communicative Language Teaching}

It is widely accepted that teaching a language by focusing on the form of the language, the grammatical rules, is inadequate for teaching learners to speak in the target language. Learning a language is fundamentally being able to communicate in that language. This means that learning a language should not only include learning the grammatical rules of that language, but also learning how to use the various forms of language appropriately. Littlewood 
(1981) suggests that teaching learners how to manipulate the structure of the foreign language is not enough. Learners must also know the relationship of these structures to their communicative function in real situations and real time. Therefore, providing learners with opportunities to use the language for communicative purposes is necessary for language teaching. Teachers have to move away from teaching various grammatical rules to teaching learners to use the rules effectively and appropriately in communicating (Nunan, 1989a).

Littlewood (1981) regards the move from a structural to a functional view of language as an important principle. The main principle proposed by Littlewood (1981) brings a structural view of language to functional views of language, because a single linguistic form can express a number of functions. On the other hand, a single communicative function can be expressed by a number of linguistic forms. For example, there are many linguistic options for asking someone to close the door. However, only some forms of these options might perform a directive function in the context of the social relationship. Other forms could be easily misunderstood. As a result, the ability to relate linguistic form to non-linguistic knowledge (social and cultural rules) is important in interpreting the functional meaning intended by the speaker.

Consequently, a teacher in a language class must be able to relate the forms of language taught to the specific meaning and function in communication, relate structure to communicative function, and relate language to social context. In addition, the teacher must be able to create communicative activities in the classroom, designing tasks, role plays, and other activities, that allow learners to speak in the given context.

The classroom is often considered an artificial environment for learning and using a foreign language. It is the place where learners can hear, practise, and experience the language being learned. Using the language being learned as soon as possible for routine classroom affairs, in order to establish the foreign 
language as the medium for organising classroom activities, provides a valuable opportunity to motivate learners (Littlewood, 1981). The use of the mother tongue in class tends to devalue the foreign language as a device for communication.

Teaching activities such as role plays, debates, discussion in small groups, and pair work are invaluable to the fostering of communicative ability (Littlewood, 1981; Nunan, 1989b; Scarcella, Andersen \& Krashen, 1990; Long, 1990). Small group work offers active participation by a number of students simultaneously. Therefore, not only the quantity but the quality of the language commonly produced in the intimate setting of a small group is of greater variety than classroom practice (Long, 1990)

\subsection{Types of Questions}

The term question is defined differently by linguists. Richards, Platt, and Weber (1985) define a question as a sentence which is addressed to a listener/reader and asks for an expression of fact, opinion, or belief. Crystal (1991) and Sneddon (1996) on the other hand define a question as a sentence used to elicit information or response. This definition is in line with a definition proposed by Lynch (1991) who indicates that a 'question' is a command or interrogative expression used to elicit information or a response or to test knowledge. This definition indicates that not all questions are in the form of interrogatives, but they can also be in the form of commands, such as 'Tell me your name' which functions to elicit information. This definition also implies that questions are not only used to obtain information or a response, but are also used to measure knowledge acquired by someone. This type of question is usually found in patterns of question-asking in the classroom by teachers. In the classroom, questions can also come from learners. Question-asking from learners are usually in forms of utterances which function to ask for more 
explanation or information, repetition, or check whether something is correct (Allen \& Guy, 1978).

There are various ways to classify questions. They can be classified on the basis of form (Quirk, 1985; Huddleston, 1988; Ellis, 1994), content (Bloom, 1965), and function (Long \& Sato, 1983; Morgan \& Saxton, 1991).

\subsubsection{Forms of questions}

In terms of the form of questions, Quirk (1973; and 1985) classifies questions into three types: yes-no questions, wh-questions, and alternative questions. Yes-no questions expect only affirmation or rejection (close questions), while wh-questions expect a reply supplying an item of information (open questions). Alternative questions are of two types; yes-no question form, and wh-question form. Both types of alternative questions are included in close questions since the alternative answers have been mentioned. This classification of questions has two aspects: the forms of questions, and the type of answers they expect.

With regard to how questions should be answered, Huddleston (1988) and Ellis (1994) proposed other types of questions. According to the answers they expect, questions can be classified into two major classes; closed questions and open questions. In closed questions, there is only one acceptable answer in mind, and in open questions, a number of different acceptable answers are permitted. Moreover, Huddleston (1988) stated that open questions are in the form of wh-questions, and closed questions are in the forms of yes-no questions or alternative questions.

\subsubsection{Contents of questions}

With regard to the content of questions, Bloom (1956), classified questions on the basis of the hierarchical structure of thinking, and proposed six types of questions which are arranged from simple to complex questions. They are 
knowledge, comprehension, application, analysis, synthesis, and evaluation. The aim of knowledge question is to know the facts; comprehension to understand the facts; application to apply the facts; analysis to take the facts apart; synthesis to put the facts together to reveal new perspective; and evaluation to evaluate the facts.

The first three questions of the six types of questions are considered as lower order questions since they demand 'lower' levels of thinking, and the last three types of questions are considered as higher-order questions, since they demand 'higher' levels of thinking. Thus, the sequence of the six questions types indicate a hierarchy in the thinking process: from the lowest order questions to the highest order questions. This classification of questions focuses on the process of thinking, while the form, meaning, and how the questions should be answered are not dealt with in this hierarchy.

\subsubsection{Functions of questions}

Functions of questions can be classified into two types: questions which function as the general function of questioning and are usually found as a teaching strategy in standard L1 classroom (Morgan \& Saxton, 1991), and questions which function as a teaching and learning strategy in a second or foreign language classroom (Long \& Sato, 1983).

Long and Sato (1983:276) suggest seven categories of the taxonomy of question functions based on the taxonomy proposed earlier by Kearsley (1976). The taxonomy of question functions describes two main functions of questions in conversation and informal discourse; they are echoic questions and epistemic questions. Echoic questions are those which ask for repetition or comprehension checks of speaker's utterances, clarification, and confirmation, while epistemic questions are those which serve the purpose of 
acquiring information. The seven categories of question functions in the two main categories are as follows.

\section{Echoic}

a. Comprehension Checks "are any expressions by a speaker designed to establish whether that speaker's preceding utterances have been understood by the interlocutor". eg. Allright?; OK?; Does anyone understand "polite"?

b. Clarification Requests "are any expression by a speaker designed to elicit clarification of the interlocutors preceding utterance". eg. What do you mean?; I don't understand, what?

\section{c. Confirmation Checks}

\section{Epistemic} eg. Carefully?; Did you say "carefully"?

a. Referential "are intended to provide contextual information about situation, events, actions, purposes, relationships or properties".

eg. Why didn't you do your homework?

b. Display "are asked to establish the addressee's knowledge of the answer (known information question)

eg. what is the opposite of "up" in English?

c. Expressive "convey attitudinal information to the addressee".

eg. It is interesting the different pronunciations we have now, isn't it?

d. Rhetorical "asked for effect only, no answer expected from listeners, answered by speaker". eg. Why do I do that? Because I ...

(Long \& Sato, 1983:276)

Long and Sato (1983) indicate that in formal learning $79 \%$ of questions occurred in class were display and $21 \%$ referential. This is understandable since questions are usually dominated by teachers (White \& Lightbown, 1984), and teachers usually know the answer of the questions they ask. In the second/foreign language class, if the communicative approach is applied, there should be more referential questions from learners than display questions. In addition, echoic questions must occur in classroom interaction, because in the process of communication, not all utterances are clearly understood by the hearer. Therefore, clarification requests or confirmation checks may occur in interaction. 
Therefore, these seven categories of questions are considered when observing second/foreign language classroom interaction, especially when identifying the functions of questions used by the Indonesian adults learning English as a foreign language.

Another classification of the function of questions was one proposed by Morgan and Saxton (1991). According to Morgan and Saxton (1991), there are three main purposes of questions: for eliciting information, for shaping understanding, and for pressing for reflection, which are then subdivided into 15 specific functions. The three broad categories can be seen below.

Category A: Questions which elicit information. These are questions which draw out what is already known in terms of both information and experience and which establish the appropriate procedures for the context of the work.

Category B: Questions which shape understanding. These are questions which help teachers and students fill in what lies between the fact and sort out, express and elaborate how they are thinking and feeling about the material.

Category C: Questions which press for reflection. These are the questions which demand intellectual and emotional commitment by challenging the individual to think critically and creatively.

(Morgan \& Saxton, 1991:41)

This classification is suitable when the questions produced by teachers in the non-language class are examined. It is difficult to apply these categories of questions in second and foreign language classrooms. If questions from learners are to be investigated, the more suitable types of questions which can be applied in the language classrooms is the classification proposed by Long and Sato (1983).

For this study, the types of question forms proposed by Quirk (1985) were also considered useful in analysing question forms produced by learners in 
classroom interaction. While for identifying the content of questions, the hierarchical thinking process of questioning (Bloom, 1956) by learners was considered appropriate.

\subsection{Stages of the Acquisition of Question Forms in English}

Recent research on language acquisition has focused on investigating the stages of second language acquisition. Pienemann in collaboration with other researchers identified the stages of adult language acquisition (Meisel, Clahsen, \& Pienemann 1981; Pienemann \& Johnston, 1987; and Pienemann, Johnston \& Brindley, 1988). Littlewood (1981), Larsen-Freemen and Long (1991), Towell and Hawkins (1994), Spada and Lightbown (1993), Ellis (1985, 1994), and Gass and Selinker (1994) on the other hand also proposed stages of language acquisition based on their studies. In this section the findings of these researches will be discussed.

Larsen-Freemen and Long (1991:92) suggest that there is a common developmental sequence in language acquisition of human beings. Learners do not acquire properties of the L2 immediately, but go through a series of 'transitional stages' toward the target language (Towell \& Hawkins, 1994). Development is interpreted as an indication of the steps on a learner's path from zero knowledge of the target language toward the standard language (Meisel, Clahsen \& Pienemann, 1981). In other words, learners pass through a number of developmental stages before attaining the target version (LarsenFreeman \& Long, 1991). Six stages in the developmental sequence of language have been identified by Pienemann and Johnston (1987:75).

1. The production of undifferentiated elements;

2. The production of strings of elements: learners can produce simple sequences of words;

3. Ability to identify the beginning and end of a string: learners can shift an element at the end of the string to the beginning;

4. Pre-syntactic operation: learners are able to move an element out of the middle of a string to either the beginning or end; 
5. Learners are able to characterise various elements within a string as being of different kinds; and

6. Learners are able to break down elements within a string into sub-strings.

Pienemann and Johnston (1987:75) indicated that the development of language is begun with the production of undifferentiated elements, followed by the production of simple sequences of words, and superseded by the more complex sequencing.

According to Tyack (1983) and Spada and Lightbown (1993:62), the stages of the development of questions in English as a first language is in line with the above language development. The earliest questions of children are single words or simple two- or three-word sentences with rising intonation. Then, they produce questions in the declarative word order. Later, children begin to use inversion in yes/no questions, followed by wh-questions.

The stage of question development in a second language seems similar to first language question development in English. Even learners whose first language has subject-auxiliary inversion for asking questions, go through a phase of using declarative word order and a period of "fronting" in forming questions in their second language (Gass \& Selinker, 1994; Ellis, 1994). However, adult progress through the developmental sequences faster than children in the early stages of syntactic development (Larsen-Freemen \& Long, 1991).

Eckmann, Moravcsik, and Wirth (1989:175) describe three order patterns of appearance of English question structures in L1 and L2 acquisition: whfronting, wh inversion, and yes-no inversion. Wh-fronting refers to the sentence-initial position of question pronouns in wh questions (eg. Whom you should see?); wh-inversion is where there is a verb-before subject order in whquestions (eg. Whom should you see?); and yes-no inversion is where there is a verb-before subject order in yes-no questions (eg. Should you see Joe?). In 
relation to universal in language acquisition, Eckmann, Moravcsik, and Wirth (1989) claim that wh-inversion occurs in languages where wh fronting arises, while yes-no inversion occurs if it also occurs in wh inversion.

Littlewood (1984:44) points out three stages of the development of questions in English as a second language. In the first stage, the learners use the declarative word order and signal the questions by intonation. In the second stage, inversion sometimes takes place but sometimes does not. In the third stage, the inversion is used appropriately. These stages are very broad and fail to include a number of question forms. Therefore, more specifically, Ellis (1985:60-61) suggests the developmental sequence of questions is as follows: (1) questions are formed by making statements with rising intonation, (2) Whquestions appear without subject-verb inversion; (3) overinversion of modal auxiliaries occurs; and (4) learners are able to differentiate between simple and embedded Wh-questions. These stages seemed to be more specific than those stated by Littlewood (1984:44) and Spada and Lightbown (1993:62), but the first stage is still too general. The term 'statement' refers to only sentences, not words or phrases. In reality, in this stage - statements with rising intonation - three possible forms will occur; word, phrase, and sentence. So, rising intonation can appear in the form of a word, phrase, and sentence.

Pienemann, Johnston, and Brindley's (1988) categorisation is more detailed. They identified six developmental stages of question formation which are interpreted by Lightbown and Spada (1993) as follows.

(1) Single word; eg. "Four children?",

(2) Declarative word order, no inversion, no fronting, eg. "The boy throw the shoes?",

(3) Fronting:

- Wh-fronting, eg. "Where the little children are?";

- do-fronting, eg. "Do you have a shoes on your picture?";

- other fronting, eg. "Is the picture has two planets on top?",

(4) Inversion in yes/no questions, eg. "Is there fish in the water?", 
(5) Inversion in Wh-questions, eg. "What is the boy doing?", "How do you say [prache]?

(6) Complex questions:

- question tag, eg. "It is better, isn't it?";

- negative question, eg. "Why can't you go?";

- embedded questions, eg. "Can you tell me what the date is today?".

These stages seem to be more complete and appropriate than the previous theories, because questions which are formed by rising intonation are differentiated. These are single word questions (eg. Four children?) and declarative word order questions (eg. The boy throw the shoes?). In addition, the stages of question development are described on the basis of language complexity.

For the purpose of the present research, the developmental stages proposed by Pienemann, Johnston, and Brindley (1988) will be employed, since they clearly and completely identify the developmental stages of question formation. In addition, this theory is appropriate to identify patterns of questions produced by the Indonesian adult learners of English as a foreign language.

\subsection{Types of Errors}

Error can be defined as the use of a linguistic item which according to fluent users of the language indicates faulty or incomplete learning of the target language (Richard, Platt \& Weber, 1985). Errors may be considered as a natural product of the acquisition process since they occur in interlanguage during the process of acquisition of a second or foreign language (Dulay, Burt \& Krashen, 1982). Every learner makes errors in the process of learning the language. The learners' proficiency can be judged from the number and sort of errors he/she makes. Therefore, it can be concluded that a learner has mastered the language well if he/she does not make many errors. On the other 
hand, the more errors the student makes, the less proficient in the language he/she is.

Adults learning a second language differ from children learning a first language, since adults may profit from grammatical explanations. Hence deductive reasoning can be employed that obviously would be inappropriate for children. In addition, adults approach a second language learning systematically and attempt to identify linguistic rules on the basis of whatever linguistic information is available to them, whether this is information from the native language (interlingual) or from the second or foreign language itself (intralingual) (Larsen-Freeman \& Long, 1991). However, there are some similarities between adults' and children's language acquisition. Adults learning a second or foreign language also manifest some of the same types of errors that occur in children learning a first language (Ellis, 1985). If we observe a foreign language classroom, it can be seen that the same errors of pronunciation, grammar, and vocabulary tend to occur in the language of different individuals (Wilkins, 1978). These types of errors can be considered as developmental errors (Dulay, Burt \& Krashen, 1982). It can be concluded that a second language is not easily mastered, as it involves very complex processes.

As a result of their contrastive analysis hypothesis, Larsen-Freeman and Long (1991) claim that errors which are found in L2 learners are caused by the similarities and differences of $L 1$ and $L 2$. It is $L 1-L 2$ difference that can best explain and predict the phenomena of avoidance in L2 learning (Laufer \& Eliasson, 1993). The hierarchy of difficulties can be described as follows by giving examples of Indonesian learning English. 


\begin{tabular}{|c|c|c|c|c|}
\hline \multirow[t]{2}{*}{ Type of Difficulty } & \multirow[t]{2}{*}{ L1 } & \multirow[t]{2}{*}{ L2 } & \multicolumn{2}{|c|}{ Examples } \\
\hline & & & Indonesian & English \\
\hline & & $\mathrm{X}$ & & what \\
\hline 1. Split & & & & \\
\hline 2. New & 0 & $X$ & agreement, & nse, gender, aux. \\
\hline 3. Absent & & 0 & - & \\
\hline 4. Coalesced & $\mathrm{X}$ & & ke mana & \\
\hline 5. Correspondence & $\mathrm{X}$ & $X$ & kapan & when \\
\hline
\end{tabular}

Most difficult of all is the split, because a single form in the L1 becomes two or more in L2. In contrary, it is coalesced if several forms in the L1 collapse in the L2. In addition, it will be difficult for learners if a form which is absent in L1 but present in L2, or present in L1 but absent in L2. The easiest linguistic difficulty of all is if the L1 and the L2 correspond structurally and functionally.

A number of types of errors have been identified by the researchers on language acquisition. Dulay, Burt and Krashen (1982:55) found six types of errors in L2 learners' speech and writing:

1. The omission of grammatical morphemes - omitting items that do not contribute much to the meaning of the sentence, such as past and plural markers.

2. The double marking of a given semantic feature in making two or more items in an utterance when only one marker is required, such as the past tense is marked more than once.

3. The regulation of irregular rules - the regular past tense marker -ed is used instead of the irregular form.

4. The use of archiforms - using one form for the several proposes, eg. Them going to town, I know them. 
5. The alternating use of two or more forms where conditions for use are still being internalised, as in the random alternation of much and many.

6. The misordering of items in constructions that require the reversal of word order rules that have been previously acquired as in I don't know who is it.

These errors are based on the surface structure of the utterances or sentences produced by English learners in general.

A number of types of errors can also be identified by investigating factors which influence second language acquisition. There are some factors that can influence second and foreign language acquisition. One factor is the first language. In acquiring a second language, a person will use whatever previous experience he or she has had with language in order to facilitate the second language learning process. The native language of second language learners is actually a part of their set of prior experiences which can influence their second language learning. In this situation, interference will occur. Interference is said to occur if the native language is negatively transferred to the second language (Brown, 1994). This is an interlingual error, since the interference is due to the influence of the mother-tongue on the language being learned (Ghadesy, 1989:54).

Another factor is the second or foreign language itself. The problem here is overgeneralisation. This is a process where the language learner generalises a particular rule beyond its legitimate bounds. Overgeneralisation is an intralingual error. It is the result of an ignorance of rule restrictions, the incomplete application of rules, or a false concept hypothesised in the language being learned (Richard, 1974; Brown, 1994).

Dulay, Burt and Krashen (1982) propose a comparative taxonomy of four error types on the basis of the structure of L2 errors: developmental, interlingual, ambiguous, and others. The taxonomy is represented in the following figure. 


\section{A Comparative taxonomy of the four error types}

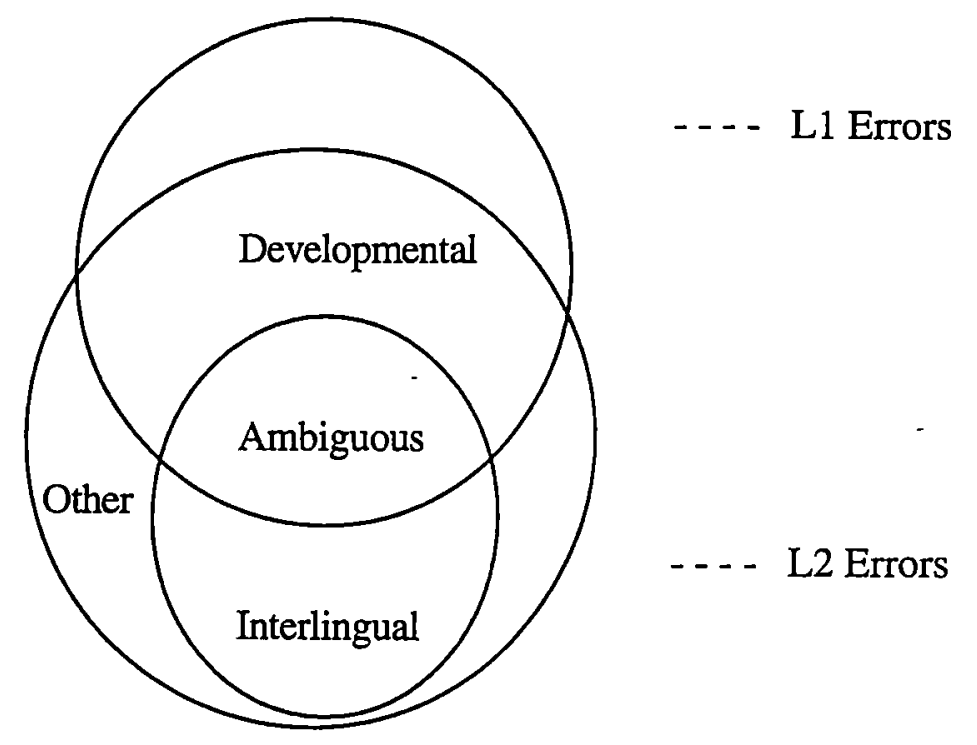

The two major error categories in this taxonomy are developmental errors and interlingual errors. Developmental errors are the errors which are similar to those made by children learning their first language. Interlingual errors are errors which are similar in structure to those in the learners' native language. The other two categories are ambiguous errors and others. Ambiguous errors are errors which are classifiable as either developmental or interlingual, and other is a grab bag category of errors which are neither of developmental nor interlingual.

\subsection{Teachers' Responses}

In the teaching-learning process, the response which is made by teachers to the learners' utterances or writing is referred to as feedback. Feedback is considered to be an important factor in the process of language acquisition. Feedback provides learners with information about the correct utterances and errors and is given by teachers (Lynch, 1996). A teacher can give two kinds of 
feedback, cognitive feedback and affective feedback. Cognitive feedback is the teacher's response to the comprehensibility or accuracy of what the learner has said. Affective feedback is where approval or disapproval of students' utterances is shown.

According to Schachter (1983), affective feedback can be categorised into four basic responses to the learning process: negative or positive in one dimension, and implicit or explicit in the other. Explicit feedback can be positive, such as confirmation (approval) or negative, such as correction (disapproval). Implicitly, positive feedback can be delivered by clues showing the addressee understands, and negative feedback can be given by signals that repair is necessary. Some have assumed that explicit feedback is more effective than implicit feedback. However, Pica (1988) found that in working in pairs, implicit correction is a more effective teaching device than explicit correction.

Seliger (1983:250) points out that the feedback provided by teachers in the language class is focused on particular errors in grammar, pronunciation or semantics. The feedback here might be applied implicitly or explicitly in the positive and negative form. However, if it is not carefully handled, the feedback given by teachers may impose on psychological burden on the learners (Lynch, 1996).

Dulay, Burt and Krashen (1982:34) suggest that there are three types of feedback in the process of learning: correction, approval (positive feedback), and expansion. Among these three types of feedback, correction and expansion are most frequently employed in classroom interaction research. Correction is regarded as adjustment made by teachers to the errors made by the learners. Expansion is an attempt to modify the learner's speech without consciously calling attention to the modification. Expansion is considered more effective than correction, since expansion involves systematic modelling of 
either a correct or more complete version of the learner's utterance without calling his attention to the activity (Brown, 1994).

In foreign language teaching-learning, most teachers' responses take the form of correction, and it is considered to be one of the language teachers' most important functions (Nunan, 1989a). However, research has found that correction of students' grammar and pronunciation can be immensely frustrating for the students, and is of little benefit in long term acquisition (Krashen, 1982). A study by Holley and King (1971) suggested that students may improve their control over spoken language forms without correction. In this study, students were permitted more uninterrupted time to rephrase their responses, and this resulted in improved performance. Hence, correction may not always be a reliable tool for helping students to correct errors. However, from the learners' perspective, some researchers have found that error correction is expected (Cathcart \& Olsen, 1976; Willing, 1988; Carrol, Swain \& Roberge, 1992). Adult learners have shown a strong preference for error correction (Willing, 1988). In addition, research by Carrol, Swain and Roberge (1992) indicates that error correction effect better achievement for adult learners. This is understandable since native speakers are able to correct their own errors, but learners can not do so (Corder, 1973).

\subsection{Summary}

Research on second language acquisition reveals that the development of second language is similar to the development of the first language. The acquisition of questions can also be described in terms of developmental stages. The acquisition of questions in the classroom context depends much on the classroom environment and the interactions between teacher and students, and students and other students. A conducive environment will enable learners to acquire and develop question forms in the language being used. Therefore, the strategies applied by the teachers in managing the class 
will influence the process of acquisition. By observing the errors made by the learners in producing questions, the developmental stages of the learners can be identified. 


\section{QUESTIONS IN ENGLISH AND INDONESIAN}

\subsection{Overview}

In this chapter, question formation in the English and Indonesian language will be discussed in order to identify the similarities and differences between the two grammatical systems. A contrastive analysis of these two systems will reveal the likely difficulties that face Indonesian students in forming English questions.

\subsection{English Question Formation}

Questions can be analysed both semantically and syntactically. Semantically, questions express a desire for more information, usually requiring a reply from the listener. Syntactically, a question typically commences with a question word or other syntactic sign to indicate the question form (Crystal, 1991). The discussion on questions in this study will examine questions syntactically.

According to Quirk and Greenbaum (1973:191), questions are sentences marked by one or more of these three criteria: (1) the placing of the operator immediately in front of the subject, (2) the initial positioning of a question word, and (3) rising intonation. Examples of sentences marked by these three criteria can be seen below.

(a) Will John speak to the boss today?

(b) Who will you speak to?

(c) You will speak to the boss? 
Sentence (a) is marked by placing the operator will before the subject. This process is also called inversion. Sentence (b) is marked by two signals; inversion and the initial positioning of question words. Sentence (c) is marked by rising intonation and is also called a declarative question. Sentences (a) and (c) can be categorised as yes-no questions, since these forms need the hearer to make the response, yes or no, to the speaker. Sentence (b) is categorised as an information question or wh-question because the adressee is required to give the information needed.

In addition to the three criteria above, Richards, Platt, and Weber (1985) and Crystal (1991) add one more criteria to indicate that a sentence can be a question when it has a question tag, such as isn't it, can he, do you, etc. For example:

\section{Patricia is a student, isn't she?}

Thus, syntactically, a question can be marked by one or more of four criteria; a question word, inversion, rising intonation, and a question tag. However, these four criteria only apply to questions in English. In other languages, the criteria may be different.

There are a number of ways to classify types of questions. Hartmann and Stork (1973:116-117) classify questions into four types. These are whquestions, yes-no questions, alternative questions, and tag questions. Quirk et al. (1985), classified questions based on the answer the questions expected and divided questions into three major classes: yes-no questions, wh-questions, and alternative questions. Tag questions are included in the class of yes/no questions by Quirk (1985) since they expect only yes or no responses.

Yes-no questions are questions that expect only affirmation or rejection (a yes or no response). In English, they are formed by placing the operator (modal auxiliary) before the subject and giving the sentence a rising intonation. 
Wh-questions are formed by placing a question word (who, whom, whose, what, which, when, where, why, how) at the beginning of the sentence. There must be an inversion of subject and operator except if the question word is the subject. Wh-questions are formed by giving the sentence a rising intonation. Wh-questions are also called information questions because they expect information as a response.

Alternative questions are of two types; yes-no question type and whquestion type. The yes-no question type differs from yes-no question only in intonation. Since the sentence contains two or more alternatives, a rising intonation occurs on each item but in the last item the intonation must fall to indicate that the list is complete. The wh-question type of alternative questions is a compound of a wh-question and an elliptical alternative question of the first type. For example:

(1) Which ice cream would you like, chocolate, vanilla, or strawberry?

(2) Which ice cream would you like? Would you like chocolate, vanilla, or strawberry?

A tag question consists of the operator plus pronoun. If the superordinate clause is positive, the tag is negative, and vice versa. The choice of tense is determined by the verb phrase in the superordinate clause. A declarative sentence in question tag is identical in form to a statement, but the final intonation is rising.

\subsection{Indonesian Question Formation}

There are a number of conflicting analyses of Indonesian grammar. Kwee (1992) for example has proposed that there are three forms of questions in Indonesian: the declarative form; putting the question word apa (what) or apakah (what) at the beginning of questions; and adding the suffix -kah to the words that demand an answer, which are placed at the beginning of a sentence. 
However, this explanation seems to be simplistic, since Indonesian question formation is more complex than Kwee's explanation implies. A more detailed explanation has been given by Moeliono (1988). He stated that there are five ways to form questions in Indonesian: (a) adding word apa or apakah, (b) subject-verb inversion, (c) using the words bukan, belum, or tidak, (d) intonation, and (e) question words. Examples of these five means of question formation can be seen in the following section.

\subsubsection{Five ways of question formation in Indonesian}

(a) By using a question marker apa or apakah

In Indonesian, all statements can be changed into questions by adding apa (what) at the beginning of the sentence. The suffix -kah can be added to apa to become apakah to make the question polite or more formal. This type of question uses falling intonation. Look at the examples below.

(i). Apa dia istri Bapak?

what she wife sir = Is she your wife?

(ii). Apakah dia istri Bapak? what she wife sir = Is she your wife?

(b) Subject-Verb Inversion

The second way to form questions in Indonesian is by changing the order of the words. There are some rules that must be followed.

1). If there is a word like dapat (able), bisa (can), harus (must), sudah (have done), or mau (want), these words can be placed at the beginning of sentence, as the following examples indicate.

a. Dapatkah dia pergi sekarang? able he go now = Can he go now? 
b. Menangiskah dia kemaren?

he yesterday = Did he cry yesterday?

2). If the predicate is an adjective or noun, the subject-predicate can be inverted, and $-k a h$ added to the adjective or noun to form a question. For example:

$$
\begin{aligned}
& \text { Anaknya malas } \Rightarrow \text { Malaskah anaknya? } \\
& \text { his son lazy } \quad \text { lazy -kah his son = Is his son lazy? }
\end{aligned}
$$

3). An intransitive verb, monotransitive verb, or semitransitive verb (together with object or complement) can be put at the beginning of sentence. Look at the following examples.

$$
\begin{aligned}
& \text {-Menarikah dia kemaren? } \\
& \text { dance she yesterday = Did she dance yesterday? }
\end{aligned}
$$

(c) Using words 'bukan', 'belum', or 'tidak'

The third way is by placing bukan (no), belum (not yet), or tidak (not) at the end of the sentence. The following examples illustrate this.

a. Dia sakit bukan?

$$
\text { He sick no = He is sick, isn't he? }
$$

c. Dia sudah pergi, apa belum?

$\mathrm{He}$ already go what not yet = Has he gone, or not yet?

b. Kamu mengerti soal ini, apa tidak? you understand question this what not = Do you understand this question, or not?

The word 'bukan' (no) can be used in any sentence to confirm something being asked. The word 'belum' (not yet) is used if the word 'sudah' (have done) is in the superordinate clause. The word 'tidak' (not) is used to confirm whether an activity happens. 
(d) Intonation

The fourth way to form question is by using a statement but with rising intonation. The order of the words is like a statement but the intonation is rising. The example below shows this.

Dia pergi ke Medan?

$\mathrm{He}$ go to Medan = He goes to Medan?

(e) Question words

The fifth way to form question is by using the question words 'siapa' (who, whom), 'kapan' (when), 'di mana' (where), and 'mengapa' (why). These question words can be placed at either the beginning or the end of a sentence, without affecting the meaning, as the following examples show.

a. Dia mencari siapa?

he look for who = Who is he looking for?

b. Kapan mereka berangkat ke Australia?

when they go to Australia = When will they go to

Australia

Some question words, however, can only be placed at the beginning of a sentence. One example of this is 'bagaimana' (how). In these examples below it can be seen that 'bagaimana' is only correct in the initial sentence position; it is unacceptable elsewhere in Indonesian.

(1) Bagaimana dia dapat memecahkan masalah itu? (acceptable) how he can solve problem that $=$ How can he solve that problem?

(2) Dia dapat memecahkan masalah itu bagaimana? (unacceptable) - he can solve problem that how $=$
How can you solve
that problem?.

In terms of types of questions in Indonesian, Sneddon (1996) proposed that four types of questions are used in Indonesian, which are the same types of 
questions as those found in English. These are yes-no questions, whquestions, alternative questions, and question tags. He suggests this because the functions of questions in Indonesian is the same as those in English.

\title{
3.2.2 Types of question forms in Indonesian
}

Whereas the previous section discussed questions in Indonesian in terms of the way questions are formed, this section will be discuss questions according to the types of question forms in Indonesian.

\section{Yes-No Questions}

In Indonesian, a yes-no question does not usually have a different word order from the corresponding statement. A yes-no question is marked by a rise in final pitch. Frequently, that is the only difference between a statement, marked by a fall in final pitch, and a yes-no question (Sneddon, 1996). Look at the following examples.
(1) Kamu sudah makan.
(Statement)
You have eaten.
(2) Kamu sudah makan?
(Question)
You have eaten?

\begin{abstract}
A yes-no question can also be made by using question markers 'apa' or 'apakah'. A question marker here is different from a question word. A question marker can be used in a yes-no question, while question words are used to form wh-questions. Look at the following example,
\end{abstract}

(3) Apa kamu sudah makan?

Have you eaten?

(4) Apakah kamu sudah makan?

Have you eaten?

(5) Kamu sudah makan apa?

What have you eaten? 
Questions (3) and (4) with 'apa' and 'apakah' are yes-no questions. Question (5) with 'apa' at the end of the sentence is a wh-question. The word 'apa' in question (5) can be replaced by an object such as apple (in Indonesian apel)

(6) Kamu sudah makan apel.

You have eaten apple.

\section{Wh-Question}

Wh-Questions usually have the same word order as a statement in Indonesian. In English, however, the question word must be placed at the beginning of the sentence, while in Indonesian some question words can be placed at the beginning of sentence and others at the end of sentence. The examples below show this.
(7) Kamu mencari siapa? (Final position only)
'You looking for who?'
*Siapa kamu mencari?
Who you looking for?
(8) Ke mana dia pergi?
(Initial and final position)
'Where he go'
Dia pergike mana?
'He go where?'

The question word 'siapa' (who) here can only be put at the end of the sentence (7), while 'ke mana' (where) can be put both at the beginning and at the end of the sentence (8).

\section{Alternative Questions}

Alternative questions can be indicated by placing 'atau' (or) or 'atau bukan' (or not) to a yes-no question.

(9) Kamu Siti atau Sri?
'you Siti or Sri' = Are you Siti or Sri? 
(10) Kamu sudah makan atau belum?

'you already eat or not' = Have you eaten or not?

\section{Tag Question}

The words 'bukan' (no) and 'ya' (yes) can function as a question tag in Indonesian. They can be attached to a statement to turn it into a question. This is usually used to seek agreement from the addressee. Look at the examples below.

(11) Kamu sudah makan bukan?

'you already eat no' = You have eaten, haven't you?

(12) Dia cantik, ya?

'she pretty, yes' = She is pretty, isn't she?

\subsection{Contrastive Analysis of English and Indonesian Question Formation}

As discussed in the section above, both English and Indonesian have four types of questions. They are questions which need a yes or no response (yes-no questions), questions that require certain information (whquestions), questions that provide an alternative to be chosen by the adressee (alternative questions), and questions that seek agreement (tag questions). Although they have some similarities in the types of questions, they differ in the ways that questions are formed, such as in the marking of tense, inversion and in the use of certain question words.

Inversion of the subject and modal auxiliary is the most important signal in English to indicate that a sentence is a question, with the exception that there is no inversion if the subject of the question is asked. In Indonesian, inversion is only applied for certain question forms, and it must be followed by the particle -kah. This type of inversion in Indonesian can only be used in yes-no questions. Inversion in English must be employed in all types of 
questions, except declarative questions. Declarative questions in Indonesian are very common.

By comparing English and Indonesian question formation rules, it is apparent that intonation is the most important question marker in Indonesian. A statement can be changed into a question simply by modifying the intonation into rising intonation. A statement can be transformed into a question by adding a question marker, apa or apakah, or question words, siapa, apa, ke mana, di mana, etc., and modifying the intonation to rising intonation.

In terms of tense markers, an inflectional tense marker is needed in English to denote the time that the action happened ( past, present or future). These signs have to be considered in forming questions in English. Indonesian has no inflectional tense marker system. Time in Indonesian is indicated by words, such as 'kemaren' (yesterday), 'besok' (tomorrow), and 'sekarang' (now). So, it is very difficult for Indonesian beginners of English to decide what tense is appropriate for the sentence to be uttered. It is possible that the Indonesian learner of English could make English questions as follows.

(13) *Where do you go yesterday?

Kemana kamu pergi kemaren?

(14) "Where do you go tomorrow?

Kemana kamu pergi besok?

There is no change in the verb form in Indonesian to indicate action in the past or in the future as seen in the examples (13) and (14) above.

In terms of question words, the use of some question words can confuse Indonesian learners. The question word 'berapa' can be expressed in English in two ways 'how many' and 'how much'. This is because English differentiates 'countable' and 'uncountable' nouns, while Indonesian does not. The other problem is a 'split' problem - when a single form in the L1 becomes two or more in the L2 - (Larsen-Freemen \& Sato, 1991). For example, the use of the question word 'siapa' can function as a possessive 
pronoun (whose) or personal pronoun (who). It is likely therefore for Indonesian learners to make the English sentence Who child is this? instead of Whose child is this? based on the Indonesian system.

Finally, the differences and similarities in forming questions in English and Indonesian are outlined in table 1 below.

Table 1

Similarities and differences in forming questions in English and Indonesian

\begin{tabular}{|c|c|}
\hline English & Indonesian \\
\hline $\begin{array}{l}\text { Yes-No Questions } \\
\text { - Subject and auxiliary inversion } \\
\text { - Rising intonation } \\
\text { - Inflectional tense marker } \\
\text { - Declarative questions } \\
\text { - Tag question } \\
\text { Wh- Questions } \\
\text { - Question word takes first position } \\
\text { - Falling intonation } \\
\text { - Subject and auxiliary inversion, except } \\
\text { when question word is subject } \\
\text { Inflectional tense marker }\end{array}$ & $\begin{array}{l}\text { Yes-No Questions } \\
\text { - Subject and verb inversion plus } \\
\text { suffix '-kah' after verb } \\
\text { - Rising intonation } \\
\text { - Beginning with word 'apakah' and } \\
\text { no inversion } \\
\text { - Declarative questions } \\
\text { - Declarative + 'atau bukan' } \\
\text { Wh Questions } \\
\text { - Question word can be taken in } \\
\text { the first position or end position } \\
\text { - Rising intonation }\end{array}$ \\
\hline
\end{tabular}

Table 1 indicates that inflectional markers and subject-auxiliary inversion cannot be found in Indonesian question formation, while subject-verb inversion cannot be found in English.

As a result of the differences between forming questions in English and Indonesian, it is possible that two components will be found in learners' interlanguage; (1) taking the rule of their L1 (Indonesian), or (2) 
overgeneralising the English question formation rules. These phenomena will be investigated in this study.

\subsection{Summary}

Indonesian and English have different ways of forming questions, because the systems to arrange questions are different, even though both languages have the same types of questions. The occurences of certain rules in English question formation, such as inversion and tense markers, may become obstacles for beginner Indonesian learners to forming English question. In addition, the knowledge of question formation in their L1 (Indonesian) influences the production of questions in English. 


\section{CHAPTER 4}

\section{METHODOLOGY}

\subsection{Overview}

This chapter will discuss the design of the study, subjects, and instruments used for the investigation of the research questions. This chapter will also describe data gathering, and methods of data analysis.

\subsection{Design of Study}

This study investigated the "process" and "product" of classroom interaction in foreign language acquisition. Ellis (1984:13) describes "process" as an interaction between learners and their linguistic environment, a continuous pattern of language development that occurs over time, while "product" is considered to be the utterances that learners actually produce. This study is process-oriented because it focuses on how learners' utterances are produced and responded to in a naturalistic classroom environment. It is also productoriented since the utterances produced by the learners will be analysed to find the non-target-like forms occuring in interlanguage systems. It is only by a product oriented approach that comparison between the utterances produced by the learners in the target language systems can be made, the errors described, and the stages of learners' language development recognised.

There are two approaches usually used in the study of language acquisition: a cross-sectional approach and a longitudinal approach. In a cross-sectional approach, a large number of learners are analysed at the same time while in a longitudinal approach a limited number of learners are investigated in the acquisition of a first, second or foreign language (Miesal, Clahsen \& Pienemann, 1981:111). A cross-sectional approach compares groups to 
characterise stages of development at several points in time, while a longitudinal approach follows the same group over time and repeated measurements are taken (Tardif, 1989; Cohen \& Manion, 1994). In a crosssectional approach, the linguistic performance data are usually collected by asking subjects to perform specific verbal tasks, whereas in a longitudinal approach the linguistic performance data are the spontaneous speech produced by subjects. A longitudinal approach involves observing the development of linguistic performance over time (process oriented) while a cross sectional approach takes place at one point in time (outcome/product oriented) (Larsen-Freeman \& Long, 1991:11). This study will use both a crosssectional approach and a longitudinal approach to investigate the acquisition of English questions by Indonesian adult learners of English as a foreign language because both process and product will be investigated.

Burns (1994) and Cohen and Manon (1994) indicate that the use of two or more methods of data collection in the study may be considered as 'triangulation'. Triangulation is used in interpretive research to investigate a case from more than one standpoint. Triangulation is commonly used to improve the internal validity (Burns, 1994). Triangulation will help to overcome the problem of 'method-boundedness'. Moreover, Cohen and Manon (1994) stated that there are six types of triangulation: time triangulation, space triangulation, combined levels of triangulation, theoretical triangulation, investigator triangulation, and methodological triangulation.

This research used three triangulation techniques: time triangulation (crosssectional and longitudinal study); investigator triangulation (teachers and learners); and methodological triangulation (a combination of quantitative, qualitative, and interpretive approaches). A quantitative approach was used to determine the frequency of questions used in the teaching-learning process, the number of errors made by learners in relation to teaching strategies used by teachers, and stages in the question development of learners. A qualitative 
approach was used to analyse errors that occur in forming questions and to study teachers' responses and teaching strategies. An interpretive approach was used to analyse the interrelationships between teaching strategies, teachers' responses, types of errors, and stages in the question development of learners.

\subsection{Subjects}

Two groups of subjects were observed in this research. The first group of subjects for this study was Indonesian adult learners registered in Semester II/1996 in the Language Training Centre (Balai Bahasa), IKIP Padang. Thirty learners were. enrolled in the English training centre at intermediate level. Their ages ranged between 27 and 41 years old. They were all university graduates with a first degree. They were lecturers at the Institute of Islamic Studies (IAIN) Padang. They had the same cultural background, Minangkabau which is one of the tribes in Indonesia. Their first language was Minangkabau, and their second language was Indonesian. Minang language was used for informal conversation, while Indonesian was used for formal conversation, because Indonesian was language of school education. English was a foreign language for them. Although they had studied English for 7 years ( 3 years at Junior High School, 3 years at Senior High School, and 1 year at university), their English language proficiency was still low. They were considered to be at the intermediate level of English. They were sent to English Language Training Centre to prepare to continue their study in an English speaking country.

"Balai Bahasa" is a place of study for adult learners of English. The learners who attend are from various study backgrounds. Usually they are university students and graduates or people who have worked in government offices and in private companies. All participants were graduates from secondary schools. The regular program in Balai Bahasa is a course provided for university 
lecturers who are preparing to study in the an English speaking country. Their level of performance varies from beginner, intermediate, to advanced level, and they are usually grouped on the basis of their level of performance.

The second group was adult learners who studied in semester II/1996 in the English department of IKIP Padang. There were three classes in the first year. Each class consisted of 30-32 learners. They had the same cultural background as the first group, Minangkabau. Their first language was Minang language, and their second language was Indonesian. They used the Minang language for informal communication, and Indonesian for formal communication. English was also a foreign language for them. They had studied English for 6 years ( 3 years at Junior High School; and 3 years at Senior High School). Their language ability was considered to be at intermediate level.

The "English Department of IKIP Padang" is an institution to train learners to become Ënglish teachers. Students were selected from hundreds of secondary graduates who were interested in studying English and wanted to become English teachers. Their level of performance varied from intermediate to advanced level, and they were usually grouped randomly into three classes: $A, B$ and $C$. For this research one of the three classes was observed. Randomly assigned, it was decided that class $A$ was the class to be observed for this research. The description of the two groups observed can be seen in Table 2 below.

Table 2

Distribution of subjects observed in classroom interaction

\begin{tabular}{|l|l|l|l|}
\hline \multirow{2}{*}{ Group } & \multicolumn{2}{|c|}{ Subject } & \multirow{2}{*}{ Total } \\
\cline { 2 - 4 } & Males & Females & 30 \\
2 & 14 & 16 & 31 \\
\hline
\end{tabular}


As can be seen in Table 2 above, there were more females than males in both groups. In Group 2 the number of female subjects was approximately three times the number of male subjects.

Since in a longitudinal approach a limited number of learners are investigated, in each group of learners eight persons were randomly selected. To avoid constraints on gender differences in producing language, it was decided that $50 \%$ of the subjects must be male, and the other $50 \%$ were female. Four males and four females observed in each group. The eight learners observed in each group were randomly chosen by writing all the names of the learners in each group on pieces of paper, which are then grouped them into two groups, a male group and a female group. From each group, four names were taken randomly. Those whose names were taken were the subjects to be observed longitudinally. The same procedure was performed for choosing subjects in Group 1 and Group 2. The description of the subjects can be seen in Table 3 below.

Table 3

Subjects studied longitudinally

\begin{tabular}{|l|l|l|l|l|l|l|l|l|}
\hline No & Code & Group & Age & Sex & Length Std Eng & Lang spkn & $\begin{array}{l}\text { Mchr } \\
\text { Tng }\end{array}$ & Occ \\
\hline 1. & L1 & 1 & 41 & M & 7 yrs & Ml, I & M1 & Lctr \\
2. & L2 & 1 & 37 & M & 7 yrs & Ml, I & M1 & Lctr \\
3. & L3 & 1 & 38 & M & 7 yrs & Ml, I & Ml & Lctr \\
4. & L4 & 1 & 40 & M & 7 yrs & Ml, I & Ml & Lctr \\
5. & L5 & 1 & 27 & F & 7 yrs & Ml, I & Ml & Lctr \\
6. & L6 & 1 & 34 & F & 7 yrs & Ml, I & Ml & Lctr \\
7. & L7 & 1 & 29 & F & 7 yrs & Ml, I & Ml & Lctr \\
8. & L8 & 1 & 27 & F & 7 yrs & Ml, I & Ml & Lctr \\
\hline 9. & S1 & 2 & 19 & M & 6 yrs & Ml, I & Ml & Std \\
10. & S2 & 2 & 20 & M & 6 yrs & Ml, I & Ml & Std \\
11. & S3 & 2 & 20 & M & 6 yrs & Ml, I & Ml & Std \\
12. & S4 & 2 & 20 & M & 6 yrs & Ml, I & Ml & Std \\
13. & S5 & 2 & 18 & F & 6 yrs & Ml, I & Ml & Std \\
14. & S6 & 2 & 20 & F & 6 yrs & Ml, I & Ml & Std \\
15. & S7 & 2 & 19 & F & 6 yrs & Ml, I & Ml & Std \\
16. & S8 & 2 & 17 & F & 6 yrs & Ml, I & Ml & Std \\
\hline
\end{tabular}

Note: Length std Eng = length of study English; Lang spkn = languages spoken; $\mathrm{M}=$ male; $\mathrm{F}=$ female; $\mathrm{Mthr}$ tng = mother tongue; $\mathrm{Ml}=$ Minang language; $\mathrm{I}=$ Indonesian; $\mathrm{Occ}=$ occupation; Std $=$ student; Lctr $=$ lecturer 
Learners in Group 1 were coded as L1 (Learner 1), L2, L3, L4, L5, L6, L7, and L8, while learners in Group 2 were coded as S1 (Student 1), S2, S3, S4, S5, S6, S7, and S8.

\subsection{Instruments}

The researcher used questionnaires, assessments, and made audiorecordings of the teaching-learning process in the classroom for data collection. Interviews were also conducted to collect additional data which could not be gained by the questionnaires. The instruments used for this study were as follows.

\section{Questionnaires}

Questionnaires were used to gain data about personal characteristics of the learners and teachers, and their perceptions on the teaching/learning process in relation to the research questions. Questionnaires are considered to be an effective and efficient means of gathering information from a large number of students (Asher, 1976; Gay, 1992; Burns, 1994). The aim of questionnaires in this research was to discover classroom environments which were more conducive to the acquisition of question forms. The data were gained from students and teachers. Since this research used a 'multi persons and multi methods strategy' (Burns, 1994), both information from students and teachers were considered to make a triangulation. To examine the classroom environment, the researcher also observed classroom interaction by attending lessons, making audio recordings, and conducting informal interviews with teachers and students.

The items of the questionnaire were arranged using the following procedure:

1) identifying variables of the problem, 2) finding out indicators of each 
variable, and 3) developing the descriptor range of each indicator of the questionnaire items (Arikunto, 1990).

The variables of the problems here means the elements needed to be considered in the process of the acquisition of questions by Indonesian adult learners of English as a foreign language. Since the condition of acquisition here was the learning process, the variables of the problems were the classroom learning environment and classroom interaction. The classroom learning environment included the frequency of using English in the classroom, teaching strategies, teacher's treatment of students, and the conditions that made students feel free to speak in the classroom (Littlewood, 1981; Dulay, Burt \& Krashen, 1982; Gass \& Madden, 1985; Nunan 1989b). Classroom interaction was the communication between teacher and students, and students and other students (Nunan, 1989a; Lynch, 1996). Classroom interaction included questions or statements from students, and questions, instructions, and responses from teachers.

The indicators of each variable, the classroom learning environment and classroom interaction, were arranged on the basis of the literature review as discussed in Chapter 2. The indicators can be described as follows.

1. Classroom learning environment

a. The teachers treat students as adult learners.

b. The methods were suitable to enhance communicative ability of the learners.

c. The teachers and the learners use English in class.

d. The teachers create various activities to enable students to speak freely.

2. Classroom Interaction

a. The tea-chers motivate students to speak in English in English class.

b. The teachers respond to the students' statements or questions. 
After the indicators were identified, the description of each indicator was made into questionaire items. A description of each indicator can be seen in the following table.

Table 4

Description of each indicator into question items

\begin{tabular}{|c|c|c|c|c|}
\hline \multirow{3}{*}{ Indicators } & \multicolumn{2}{|r|}{ Question } & \multicolumn{2}{|l|}{ items } \\
\hline & \multicolumn{2}{|c|}{ Leamers' Questionnarre } & Teachers' & Questionnaire \\
\hline & Q items & No in Questioner & Q item & No in Questionrs \\
\hline 1. Classroom learning environment & & & & \\
\hline a. Treat students as adult leamers & 2 & $1-2$ & & $1-2$ \\
\hline b. Methods enhance communicative ability & 4 & $3-6$ & 4 & $3-6$ \\
\hline c. Use English for communication & 2 & $7-8$ & 2 & $7=8$ \\
\hline $\begin{array}{l}\text { d. Create various activity to enable students to } \\
\text { speak freely }\end{array}$ & 2 & $9-10$ & 2 & $9-10$ \\
\hline 2. Classroom interaction & & & & \\
\hline a. Motivate students to speak English in class & 6 & $11-16$ & 6 & $11-16$ \\
\hline b. Give response to the students' questions & 7 & $17-23$ & 4 & $17-20$ \\
\hline
\end{tabular}

The total number of questions for the learners' questionnaire was 23 , and for teachers' questionnaire was 20.

The questions were arranged in the form of a semantic differential scale (Larsen-Freemen and Long, 1991:36). The students and the teachers were asked to answer each item on the basis of what they did or experienced by choosing one of five choices; always, often, sometimes, rarely, and never. This system was chosen because in the Likert scale or the semantic differential scale many choices are given. It is considered that this system generates more reliable data. 


\section{Assessments}

Structured assessments were given to gain data on the learners' performance in asking questions in English. Both a written and an oral assessment were given to assess the level of development in question formation of the learners, and to decide which stages of development they had attained. The oral assessment was conducted by using 'communicative tasks' arranged by Mackey (1994a). These tasks were designed to promote conversational interaction. Research has shown that these tasks are successful at eliciting targeted grammatical structures in English as a second language (Mackey, 1994b).

Larsen-Freeman and Long (1991) differentiate two types of assessments in second language acquisition research: test and task. Test is a device to measure what the learner knows and does not know, of the target language, while a task is a device to reveal what a learner knows only. In addition, Corder (1981) stated that by giving a task, the researcher will identify the rules the learner is using and the systems and categories he is working with. This study used both test and task as assessment to gain data from the subjects, so that all grammatical properties of question forms could be investigated.

Written assessment was in the form of an English language test which focused on how to form questions in English. By using the elicitation procedure (Larsen-Freemen \& Long, 1991) two types of questions were given. The first one was to write suitable questions based on the answer given (structured exercises), and the second one was to write questions based on the picture given (unstructured exercises). Hence, if the first one was in the form of closed -questions, the second one was in the form of open questions. The number of questions for the first type were 15 questions, and for the second type 10 questions. There were three tests given during the longitudinal study. A pretest 
was given at the beginning of their study, a whilst-test was given at the middle of the study, and a post-test was given at the end of the study.

Oral competence was assessed by using 'communicative tasks'. Three sets of pictures were given as a pretest, whilst-test, and post-test. The tasks were called 'picture differences'. Each task consisted of two pictures. Learners in pairs were given one picture each. The pictures were very similar, but there were at least ten differences (Mackey, 1994a). To do the tasks, the learners worked together giving descriptions, asking questions, and responding in order to find out what the differences were. The three tasks were a park scene, a series of animals, and an aliens scene. Since task three, the aliens scene, was not suitable to the culture of the learners, they were not familiar with the pictures, so the researcher did not apply this task. To replace this, the first picture was reused again as a post test. The conversation between the two learners in doing the tasks was tape recorded, so that it would be easier to make a written record later.

\section{Observation and Audio Recordings}

Hopkins (1993:100) proposed two types of observation; structured observation and unstructured observation. Structured observation is an observation which counts frequency of the behaviour of the subjects observed. Usually the researcher uses a check-list to observe the behaviour of the subjects. Unstructured observation on the other hand is an observation which records only the relevant data in accordance with the focus of research. The researcher here undertook unstructured observation. This meant that the researcher observed classroom interaction and recorded anything relevant to the focus of the research. Audio recordings were-made to check whether all data had been recorded. Hence, in classroom observation, the researcher combined written recording (note taking) and audio recording. 
Note taking and audio recording at the same time in observation is in line with Nunan's proposed method of data collection (Nunan, 1992). Both were done because of the strengths and weaknesses of these two techniques. The strengths of audio recording are that data can be reanalysed after the event, but it is time consuming to transcribe, besides context can not be recorded. In note taking, context can be recorded while actual linguistic data is not recorded. So, combining two techniques is the solution. If note taking and audio recording are combined, the whole situation of the classroom interaction can be observed.

Observation was conducted over one semester which consisted of 16 weeks, starting on September 2, 1996 and ending on December 21, 1996. The researcher observed the class from the beginning of semester until the end of semester. Although audio recording and note taking were done at the first meeting, they were not analysed, since the presence of the researcher made the situation unnatural. But after two weeks the subjects had become accustomed to the researcher, the students considered the researcher as their collegue, and the class worked normally.

Audio recordings were made to examine the authentic and naturalistic classroom interaction. These basic data were transcribed and analysed to find the errors made by learners in forming questions and to find what types of questions were usually used by learners in classroom interactions. The audio recordings were made during classroom observation by using the stereo cassette recorder JS Z15 AIWA. This recorder is a good quality recorder because it can record clearly the utterances produced by the learners in a 5 meter square classroom.

Two classes were observed for each group: a speaking class and a structure class. This meant that the researcher attended two classes with the same group every week. There were two hours per week for each subject. For 
analysis, the researcher took only five sessions per class. Therefore, there were 10 sessions per group, or 20 sessions altogether.

\section{Interviews}

Interviews were undertaken to gain additional information about what had been done or experienced by the students and the teachers during the observation period. In other words, interviews were aimed to elicit covert strategies used by the learners and the teachers and encourage reflection on the teaching/learning process. The interviews were undertaken in semistructured interviews, that is ranging from general ideas to specific ideas. This was done in order that the researcher, as interviewer, develop a close relationship with the interviewee. A trusting relationship is important in an interview. As mentioned by Silverman (1993), familiarity is needed in an interview so that the interviewee does not feel strange with the interviewer and feels free to share opinions.

In interviews, the researcher asked the learners and teachers to comment on what they had experienced and felt about their activities in the classroom interaction.

\section{Validity and Reliability}

The questionnaire and written assessment, since they were constructed by the researcher, needed to be tried out to ensure they were valid and reliable. The validation procedure was used to determine the construct validity of the questionnaire, to measure the attributes and qualities (construct) that the students were presumed to possess (Gay, 1992:157). The reliability procedure is used to measure consistency of the questions items (Gay, 1992:161). Borg (1983) suggests that the subject which is used for try out should be at the same level as the samples used in the research. The questionnaires and the written 
assessments were trialed out on some of the first year students of the English department of IKIP Padang who were not the subjects of this research. Therefore, it can be assumed that the students were at the same level as the subjects of this research.

The trial test was done in order to see whether the students could understand the instructions of the test and if there were any ambiguous words and sentences. After analysing the results of the tried out test, the researcher found that the students understood the meaning of the instructions, but some ambiguous words and sentences needed to be revised.

In conclusion, in order to have well organised questionaires and assessment, the researcher employed the following procedures: (a) planning the questionnaires and assessment, (b) trying them out, (c) analysing the questionnaire and assessment items, (d) revising the questionnaires and tests, and (e) constructing the final questionnaires and assessment

\subsection{Data Gathering}

This study used multi-methods and multi-persons for the data collection. The multi-methods used were questionnaires, assessments, interviews, and audiorecordings, while the multi-persons used were teachers and learners. The following procedures were used to collect data.

\section{Audio Recordings}

Audio-recordings were made of the teaching-learning process to obtain data from the learners' oral production in classroom interaction. There were six units in the course, namely listening, reading, writing, speaking, vocabulary, and grammar. However, in this study, only two units of the courses were recorded and analysed, namely speaking and grammar, because in both classes it was possible to use a grammar-based approach and a 
communicative approach in the teaching-learning process. Audio-recordings of authentic and naturalistic classroom interactions were made of those two unit courses. There were 16 teaching weeks in one session, and each unit course had two hours of teaching per-week. Hence, there were two hours of audio-recording for weekly classroom interactions, totalling 32 hours for each unit course, giving 64 hours overall for two unit courses, and 128 hours overall for the four unit courses of the two groups observed.

\section{Pre-Test}

Pre-tests were given to the subjects the first week they attended the class to determine the basic level of the students' proficiency in asking questions in English. The pre-test was given in written and oral forms. The written test was given first. The test was given to all students attending the class. There were 30 students altogether. Since this study was a longitudinal study, the researcher chose only 8 students in one class to be observed, 4 males and 4 females. The eight students to be observed were chosen randomly as indicated in the section of the subjects. Therefore, the tests that were analysed were only the tests done by these students. The researcher did the same procedure for both groups, Group 1 and Group 2.

Since the persons to be observed had been chosen, for the oral tests, the researcher only examined those eight persons per group. Oral tests were given after the class, so that the researcher was able to test two persons together. The test was in the form of 'communicative tasks' as mentioned in the section of assessment before. The communication between these two persons was tape-recorded to be transcribed and analysed later. 


\section{Whilst-Test}

In the middle of semester, a whilst-test was given to the subjects to identify which stages of development they had attended. The assessments given were both in written and oral forms. As was done in the pretest, written test 2 was also given in the structure class. All students did the test, but the ones analysed were only the eight learners chosen. The test was given in the 30 minutes at the end of the structure class at week 8.

Oral test 2 was also done after the class by asking two persons to work together giving descriptions and asking questions about the pictures given. It took about a whole week in week 8 to administer this test.

\section{Post-Test}

At the end of the semester, post-tests were given to the subjects to determine the development of the students' proficiency in forming questions in English. The post-tests were given in written and oral forms. The procedures to give the test were the same as those in the whilst test. It was conducted in week 16.

\section{Interview}

Interviews with the subjects and teachers were conducted to obtain data on learners' and teachers' comments on the process of interaction in the classroom. The interviews were conducted informally outside the classroom. The researcher negotiated with the interviewee about the time and place of the interview. For some of them, it was convenient to do the interview in the office, but others felt better having their interview at home. 


\section{Questionnaires}

Questionnaires were given to students and teachers at the end of semester to gather data on perceptions of the classroom learning environment and classroom interaction between the students and the teachers. Since it did not take a long time to answer the questionnaire, the researcher asked students to do the questionnaire after they had finished written test 3 (post test).

Since the questionnaire was anonymous, the researcher put numbers on questionnaire so that it was easy to identify which questionnaire was done by the subjects. Only the questionnaires answered by the subjects were analysed. For teachers' questionnaires, the researcher asked the teachers to answer the questionnaire after the last class at the end of semester (week 16).

\subsection{Methods of Data Analysis}

The methods of data analysis used were a combination of quantitative, qualitative and interpretive approaches.

\section{A Quantitative Approach}

The quantitative approach used in this research was descriptive quantitative. It was used to determine the frequency of question occurences, the percentage of correct and incorrect questions produced by learners, and the mean scores of the responses on questionnaires. Three types of data were analysed; 1) audio recordings of classroom interaction, 2) assessments, and 3) questionnaires.

The data obtained by audio recordings in classroom interaction were analysed in the following ways: 
1) Audio-recordings on the teaching-learning process were transcribed by using 'Lanier Voice Writer 110' to obtain classroom interaction data in the forms of learners' questions, and teachers' responses to the questions asked by learners.

2) Questions asked by learners and responses given by teachers were transcribed.

3) The frequency of questions asked by the learners in each session and in total were counted.

4) Then, the questions were grouped into three types of questions: the form of questions, the content of questions and the functions of questions. The types of questions were analysed based on Quirk (1985), Bloom (1956), and Long and Sato's (1983) classification systems.

5) Types of syntactic errors made by learners in forming questions were identified.

6) Teachers' responses to questions asked by learners were analysed.

7)Teaching strategies used in the teaching-learning process were investigated to determine which strategies were best able to encourage learners to ask questions.

The assessments of the learners, written tests and oral tasks, were analysed in the following ways.

1) Oral tasks were transcribed.

2) All questions gained from the subjects observed, in written test and oral tasks, were grouped into correct and incorrect sentences for each subject.

3) The incorrect sentences were analysed and grouped according to the types of errors made.

4) Sequential stages in the acquisition of questions were developed based on identification of the types of errors made by learners by using frequency analysis (Ellis, 1994). 
Questionnaires given to the students and teachers were analysed in the following ways:

1) The choices given by learners and teachers in questionnaires were tallied.

2) The mean score of each item chosen by the learners and teachers was counted.

3) The results were interpreted.

\section{A Qualitative Approach}

A qualitative approach was used to determine conditions that enable learners to acquire question forms in English. Therefore, errors that occur in forming questions, teachers' responses to the questions made by the learners, and teaching strategies used by the teachers were analysed. The sources of data to do this were audio-recordings of classroom interaction, assessments and interviews. By combining the data from audio recordings of classroom interaction, written and oral assessments, and interviews, the conditions that enable Indonesian adult learners of English as a foreign language to acquire questions in English was identified. This approach answered the research questions 2, 3 and 4.

\section{An Interpretive Approach}

An interpretive approach was used to interpret the interrelationship of questions produced by learners, teaching strategies used by teachers, teachers' responses to the errors made by learners, types of errors made by learners in forming questions, and stages of question development of the learners. This approach answered questions 1 - 5.

In conclusion the process of data gathering, data analysis, and interpretation can be drawn in a frame work of study as follows. 


\section{Framework of Study}

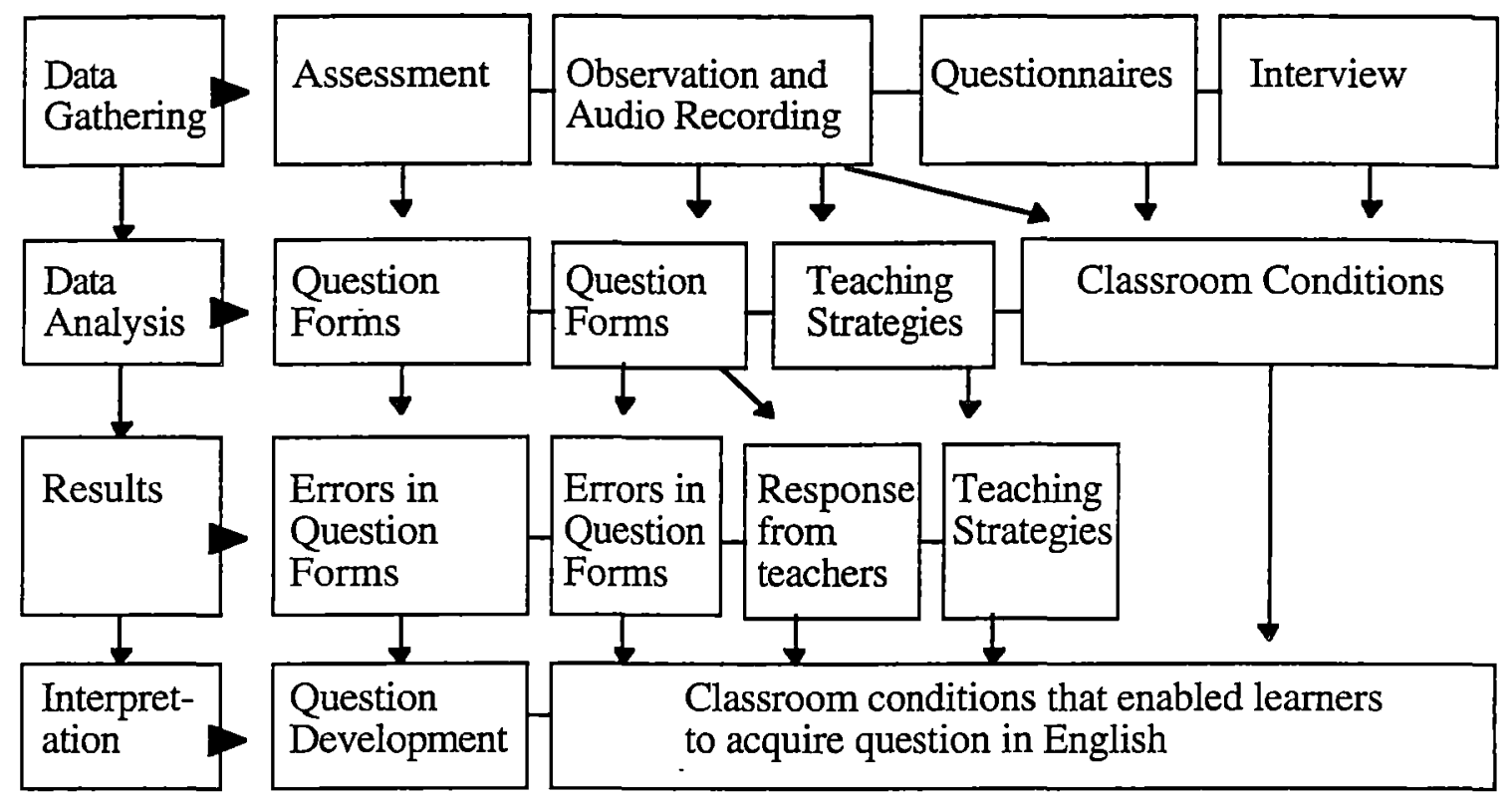

In terms of methods for investigating developmental patterns, Ellis (1994) states that there are three methods used by researchers: obligatory-occasion analysis, target-like use analysis, and frequency analysis. Obligatory-occasion analysis is made by calculating the accuracy with which the feature is actually supplied in utterances. Target-like use analysis takes into account the incorrect use of specific grammatical features in context that do not require them in the target language. Frequency analysis is made by counting the frequency of occurences of the variants of a given structure. Research by Wagner-Goughs (1975), Larsen-Freeman (1978), and Tyack (1983) indicates that there is a positive correlation between the frequency of occurences of the variants and the developmental patterns of language. Therefore, this study will use frequency -analysis to determine the developmental patterns of English questions by Indonesian adult learners of English as a foreign language. 


\subsection{Summary}

This study was a process and product research. It was process oriented since the classroom interaction was analysed in terms of acquisition of questions by adult learners. It was also product oriented since the language produced by the learners was analysed. By using a number of instruments to collect data, namely questionnaires, assessments, interview, and classroom observation, this research used a combination of quantitative, qualitative, and interpretive approaches to analyse the data. A limited number of students, 16 persons, were observed to identify their developmental stages in the acquisition of question forms in English. The observation was conducted over a period of one semester. Two groups of adult learners of English as a foreign language in two study centers were observed. 


\section{CHAPTER 5}

\section{DATA ANALYSIS AND RESULTS}

\subsection{Overview}

In this chapter, the data collected from the subjects in this study will be analysed by a combination of quantitative, qualitative and interpretative approaches. The quantitative approach used was descriptive-quantitative to determine the frequency of question in classroom interactions, errors in forming questions, and stages of question development; and to analyse teacher and learner questionnaires by finding the mean scores and percentage of the data. A qualitative approach was used to examine teachers' responses and teaching strategies. An interpretative approach was used to find the interrelationships between teaching strategies, teachers' responses, types of errors, and stages of question development of the learners.

These analyses were conducted to answer the research questions as indicated in Chapter 1. To summarise, there were five major issues to be investigated; (1) the acquisition of question forms in classroom interaction, (2) types of errors made by the respondents, (3) teachers' responses to the questions made by learners, (5) teaching strategies, and (5) the development of question forms.

\subsection{The acquisition of question forms in classroom interaction}

In analysing the acquisition of question forms, three main aspects were investigated; (1) conditions that enabled learners to acquire question forms in classroom interactions, (2) teaching strategies used by teachers to enable learners to ask questions in English, (3) teaching strategies for encouraging learners to ask questions, and (4) the frequency of questions in classroom interaction. 
The analyses were based on data gathered from classroom observation which comprised of note taking and audio recordings of the classroom interaction, questionnaires to teachers and learners, and interviews with the teachers and learners. These data from the classroom observations, questionnaires, and interviews were then analysed to find the classroom conditions that enabled students acquire questions.

The frequency of questions in classroom interaction and the type of questions most frequently used in the teaching-learning process were analysed on the basis of note taking in the observation and audio-recordings which were made during observation.

\subsubsection{The conditions that enable learners to acquire questions in classroom interaction}

In the classroom, an interaction might occur between a teacher and the student, the teacher and the whole class, a student and another student, or a student and a group of students. The observation revealed that the classroom interactions in English as a foreign language classes (EFL) were varied. Teacher-student interactions occurred when the teacher gave an explanation, instruction, and during supervision of students' work. Student-student interaction occurred in various contexts as well, eg. pair work, small group work, and class work. The learners seemed eager to interact with each other in these activities. These activities enabled them to listen, imitate, express an idea, and even ask questions whenever they need to do so. These conditions empowered the students to develop their English communication abilities.

In the following section, the data from the questionnaires, interviews, and classroom observation are analysed separately to identify the classroom conditions that enabled the learners to acquire question forms in English. 


\section{Data from questionnaires}

Questionnaires were given to eight teachers and sixteen learners to examine what they did, experienced, and observed in the classroom during the teaching learning process. The respondents were all asked to answer the questions based on the reality what they experienced in the classroom. Since these questionnaires were anonymous, the answers given by respondents were considered to be an accurate reflection of the actual class conditions. There were five choices given in the questionnaires: always, often, sometimes, rarely, and never. Respondents had to choose the one which was pertinent to what they did, experienced, and observed in the classroom.

\section{Teacher Questionnaire}

Table 5 shows that questionnaire items were described in two ways, by indicators and by question items. There were six indicators covered in this questionnaire, indicated by capital letters in Table 5 above. Below each indicator, question items were incorporated. The total number of question items was 20 questions for this questionnaire. The mean scores of the responses from the teacher questionnaire were computed. The mean scores were given for each indicator and question item. Table 5 was included to clarify figures 1 and 2 below. The figures and explanation given are based on this table.

In this questionnaire, the highest possible score was 5 and the lowest possible score was 1. Score 5 was given for the answer always, 4 for often, 3 for sometimes, 2 for rarely, and 1 for never. Since the aim of this questionnaire was to measure the frequency of occurrences whether certain condition occurred always, often, sometimes, rarely, or never, the index level of the mean scores was decided as follows: always $=4.51-5.00$, often $=3.51$ 4.50 , sometimes $=2.51-3.50$, rarely $=1.50-2.50=$, and never $=1.00-1.50$. 
Table 5

The mean scores of teacher questionnaires ( $n=4$ in each group)

\begin{tabular}{|c|c|c|}
\hline Ques & Group 1 & Group 2 \\
\hline $\begin{array}{l}\text { TREAT STUDENTS AS ADULT } \\
\text { 1. Teachers create situations that makes learners feel free to speak in class. } \\
\text { 2. Teachers treat learners as adults. }\end{array}$ & $\begin{array}{l}4.75^{4.50} \\
4.25\end{array}$ & $\begin{array}{l}3.75^{3.75} \\
3.75\end{array}$ \\
\hline METHODS ENHANCE COMMUNICATIVE ABILITY & 3.38 & 4.19 \\
\hline $\begin{array}{l}\text { 3. Teachers do not spend much time explaining or practising grammatical } \\
\text { rules. } \\
\text { 4. Teachers do not use grammar translation method as the teaching strategy. } \\
\text { 5. Teachers use audio lingual methods. } \\
\text { 6. Teachers use the communicative method. }\end{array}$ & $\begin{array}{l}2.75 \\
4.50 \\
2.25 \\
4.00\end{array}$ & $\begin{array}{l}4.25 \\
5.00 \\
3.00 \\
4.50\end{array}$ \\
\hline $\begin{array}{l}\text { USE ENGLISH FOR COMMUNICATION } \\
\text { 7. Teachers use English in classroom interaction. } \\
\text { 8. Teachers make students use English in class. }\end{array}$ & $\begin{array}{l}4.00^{3.50} \\
3.00\end{array}$ & $\begin{array}{l}4.25^{4.50} \\
4.75\end{array}$ \\
\hline $\begin{array}{l}\text { CREATE VARIOUS ACTIVITIES TO SPEAK ENGLISH FREELY } \\
\text { 9. Teachers create activities that enable learners to practise English. } \\
\text { 10. The class activities enable learners to speak in English. }\end{array}$ & $\begin{array}{l}4.50^{4.38} \\
4.25\end{array}$ & $\begin{array}{l}3.25^{3.62} \\
4.00\end{array}$ \\
\hline $\begin{array}{l}\text { QUESTION-ASKING IN CLASS BY LEARNERS } \\
\text { 11. Learners ask questions during the learning process. } \\
\text { 12. Learners ask questions if they do not understand certain topics. } \\
\text { 13. Learners ask questions if the teachers request them to. } \\
\text { 14. Learners use English to communicate with other learners. } \\
\text { 15. Learners ask questions spontaneously. } \\
\text { 16. Learners ask questions in English. }\end{array}$ & \begin{tabular}{l|}
4.50 \\
4.25 \\
3.50 \\
2.75 \\
3.75 \\
4.00
\end{tabular} & $\begin{array}{l}2.00 \\
3.25 \\
2.25 \\
3.75 \\
4.00 \\
4.00\end{array}$ \\
\hline $\begin{array}{l}\text { TEACHERS' RESPONSE TO LEARNERS' QUESTIONS } \\
\text { 17. Teachers correct students' mistakes in grammar. } \\
\text { 18. Teachers correct students' mistakes in vocabulary. } \\
\text { 19. Teachers correct students' mistakes in pronunciation. } \\
\text { 20. Teachers answer questions asked by the learners. }\end{array}$ & \begin{tabular}{l|}
2.50 \\
2.50 \\
2.75 \\
4.50
\end{tabular} & $\begin{array}{l}2.00 \\
3.00 \\
2.75 \\
4.75\end{array}$ \\
\hline
\end{tabular}

Note: Always $=4.51-5.00$

Sometimes $=3.51-4.50$

Often $=2.51-3.50$

Rarely $=1.50-2.50$

Never $\quad=1.50-2.50$

Figure 1 below presents the classroom conditions according to the teachers' perception by group. Teachers' overall perceptions of the classroom conditions were analysed in each indicator. 
Figure 1

Classroom Conditions according to teachers of Groups 1 and 2

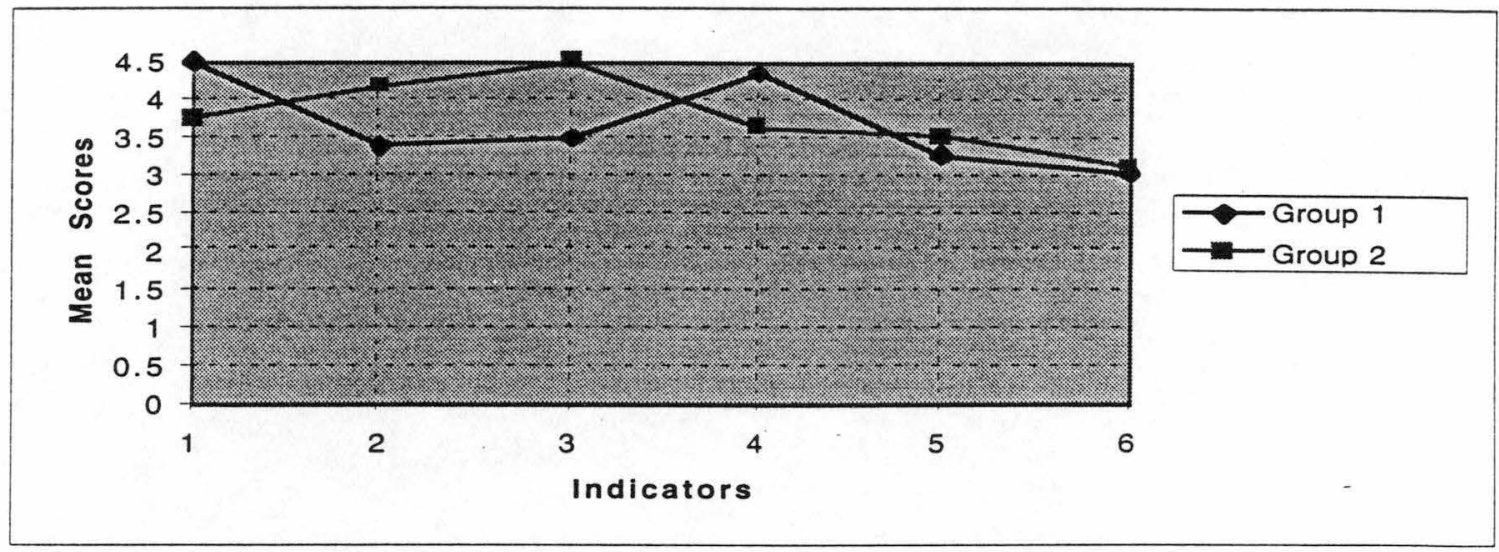

Note : Indicators

$1=$ treat learners as adult

$4=$ create various activities to speak freely

$2=$ methods used enhance communicative ability

$5=$ question asking in class

$3=$ using English for communication in class

$6=$ response to students' question

Figure 1 above shows that the two groups had different classroom conditions. The treatment of learners as adults by teachers was higher in Group 1 (mean score 4.50) than Group 2 (mean score 3.75). However, methods that enhanced communicative ability were more frequently used in Group 2 (mean score 4.19) than Group 1 (mean score 3.37), and the use of English for communication in the English classes was also more frequent in Group 2 (mean score 4.5) than Group 1 (mean score 3.5). On the other hand, in terms of creating activities to encourage students to speak freely in the classroom, Group 1 (mean score 4.37) scored higher than Group 2 (mean score 3.62). Whereas question asking by the learners and teachers' responses to learners' questions were similar (mean scores were 3.06 and 3.12 respectively).

Therefore, it seems that the classroom conditions in Group 1 were more conducive than Group 2 in treating learners as adults and creating activities to speak English freely in class. On the other hand, the classroom conditions in Group 2 were better than Group 1 in using methods that enhance communicative ability and also in using English for communication in class. 
However, the index level of differences reveals some of the classroom conditions were similar such as treating learners as adults, using English for communication in class, and creating activities to speak English freely in class. For indicator methods used to enhance communicative ability, the two groups were different. The table reveals that Group 2 'often' used methods that enhance communicative ability, while Group 1 only used that method 'sometimes'.

Figure 2 below reveals the classroom conditions according to teachers in detail by showing responses to each question item. As indicated in Table 5 above, this questionnaire contained 20 questions with six indicators. The responses of the eight teachers teaching these two groups are presented as mean scores per question item in the questionnaires.

Figure 2

Classroom condition according to teachers by questionnaire item

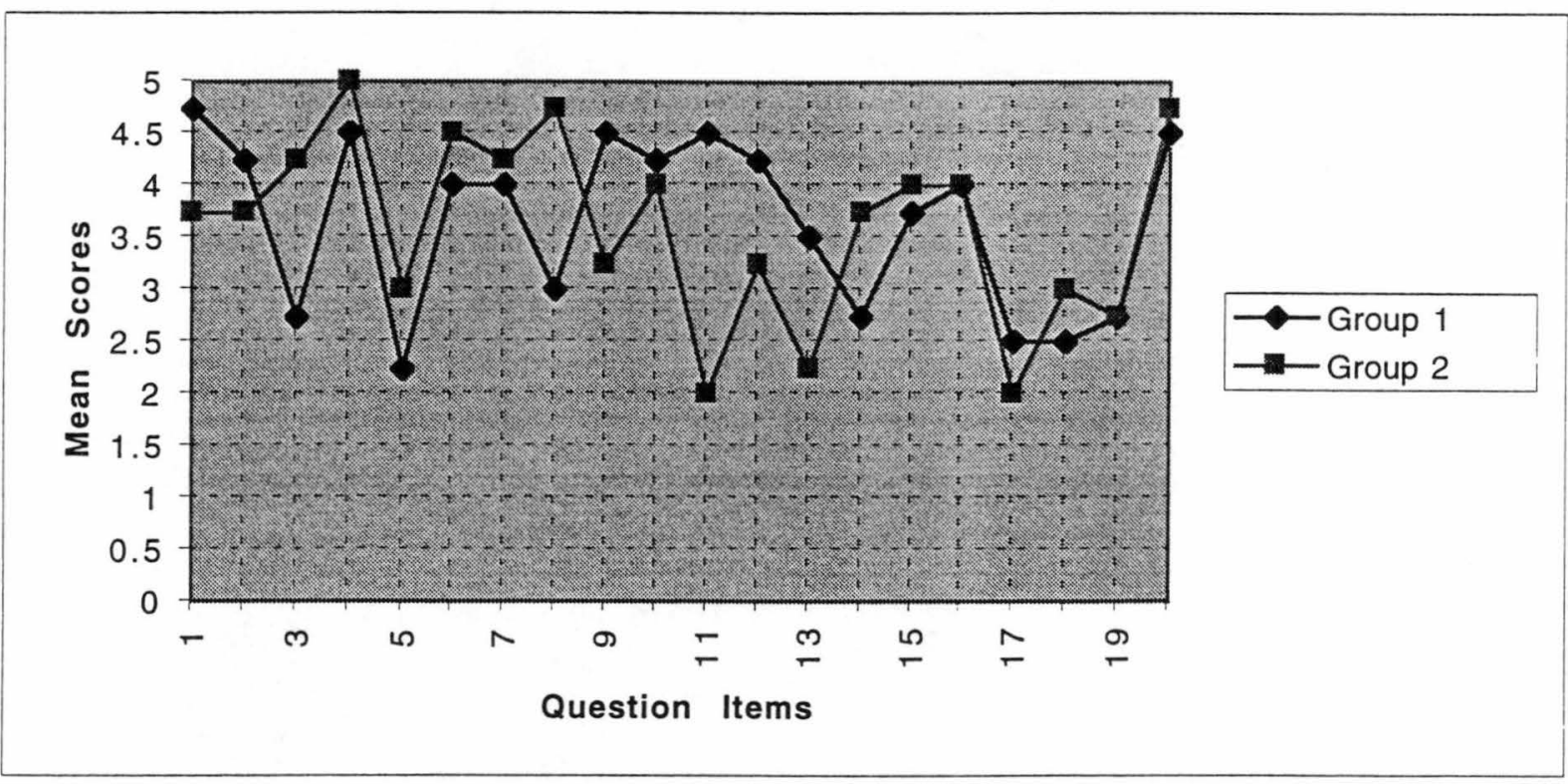

Figure 2 above shows that responses to many items were very similar and followed a similar pattern with the main variation on question items 1, 3, 8, 9, $11,12,13$ and 14. Teachers' endeavours to create an environment in which students felt free to speak (Question item 1, or Q1) was indicated 'always' in 
Group 1 (mean score 4.75), while in Group 2, it was only indicated as 'often' (mean score 3.75). Teachers in Group 1 spent most of their time explaining and practising grammatical rules (Q3) (mean score 2.75), while in Group 2 they did not (mean score 4.25). The attempts to force learners to use English in the class (Q8) was 'always' in Group 2 (mean score 4.75), while in Group 1 teachers did not force learners to speak English in class (sometimes) (mean score 3.00), they just let them speak independently. There was more variety in activities (Q9) in Group 1 (mean score 4.50) than Group 2 (mean score 3.25). That was why the learners in Group 1 asked more questions in classroom interaction (Q11) than Group 2. This is revealed in the mean score of Group 1 (4.50) and Group 2 (2.00). The initiative to ask questions if the learners did not understand certain topics (Q12) more frequently occurred in Group 1 (mean score 4.25) than Group 2 (mean score 3.25). In terms of initiative making questions coming from teachers, if the teachers asked the learners to ask questions (Q13), more questions came from Group 1 (mean score 3.5) rather than Group 2 (mean score 2.25). The frequency of using English to communicate with other students (Q14) was higher in Group 2 (mean score 3.75) than Group 1 (mean score 2.75).

From the investigation above, it can be concluded that although some differences in the mean scores were largely at the same frequency level for both groups, others were at a the different level, such as 'always' (Group 1) and 'often' (Group 2) in creating an environment that enabled learners to speak English freely (Q1) and 'often' (Group 1) and 'sometimes' (Group 2) for the variety of activities that enable learners to speak English in class (Q9). The larger differences were in teachers' attempts to force learners to use English in class (Q8), where Group 2 teachers 'always' did this, but Group 1 teachers only did it 'sometimes'. In the frequency of asking questions (Q11), in Group 1 learners 'always' asked questions, while in Group 2, learners 'rarely' did. To indicate whether initiative making questions came from teachers (Q13) or 
Table 6

The mean scores of learner questionnaires ( $n=8$ in each group)

\begin{tabular}{|c|c|c|c|c|}
\hline \multirow{2}{*}{ Question Items } & \multicolumn{2}{|l|}{ Group 1} & \multicolumn{2}{|l|}{ Group 2} \\
\hline & Spk & Str & Spk & Str \\
\hline TREAT LEARNERS AS ADULT & 3.81 & 3.88 & 4.00 & 3.94 \\
\hline 1. Learners were treated as adult. & 3.63 & 3.88 & 4.00 & 4.00 \\
\hline 2. Learners feel free to speak English in class. & 4.00 & 3.88 & 4.00 & 3.88 \\
\hline METHODS ENHANCE COMMUNICATIVE ABILITY & 3.85 & 4.13 & 4.13 & 3.94 \\
\hline $\begin{array}{l}\text { 3. Classroom environment enables learners to practise } \\
\text { English in class. }\end{array}$ & 4.50 & 4.00 & 4.38 & 4.25 \\
\hline $\begin{array}{l}\text { 4. Teachers are able to adjust their teaching strategies to } \\
\text { learners' level of English. }\end{array}$ & 3.63 & 4.13 & 4.13 & 3.75 \\
\hline 5. Teaching methods enhance learners' English & 3.88 & 4.25 & 4.50 & 4.50 \\
\hline 6. Teachers spend most of the time explaining grammar. & 3.38 & 4.13 & 3.50 & 3.25 \\
\hline USE ENGLISH FOR COMMUNICATION & 4.31 & 3.31 & 4.00 & 3.50 \\
\hline 7. Teachers use English in class. & 4.25 & 3.63 & 4.25 & 3.75 \\
\hline 8. English is used to explain grammar. & 4.38 & 3.00 & 3.75 & 3.25 \\
\hline CREATE VARIOUS ACTIVITIES TO SPEAK FREELY & 4.00 & 4.00 & 4.25 & 4.06 \\
\hline 9. Class activities force learners to practise English. & 4.00 & 3.88 & 4.38 & 4.25 \\
\hline 10.There are a lot of activities to practise English in class. & 4.00 & 4.13 & 4.13 & 3.88 \\
\hline QUESTION-ASKING IN CLASS BY LEARNERS & 3.31 & 3.50 & 3.67 & 3.29 \\
\hline 11. Learners ask questions in class. & 3.25 & 3.63 & 3.38 & 3.50 \\
\hline 12. Learners ask questions in English. & 2.75 & 3.38 & 3.63 & 3.00 \\
\hline $\begin{array}{l}\text { 13. Learners ask questions if they do not understand certain } \\
\text { topics. }\end{array}$ & 3.88 & 4.00 & 4.38 & 4.00 \\
\hline 14. Learners ask questions just to practise English. & 2.38 & 2.38 & 2.38 & 2.38 \\
\hline $\begin{array}{l}\text { 15. Learners ask questions to repeat phrase that they do } \\
\text { not understand. }\end{array}$ & 4.00 & 3.38 & 4.50 & 3.50 \\
\hline 16. Learners ask questions to their friends in class. & 3.63 & 4.25 & 3.75 & 3.38 \\
\hline RESPONSES ON LEARNERS' QUESTIONS & 4.32 & 4.24 & 4.09 & 4.25 \\
\hline 17. Teachers correct mistakes in grammar. & 4.00 & 4.00 & 3.88 & 3.88 \\
\hline 18. Teachers correct mistakes in pronunciation. & 4.13 & 4.00 & 3.50 & 4.00 \\
\hline 19. Teachers correct mistakes in vocabulary. & 3.75 & 4.13 & 3.50 & 3.88 \\
\hline 20. Teachers answer questions asked by learners. & 4.50 & 4.38 & 4.50 & 4.38 \\
\hline $\begin{array}{l}\text { 21. Learners like the teachers correct their mistakes in } \\
\text { grammar. }\end{array}$ & 4.63 & 4.38 & 4.38 & 4.63 \\
\hline $\begin{array}{l}\text { 22. Learners like the teachers correct their mistakes in } \\
\text { pronunciation. }\end{array}$ & 4.63 & 4.38 & 4.50 & 4.63 \\
\hline $\begin{array}{l}\text { 23. Learners like the teachers correct their mistakes in } \\
\text { vocabulary. }\end{array}$ & 4.63 & 4.38 & 4.38 & 4.38 \\
\hline
\end{tabular}

Note: Always $=4.51-5.00$

Sometimes $=3.51-4.50$

Often $=2.51-3.50$ Rarely $=1.50-2.50$

Never $=1.50-2.50$ 
learners (Q12), Group 1 seemed better than Group 2. However, the frequency of learner questions (Q15) was higher in Group 2 than Group 1.

\section{Learner Questionnaire}

The learner questionnaire which was analysed came from the responses by the eight learners in the two groups that were observed longitudinally over one semester. The total number of questionnaires arranged then was 16. For these present analyses, the responses from the two groups of learners were analysed separately to examine the conditions in classes by group. In this table, mean scores per indicator and per question items were presented.

Table 6 above shows that the mean scores of the learner questionnaire items to indicate their perceptions of classroom conditions. There were six indicators in this questionnaire, the same as those on the teacher questionnaire. The mean scores of the students' responses to the questionnaires were given both by indicator and by question item. This table formed the basis for investigating the classroom conditions according to the learners as described in Figures 3, 4 and 5 below.

Figure 3

Classroom condition according to learners in each class for Groups I and 2
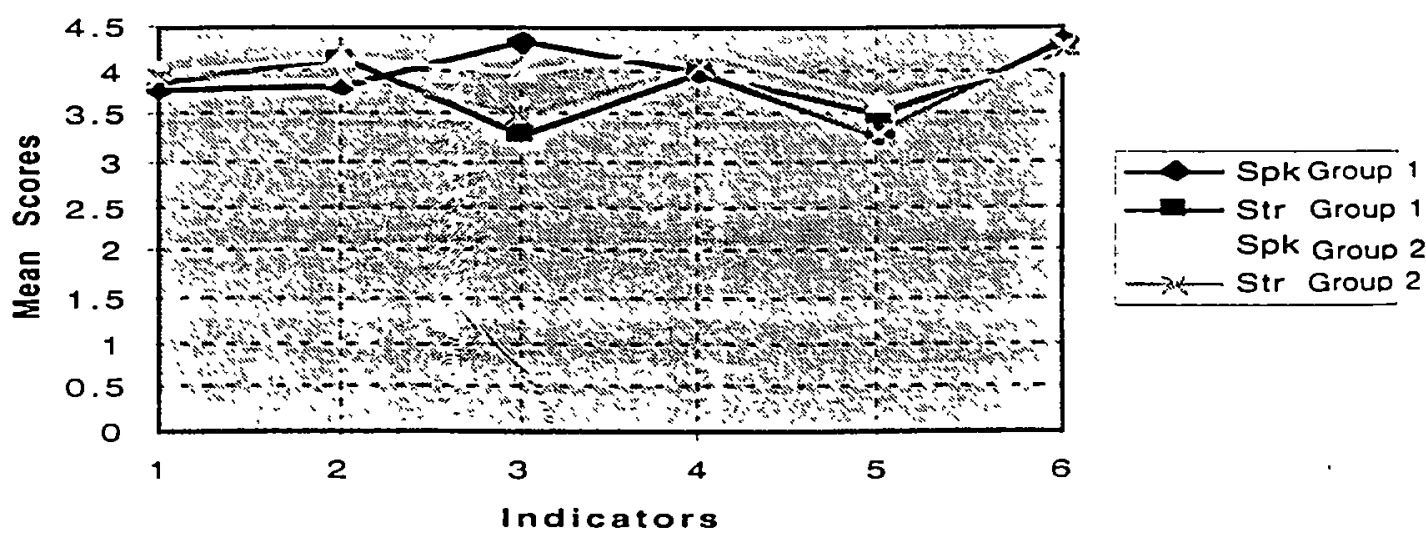

Note: $1=$ treat learners as adult

$4=$ crealte various activity to speak lirecly

2 = methods used enhance communicative ability $5=$ question asking in class

$3=$ using English for communication in class $6=$ response to students' question 
Figure 3 above reveals that the conditions of the classroom for structure class and speaking class for both groups were quite similar. The only difference was in the use of English in class (indicator 3), where in both groups English was more frequently used in the speaking class (mean scores 4.31 and 4.00 ) rather than structure class (mean scores 3.31 and 3.50). Questions from students (indicator 5) occurred more in the speaking class at Group 2 (mean score 3.67) rather than the speaking class at Group 1 (mean score 3.31). However, for the structure class, the learners at Group 1 asked questions more frequently (mean score 3.50) than the learners of Group 2 (mean score 3.29).

The data from Figure 3 reveal that English was 'often' used in speaking classes, but English was used only 'sometimes' in structure classes. Teachers felt that they 'often' treated learners as adults, using methods that enhanced communicative ability, created various activities to encourage students to speak freely in class, and gave responses to learners' questions. Question asking in class occurred 'often' in the speaking class of Group 2 and 'sometimes' for the speaking class at Group 1 and the structure class at Group

2. More detailed information can be seen in Figures 4 and 5 below.

Figure 4

Classroom condition according to learners of Group 1 by questionnaire item

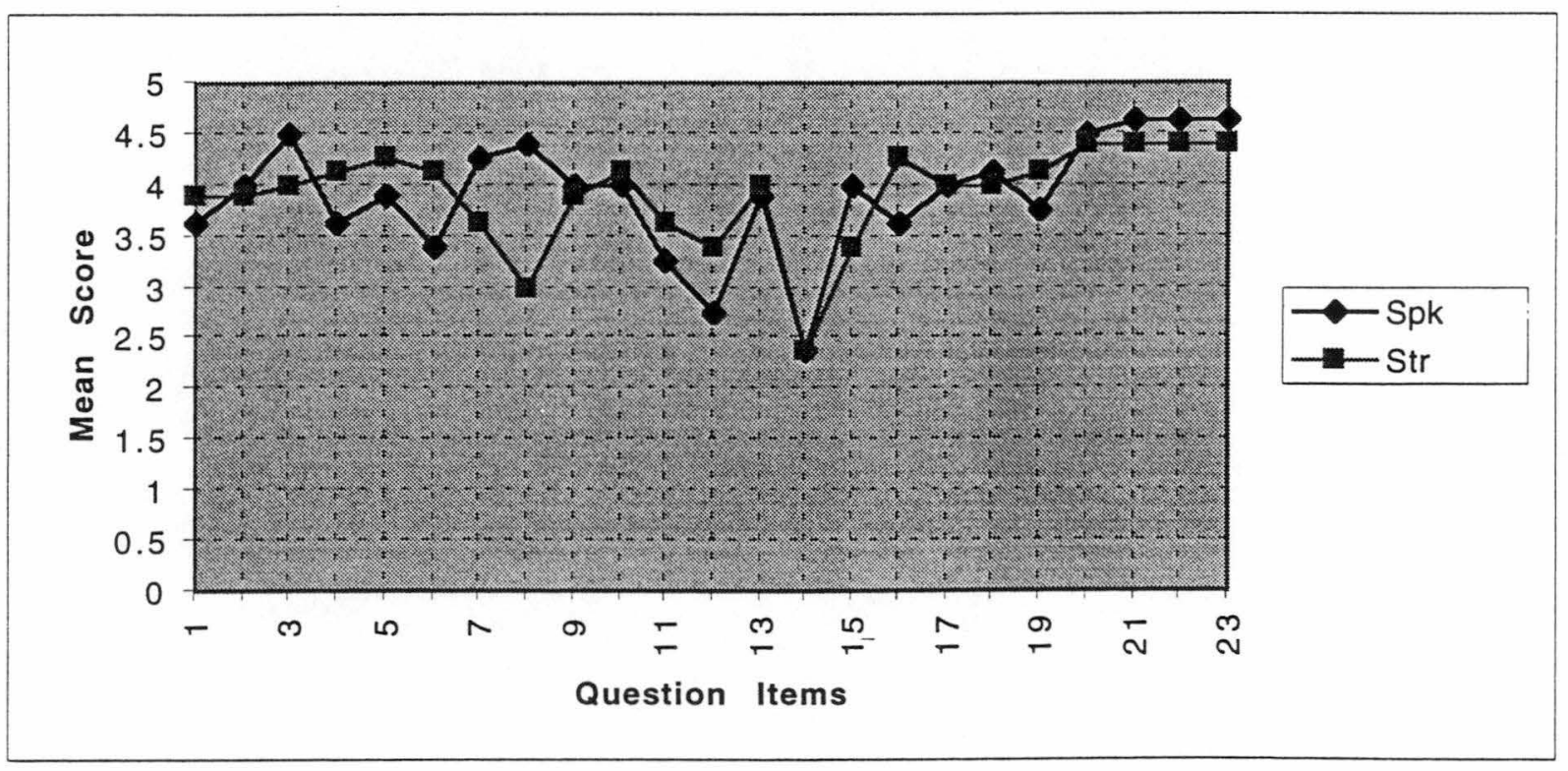


Figure 4 above indicates that learners' views of the conditions of their classes of speaking and structure were different from and not as extreme as the teachers' perception. The most prominent difference here was in the use of English to explain grammatical rules (Q8). Both speaking and structure teachers, explained grammar in their classes, and English was 'always' used to explain grammar in speaking class (mean score 4.38), while in the structure classes English was 'often' used (mean score 3.00). This means that Indonesian was also 'sometimes' used to explain grammar by structure teachers. The class that enabled learners to practise English more (Q3) was the speaking class (mean score 4.5) than the structure class (mean score 4.00). However, structure teachers were more flexible (Q4) (mean score 4.13) than speaking teachers (mean score 3.63). Teaching methods that enhanced learners' English proficiency (Q5) were more frequently employed in the structure class (mean score 4.25) than the speaking class (mean score 3.88). Teachers spent more time explaining grammatical structures (Q6) in the structure class (mean score 4.13) than the speaking class (mean score 3.38). However in terms of using English in class (Q7) speaking teachers used more English (mean score 4.25) than the structure class (mean score 3.63). Learners asked more questions (Q11 and Q12) in the structure class (mean score 3.63 and 3.38 ) rather than the speaking class (mean score 3.25 and 2.75). Learners asked teachers to repeat phrases that the learners did not understand (Q15) more frequently in the speaking class (mean score 4.00) than the structure class (mean score 3.38). In the structure class, learners asked questions of friends (Q16) more frequently (mean score 4.25) than in the speaking classes (mean score 3.63).

It can be concluded that the speaking class environments of Group 1 encouraged learners to practise English (Q3), teachers used English more frequently (Q7), and English was used to explain grammar more frequently than in the structure class (Q8). On the other hand, teachers in the structure class used methods that enhanced communicative ability (Q5), learners asked 
more questions (Q11 and Q12), and there was more interaction among learners (Q16).

Figure 5 below displays the conditions of class according to learners of Group 2.

Figure 5

Classroom conditions according to learners of Group 2 by questionnaire item

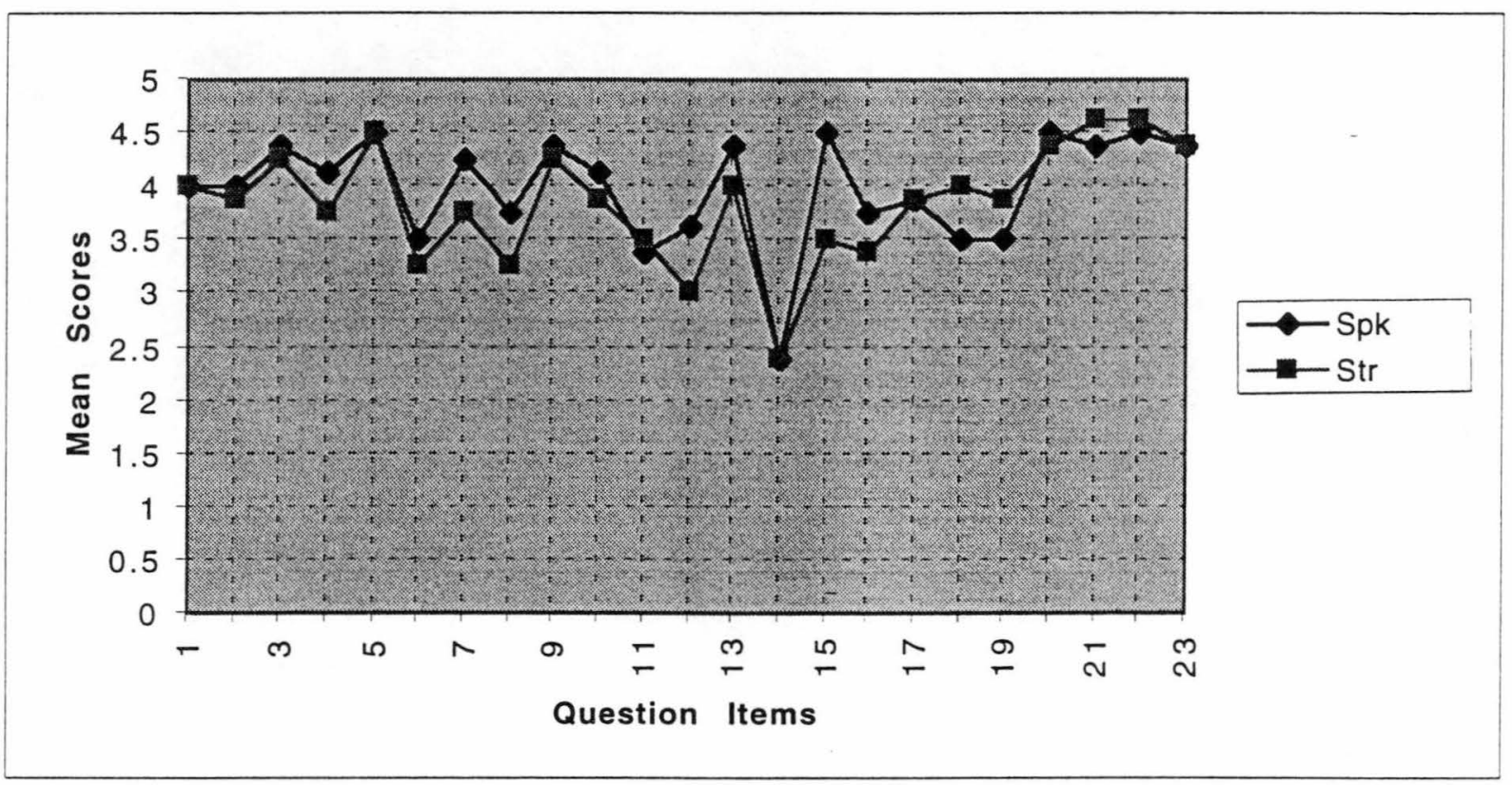

Figure 5 above indicates that the different environment of the classes were not as extreme as perceived by the teachers. For the ability to adjust teaching strategies to learners' level of English (Q4), the speaking class was higher (mean score 4.13) than the structure class (mean score 3.75). The use of English in class by teachers (Q7) and to explain grammar (Q8) was more frequently used in the speaking class (mean score 4.25 and 3.75) than the structure class (mean score 3.75 and 3.25). Learners in the speaking class asked more questions (Q12) in English (Q13) (mean score 3.63 and 4.38) than the structure class (mean score 3.00 and 4.00). Learners' questions, whether to repeat a phrase they did not understand (Q15) or to ask questions of other friends (Q16), also occurred more frequently in the speaking class (mean 
score 4.50 and 3.75) than the structure class (mean score 3.50 and 3.38). However, teacher correction of vocabulary (Q18) and grammar (Q19) were more frequent in the structure class (mean score 4.00 and 3.88 ) than the speaking class (mean score 3.50 and 3.50).

\section{Data from Interview}

As discussed in the chapter on methodology (Chapter 4), the interviews were unstructured. Since the researcher, as the interviewer, observed the interviewees in many occasions so he was able to see their circumstances on the basis of their usual operation.

In terms of the classroom learning environment, Group 1 seemed to be more active than Group 2. The initiative to get involved in classroom interaction more frequently occurred in Group 1 than Group 2. The following responses from teachers in Group 1 illustrate that they are aware of this.

They are willing to ask questions. I don't think I possess the problem. They ask about subject matter, vocabulary, and pronunciation. (T1)

In IAIN, it is not difficult for me to find an initiative to get students ask questions in classroom interaction, because they will ask questions simultaneously, although the questions are not grammatically correct, but they will ask questions. They ask questions because the problem they face. (T2)

The above responses revealed that learners actively engaged in classroom interaction. The teachers did not feel they need to ask questions of the learners in Group 1, since the learners asked questions spontaneously. This might be because they had difficulties in organising ideas, vocabulary, pronunciation, or grammar in English. Therefore, they asked questions.

The situation was slightly different in Group 2 as the responses from the teachers show.

They never ask me question. I feel like I wish they ask me more questions. And, I think, since I am an American, I think that American 
students take more initiative to ask their own questions, or if they confuse they ask questions for sure. But, since Indonesians are so usually unified instead of very individual, and I feel like if they feel that other people understand them, they should understand, and may be they shouldn't ask questions. May be that is why they don't ask a lot of questions or may be they are just too shy to ask questions. I think they are capable in asking questions that they want to ask, but may be they don't want to interrupt me or may be they feel that if everybody understand them they don't want to ask the question. But 1 do think that a lot they will do with culture, because in American classroom, we are taught to have a lot of questions all the time if we don't understand. (T5)

They seldom ask question. So, to make them ask question, I ask one of them to explain first, give him a topic. Other students will ask questions, this is one way. (T7)

The above responses reveal that the native-speaker English teacher (T5) was frustrated by the classroom conditions of Group 2, since the classroom conditions were different from the situation in the American context. She regarded this condition as the result of Indonesian cultural factors, and she also guessed that the problems might be because the students were too shy to ask questions. The same problem was faced by $\pi 7$, and she tried to solve the problem by creating activities that forced students to speak, respond, and ask questions. She asked a learner to explain a topic and then the other students asked relevant questions.

Creating activities that enabled learners to speak English in class was the main concern of teachers in both groups. The responses from teachers in both groups below reflect this concern.

Usually I start from small group activity. First I try to control them, go around, use only English. I also said use English, never mind whether you make mistakes, never mind, that you use English. And after that I ask them to bring it into class discussion. (T2)

It is first two by two, and then for about ten minutes, I combine one group to another become four by four, and then eight by eight, and then become classroom discussion. (T7) 
I ask them to make pair conversation, and then try to present them in front of their friends. (T3)

I ask them to interview their friends, the students who sit next to him. Give them topic to ask, for example ask about his or her family. (T4)

I feel like if they are in small group. They will actually speak. They won't be too shy to speak and may be they may ask each other questions if they don't understand. Like today, I have put them in small group either in pairs or in small groups. (T5)

I prefer small group activity. In small group activity, students have greater possibility to ask and answer questions, and later probably after working in small groups, we can have class activity led by teacher. (T6)

These responses reveal that the teachers realised that working in small groups would give learners greater opportunities to ask and answer questions. The learners would not feel too shy to speak, and they might also ask each other questions if they did not understand the topic.

Learners' interview responses to the questions related to classroom condition are presented below.

Because the explanation from lecturer is clear, so no more to be questioned. (L2)

Usually someone ask a question if he does not understand. So I did not ask question because I understand what the teacher said. (L5)

Not often, because sometimes I don't understand what the teacher said, after that I ask to my friend beside me. Then, I understand, I did not ask to my teacher. (L8)

Not often, because I am afraid to make mistakes. I have something to ask, but sometimes I feel shy because some of my friends are very good in English. (L7)

I think I want to ask question, but I do not know what to ask. (S1)

I rarely ask question. I am afraid that I make mistake because my vocabulary is very limited. (S4) 
Learners had different reasons for not asking questions in class. Some of them were because the teacher's explanation was clear (L2 and L5), because they clarified the point that they did not understand with their friends (L8), because they were afraid to make mistakes (L7), because they did not know what to ask (S1), and because of limited vocabulary (S4).

The classroom activities that the learners preferred for enabling them to practise English were group discussion, as the following responses by the learners indicate.

Small group discussion and activities that can make us speak in English. Although we make mistakes but we are not afraid to speak. (L6)

The most effective one is beginning with small group, big group, and then class discussion, so that the students will be brave to speak. (L2)

Discussion, report. I like them because I can practice my English. (L8)

Discussion, it forces me to make sentences and questions. (L1)

A student comes to the front of class to explain a topic and other students will ask questions. (S2)

Quiz, conversation, small group activity. It is very interesting for me because I can speak very much. (S3)

The responses above indicate that the most preferred activities of learners are small group activities and discussion. The others are conversations, reports, and quizzes. 


\section{Data from Classroom Observation}

Although the learners had different reasons for undertaking the English course, they all had the same main aim: to communicate in English. Both groups had the same level of English when they entered English classes. However, difference in ages made the classroom conditions quite different. The learners in Group 1 were generally older (age range 27-41 years) than those in Group 2 (age range 17-20 years). This differece leads to different cohesion in class.

The closeness among the learners in Group 1 was achieved in a shorter time compared to Group 2. In addition, a positive relationship with the teachers who taught them in class seemed better in Group 1 than Group 2. This condition made the learners in Group 1 feel freer to speak to the teachers. This could be seen before the class began and when the class ended. More interaction happened between learners and teachers in Group 1, while in Group 2, learners tended to keep silent until the teacher began the lesson.

In the learning process, spontaneous questions from the learners occurred more in Group 1 than Group 2. However most of the questions produced by the learners were not well-formed questions $(54 \%$ grammatical and $48 \%$ ungrammatical). Forexample:

(i) If you say, but anybody don't action, what about? (Speaking class)

(ii) What about the others, we did so about here? (Speaking class)

(iii) Look up set the same the meaning worried? (Structure class)

(iv) Is it be able when we make the question 'with who did he go to movie'? (Structure class)

For learners in Group 2, although only limited questions were asked, the forms of questions seemed mostly grammatically correct $(74 \%$ grammatical and $26 \%$ ungrammatical). 


\subsubsection{Teaching strategies used by teachers to enable learners to ask questions in English}

A strategy, here, is considered to be a procedure used by teachers in the teaching-learning process as a way of reaching a goal (Richard, Platt, and Weber, 1985). As discussed in Chapter 1 the goal of learning a foreign language is to enable the learner to communicate in the language being learned. To achieve this goal, two main approaches are used by teachers, grammar based teaching and communicative based teaching. This study examines both approaches, that is why a structure class and a speaking class were studied. It was assumed that the structure class applied grammar based teaching, and the speaking class employed communicative based teaching in the teaching-learning process.

From the interview with teachers in both classes, teachers mentioned that they focused their teaching on communication. Therefore, whether structure or speaking was taught, the goal was to enable learners to communicate in English. In discussion of the main focus of their teaching, the speaking teachers made the following comments.

Communication of course, because 1 am teaching speaking, communication. (T6)

I give more chance to students to speak in class, get them to be more confident when they are speaking. (T5)

When the same question was asked of structure teachers, they responded with the following.

It seems to me that I focused on communication; I mean I teach grammar, but I want the children able to use the grammar itself. (T7)

Communication, the book help me to use the grammar or structure in communication. So, the way the writer uses the activity is good. So, it can be applied in communication. (T3) 
Of course communication, so grammar is only the tool, our main focus is communication (T5).

The answer from the teachers above indicates that although the structure class teachers used grammar based teaching, the goal to be achieved was communication, the same as the goal of speaking teachers.

In the following section, the teaching strategies used by both speaking teachers and structure teachers will be investigated based on observation, interview, and questionnaires given to the teachers and learners.

\section{Speaking Class}

Because the orientation of speaking class was communication, the teachers mainly used task oriented teaching strategies. The classes usually began with the teacher giving an explanation or instruction to the learners. The teacher presented a topic to be discussed, then gave some useful expressions on how to express an idea in relation to the topic given. These were things that the learners were going to play with or use. After that, the learners practised in small group activities.

In general, there were two types of activities in speaking class, class work activities, and group work activities. In class work activities, teachers explained anything in relation to the topic to be discussed or done that day. In this situation, some questions might be asked by learners about the procedures, expressions to be used, and problems in relation to the tasks to be done. After everything was clarified, the teacher then asked the learners to work in groups. Since the learners got involved in the task, more questions might arise from the learners about the way to express an idea or vocabulary item. Usually, more questions appeared when learners did the tasks. 


\section{Structure Class}

In the structure class, the focus of teaching was on learners being able to use the target sentence correctly in communication. This was a kind of practiceoriented teaching strategy. The class usually began with a lecture from the teacher about the grammatical rules by giving some examples of sentences in a given context. Then, the learners practised making sentences orally with teacher's guidance. Next, the learners were asked to make their own sentences in accordance with the rules as explained previously. Finally, the teachers asked the learners to make short conversations in their own words practising the sentences in the context given by the teacher.

Generally, the class began with a class activity which was followed by a small group activity. Pair work was sometimes done to practise making sentences in light of the patterns or rules of grammar presented. There were two kinds of pair work activities: pair work with a neighbour and pair work with somebody else who was not the neighbour. For the latter, a learner was free to choose who would be his/her partner to make a conversation. In this type of work, all members in class were able to listen and to be chosen as the partner of a conversation by a learner. The difference between pair work with a neighbour and pair work with someone else without the neighbour was that the first could be done at the same time by all members in class, but the second one was only done by one pair of learners at one time.

The explanation above shows that there were some patterns in the classroom interaction observed. The patterns of classroom interaction in both classes, speaking and structure classes, can be described as follows. 
1) Classroom Interaction A : One way and two way teacher-student interaction

This type of classroom interaction is one way and two way communication between the teacher and the students. Usually, this happened in the class where the teacher explained something or gave instructions to learners, and learners were able to ask questions or respond to the teacher.

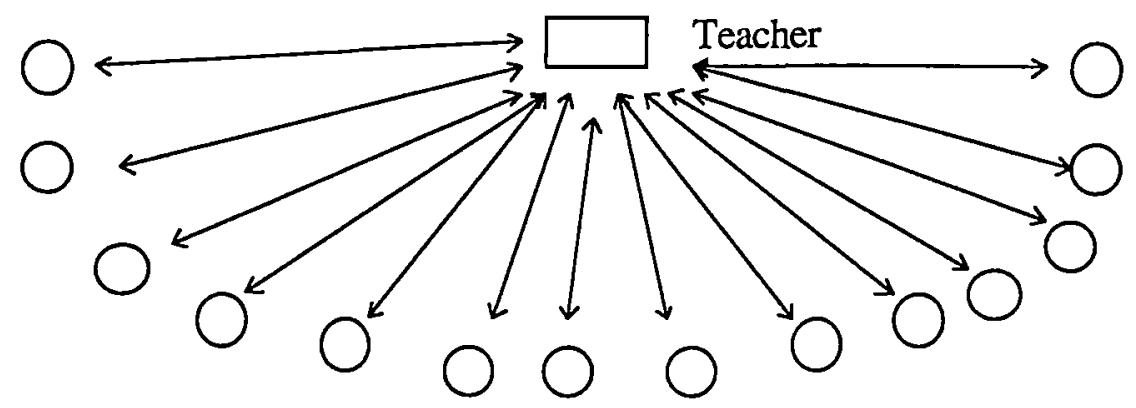

Learners

2) Classroom Interaction $B$ : Two way learner/learner interaction

This type of interaction happened if the teacher asked a learner to make a report, or explain something to his/her friends. There may be one or two way communication between the learner doing the task and other learners in class.

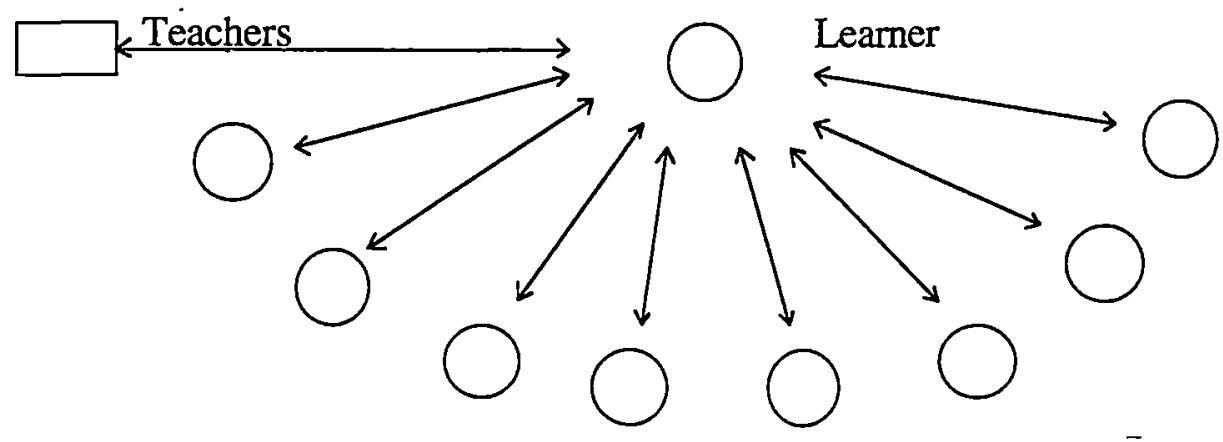

Learners 
3) Pair Work A : Two way learner-learner interaction

This type of activity is pair work with a neighbour. Learners undertook the activity to practise language, or to discuss certain problems as directed by the teacher.
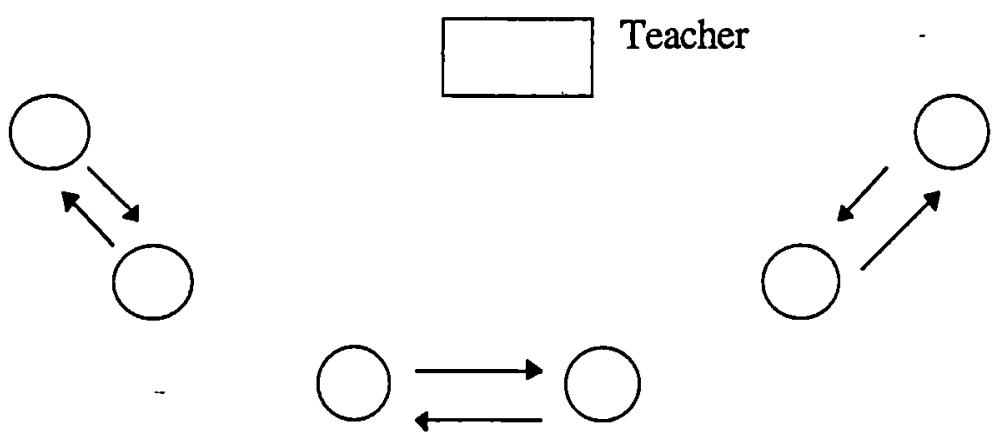

Learners

4) Pair Work $B$

This activity was usually undertaken to practise a conversation with someone not the neighbour. A learner was free to choose a member of the class to be his/her pair work partner in conversation, or in asking questions.

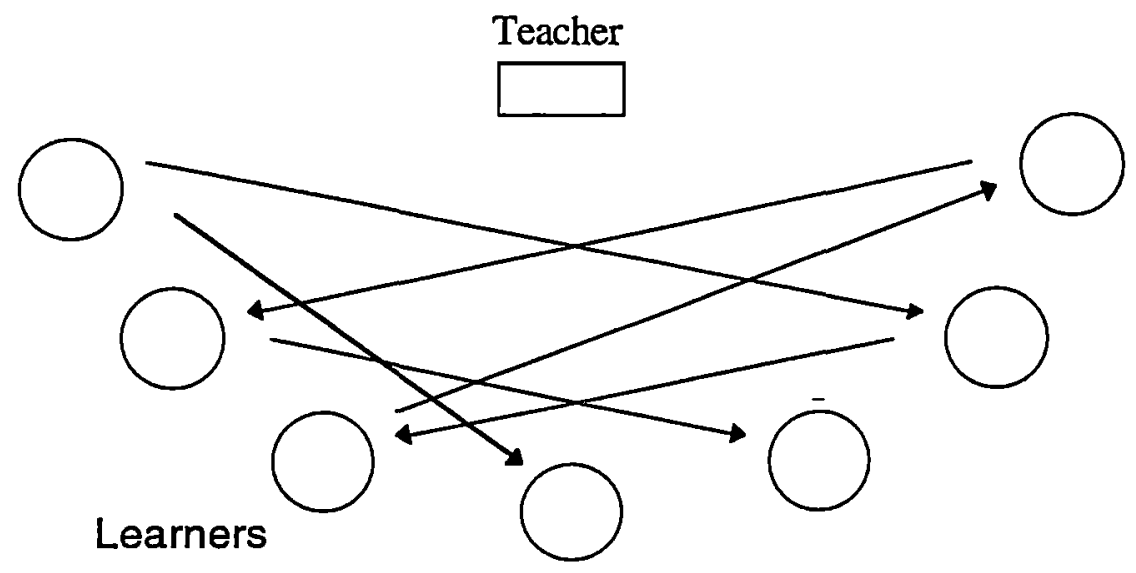




\section{5) Group Work}

Group work is an activity where learners were divided into four or five people in a group to do a task given by the teacher.

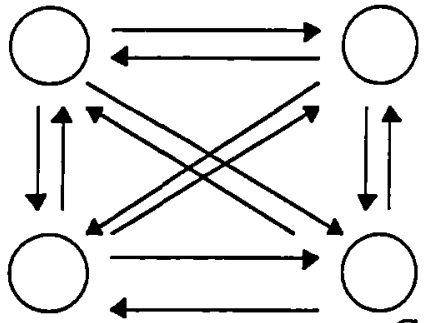

Group 1
Teacher

Group 2

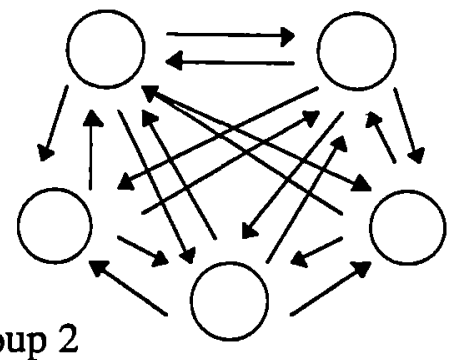

In this type of activity, more interaction among the members of group occurred.

\subsubsection{Teaching strategies for encouraging learners to ask question}

When the researcher asked teachers about their strategies for encouraging learners to ask questions, the teachers responded in the following ways.

I think if we give problem to them, and then we ask them, may be to work in pair or in group, and after that we ask them to tell what they have got in the discussion, and then we encourage other students to ask them questions. 'You may ask your friends as many as you can, asking for clarification, or may be if you disagree you may say that you disagree. So, I think peer or pair, work in pair group or may be class discussion will make the students ask questions. (T2)

I asked them to work in pair. I give them a topic to ask them to interview their friends, and later I check whether they create the correct questions or not. (T4)

I love that when they are in small group, people say, 'How do you call it? What does it mean if...?' (T5)

I prefer small group activity. In small group activity students have greater possibility to ask and answer question, and later after 
working in small group, we can have class activity led by teachers. (T6)

The responses of the teachers show that small group activities encourage learners to ask and answer questions.

From the learners' point of view, when the researcher asked them which activities were best suited to improving their ability in asking and answering questions, the learners answered:

Discuss in small group, and report, I like them because I can practise my English. (L8)

Small group activity; we feel free to speak because we have the same level of ability. (L7)

Group discussion; although we make mistakes but we are not afraid to speak. (L6)

The answers from the learners show that small group activities, reports, and discussion enable learners to ask and answer questions, because they feel free to speak and are not afraid to make mistakes.

\subsubsection{The frequency of questions in classroom interaction}

The frequency of questions in classroom interaction was analysed based on the audio recordings made in observing classroom interaction. There were 16 meetings in a semester for each class. Five meetings (30\%) were randomly selected for analysis as samples. The frequency of questions produced by the Indonesian adult learners of English as a foreign language class is investigated in the Tables $6 \mathrm{~A}, 6 \mathrm{~B}$, and $6 \mathrm{C}$.

Table 7 below displays the frequency of questions by learners both in groups 1 and 2 over the five classroom interaction sections. 
Table 7

The frequency of questions produced by learners in classroom interactions in Groups 1 and 2

\begin{tabular}{|c|c|c|c|c|c|c|c|}
\hline \multirow[b]{2}{*}{ Classes } & \multicolumn{5}{|c|}{$S$ a m p l e $s$} & \multirow[t]{2}{*}{ Total } & \multirow{2}{*}{$\begin{array}{l}\text { Mean } \\
\text { Scores }\end{array}$} \\
\hline & 1 & 2 & 3 & 4 & 5 & & \\
\hline Group 1 & 64 & 45 & 45 & 47 & 59 & 260 & 26 \\
\hline Group 2 & 17 & 22 & 52 & 48 & 48 & 187 & 19 \\
\hline Total & 81 & 67 & 97 & 95 & 107 & 447 & 22 \\
\hline
\end{tabular}

Table 7 above lists the frequency of questions for Groups 1 and 2 in the frequency of question occurrences. Overall, Group 1 produced more questions in classroom interactions than Group 2. The total number of questions in Group 1 was 260 questions (mean score $=26$ ), while in Group 2, there were 187 questions (mean score $=19$ ). When both groups were combined, a total of 447 questions, with a mean score of 22 were generated. Tables $6 \mathrm{~B}$ and $6 \mathrm{C}$ will describe in detail the frequency of questions produced by learners by class and by session samples in each group.

Table 8

The frequency of questions produced by learners in classroom interactions in Group 1

\begin{tabular}{|c|c|c|c|c|c|c|c|}
\hline \multirow[b]{2}{*}{ Classes } & \multicolumn{5}{|c|}{$\begin{array}{llllll}S & a & m & p & l & e\end{array}$} & \multirow[t]{2}{*}{ Total } & \multirow{2}{*}{$\begin{array}{l}\text { Mean } \\
\text { Scores }\end{array}$} \\
\hline & 1 & 2 & 3 & 4 & 5 & & \\
\hline Speaking Class & 22 & 12 & 11 & 10 & 28 & 83 & 17 \\
\hline Structure Class & 42 & 33 & 34 & 37 & 31 & 177 & 35 \\
\hline Total & 64 & 45 & 45 & 47 & 59 & 260 & 26 \\
\hline
\end{tabular}

Table 8 above shows that the frequency of questions produced varied by class and by session samples, from 10 questions (lowest score) to 42 questions (highest score). It also shows that there was a greater frequency of questions in the structure class rather than in the speaking class. The total number of questions for the five meetings of the structure class was 83 questions with a 
mean score of 17 . The total number of questions of the five meetings in the speaking class was 177 questions, with a mean score 35. Therefore, in the structure class questions were produced twice as frequently as in the speaking class. Overall, both classes produced 260 questions, with a mean score of 26.

Table 9

The frequency of questions produced by leamers in classroom interactions in Group 2

\begin{tabular}{|c|c|c|c|c|c|c|c|}
\hline \multirow[b]{2}{*}{ Classes } & \multicolumn{5}{|c|}{$S$ a m } & \multirow[t]{2}{*}{ Total } & \multirow{2}{*}{$\begin{array}{l}\text { Mean } \\
\text { Score }\end{array}$} \\
\hline & 1 & 2 & 3 & 4 & 5 & & \\
\hline Speaking Class & 8 & 6 & 46 & 43 & 31 & 134 & 27 \\
\hline Structure Class & 9 & 16 & 6 & 5 & 17 & 53 & 11 \\
\hline Total & 17 & 22 & 52 & 48 & 48 & 187 & 19 \\
\hline
\end{tabular}

Table 9 shows a very different pattern of question production in Group 2 compared with Group 1. It indicates that the lowest frequency of questions was 5 in one meeting, and the highest number of questions was 46 . Once again it appears that more questions were asked in the speaking class than the structure class. The total number of questions in the speaking class was 134 questions, with a mean score of 27 . By comparison, the total number of questions in the structure class was 53 questions, with a mean score of 11. Thus, the learners in speaking class produced $250 \%$ more questions than the structure class. In total, learners in the speaking class and the structure class of Group 2 generated a total of 187 questions, with a mean score of 19 (range 546).

By investigating the results of the data shown in tables $6 \mathrm{~A}, 6 \mathrm{~B}$, and $6 \mathrm{C}$, it can be deduced that the frequency of questions occurrences was not related consistently to the subject taught: speaking or structure. The data show that learners in the speaking class, where communicative activities were the focus of teaching, did not always produce more questions than those in the structure 
class. On the other hand, learners in the structure class, where explaining and practising grammatical rules were the focus of teaching, did not always produce less questions than those in speaking class. Although in Group 1 the structure class produced more questions than the speaking class (the mean scores were 35 and 17 respectively), the speaking class of Group 2 produced more questions than the structure class (the mean scores were 27 and 11 respectively).

By comparing Groups 1 and 2 in terms of frequency of question production (Table 9), it was discovered that Group 1 produced more questions than Group 2. This result is consistent with what was found in the classroom conditions (section 5.1.1.1), which indicated that more questions occurred in Group 1 compared to Group 2, since learners in Group 1 were willing to ask questions spontaneously in classroom interaction.

\subsection{Type of questions most frequently used by learners in teaching-learning process}

Types of questions can be categorised in three ways; (1) based on the forms of questions (Quirk, 1985), (2) based on the content of questions or hierarchical structure of thinking (Bloom, 1956), and (3) based on the function of questions (Long and Sato, 1983). This section will investigate these three types of questions to identify question forms most frequently used by Indonesian adult learners of English as a foreign language. 


\subsubsection{Types of forms of questions most frequently used in classroom interaction}

Quirk (1985) classified question forms into three types: wh-questions, yes-no questions, and alternative questions. In classroom interaction, the question forms used by adult learners can be described in these terms.

Table 10 below displays the types of questions frequently used by the learners in Groups 1 and 2 in classroom interaction.

Table 10

Types of question forms frequently used by learners in classroom interactions in Groups 1 and 2

\begin{tabular}{|c|c|c|c|c|}
\hline \multirow[b]{2}{*}{ Classes } & \multicolumn{3}{|c|}{ Types of Questions } & \multirow[b]{2}{*}{ Total } \\
\hline & Wh-Question & Yes-No Question & Alternative Question & \\
\hline Group 1 & $114(44 \%)$ & $142(55 \%)$ & $4(1 \%)$ & $260(100 \%)$ \\
\hline Group 2 & $81(43 \%)$ & $102(55 \%)$ & $4(2 \%)$ & $187(100 \%)$ \\
\hline Total & $195(43 \%)$ & $244(55 \%)$ & $8(2 \%)$ & $447(100 \%)$ \\
\hline
\end{tabular}

Table 10 above reveals that both groups, in general, showed a preference for using yes-no questions in classroom interaction (55\%). Wh-Questions were the second preference $(43 \%)$. Alternative questions were clearly the third preference and were used very rarely $(2 \%)$ by learners.

Tables 11 and 12 below show the types of questions forms by frequency of use in Group 1 and Group 2 for each class in the classroom interaction context.

Table 11

Types of question forms frequently used by learners in classroom interactions in Group 1

\begin{tabular}{|c|c|c|c|c|}
\hline \multirow[b]{2}{*}{ Classes } & \multicolumn{3}{|c|}{ Types of Questions } & \multirow[b]{2}{*}{ Total } \\
\hline & Wh-Question & Yes-No Question & $\begin{array}{l}\text { Alternative } \\
\text { Question }\end{array}$ & \\
\hline Speaking class & $38(46 \%)$ & $43(52 \%)$ & $2(2 \%)$ & $83(100 \%)$ \\
\hline Structure class & $76(43 \%)$ & $99(56 \%)$ & $2(1 \%)$ & $177(100 \%)$ \\
\hline Total & $114(44 \%)$ & $142(55 \%)$ & $4(1 \%)$ & $260(100 \%)$ \\
\hline
\end{tabular}


Table 11 above shows that yes-no questions were the type of questions most frequently used by the learners in classroom interaction. In the speaking class, $52 \%$ of the questions were in the form of yes-no questions, and in the structure class, $56 \%$ of the questions were of this type. Moreover, wh-questions made up $46 \%$ of questions in the speaking class and $43 \%$ in the structure class. For both classes, the speaking class and the structure class, alternative questions were used very rarely ( $2 \%$ and $1 \%$ respectively) by the learners. In total, for both classes, yes-no questions made up 55\% of all questions, wh-questions were $44 \%$, and alternative questions were only $1 \%$.

Table 12

Types of question forms frequently used by learners in classroom interactions in Group 2

\begin{tabular}{|c|c|c|c|c|}
\hline \multirow[b]{2}{*}{ Classes } & \multicolumn{4}{|c|}{ Types of Questions } \\
\hline & Wh-Question & Yes-No Question & $\begin{array}{l}\text { Alternative } \\
\text { Question }\end{array}$ & Total \\
\hline Speaking class & $58(43 \%)$ & $74(55 \%)$ & $2(2 \%)$ & $134(100 \%)$ \\
\hline Structure class & $23(43 \%)$ & $28(53 \%)$ & $2(4 \%)$ & $53(100 \%)$ \\
\hline . Total & $81(43 \%)$ & $102(55 \%)$ & $4(2 \%)$ & $187(100 \%)$ \\
\hline
\end{tabular}

Table 12 above reveals that yes-no questions were most frequently employed in both the speaking class and the structure class. Alternative questions were employed very rarely by the students. In the speaking class, $55 \%$ of questions produced by learners of Group 2 were yes-no questions, $43 \%$ wh-questions, and $2 \%$ alternative questions. In the structure class, $53 \%$ of questions produced were yes-no questions, $43 \%$ wh-questions, and $4 \%$ alternative questions. In total, for both the speaking and the structure classes, $55 \%$ of questions were yes-no questions, $43 \%$ wh-questions, and only $2 \%$ alternative - questions. 
Table 11 and $7 \mathrm{C}$ show that the two groups are almost identical in the percentages of question forms in classroom interaction. Although the frequency of question occurrences in Group 2 was less than Group 1, in percentage they are similar.

\subsubsection{Types of content of questions most frequently used in classroom interaction}

Bloom (1956) identified six types of questions based on the content of the questions, that is the hierarchical structure of thinking. The types of questions are knowledge, comprehension, application, analysis, synthesis and evaluation. This taxonomy suggests that we are able to value or judge something by having the ability to (1) know the facts (knowledge), (2) understand the facts (comprehension), (3) apply the facts (application), (4) take the facts apart (analysis), (5) put the facts together in such away to discover a new perspective (synthesis), and (6) evaluate the facts (evaluation) (Bloom, 1956; Morgan and Saxton, 1991). This hierarchy of thinking is arranged from the simple (recall facts) to the complex (evaluate facts). That is why the first three levels of the taxonomy are considered to be the lower-order questions, and the last three of the taxonomy are regarded as higher order questions (Morgan and Saxton, 1991). Tables $8 \mathrm{~A}, 8 \mathrm{~B}$, and $8 \mathrm{C}$ shows the frequency of each type of question used by Indonesian adult learners in classroom interaction based on the Blooms taxonomy above.

Table 13 below presents Groups 1 and 2 in terms of types of questions frequently used by learners in classroom interaction based on the hierarchical structure of thinking. 
Table 13

Types of questions frequently used in classroom interaction

based on hierarchical structure of thinking in Groups 1 and 2

\begin{tabular}{|c|c|c|c|c|c|c|c|}
\hline \multirow{3}{*}{ Classes } & \multicolumn{6}{|c|}{ Types of Questions } & \multirow[b]{3}{*}{ Total } \\
\hline & \multicolumn{3}{|c|}{ Lower Order Questions } & \multicolumn{3}{|c|}{ Higher Order Questions } & \\
\hline & Knowledge & Comprehension & Application & Analysis & Synthesis & Evaluation & \\
\hline Group 1 & $177(68 \%)$ & $48(18 \%)$ & $9(4 \%)$ & $13(5 \%)$ & $5(2 \%)$ & $8(3 \%)$ & $260(100 \%)$ \\
\hline Group 2 & $106(57 \%)$ & $48(26 \%)$ & $10(5 \%)$ & $9(5 \%)$ & $10(5 \%)$ & $4(2 \%)$ & $187(100 \%)$ \\
\hline Total & $283(63 \%)$ & $96(21 \%)$ & $19(5 \%)$ & $22(5 \%)$ & $15(3 \%)$ & $12(3 \%)$ & $447(100 \%)$ \\
\hline
\end{tabular}

Table 13 above reveals that in both groups, the most frequently occurring questions in classroom interaction were at the level of knowledge $(63 \%)$. Comprehension questions were second (21\%). Application and analysis were third and fourth (both 5\%), while synthesis and evaluation were fifth and sixth (both $3 \%$ ). In conclusion, for both groups, $89 \%$ of questions were lower-order questions, and only $11 \%$ were higher order questions.

Tables $8 \mathrm{~B}$ and $8 \mathrm{C}$ below show in detail the frequency of questions for each class in each group.

Table 14

Types of questions frequently used in classroom interactions based on hierarchical structure of thinking in Group 1

\begin{tabular}{|c|c|c|c|c|c|c|c|}
\hline \multirow[b]{3}{*}{ Classes } & \multicolumn{6}{|c|}{ Types of Questions } & \multirow[b]{3}{*}{ Total } \\
\hline & \multicolumn{3}{|c|}{ Lower Order Questions } & \multicolumn{3}{|c|}{ Higher Order Questions } & \\
\hline & Knowledge & Comprehension & Application & Analysis & Synthesis & Evaluation & \\
\hline Speaking Class & $53(64 \%)$ & $21(26 \%)$ & $2(2 \%)$ & $1(1 \%)$ & $1(1 \%)$ & $5(6 \%)$ & $83(100 \%)$ \\
\hline Structure Class & $124(70 \%$ & $27(15 \%)$ & $7(4 \%)$ & $12(7 \%)$ & $4(2 \%)$ & $3(2 \%)$ & $177(100 \%)$ \\
\hline Total & $177(68 \%)$ & $48(18 \%)$ & $9(4 \%)$ & $13(5 \%)$ & $5(2 \%)$ & $8(3 \%)$ & $260(100 \%)$ \\
\hline
\end{tabular}


Table 14 above reveals that most of the questions which occurred in the classroom interactions were knowledge questions (to know the facts) which is the lowest level in the taxonomy of hierarchical structure of thinking (Bloom, 1956). Sixty-five percent of questions in the speaking class were of this level, and $70 \%$ of questions in the structure class were of this level. The second most frequently used question type was comprehension, which comprised $26 \%$ of questions for the speaking class and $15 \%$ for the structure class. The third and the fourth types varied for both classes. The speaking class used evaluation $(6 \%)$ the third most frequent and application (2\%) fourth, while the structure class used analysis (7\%) third and application (4\%) fourth.

From Table 14 above, it can be concluded that lower-order questions dominated classroom interaction, where $92 \%$ of questions in speaking class were at this level, the other $8 \%$ of questions were higher-order questions. In the structure class, $89 \%$ of questions were the lower-order questions, and the other $11 \%$ of questions were the higher order questions. In total, for both classes, $90 \%$ of questions were lower-order questions and $10 \%$ of questions were higher-order questions.

Table 15

Types of questions frequently used in classroom interactions based on hierarchical structure of thinking in Group 2

\begin{tabular}{|c|c|c|c|c|c|c|c|}
\hline \multirow{3}{*}{ Classes } & \multicolumn{6}{|c|}{ Types of Questions } & \multirow[b]{3}{*}{ Total } \\
\hline & \multicolumn{3}{|c|}{ Lower Order Questions } & \multicolumn{3}{|c|}{ Higher Order Questions } & \\
\hline & Knowledge & Comprehension & Application & Analysis & Synthesis & Evaluation & \\
\hline Speaking Class & $79(59 \%)$ & $34(25 \%)$ & $7(5 \%)$ & $3(2 \%)$ & $9(7 \%)$ & $2(2 \%)$ & $134(100 \%)$ \\
\hline Structure Class & $27(51 \%)$ & $14(26 \%)$ & $3(6 \%)$ & $6(11 \%)$ & $1(2 \%)$ & $2(4 \%)$ & $53(100 \%)$ \\
\hline Total & $106(57 \%)$ & $48(26 \%)$ & $10(5 \%)$ & $9(5 \%)$ & $10(5 \%)$ & $4(2 \%)$ & $187(100 \%)$ \\
\hline
\end{tabular}


Table 15 above reveals that knowledge was the level of questions most frequently employed by learners in Group 2 in classroom interaction. Fifty-nine percent of questions in the speaking class were at this level of questions, and $51 \%$ of questions in the structure class were at this level as well. Second was comprehension, where $25 \%$ of questions in the speaking class were at this level, and $26 \%$ of questions in the structure class were at this level. The third and fourth types varied for both classes. In the speaking class, the third was synthesis, where $(7 \%)$ of questions were at this level, and fourth was application (5\%). In structure class, third was analysis (11\%), and fourth was application (6\%). In both classes, the order of frequency of question occurrences in class were as follows: knowledge $(57 \%)$, comprehension $(20 \%)$, application, analysis, and synthesis $(5 \%)$, and evaluation $(2 \%)$.

Lower-order questions governed classroom interaction in Group 2. Eighty nine percent of questions were at this level, and only $11 \%$ of questions were higherorder questions in the speaking class. For the structure class, $83 \%$ of questions were lower-order questions, and only $17 \%$ of questions were higher-order questions. In both classes, it can be observed that $88 \%$ questions were lower-order questions, and $12 \%$ were higher order questions.

\subsubsection{Types of functions of questions most frequently used in classroom interaction}

The taxonomy of question functions proposed by Long and Sato (1983) will be employed in this section. According to Long and Sato, there are two main functions of questions; echoic and epistemic. The questions which asked for comprehension checks, clarification request, and confirmation check were designated echoic functions. By contrast, the questions which served the purpōse of acquiring information were grouped into epistemic functions: referential, display, expressive, and rhetorical functions. Referential questions deal with requesting contextual information, display questions deal with asking 
the addressee's knowledge, expressive questions assign attitudinal information to the addressee, and rhetorical questions deal with the situation where no answer is expected from the listeners, in other words it is for effect only.

Employing these seven categories, the type of questions most frequently occurring in the classroom interaction of Indonesian adult learners can be seen in Tables $9 A, 9 B$ and $9 C$ below.

Table 16 below, the function of questions frequently used by learners in groups 1 and 2 is presented.

Table 16

Functions of questions frequently used by the learners in Groups 1 and 2

\begin{tabular}{|l|l|l|l|l|l|l|l|l|}
\hline & \multicolumn{3}{|c|}{ Echoic } & \multicolumn{3}{|c|}{ Epistemic } & \multirow{2}{*}{ Total } \\
\cline { 2 - 9 } & $\begin{array}{l}\text { Comprehension } \\
\text { Checks }\end{array}$ & $\begin{array}{l}\text { Clarfication } \\
\text { Request }\end{array}$ & $\begin{array}{l}\text { Confirmation } \\
\text { Check }\end{array}$ & Referential & Display & Expressive & Rhetorical & \\
\hline Group 1 & $2(1 \%)$ & $12(5 \%)$ & $39(15 \%)$ & $149(57 \%)$ & $47(18 \%)$ & $11(4 \%) \cdot$ & & $260(100 \%)$ \\
\hline Group 2 & $1(1 \%)$ & $7(4 \%)$ & $13(7 \%)$ & $123(66 \%)$ & $38(20 \%)$ & $5(2 \%)$ & & $187(100 \%)$ \\
\hline & $3(1 \%)$ & $19(4 \%)$ & $52(12 \%)$ & $272(61 \%)$ & $85(19 \%)$ & $16(3 \%)$ & & $447(100 \%)$ \\
\hline
\end{tabular}

Table 16 above reveals that referential questions were the most frequent question functions used by the learners in both groups 1 and $2(57 \%$ and $66 \%)$. Second were display questions (18\% and $20 \%$ ), third were confirmation checks $(15 \%$ and $7 \%)$, fourth were clarification requests $(4 \%)$, fifth were expressive questions $(3 \%)$, and sixth were comprehension checks $(1 \%)$. Overall, for both groups, the order of function of questions frequently used by the learners were as follows: referential $(61 \%)$, display (19\%), confirmation check $(12 \%)$, clarification request $(4 \%)$, expression $(3 \%)$, and comprehension check $(1 \%)$. None of the questions used by learners was rhetorical. 
Tables $9 \mathrm{~B}$ and $9 \mathrm{C}$ below show in detail the functions of questions frequently used by learners in each class in Group 1 and Group 2.

Table 17

Functions of questions frequently used by the learners in Group 1

\begin{tabular}{|r|l|l|l|l|l|l|l|l|}
\hline \multirow{2}{*}{ Classes } & \multicolumn{5}{|c|}{ Echoic } & \multicolumn{5}{c|}{ Epistemic } & \multirow{2}{*}{\begin{tabular}{l} 
Comprehension \\
\cline { 2 - 8 } \\
\cline { 2 - 8 } \\
Checks
\end{tabular}} & $\begin{array}{l}\text { Clarification } \\
\text { Request }\end{array}$ & $\begin{array}{l}\text { Check } \\
\text { Speaking Class }\end{array}$ & $2(2 \%)$ & $6(7 \%)$ & $16(19 \%)$ & $29(35 \%)$ & $22(27 \%)$ & $8(10 \%)$ & - & Referential & Display & Expressive & Rhetoncal & $83(100 \%)$ \\
\hline Structure Class & - & $6(3 \%)$ & $23(13 \%)$ & $120(68 \%)$ & $25(14 \%)$ & $3(2 \%)$ & - & $177(100 \%)$ \\
\hline Total & $2(1 \%)$ & $12(5 \%)$ & $39(15 \%)$ & $149(57 \%)$ & $47(18 \%)$ & $11(4 \%)$ & - & $260(100 \%)$ \\
\hline
\end{tabular}

Table 17 above reveals that most questions from learners were referential, that is requesting contextual information. In the speaking class, $35 \%$ of questions performed this function, while in the structure class $68 \%$ of questions performed this function. Display questions were second with $27 \%$ of questions in speaking class and $14 \%$ of questions in the structure class. Third was confirmation check; $14 \%$ of questions for the speaking class and $13 \%$ of questions for the structure class. In total, for both classes, referential questions comprised $57 \%$ of questions, display questions $18 \%$, confirmation checks $15 \%$, clarification requests $5 \%$, expressive questions $4 \%$, and the least frequent were comprehension checks at only $1 \%$. Rhetorical questions were not used in either of these two classes.

Table 18

Functions of questions frequently used by the learners in Group 2

\begin{tabular}{|c|c|c|c|c|c|c|c|c|}
\hline & \multicolumn{3}{|c|}{ Echoic } & \multicolumn{4}{|c|}{ Epistemic } & \multirow[b]{2}{*}{ Total } \\
\hline & $\begin{array}{l}\text { Comprehension } \\
\text { Checks }\end{array}$ & $\begin{array}{l}\text { Clarification } \\
\text { Request }\end{array}$ & $\begin{array}{l}\text { Confirmation } \\
\text { Check }\end{array}$ & Referential & Display & Expressive & Rhetorical & \\
\hline Speaking class & - & $6(4 \%)$ & $10(8 \%)$ & $102(76 \%)$ & $13(10 \%)$ & $3(2 \%)$ & - & $134(100 \%)$ \\
\hline Structure class & $1(1 \%)$ & $1(1 \%)$ & $3(6 \%)$ & $21(39 \%)$ & $25(47 \%)$ & $2(4 \%)$ & - & $53(100 \%)$ \\
\hline Total & $1(1 \%)$ & $7(4 \%)$ & $13(7 \%)$ & $123(66 \%)$ & $38(20 \%)$ & $5(2 \%)$ & - & $187(100 \%)$ \\
\hline
\end{tabular}


Table 18 above indicates that referential questions were most frequently used in the speaking class $(76 \%)$, while in the structure class, display questions were most frequently used (47\%). The second most frequently used question function in the speaking class were display questions (10\%), and third were confirmation checks (8\%). For the structure class, the second most frequently used question function was referential $(39 \%)$, and third were confirmation checks $(6 \%)$. In total, for both classes, referential questions were first $(60 \%)$, display questions were second $(20 \%)$, confirmation checks were third $(7 \%)$, clarification requests were fourth (4\%), expressive questions were fifth $(2 \%)$, and comprehension checks were sixth $(1 \%)$. There were no rhetorical questions.

It can be concluded that there there seems to be a consistency between the form of questions, the hierarchical structure of thinking, and the function of questions used by learners. The finding that yes-no questions were the type of question forms most frequently employed by the learners is-consistent with the finding that knowledge questions were also the most frequently used by learners. This finding, that referential questions is the most frequently used question function, is also consistent with the results of the previous analysis. Wh-questions, the second type of question forms frequently used by learners, were in the form of knowledge questions, as indicated by the findings in the hierarchical structure of thinking questions produced by the learners. This type of question can function as referential or display in the functions of questions.

\subsection{Types of errors}

\subsubsection{Types of errors usually made by Indonesian adult learners in forming questions in English}

The errors analysed here were based on the questions gathered from classroom interaction in the structure and the speaking class and the 
assessments given to subjects who were observed longitudinally. Questions from classroom interaction were recorded in writing by the researcher while observing the classroom interaction. In addition, questions from classroom interactions were audio taped so that the researcher was able to recheck whether all questions in the classroom interaction had been recorded. The assessments were given in writing and orally repeated over one semester. Three tests were given to the learners. The first test was given at the beginning of the semester, the second test was at the middle of semester, and the third test was at the end of semester.

Table 19 below shows that more errors were found in assessment than classroom interaction settings.

Table 19

Correct and incorrect questions produced by learners in classroom interactions and assessment

\begin{tabular}{|l|l|l|l|l|l|l|}
\hline \multirow{2}{*}{ Source of Data } & \multicolumn{1}{|l|}{ Correct } & questions & \multicolumn{1}{l|}{ Incorrect } & \multicolumn{2}{l|}{ questions } & \multicolumn{2}{l|}{ Total } \\
\cline { 2 - 7 } & frequency & $\%$ & frequency & $\%$ & frequency & $\%$ \\
\hline Classroom interaction & 308 & $69 \%$ & 139 & $31 \%$ & 447 & $100 \%$ \\
Assessment & 1117 & $55 \%$ & 897 & $45 \%$ & 2014 & $100 \%$ \\
\hline Total & 1425 & $58 \%$ & 1036 & $42 \%$ & 2461 & $100 \%$ \\
\hline
\end{tabular}

Table 19 shows that from 447 questions gathered from classroom interaction, only $31 \%$ (139 questions) were incorrect syntactically. In assessments, from 2014 questions which were gathered by written and oral assessments, 45\% (897 questions) were incorrect. The total number of questions analysed was 2461 , among them 1036 questions (42\%) were incorrect, and 1425 questions $(58 \%)$ were correct.

The incorrect questions were then analysed to find the types of errors produced by the learners in forming questions in English. The analysis revealed that more variety in the type of errors occurred in the assessment than classroom interaction settings (see table 20 below). 
Table 20

Types of errors made by learners in forming questions in English

\begin{tabular}{|c|c|c|c|c|c|c|}
\hline \multirow[b]{2}{*}{ Types of Errors } & \multirow{2}{*}{$\begin{array}{l}\text { Classroom } \\
\text { frequency }\end{array}$} & \multirow{2}{*}{$\begin{array}{l}\text { Interaction } \\
\% \\
\end{array}$} & \multicolumn{2}{|l|}{ Assessment } & \multicolumn{2}{|l|}{ Total } \\
\hline & & & frequency & $\%$ & frequency & $\%$ \\
\hline DEVELOPMENTAL ERRORS & & & & & & \\
\hline 1. Single word & 60 & $43.16 \%$ & 28 & $3.12 \%$ & 88 & $8.49 \%$ \\
\hline $\begin{array}{l}\text { 2. Declarative word order } \\
\text { 3. Fronting }\end{array}$ & 34 & $24.46 \%$ & 60 & $6.69 \%$ & 94 & $9.07 \%$ \\
\hline a. Wh Fronting & 33 & $23.74 \%$ & 387 & $43,14 \%$ & 420 & $40.54 \%$ \\
\hline b. Do Fronting & 1 & $0.72 \%$ & 28 & $3.12 \%$ & 29 & $2.80 \%$ \\
\hline c. Is Fronting & - & & 68 & $7.58 \%$ & 69 & $6.66 \%$ \\
\hline d. Wh + Aux Fronting & 1 & $0.72 \%$ & 191 & $21.29 \%$ & 191 & $18.44 \%$ \\
\hline INTERLINGUAL ERRORS & & & & & & \\
\hline 1. Non-verb sentence & - & - & 25 & $2.79 \%$ & 25 & $2.41 \%$ \\
\hline 2. Yes-No in Wh Questions form & - & - & 9 & $0.87 \%$ & 9 & $0.87 \%$ \\
\hline 3. Question word problems & - & - & 41 & $4.57 \%$ & 41 & $3.96 \%$ \\
\hline 4. Tense & - & 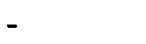 & 8 & $0.89 \%$ & 8 & $0.77 \%$ \\
\hline 5. Worci order & - & . & 9 & 0.87 & 9 & $0.87 \%$ \\
\hline 6. Question tag & 2 & $1.44 \%$ & 1 & $0.11 \%$ & 3 & $0.29 \%$ \\
\hline OTHERS & & & & & & \\
\hline 1. Agreement & - & - & 38 & $4.24 \%$ & 38 & $3.67 \%$ \\
\hline 2. Question word only & 8 & $5.76 \%$ & 3 & 0.34 & 11 & $1.06 \%$ \\
\hline Total & 139 & $100 \%$ & 897 & $100 \%$ & 1036 & $100 \%$ \\
\hline
\end{tabular}

Table 20 shows that classroom interaction produces only developmental errors, and it cannot retrieve interlingual errors. Since more questions occurred in assessments, a greater variety of questions could be investigated and more types of errors identified.

In the following section, the types of errors found in both classroom interaction and assessments will be described in detail. The errors which are to be analysed are fronting, non-verb sentences, yes-no questions in wh-question forms, problems in the use of wh-questions, word order, tense, question tag. and agreement. 


\section{Fronting}

Fronting is considered to be stage 3 in language development after single word questions (the first stage), and declarative word order questions (the second stage). Unlike single word questions and declarative word orders which are considered (Quirk, 1985) to be acceptable, fronting is considered to be ungrammatical. There are four types of fronting found in the question forms of Indonesian adult learners; wh fronting, do fronting, is fronting, and wh + aux fronting.

\section{a. Wh Fronting}

Wh fronting was formed by putting question words at the beginning of sentence in order to form a question. Look at the following sentences.

(1) Where she wait her friends? (S2)

(2) When Aminullah is hungry? (S4)

(3) What time you meet him? (L6)

(4) What you have told him several times? (L7)

(5) Why they wearing hat? (S8)

Sentences (1) - (5) above show that question words such as what, where, when, why, and what time were put at the beginning of a declarative statement to form questions in English. This is considered to be an incomplete process in forming English questions. There was one more rule that was not recognised by the learners, that was the use of auxiliary verbs such as do, does, and did. Not only at the beginning of sentences, in some other forms of questions, question words were put before words or phrases. Look at the following examples.

(6) What colour your mouse? (S1)

(7) How many people on the picture? (S3)

(8) What about bird? (L3) 
Sentences (6) - (8) reveal that question words such as what, how many, and what about were placed before a word or phrase to ask about the word and phrase itself without using a verb or auxiliary.

\section{b. Do Fronting}

Do fronting here means to put auxiliary (do, does, did) at the beginning of a sentence to form questions. Errors in do fronting can be found in the following sentences.

(9) Does she wearing white shoes? (S8)

(10) Did they are married? (L3)

(11) Do you went shopping? (L4)

(12) Do they studying English? (L7)

(13) Do they tired? (L8)

Sentences $(9):(13)$ above show that auxiliary do, does. and did were used inappropriately by learners. In terms of agreement with the subject of the sentence, the learners seemed to use the auxiliary verbs correctly, whereas in agreement with main verbs, the learners had difficulty. This problem can be seen in the use of do and does with verb-ing in sentences (9) and (12), did is used with verb 'are' in sentence (10), do with verb 'went' in sentence (11), and do with the adjective 'tired' in sentence (13).

This suggests that at this stage, learners knew that do, does, and did performed to make yes-no questions, but they did not recognise that they needed to be modified in agreement with the verbs. Therefore, only one rule was applied by the learners, that was to put the auxiliary do, does, or did at the beginning of sentence to form questions in English.

c. Is Fronting

'Is fronting' usually applies to questions in the continuous, future (be going to), and passive forms. But here, the learners employed the copula forms 'is' and 
'are' to construct yes/no questions in general, as the following sentences show.

(14) Are they have a lot of friends? (S6)

(15) Is the woman sit on the chair? (S7)

(16) Is she arrived last week? (L2)

(17) Is the childs are playing the ball? (L5)

(18) Are all the books are here? (L7)

Sentences (14) - (18) above show that the learners used 'are' and 'is' to form yes-no questions. They were not concerned about whether the sentence had a full verb, such as sentences (14), (15), and (16) or whether there was the verb 'be' there, such as in sentences (17) and (18). They did not pay attention whether the sentence was in the present tense such as sentences (14), and (15) or past tense, such as sentence (16).

This problem indicated that when the learners attempted to form questions in English, only one rule he/she was remembered, that was the use of 'to be' in forming yes-no questions in English. Consequently, all yes-no questions produced at that time were 'is fronting' questions.

\section{d. $W h+$ Aux Fronting}

For the rule to form wh-questions in English, the sentence must begin with a question word, followed by an auxiliary verb or modal auxiliary, then followed by a clause/sentence. But here, the learners applied the modal auxiliary inappropriately, so that there was no agreement between the auxiliary used and the verb in the sentence as the following sentences show.

(19) Where is John studies? (S1)

(20) Who was Mary invite? (S2)

(21) When was they do this recreation? (S3)

(22) Who is sit in the corner? (L2)

(23) Why are they have lunch in the garden? (L3) 
(24) What is she eat? (L4)

(25) What are the children are speaking? (L7)

In sentences (19) - (25), to be 'is', 'was', and 'are' appear after question words without modifying in accordance with the main verb in the sentence. Sometimes, the verb has no agreement with the subject of the sentence, such as sentence (21).

In the following sentences, question words 'when', 'who', 'what', and 'how many' were followed by the auxiliary 'do'- or 'did' to form questions in an inappropriate manner. The examples below show.

(26) When did you told him? (S1)

(27) Who did invite Mary?

(28) How many times do you have told him? (L6)

(29) Who does have a large number of book? (S4)

(30) What did they doing at nine o'clock? (S5)

Sentences (27) - (31) above show that the use of 'do', 'does', and 'did' after question words was very unpredictable. They appeared spontaneously in the utterances produced by the learners without considering the form of verbs, the occurrances of subjects, and the tenses used.

In this form of question, learners seemed to combine the rules of 'wh fronting' with 'do fronting' and 'is fronting', since all the problems which occurred in 'wh fronting', 'do fronting', and 'is fronting' appeared in this form of question. It appears that the learners tried to apply two rules of question function, but in inappropriate ways.

\section{Non-Verb Sentence}

The presence of a verb, whether a 'full verb' or a 'be verb', is a necessary condition for a grammatical sentence in English. A sentence is considered to 
be incomplete if there is no main verb in the sentence. Some of the sentences produced by the learners used non-verb sentences, as the following examples show.
(31) The box under the table? (S5)
(32) When Amarullah here? (S6)
(33) So, three people on the chair? (S7)
(34) How many person there? (S8)

Sentences (32) - (35) above revealed that the learners did not use verbs at all in forming the questions, nor is there an auxiliary present. Sentences (31) and (33) are intended as yes-no questions, and sentences (32) and (34) are intended as wh questions. The verbs that should appear could be a full verb or verb be. The following analysis illustrate this.

(31) a. The box (is) under the table?

b. (is) the box under the table?

(32) a. When (will) Amarullah (be) here?

b. When (will) Amarullah (come) here?

(33) a. So, three people (are) on the chair?

b. So, three people (sit) on the chair?

(34) a. How many persons (are) there?

b. How many persons (study) there?

In Indonesian, non-verb sentences are very common, and are referred to as 'nominal sentences' (Moeljono, 1992). The sentences (31) - (34) above reflect the 'nominal sentences' of Indonesian, as the following sentences show.

(31) a. Adakah kotak di bawah meja?

b. There box - under table?

(32) a. Kapan Amarullah ke sini?

b. When Amarullah here? 
(33) a. Jadi, tiga orang di kursi?

b. So, three person on the chair?

(34) a. Berapa orang di sana?

b. How many persons there?

Therefore, the non-verb questions produced by the learners can be considered as interference of the mother tongue, Indonesian.

\section{Yes-No Question in Wh Question Form}

The 'yes-no question in wh question form' problem might occur in questions produced by the Indonesian adult learners, because word 'apa' in Indonesian (meaning 'what') can be used to form both 'wh questions' and 'yes-no questions'. Some learners might confuse them. Look at the following sentences.

(35) What you with your father? (L3)

(36) What she studies here every Tuesday? (L5)

(37) What did you go shopping? (L1)

(38) What all of the students are here? (L3)

Sentences (36) - (39) above were intended by the learners to be 'yes-no questions'. The correct forms of the sentences are:

(35) a. Are you with your father?

(36) a. Does she study here every Tuesday?

(37) a. Did you go shopping?

(38) a. Are all of the students here?

The use of the question word 'what' in these sentences was influenced by their first language, Indonesian, since questions (35) - (38) above were direct translations of the Indonesian question forms with 'apa' translated as 'what' in English by the learners. The following comparison show this. 
(35) b. Apa kamu bersama bapak mu?

c. What you with your father?

(36) b. Apa dia belajar di sini setiap selasa?

c. What she study here every Tuesday?

(37) b. Apa kamu pergi berbelanja?

c. What you go shopping?

(38) b. Apa semua siswa di sini?

c. What all students here?

The learners might feel that the Indonesian expressions in (35b) - (38b) could be translated into English in the forms of questions such as (35c) - (38c). These sentences were actually influenced by the sentences with 'what' for wh questions such as the following example:

(39) a. Apa yang kamu kerjakan di sini?

b. What are you doing here?

The translation of 'apa' (39a) as 'what' (39b) in this sentence is correct, because this question is asking for information of 'what are you doing here?", not just clarifying a situation that can be answered by yes or no.

In contrast with the problems found in sentences (35) - (38) above, in the following sentence, the learner applied the yes-no question form instead of the wh-question form, where 'what' should be used. Look at the following sentences.

(40) a. Are the children saying when they were going? (L5)

b. Apa yang dikatakan anak-anak ketika mereka pergi?

c. What are the children saying when they were going?

Sentence (40a) is the equivalent form of sentence (40b) in Indonesian, while what the speaker intended was sentence $(40 \mathrm{c})$. Therefore, the occurrence of the yes-no question in the form of a wh question or vice versa in the questions 
produced by the Indonesian learners can be considered to be influenced by the mother tongue, Indonesian.

4. Problems in the use of question words

Problems in the use of English question words might occur when there is no parallel form of an English word in Indonesian. Consequently, the learners tended to confuse forms similar in meaning. Look at the following sentences.

(41) Whose have this assignment? (S6)

(42) Whose has that note book? (S7)

(43) Whom has a large number of books (L6)

(44) What there are trees? (L7)

(45) What are all of students here? (L8)

Sentences (41) - (45) above show that the question words whose, whom, and what were not appropriately used. The preference to use 'whose' rather than 'who' by learners in questions (41) and (42) above was influenced by the verb 'have' and 'has'. The use of 'whom' instead of 'who' occurred because learners confused the question words 'who' and 'whom'. The choice of 'what'. in sentence (44) was influenced by two possible meanings of 'apa' in Indonesian as explained in section 3 above. In sentence (45), the learners used the question word 'what' instead of 'who' because it was influenced by the sentence 'What is your name?' which can be translated in Indonesian into 'siapa namamu?' (who is your name?). So, to make sentence 'who are all of the students here?', the learner applied the question word 'what' as indicated in sentence (45). These errors reflect the interference of Indonesian in the questions produced by the learners. 


\section{Word Order}

Problems in word order in the following sentences might have been caused by the interference of the mother tongue of the learners. Look at the following sentences.

(46) What is colour the dress the parents? (S2)

(47) Who is driver car? (L3)

(48) What name is your bird? (L4)

(49) Is the mother making dress daughter? (L6)

The underlined words in sentences (46) - (49) above indicate inappropriate word order in English. These word orders were influenced by the mother tongue, Indonesian. Below is a comparison of both languages.

(46) a. What is colour the dress the parents?

b. Apa warna baju orang tuanya?

(47) a. Who is driver car?

b. Siapa pengemudi mobil itu?

(48) a. What name is your bird?

b. Apa nama burungmu?

(49) a. Is the mother making dress daughter?

b. Apa ibu membuatkan baju anaknya?

The underlined words in sentences (46a) - (49a) above signify the similar word order indicated in sentences (46b) - (49b).

\section{Tense}

Indonesian does not have a tense system. Time is indicated by lexical items such as 'sekarang' (now), 'besok' (tomorrow), and 'kemaren' (yesterday), and there is no change in verb form. So, errors in some form of tenses made by Indonesian learners can be considered a result of the absence of a tense 
system in Indonesian. That is why the Indonesian learners made the following sentences.

(50) Who does he visit to hospital last week? (S2)

(51) What did they doing at nine o'clock? (S5)

(52) Where did you had lunch? (S6)

(53) Does he arrive last week? (S1)

(54) Did Paul arrive next week? (S7)

(55) Will he going to Jakarta? (L4)

Sentences (50) - (55) above show that learners lack knowledge of the English tense system, so that they use the auxiliary verb 'does' with the time signal 'last week' in sentences (50) and (53), 'did' for the time signal 'next week' such as in sentence (54), and often did not change the verb. However the learners used the auxiliary verb 'did' in sentences (51) and (52).

\section{Question Tag}

In Indonesian, questions which are similar to the question tag in English can be formed by adding 'ya' (yes) at the end of a question. This phenomena can be seen in the production of learners' questions in English. Look at the following examples.

(56) May be you know, but you can't say it in English, yes? (S3)

(57) The people are cuddling it, that right? (S4)

(58) I am here, OK? (L5)

Sentences (56) - (58) above show that 'yes', 'that right', and 'OK' were intended to make tag questions, where in English they should have been in the forms of 'can you' (56), 'aren't they' (57), and 'aren't you' (58). Thus, the learners' attempts to use the question tag in English were inappropriate and were influenced by the similar question tag form in Indonesian. 


\section{Agreement}

Unlike English, Indonesian has no agreement system of subject and verb. So, it is very common to find agreement errors in learners' sentences. Look at the following examples.

(59) Are the child friend in the beach? (L2)

(60) What are she doing now? (L4)

(61) Are there a fish in your picture? (L7)

(62) Where is the children playing? (L8)

(63) Was you in the city yesterday? (L1)

(64) What is they doing? (L5)

Sentences (59) - (63) above show that there was no agreement between the auxiliary used (are, is, and was) and the subjects of the questions. The learners used 'are' for the subject 'child" (59), she (60), and 'a fish' (61). In another question, a learner used 'is' for the plural subject 'children' (62), and 'they (64), and 'was' for the second person pronoun 'you' (63).

In some questions, no agreement was found between the auxiliary and the main verb. Look at the following sentences.

(64) Do you went shopping? (L4)

(66) Does she studies here every Tuesday? (L4)

(67) Did Paul arrived last week? (L6)

In sentences (65) - (67) above, there is no agreement between the auxiliary used and the verb such as in sentence (65) 'do' and verb 'went' (66) 'does' and (67) verb 'studies', and 'did' and verb 'arrived'.

\subsubsection{The cause of error occurrences}

The cause of error occurrences will be discussed in this section with particular reference to the theory proposed by Dulay, Burt, and Krashen (1982), and the theory proposed by Biggs and Collis (1982). 
Dulay, Burt, and Krashen (1982) proposed four error types of L2 in a comparative taxonomy. They are developmental errors, interlingual errors, ambiguous errors, and others. Developmental errors are considered to be errors similar to the ones made by children learning their first language. Interlingual errors are errors caused by learners knowledge of their first language, and ambiguous errors are errors which are considered both developmental and interlingual. Others are errors which are neither developmental nor interlingual.

Errors in the surface structures of the sentences can be categorised into four types: omission, addition, misformation and misorder (Dulay, Burt, and Krashen, 1982). Omission errors occur when an item that must be present in a well-formed sentence is absent. The opposite of omission is addition, that is an item that should not appear in a well-formed sentence occurs. Misformation errors are the use of a wrong form or structure, for example an irregular verb is used as a verb regular. Misorderings are the incorrect ordering of items in a sentence. These four types of errors can be found in developmental and interlingual errors.

In the previous section, types of errors of questions were discussed according to grammatical errors the students made such as fronting, non-verb sentence, yes-no question in wh question forms, etc. The cause of these errors will be discussed in terms of the theory proposed by Dulay, Burt, and Krashen (1982) above. This section will apply the four surface structure error categories of omission, addition, misformation, and misorder to errors in fronting found in Indonesian adult learners' questions.

In the following sentences a number of errors occurred.

(68) Where she wait her friends? (S2)

(69) What you have told him several times? (L7)

(70) Are they have a lot of friends? (L8)

(71) Is the childs are playing the ball? (S1) 
The error in sentence (68) is the omission of the auxiliary, which could be 'does' or 'did', and should have been put after the question word 'where'. The error in sentence (69) is caused by misordering. The auxiliary 'have' should have been put after the question word 'what' (inversion process). The error in sentence (70) is addition. The use of 'are' is not correct for this question, the use of the auxiliary verb 'do' or 'did' is more appropriate. In sentence (71), an error is found in the forming of the word 'childs', which must be 'children'. This is a misformation error. Therefore these types of errors can be considered developmental errors, because the learners did not apply the English question formation rules appropriately.

However, when considering the fact that the learners who formed these questions were Indonesian, a different conclusion can be made. In Indonesian, wh-questions are formed by placing a question word before declarative sentence (Moeljono, 1992; Sneddon, 1996), as in the following sentences.

(72) a. Dia belajar bahasa Inggris.

b. He studies English.

(Statement)

(73) a. Di mana dia belajar bahasa Inggris? (Question) b. Where he studies English?

Sentences (72) and (73) above show that there is no change in the form of the word and the order of words in forming questions in Indonesian. To form a whquestion in Indonesian, a question word only needs to be placed at the beginning of the sentence (see sentence 73a). Therefore, errors in sentences (68) and (69) above can also be considered interlingual errors, where the mother tongue of the learners interfered with the language produced by the learners. Below is a comparison of the two languages in these sentences.

(74) a. Where she wait her friends? (S2)

b. Di mana dia menunggu teman-temannya? 
(75) a. What you have told him several times? (L7)

b. Apa yang kamu telah katakan padanya beberapa kali?

When Indonesian is considered, there is no omission and misordering of the words. However, since English is being considered, omission and misordering in those questions happened in forming English questions according to the English question formation rules.

The following sentences can be considered interlingual errors, and not developmental errors. In these sentences, omission, misformation, and misordering can be found.

(76) What you with your father? (L3) Apa kamu bersama bapakmu?

(77) What is colour the dress the parent? (S2) Apa warna baju orangtuanya?

The error in sentence (76) is in the use of the question word, and the error in sentence (77) is in the order of the words (word order). There is an omission in sentence (76) that is to be 'are' must replace 'what' to form a correct English question. Thus, the learner misforms the question. In sentence (77), there appears to be a misordering of the phrase parent's dress or the dress of the parent to become the dress the parent.

In the following section, the cause of errors will be examined on the basis of the cognitive aspects in language learning. The cognitive aspects in language learning can be seen in the ability of the learners to work within the structure of the new language (Collis and Biggs, 1978). Based on Piaget's theory of cognitive development which indicates that cognitive development is a continuous process that begins at birth, Biggs and Collis (1982) made a distinction between the generalised cognitive structure of the individual and the structure of the actual responses of students to a specific task. The first term 
refers to a person's developmental stage, while the second refers to the structure of the observed learning outcome (which is abbreviated as SOLO). The SOLO taxonomy reveals how learning becomes more structured with the growth of competence (Zaim, 1996).

The SOLO taxonomy has five structural levels of learning outcomes: prestructural, unistructural, multistructural, relational and extended abstract. The prestructural level is preliminary preparation, where the tasks are not addressed in an appropriate way. In the unistructural level, one aspect of a task is picked up, but in an unrelated manner. Next, in the relational level, learners are able to integrate several aspects into a coherent structure. Finally, learners are able to generalise the structure to take more abstract features in the level of extended abstract. Among the five levels above, the prestructural level is considered to be in the mode of previous, and the middle three unistructural, multistructural, and relational - are where the process of acquiring and learning the structure happens. The last one, extended abstract, is the target mode to be achieved by learners (Biggs \& Collis, 1982).

In terms of the acquisition of question forms in English, a number of rules must be applied in order to make an acceptable question form. The ability to apply one rule, two rules or more may indicate the level of complexity which has been acquired by the learners. Some indicators to forming questions in English are intonation, fronting, and inversion. Others are agreement between the subject and verb, auxiliary and verb, and verb with the tense used, and the use of question words, and word order.

In the prestructural level which is considered to be in the mode of previous, the learners know only one indicator for differentiating questions and other forms of sentences, that is intonation. That is why, without using question words, the learners are able to form questions as one word/phrase questions, or 
declarative questions. The next stages, fronting, and inversion, can be considered as the unistructural, multistructural and relational levels.

The level of SOLO taxonomy at which a learner is forming questions can be identified by analysing the types of errors made. Look at the following sentences.

(78) What time you meet him? (L6)

(79) When did you told him? (S1)

(80) Where did they study yesterday? (L7)

Sentences (78) - (80) above indicate three levels of learning outcomes according to the SOLO taxonomy. Sentence (78) is considered to be at the unistructural level in the competence to form questions in English, since the learner is able to apply only one aspect of question formation rules, that is whfronting. Sentence (79) is considered to be at the multistructural level, since the learner is able to apply two aspects of question formation rules; wh fronting, and do-fronting at the same time, although they are applied in inappropriate manner. Sentence $(80)$ is considered to be at the relational level, since the learner is able to make a coherent relationship in some aspects of question formation rules, such as wh fronting, do fronting, and agreement (with subject, with verb, and with tense used). This will eventually lead the learner to the stage of extended abstract where more complicated rules can be applied appropriately.

From the discussion above, it is reasonable to deduce that the cause of errors can be found in the performance of the surface structure produced by the learners (Dulay, Burt, and Krashen, 1982). The cause of errors can also be seen in the structure of the observed learning outcomes (Biggs and Collis, 1982). Omission, addition, misformation, and misordering are the cause of errors in the surface structure of questions produced by the learners. Whether one rule or more can be applied by learners in forming questions depends on 
their cognitive development and is reflected in the structure of the learning outcome. While the stage of learners' acquisition is governed by their cognitive development, the source of their errors is not only developmental but can be interlingual.

\subsection{Teachers' Responses}

\subsubsection{Teachers' responses to learners' questions}

Teachers' responses are the feedback given to learners in classroom interaction to clarify, explain or reinforce learners' questions, statements, or utterances in general. According to Lynch (1996), there are two kinds of feedback in classroom interaction: cognitive feedback and affective feedback. Teachers' responses on the comprehensibility of what the learners have said is called cognitive feedback, while teachers' response showing approval or disapproval of students utterances is affective feedback. In language classes both responses are used by teachers in responding learners' utterances.

Cognitive feedback, in terms of questions and responses in language class, is mostly in the form of grammar, vocabulary, and pronunciation. Cognitive feedback can be investigated by observing learners and teachers conversation in classroom interaction. The following response from the teacher is about grammatical use as requested by a learner in the speaking class of group 2 ( $L$ is learner, and $T$ is teacher.)

L: There is eight children in my family. Is it correct or not, I come from a family of eight.

T. I think that's right. I think that is right to say I come from a family of eight if there are eight children. I think so. 
The above interaction shows that the response given by teacher not only answered the student's question, but also indirectly corrected the error made by the learner who said 'there is eight children in my family'. The teacher, then, modified that sentence by saying 'if there are eight children'. Hence, both cognitive and affective feedback were given in this interaction.

On some occasions, teachers paid little attention to the errors made by the learners, instead, they just answered learners' questions. Look at the following interaction in the speaking class of Group 1.

L: 'I'm sorry but I am busy', what the function of but in this sentence?

$\mathrm{T}$ : Just the linking word!

The above interaction showed us that although the learner's question 'what the function of but in this sentence?' was not grammatically correct, the teacher did not correct it. He just answered the content of the question directly.

Most of the questions in the speaking class were about vocabulary and pronunciation. In the following interaction, the learner spontaneously asked how to pronounce a word.

L: How to pronounce orphan?

T: Orphan?

L: No mother no father?

$\mathrm{T}$ : Orphan!

Questions from learners did not always come spontaneously, sometimes teachers asked for questions. In the following example, questions by the learners occurred because the teacher asked for questions.

T: Any question on vocabulary or pronunciation?

L: Surgery?

$\mathrm{T}:$ Again?

L: Surgery? 
T: Surgery! Operasi.

L: Extremely?

T: Very much.

L: Available.

T: Ready.

These interactions seem to be simple questions and answers, since the teacher only gave the equivalent of the word asked by the learners. The equivalent of the words was given in English or in Indonesian. All the questions above were about vocabulary and pronunciation.

Unlike the speaking class, in the structure class most of the questions from students were about the grammatical forms of English, as in the following examples.

L: Excuse me miss, what about when we say.....she is the most diligent....without I know?

$\mathrm{T}$ : She is the most diligent? Yes!

L: Without I know?

T: Yes!

Sometimes, questions in vocabulary also occurred.

L: I'm sorry mum. I don't know what is the meaning .....went out.

$\mathrm{T}$ : Went out? If there is no electricity current, we say the light went out.

In this interaction, the teacher tried to explain the word 'went out' in the context where this word could be used or in the context where this question appeared.

\subsubsection{Types of responses to the questions made by learners}

In language learning, responses from teachers to the utterances produced by learners are very important to develop language ability. Littlewood (1981:90) stated that response or feedback provides learners with knowledge of how successful their performance has been. In addition, Collis and Biggs (1978) 
also claimed that feedback about errors is a device by which learners can learn.

Dulay, Burt, and Krashen (1982:34) indicate that the types of responses made by teachers can be in forms of correction, approval (positive feedback), and expansion. In the following section, these types of responses will be discussed by investigating responses by teachers when the questions from students appeared in classroom interaction.

\section{Correction}

Correction is considered to be negative feedback to learners utterances. Correction given to learners in language class can be in relation to language forms, vocabulary, or pronunciation.

1) Correction in language forms

Most corrections come from teachers, however sometimes correction can also come from students as in the following examples.

L1: What did you do yesterday?

L2: I went to bowling.

$T: I \ldots . . . .$.

L2: I went to....

$T$ : There is no to here

L2: I went bowling.

L1: Who did you go to bowling?

L2: No body, I went bowling by I'm self.

L3: myself...

L2: by myself... l'm sorry...

$T$ : by myself.....

The interaction above shows that the conversation happened between $L 1$ and L2. Since there was an error in L2 utterance, the teacher corrected it immediately, then L2 corrected the sentence. When L1 made the same error, the teacher did not correct it anymore, but when L2 made other mistakes, in the 
reflective pronoun 'I'm self', another student, L3, tried to correct it by saying 'myself', and the teacher affirmed the correction.

2) Correction in pronunciation

Correction in pronunciation occurred in response to a question from the learner, as in the following dialogue.

L: How to pronounce orphan?

T: Orphan?

L: No mother no father?

T: Orphan.

Correction in pronunciation also came directly from teacher when the learner made a mistake in a question.

L: Do you think your friend is very polit?

T: Polait!

L: Do you think your friend is very polait?

T: Good!

The error in pronouncing 'polite' when a learner asked a question was immediately corrected by the teacher, then the learner pronounced it correctly.

\section{Approval}

Approval can be considered as teachers' acceptance of the correct utterances given by learners. In other words, approval is given because the learner has made the correct form of a question. The following conversation is an example of approval.

L: Can you tell me when my car will be ready?

T: When.....

$L:$ When my car will be ready?

T: When my car will be ready? Yes! 
Reinforcement of the learner's attempt to make a question, even if it is not correct in form, is important. It can build students' self confidence to ask questions in classroom interaction, as in the following interaction.

L: I think if we make combine sentence if one sentence is past tense the other than have to past continuous...why it is wrong?

$\mathrm{T}$ : Good.... that is a good question.

The teacher's response by saying 'good!... that is a good question! should encourage the student to ask questions in class.

\section{Expansion}

Expansion means systematic modeling of more a complete version of the learners' utterances without calling attention to the activity (Brown, 1985). This is done in the following conversation.

L: I want to know how to different uncountable and countable noun.

$\mathrm{T}$ : Right, your friend want to know how to differentiate uncountable and countable noun .....

The response from the teacher above actually corrected the error made by the learner. However, since the teacher did not pay attention to the error itself, but repeated the learner's sentence correctly, an expansion was made. The learner will know that his sentence was not correct after the teacher repeated his sentence.

Therefore, the three types of responses given by teachers: correction, approval, and expansion, occurred in the classroom interaction observed. It seemed that corrections were the most frequent response given to learners. 


\subsection{The development of question forms}

\subsubsection{The sequential stages of the question forms of Indonesian adult learners}

The discussion of the development of question structure is based on the theory proposed by Pienemann, Johnston and Brindley (1988) who identified six developmental stages of question formation from simple to complex questions. These are (1) single word questions, (2) declarative word order questions, (3) fronting, (4) inversion in yes-no question, (5) inversion in wh-question, and (6) complex questions. The present study investigated two groups of eight adult learners $(\mathrm{N}=16)$ whose mother tongue was Indonesian with a longitudinal and cross-sectional study. The learners from each group were observed longitudinally over one semester of learning EFL in Padang, Indonesia.

The question data were collected by giving learners three sets of assessments. Assessments were given three times in the study with both oral and written tests were given for each assessment. Assessment 1 was given at the beginning of their learning (week 1), assessment 2 was given at the middle of semester (week 8), and assessment 3 was given at the end of semester (week 16). Questions produced by each learner were tallied and analysed on the basis of the theory mentioned above. The results are presented and discussed in the following section for both groups separately.

Group 1 comprised 8 adult learners who were studying English at the English training centre. They were part of a group of lecturers of IAIN (Institut Agama Islam Negeri = Institute for (slamic Studies) who intended to continue their post graduate study in an English-speaking country. Their ages ranged from 27 to 41 years old. They had all studied English for 7 years previously, and their English was considered to be at intermediate level. 
The development of question forms in Group 1 learners observed over one semester is shown in the following table. The eight learners were coded as L1 - L8 and the numbers 1 - 6 indicates the stages of question development $(1=$ lowest, 6 = highest).

Table 21

The development of questions by Group 1 of Indonesian adult learners of EFL in percentage (\%)

\begin{tabular}{|c|c|c|c|c|c|c|c|c|}
\hline \multirow[b]{2}{*}{ Learners } & \multirow[b]{2}{*}{ Assessments } & \multicolumn{4}{|c|}{ Stage of Questions } & \multicolumn{2}{|c|}{ Development } & \multirow[t]{2}{*}{ Total } \\
\hline & & 1 & 2 & 3 & 4 & 5 & 6 & \\
\hline \multirow{3}{*}{ L1 } & Test 1 & 2.94 & 5.88 & 52.94 & 20.59 & 17.65 & - & $100 \%$ \\
\hline & Test 2 & 3.13 & 6.25 & 46.87 & 25.00 & 18.75 & - & $100 \%$ \\
\hline & Test 3 & 2.50 & 5.00 & 40.00 & 25.00 & 27.50 & - & $100 \%$ \\
\hline \multirow{3}{*}{ L2 } & Test 1 & - & - & 65.63 & 12.50 & 21.87 & - & $100 \%$ \\
\hline & Test 2 & 2.56 & 2.56 & 56.41 & 17.95 & 20.52 & - & $100 \%$ \\
\hline & Test 3 & - & - & 46.81 & 25.53 & 27.66 & - & $100 \%$ \\
\hline \multirow{3}{*}{ L3 } & Test 1 & $6.67-$ & - & 43.33 & 10.00 & 40.00 & - & $100 \%$ \\
\hline & Test 2 & 2.70 & - & 29.73 & 35.14 & 32.43 & - & $100 \%$ \\
\hline & Test 3 & - & - & 16.67 & 35.71 & 47.62 & - & $100 \%$ \\
\hline \multirow{3}{*}{ L4 } & Test 1 & 2.33 & - & 39.53 & 30.23 & 25.58 & 2.33 & $100 \%$ \\
\hline & Test 2 & - & - & 41.66 & 29.17 & 29.17 & - & $100 \%$ \\
\hline & Test 3 & $=$ & - & 24.45 & 44.44 & 31.11 & - & $100 \%$ \\
\hline \multirow{3}{*}{ L5 } & Test 1 & - & - & 20.00 & 35.00 & 45.00 & - & $100 \%$ \\
\hline & Test 2 & $=$ & - & 21.95 & 43.90 & 34.15 & - & $100 \%$ \\
\hline & Test 3 & 1.96 & - & 21.57 & 31.37 & 45.10 & - & $100 \%$ \\
\hline \multirow{3}{*}{ L6 } & Test 1 & - & - & 52.63 & 21.05 & 26.32 & - & $100 \%$ \\
\hline & Test 2 & - & 2.17 & 58.69 & 19.57 & 19.57 & - & $100 \%$ \\
\hline & Test 3 & - & - & 48.00 & 28.00 & 24.00 & - & $100 \%$ \\
\hline \multirow{3}{*}{ L7 } & Test 1 & 5.26 & - & 47.37 & 21.05 & 26.32 & - & $100 \%$ \\
\hline & Test 2 & 8.57 & 2.86 & 31.43 & 17.14 & 40.00 & - & $100 \%$ \\
\hline & Test 3 & - & - & 31.43 & 25.71 & 42.86 & - & $100 \%$ \\
\hline \multirow{3}{*}{ L8 } & Test 1 & - & - & 51.35 & 16.22 & 32.43 & - & $100 \%$ \\
\hline & Test 2 & 4.65 & 13.95 & 23.26 & 27.91 & 30.23 & - & $100 \%$ \\
\hline & Test 3 & - & 2.17 & 21.74 & 45.65 & 30.44 & - & $100 \%$ \\
\hline
\end{tabular}

Note: 1 = Single word question

$2=$ Declarative word order questions

$3=$ Fronting
4 = Inversion in yes-no questions

$5=$ Inversion in wh-questions

$6=$ Complex questions

The table shows that, as the learners were in the intermediate stage, the majority of their questions were in stages 3 as for question formation is concerned. However, the table also show that learners showed an increasing $\%$ of questions in stages 4 and 5 over the three assessments indicate a 
developmental stage toward more complex question formation. Only one student showed evidence of stage 6 question, but by test 3 only 2 students were producing stage 1 question.

The table above shows that for the majority of learners there is a decrease in the percentage of single word questions (1), declarative word order questions (2), and fronting (3) in test 1 , test 2 , and test 3 . The decrease in these three types of questions was followed by a corresponding increase in the percentage of inversion in yes-no questions (4), and inversion in wh-questions (5). The percentage of the decrease in types 1,2 , and 3, and increase in types 4 , and 5 varied from learner to learner.

Table 22

The development of questions by Group 2 of Indonesian adult learners of EFL in percentage (\%)

\begin{tabular}{|c|c|c|c|c|c|c|c|c|}
\hline \multirow[b]{2}{*}{ Learners } & \multirow[b]{2}{*}{ Assessments } & \multicolumn{6}{|c|}{ Types of Questions } & \multirow[t]{2}{*}{ Total } \\
\hline & & 1 & 2 & 3 & 4 & 5 & 6 & \\
\hline \multirow{3}{*}{ S1 } & Test 1 & - & 2.27 & 38.64 & 22.73 & 36.36 & - & $100 \%$ \\
\hline & Test 2 & 2.04 & 2.04 & 26.53 & 24.49 & 44.90 & - & $100 \%$ \\
\hline & Test 3 & - & - & 25.53 & 25.53 & 48.94 & - & $100 \%$ \\
\hline \multirow{3}{*}{ S2 } & Test 1 & 4.88 & 7.32 & 51.22 & 14.63 & 21.95 & - & $100 \%$ \\
\hline & Test 2 & 5.88 & 2.94 & 35.29 & 8.83 & 41.18 & 5.88 & $100 \%$ \\
\hline & Test 3 & - & 2.94 & 23.53 & 14.70 & 58.83 & - & $100 \%$ \\
\hline \multirow{3}{*}{ S3 } & Test 1 & 4.00 & 4.00 & 46.00 & 16.00 & 30.00 & - & $100 \%$ \\
\hline & Test 2 & - & 16.95 & 28.82 & 18.64 & 35.59 & - & $100 \%$ \\
\hline & Test 3 & - & 5.13 & 25.64 & 28.21 & 41.02 & - & $100 \%$ \\
\hline \multirow{3}{*}{ S4 } & Test 1 & 2.22 & 6.67 & 24.44 & 22.22 & 44.45 & - & $100 \%$ \\
\hline & Test 2 & - & 5.41 & 10.81 & 37.84 & 45.94 & - & $100 \%$ \\
\hline & Test 3 & - & - & 10.81 & 40.54 & 48.65 & - & $100 \%$ \\
\hline \multirow{3}{*}{ S5 } & Test 1 & 1.92 & 7.69 & 30.77 & 32.69 & 26.93 & - & $100 \%$ \\
\hline & Test 2 & 2.22 & - & 28.89 & 40.00 & 28.89 & - & $100 \%$ \\
\hline & Test 3 & 2.44 & - & 26.83 & 39.02 & 31.71 & - & $100 \%$ \\
\hline \multirow{3}{*}{ S6 } & Test 1 & 3.12 & 9.37 & 43.75 & 21.88 & 21.88 & - & $100 \%$ \\
\hline & Test 2 & 2.38 & - & 30.95 & 26.19 & 40.48 & - & $100 \%$ \\
\hline & Test 3 & - & - & 19.52 & 41.46 & 39.02 & - & $100 \%$ \\
\hline \multirow{3}{*}{ S7 } & Test 1 & - & 5.71 & 40.00 & 22.86 & 31.43 & - & $100 \%$ \\
\hline & Test 2 & - & 5.88 & 44.12 & 26.47 & 23.53 & - & $100 \%$ \\
\hline & Test 3 & - & - & 30.00 & 40.00 & 30.00 & - & $100 \%$ \\
\hline \multirow{3}{*}{ S8 } & Test 1 & - & 4.45 & 53.33 & 20.00 & 22.22 & - & $100 \%$ \\
\hline & Test 2 & - & 6.67 & 46.67 & 15.55 & 31.11 & - & $100 \%$ \\
\hline & Test 3 & - & 1.89 & 30.19 & 26.42 & 41.50 & - & $100 \%$ \\
\hline
\end{tabular}


Note: 1 = Single word question

2 = Declarative word order questions

$3=$ Fronting
$4=$ Inversion in yes-no questions

$5=$ Inversion in wh-questions

$6=$ Complex questions

Group 2 observed comprised of 8 adult leamers who studied English at the English department IKIP (Institut Keguruan dan IImu Pendidikan = Institute for Teacher Training and Pedagogy) Padang. Their ages ranged between 17 and 20 years old. The learners had just graduated from secondary school and were continuing their study at IKIP to be trained. as English teachers for secondary schools. They had studied English for six years, and their English was also at the intermediate level.

Table 22 above shows the percentage occurrence of each type of question for the eight learners in Group 2 (S1, S2, S3, S4, S5, S6, S7 and S8). For question types 1,2 , and 3 , the percentage of questions decreased for some learners, and for question types 4 and 5 , the percentage of questions increased. The shift is really from stage 3 questions to stages 4 and 5 . There are few questions in stages 1 and 2 (as these are intermediate students), but the highest percentage shift from stage 3 to stages 4 and 5 , and in some learners consolidate within a stage.

The decrease in percentage in questions types 1,2, and 3 and the increase in questions types 4 and 5 for both groups, suggests that the language skill of the learners improved. Questions 1,2, and 3 were the types of questions which are considered as interlanguage. Some errors occurred in forming questions. Questions 4, 5 and 6 on the other hand are considered as the types of questions which are grammatically correct; the inversion in yes-no questions was acceptable, the inversion in wh questions was done appropriately, and complex questions were also done in a well-formed manner, according to English question formation rules. Among the 16 learners observed, only two learners were able to form type 6 questions or complex questions; they were L4 in Group 1 and S2 in Group 2. 
In the following section, each learner will be investigated. The learners' development in acquiring question forms for one semester will be analysed on the basis of the results of the tests given at the beginning of their study (test 1 ), at the middle of their study (test 2), and at the end of their study (test 3).

\section{The development of question form of learners in group 1}

\section{1) L1}

L1 was a male aged 41 years old. He was not an active learner since he rarely asked questions in classroom interaction. His English was considered to be at low intermediate level when he first came to the English training centre.

His ability to form questions was very low when he first entered the class. This was indicated by the test 1 result which showed that $62 \%$ of the questions produced at that time were incorrect (38\% correct). Of the $62 \%$ incorrect questions, $53 \%$ were stage 3 errors in fronting eg. 'Why his children not drink?' (wh-fronting), 'Do Paul arrived last week?' (do-fronting), and 'When do they watched TV?' (Wh + aux fronting). Grammatically, there were also problems in tenses, and agreement. He also had problems in choosing suitable question words like 'whose' and 'what'. He preferred to form yes-no questions in whquestion forms, eg., 'What do you see your picture a cat?' instead of 'Do you see a cat in your picture?'. In this sentence, not only did he have problems with question words, but also word order. The above example was actually a word for word translation of the Indonesian sentence 'Apakah kamu melihat di gambarmu seekor kucing?'. A limited number of single word questions and declarative word order questions were also produced by this learner ( $3 \%$ and $6 \%$ respectively). 


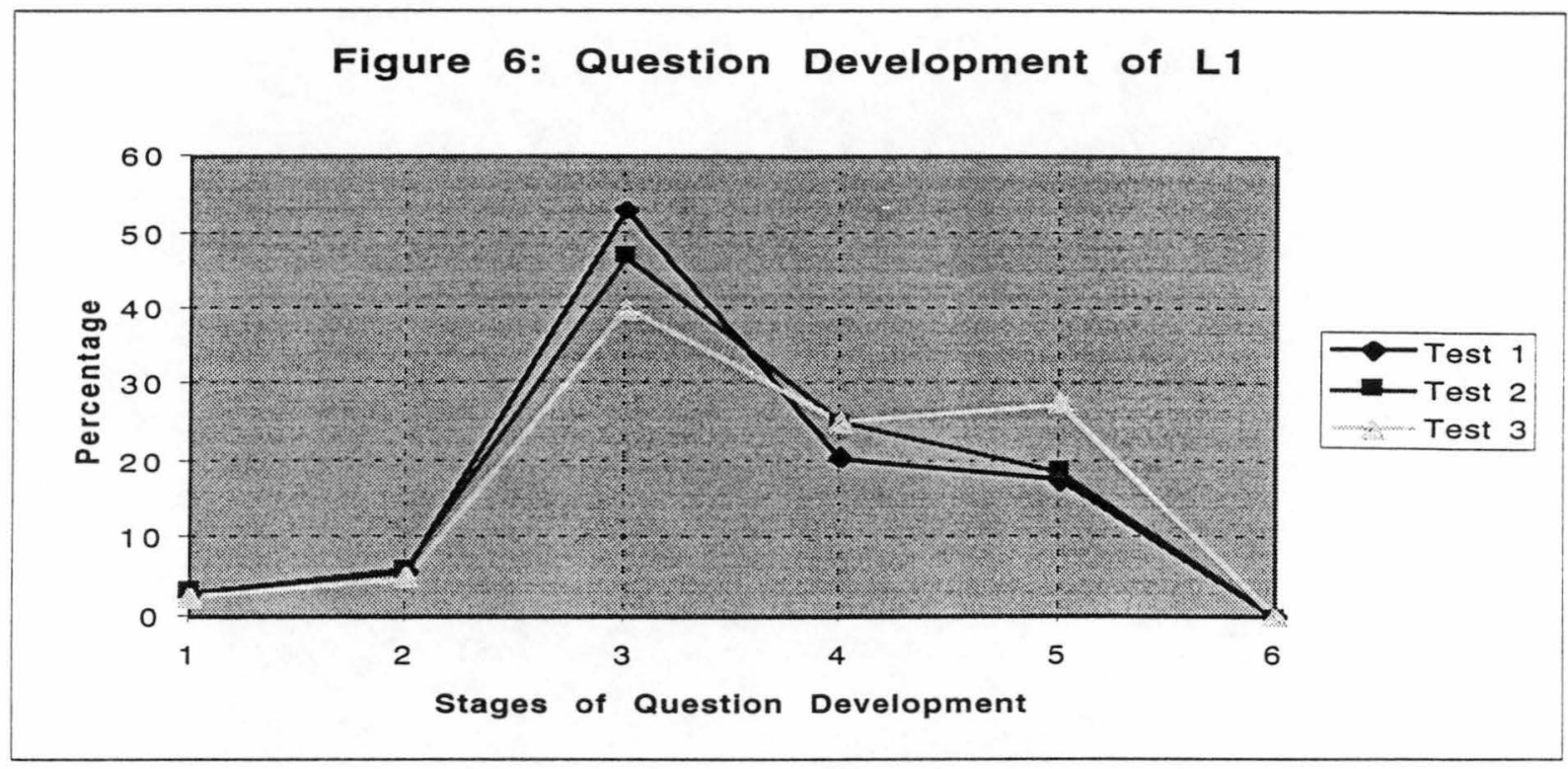

In test 2 and test 3 , the same types of errors were still made by this learner, but the number declined. A number of the correct forms of questions eg. 'Did robber of bank shoot policeman?' which indicates stage 4 of question development, and 'What is he doing?' and 'What are they speaking about?' which indicate stage 5 of question development were produced more frequently, as can be seen in figure 6 . In test 2 , the percentage of fronting (3) decreased (from $53 \%$ in test 1 to $47 \%$ in test 2), yes-no question forms increased (from $21 \%$ in test 1 to $25 \%$ in test 2), and wh-question also increased (from $18 \%$ in test 1 to $19 \%$ in test 2). In test 3, fronting decreased, but yes-no questions did not change. However, wh-questions dramatically increased in test 3 (from $19 \%$ in test 2 to $28 \%$ in test 3 ).

\section{2) L2}

L2 was a male of 37 years of age. His proficiency in English was similar to L1, but he had different problems in forming English questions. 


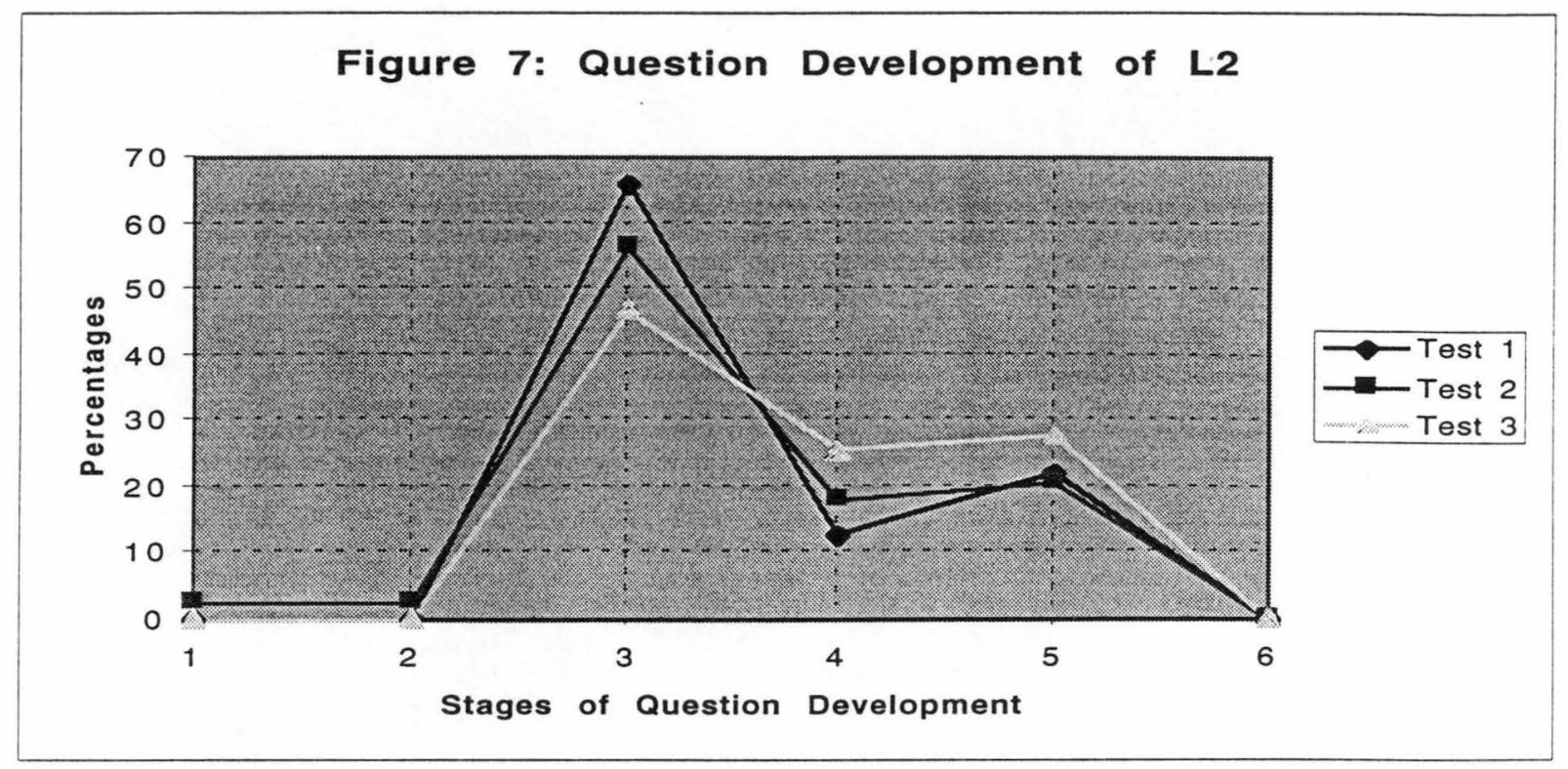

Test 1 indicated that $66 \%$ of the questions produced by $L 2$ were incorrect, or only $34 \%$ questions were correct. All the incorrect question forms were in 'fronting', especially is-fronting and wh + aux fronting eg. 'Is she arrived last week?', and 'Where are he wait?'. It appeared that learners' errors in isfronting to form 'yes-no questions' make them use wh + aux (be) fronting in whquestions as seen in the examples given above. This was different from the problems encountered by L1 who did not use do-fronting or is-fronting in his questions, though wh + aux fronting appeared in the form of wh + do, rather than $w h+$ be.

In test 2 and test 3 , is-fronting and wh + aux (be) fronting had diminished. The forms of questions now appearing were wh-fronting and wh + aux (do) fronting eg., 'What the animal beside the cat?' (wh-fronting), 'What she want?'(whfronting), and 'What do the woman and man in your picture?' (wh + aux (do) fronting). In these two tests, L2 produced many non-verb sentences eg. the first and the last sentences given above. Other examples of these types were, 'How many woman your picture?', 'What the animal beside the cat?', and 'When you photo the animal?'. Such sentences, in Indonesian, can be made as nominal 
sentences or non verb sentences eg., 'Berapa orang wanita di gambarmu?', 'Binatang apa di samping kucing?, and 'Kapan kamu foto binatang itu?'. These questions reveal interference of Indonesian in the English produced by the learners.

The development of questions forms produced by $L 2$ reveals his ability to generate more correct questions (stage 4 and 5) and to decrease the number of errors in fronting from $66 \%$ of errors in test 1 to $47 \%$ in test 3 . While yesnoquestions (4) and wh questions (5) increased from $13 \%$ and $22 \%$ to $26 \%$ and $28 \%$ respectively in test 3 (see figure 7 ).

\section{3) L3}

L3 was a 38 year old male. He was an active learner. Although his language performance was at a low level, his attempts to be active in class, by asking questions, responding and commenting in English helped him in English performance, especially in forming questions in English.

In test 1, his ability to form questions in English was balanced equally between correct and incorrect questions (50\% correct questions and 50\% incorrect questions). Most of errors he made were in fronting ( $43 \%)$, and the other $(7 \%)$ were in single word questions. In test 2 , his errors in fronting decreased to $28 \%$, and in test 3 became $17 \%$. The ability to form correct questions in yes-no questions increased from $10 \%$ in test 1 , became $35 \%$ in test 2 , and $36 \%$ in test 3 , not much different from the result of test 2 . His ability to form correct questions in Wh-questions decreased from $40 \%$ in test 1 to $32 \%$ in test 2, but increased to $48 \%$ in test 3 . These percentages can be seen in figure 8 . 


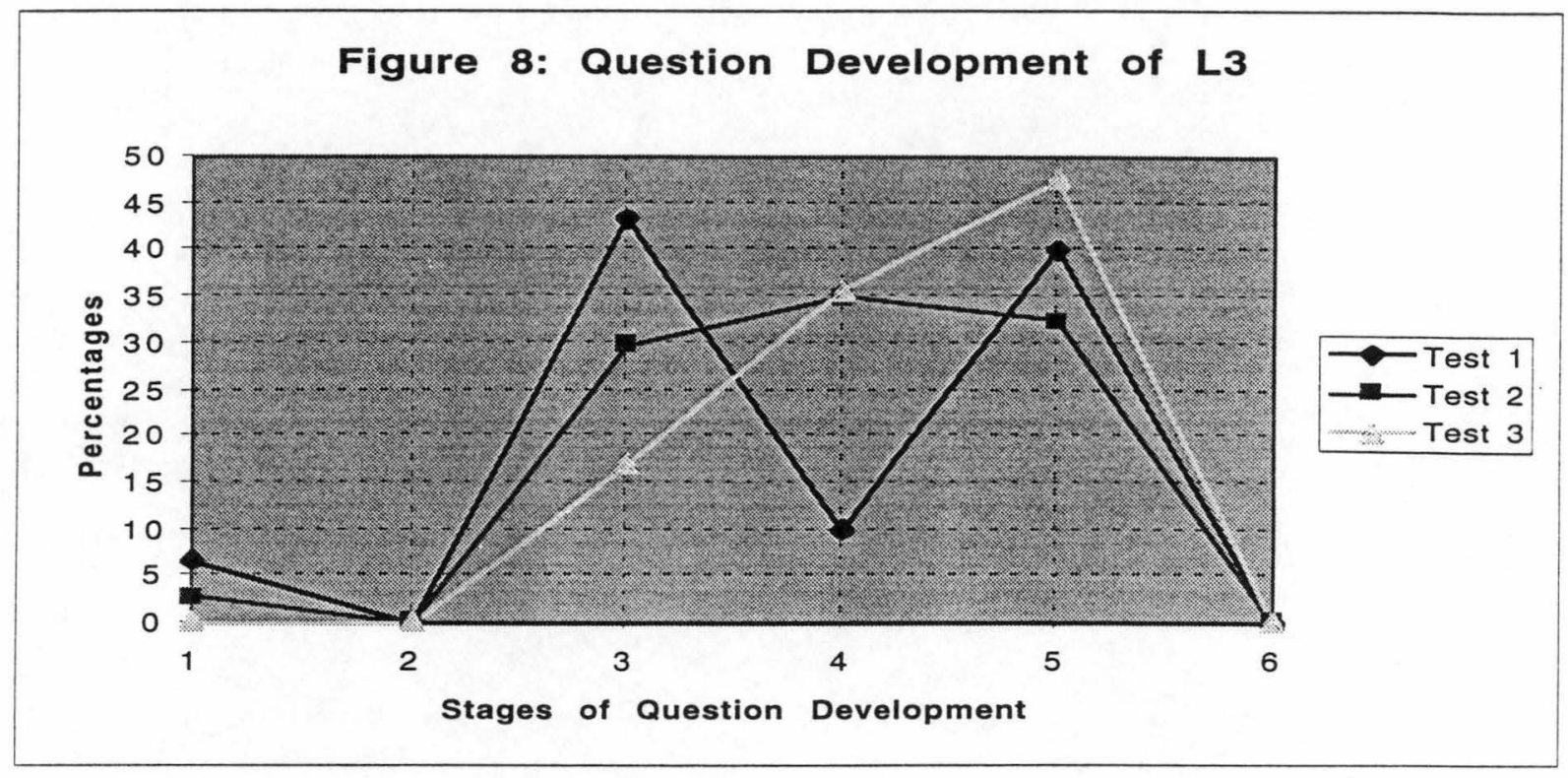

Most of the errors he made in test 1 were in wh + aux fronting. He was not able to use the correct form of the auxiliary to form questions. He tended to use the verb to 'be' instead of other possible auxiliaries eg. 'Why are they have lunch in the garden?', 'Which is you like?', and 'When were they watched TV?' Some of his 'yes-no questions' were formed as 'wh-question forms', eg. 'What you with your father?', and 'What is the police wearing gun?' instead of 'Are you with your father?' and '/s the police wearing gun?'. In test 3 , these types of errors still occurred though they decreased, whereas correct yes-no questions (4) and wh-questions (5) occurred more frequently than incorrect ones.

4) L4

L4 was a 40 year old male. He was categorised as an active learner who asked questions, and participated in classroom interaction. His performance in English was considered to be -at intermediate level, since he could communicate in English more fluently than L1, L2, and L3. 


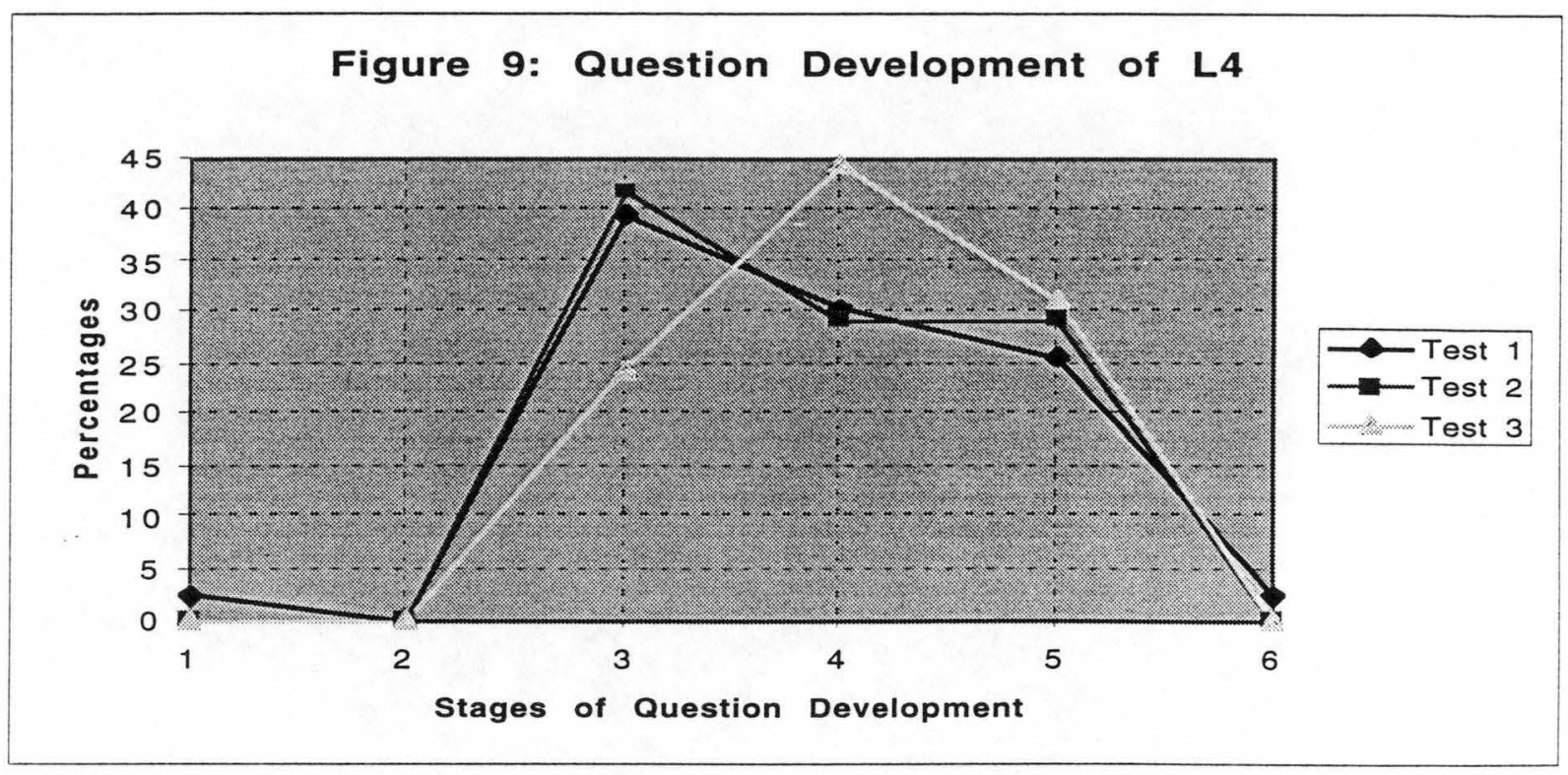

Test 1 indicated that L4 produced $42 \%$ incorrect questions and $58 \%$ correct questions. The errors were in 'fronting' (40\%), and in single word questions $(2 \%)$. The errors in 'fronting' were in wh-fronting and wh + aux fronting. He had no problems in forming yes-no questions (do fronting and is fronting). Errors in wh-questions were made because there was no verb in the questions, in other words, he made non verb sentences like, 'How many birds in the picture?' and 'What colour the flowers in your picture? This type of error was made by L2, and can be considered interference of Indonesian, the mother tongue. For wh + aux fronting, L4 used 'be' as an auxiliary in constructing wh-questions, eg. 'When were they watch TV yesterday?' or 'Where is John study?' These types of errors still appeared in test 2 and 3 , but the number decreased.

In Figure 9, it can seen that between test 1 and test 2, L4 did not show clear develop in his proficiency to form questions. However, test 3 indicated that the number of errors in 'fronting' (3) decreased from $40 \%$ in test 1 to $24 \%$, while the number of correct 'yes-no questions' forms increased from $30 \%$ (test 1) to $44 \%$ (test 3 ). The ability to develop wh-questions did not improve much for L4, since it only increased from $26 \%$ in test 1 , and $29 \%$ in test 2 , to $31 \%$ in test 3 . 


\section{5) L5}

L5 was a 27 year old female. Her English was considered to be upper intermediate when she entered the English training centre. She was an active student who always wanted to participate in classroom interaction.

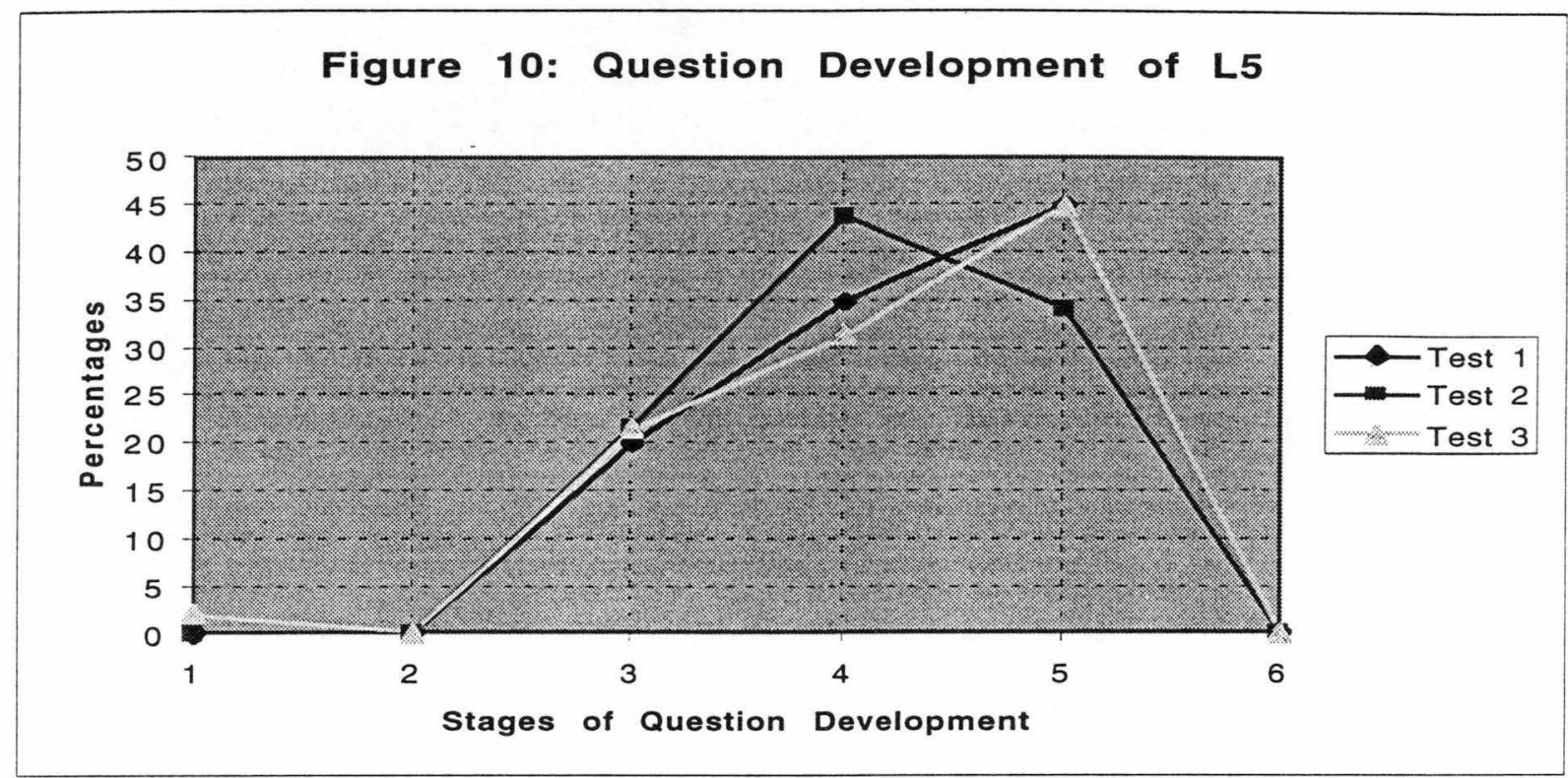

Test 1 showed that $20 \%$ of her questions were incorrect and $80 \%$ were correct. Most of the errors she made were in 'fronting', especially in wh-fronting and wh + aux fronting, eg. 'Where the bird in your picture?' or 'What the colour his dress?. These questions were probably influenced by the Indonesian questions, 'Di mana burung di gambarmu?' or 'Apa warna bajunya?', the same errors as those made by L2 and L4. Errors in wh + aux fronting were in the use of 'be' instead of 'do', 'does', or 'did', eg. 'What are her mother say?', and 'Where is the fish face to?, or overuse of modal auxiliaries eg. 'Who did visit Mary?' and 'Who does study in the library?'. These types of errors could still be found in tests 2 and 3 .

The results did not show much development in the ability to form questions. The number of errors she made remained the same $(20 \%, 22 \%$, and $22 \%$ in 
test 1, 2 and 3respectively), while the number of correct questions in yes-no questions fluctuated $(35 \%, 44 \%$, and $31 \%$ in test 1,2 and 3 respectively). The number of correct questions in the wh-questions form also fluctuated $(45 \%$, $34 \%$, and $45 \%$ in test 1,2 , and 3 respectively).

6) L6

L6 was a 34 year old female. She was not an active learner since she only responded if directly requested by the teacher.

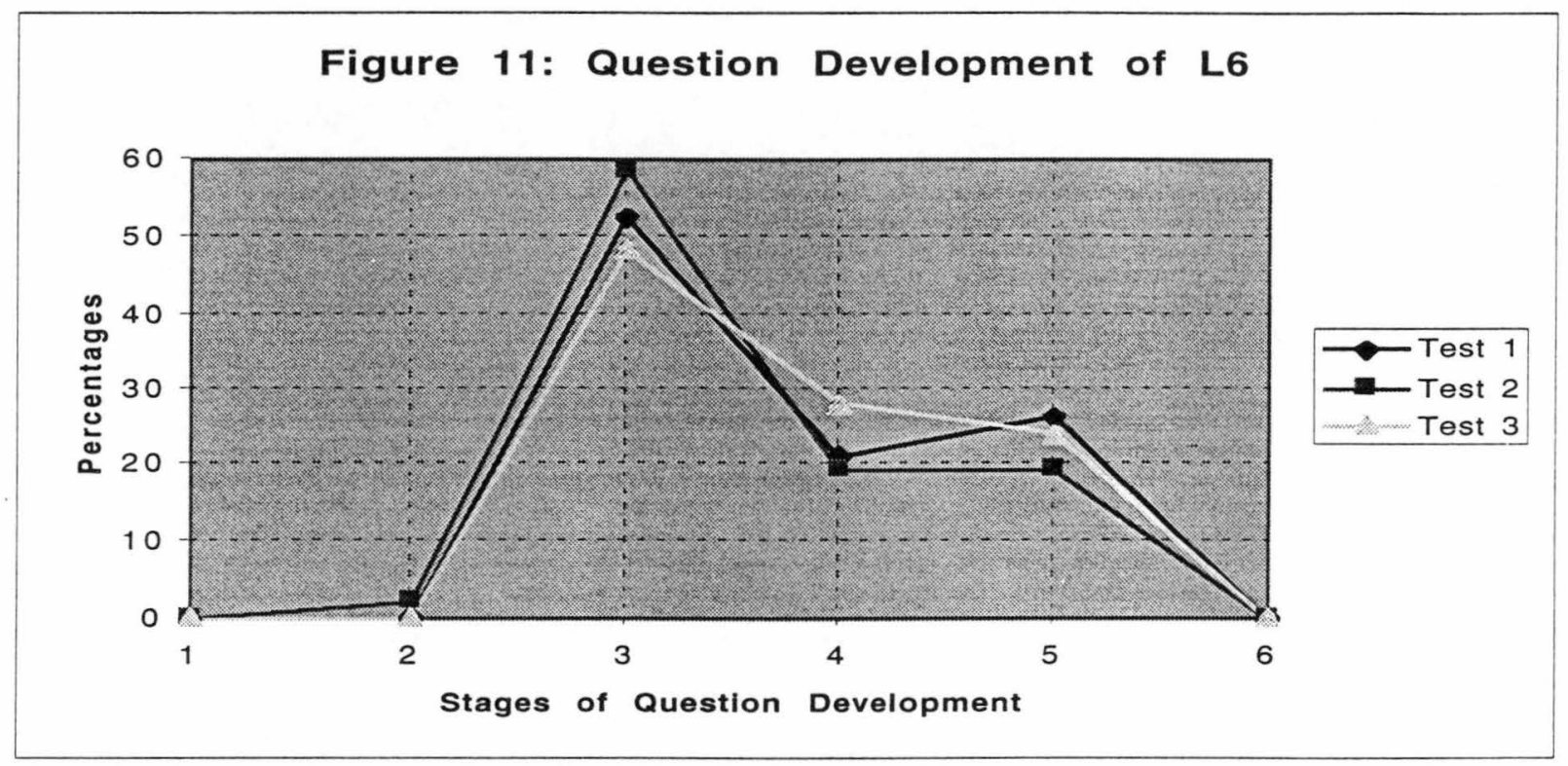

Test 1 indicated that $53 \%$ of her questions were incorrect, while the other $47 \%$ were correct. She mainly had problems in wh-fronting and wh + aux fronting eg., 'How many times you have told him?', 'Who did visit Mary?', and 'Where are they come from?. The question word was followed by a declarative sentence in the first example above, in the second and third examples the use of the auxiliary 'did' and 'are' were not appropriate. L6 also used is-fronting eg. 'Is the mother wear red dress?' and 'Are they feel happy together?'. L6 also had problems in using question words, therefore some 'yes-no questions' were made in 'wh-question forms', eg. 'What all of the books are here?', and 
'What there are tree?' when she meant 'Are all of the books here?' and 'Are there some trees (there)? In test 2 and test 3, is-fronting, wh + aux fronting, and 'yes-no questions in wh question forms' diminished, and L6 only had problems in wh-fronting.

Although the decrease in incorrect questions was good, the increase of correct questions in 'yes-no questions' and 'wh-questions' was irregular. 'Yes-no questions' in test 1 were $21 \%$ and decreased to $20 \%$ in test 2 , then increased to $28 \%$ in test 3 . Wh- questions, were $26 \%$ in test 1 , and decreased to $20 \%$ in test 2 , then increased to $24 \%$ in test 3 . So, the flow of development was not good for $L 6$.

\section{7) L7}

L7 was a 29 year old female. She was a shy learner. She never asked questions in classroom interaction, but she got involved, asked some questions and gave responses when she was in small group discussion.

Test 1 indicated that $53 \%$ of her questions were incorrect and the other $47 \%$ questions were correct. She had problems in 'frontings', and also used 'single word questions' (5\%). 'Yes-no questions in wh question forms' were also found in her questions, eg. 'What she is studying dancing?', and 'What Mary have a lot of books?'. Problems in 'wh-fronting' eg. 'Where they playing now?', 'What they speak?', and wh + aux fronting eg. 'What are they eat?', 'What is she do? reflected that she also made mistakes in is-fronting, eg. '/s the police ask the boy?', and 'Are the children are speaking?'. is-fronting (and 'are fronting' possibly) followed by a declarative sentence to form 'yes-no questions', was also encountered with her use of wh fronting and wh + aux fronting questions. 


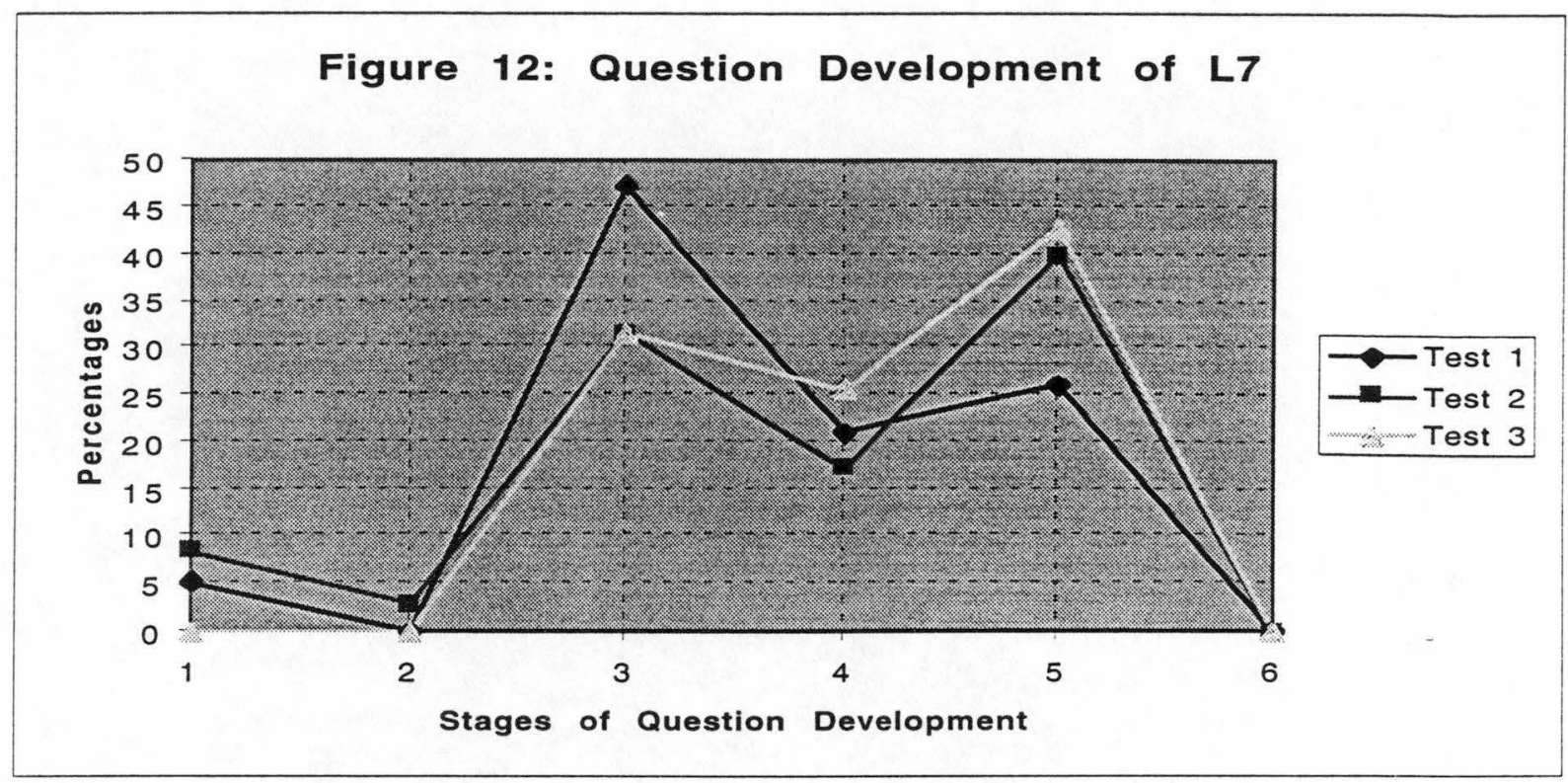

In test 2, in addition to 'single word questions' (9\%), 'declarative word order questions' appeared (3\%), but the number of 'fronting' and 'yes-no questions' decreased, while the number of wh- questions increased.

In test 3, no single word questions or declarative word order questions were found, and the number of errors in fronting remained the same as test $2(31 \%)$, while the number of 'yes-no questions' and wh- questions increased (from $17 \%$ to $26 \%$ in yes-no questions, and from $40 \%$ to $43 \%$ in wh-questions), as can be seen in figure 12 .

8) L8

L8 was a 27 year old female. She was not an active learner, but she sometimes responded in classroom interaction. 


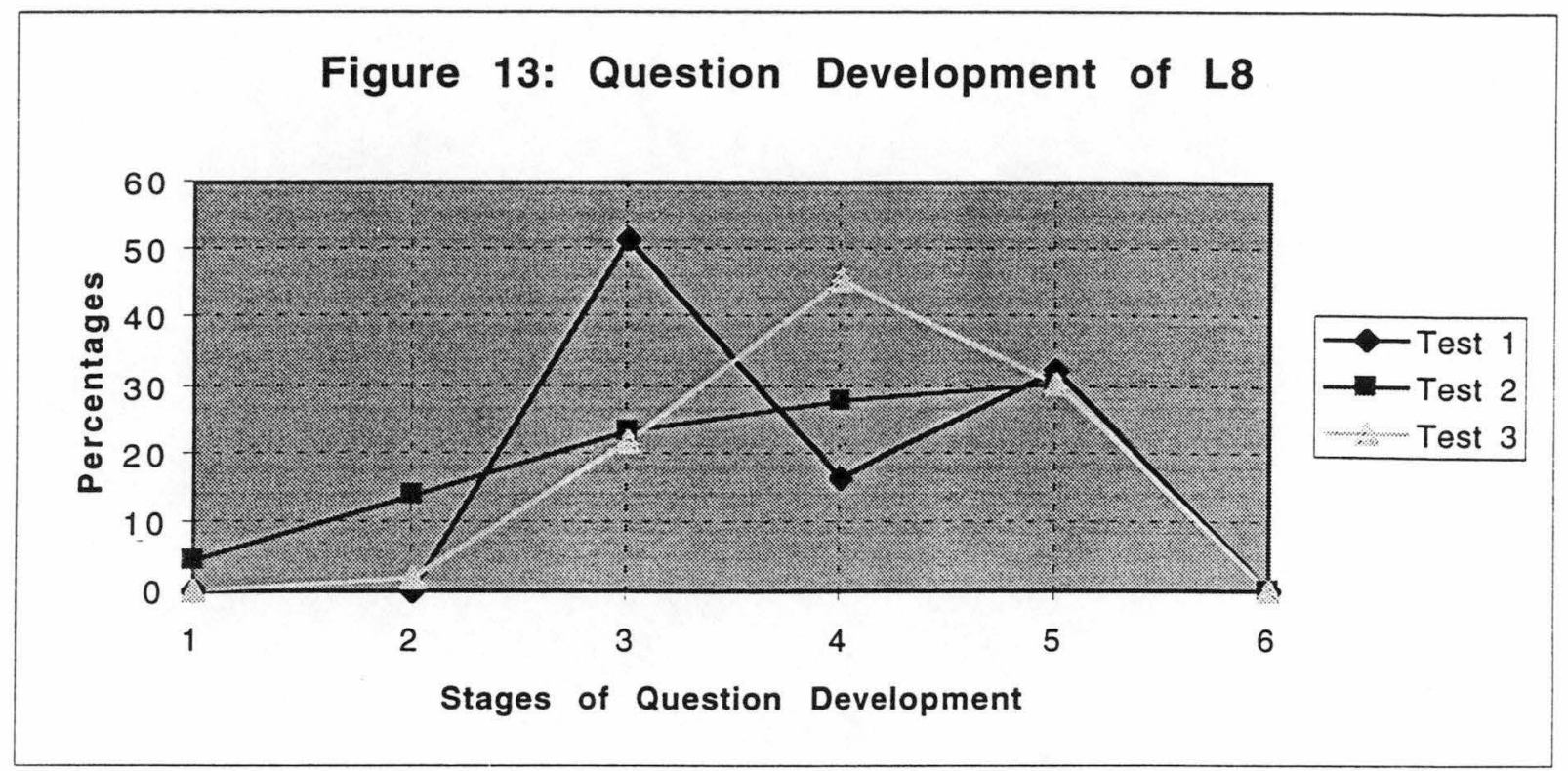

Test 1 revealed that $51 \%$ of her questions were incorrect, while the other $49 \%$ were correct. All of the incorrect questions were in 'fronting', like 'Why their parents sits on the chair?' (wh fronting), 'Do they tired?' (do fronting), 'Are they play in the garden?', and 'When were they play in the park?' (wh + aux fronting). She also had problems in using question words. 'Yes-no questions' were formed in 'wh question forms', eg. 'What is in your picture have birds?' instead of 'Does your picture have birds?'. She also had problems in the agreement between the subject and verbs and auxiliary and verbs, like 'Where is the children playing?', and 'Did Paul arrived last week?'

Test 2 indicated that errors in do-fronting and is-fronting were not found, and the number of errors in agreements had decreased (from 51\% to $22 \%$ ). Test 3 showed that there was great improvement in forming 'yes-no questions' (from $16 \%$ to $46 \%$ ), although there were still errors in 'frontings', especially whfronting and $w h+$ aux fronting. 
The decrease in the number of questions in tests 2 and 3 in 'fronting' and the increase in the number of yes-no questions indicate that the learner developed her proficiency in forming questions in English.

The development of question forms of learners in group 2

9) $\mathrm{S} 1$

S1 was a 19 year old male. He was an active learner and he often participated in classroom interaction.

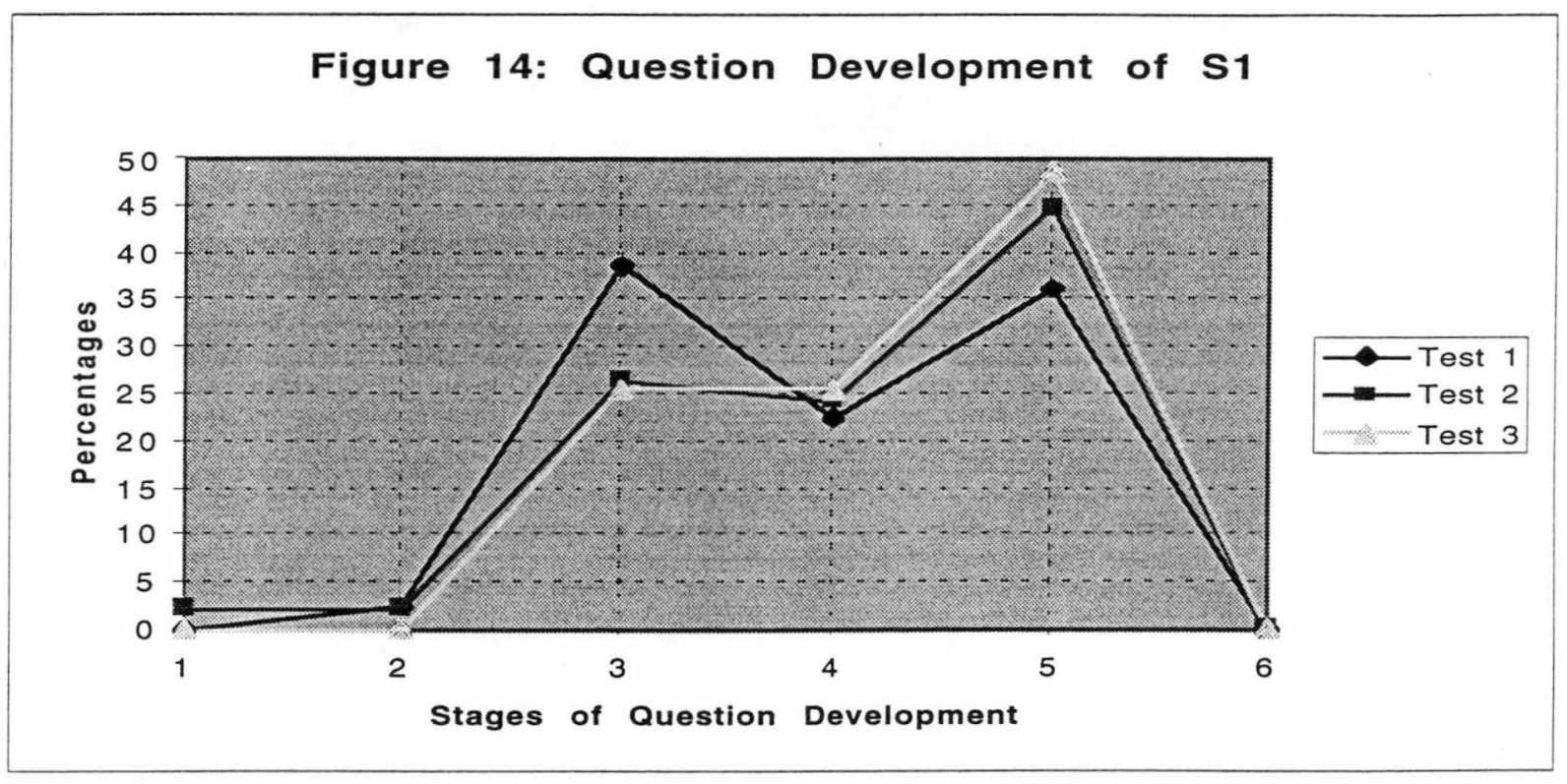

Test 1 indicated that $41 \%$ questions generated by $\mathrm{S} 1$ were incorrect, while the other $59 \%$ were correct. The main problems faced by the learner were in fronting, especially wh-fronting, is-fronting, and wh + aux fronting. $\mathrm{He}$ produced sentences like 'What they are doing in the yard?' (wh-fronting), '/s she studies here every Tuesday?' (is fronting), and 'Who is Mary invited?' (wh + aux fronting). Sentences like 'How many children holding the coconut tree?, where the verb was formed in -ing form, frequently occured in whfronting. Grammatically, this learner had problems in subject-verb + auxverb agreements. 
In test 2 and test 3 , these types of errors still occured but in limited numbers since correct questions in yes-no questions and wh-questions increased (from $23 \%$ to $25 \%$ in yes no question, and from $36 \%$ to $49 \%$ in whquestions) as seen in figure 14. The errors in 'fronting' decreased from $39 \%$ in test 1 to $26 \%$ in test 3 .

\section{0) $\mathrm{S2}$}

S2 was a 20 year old male. He was not very active in class, but he did sometimes participate in classroom activities.

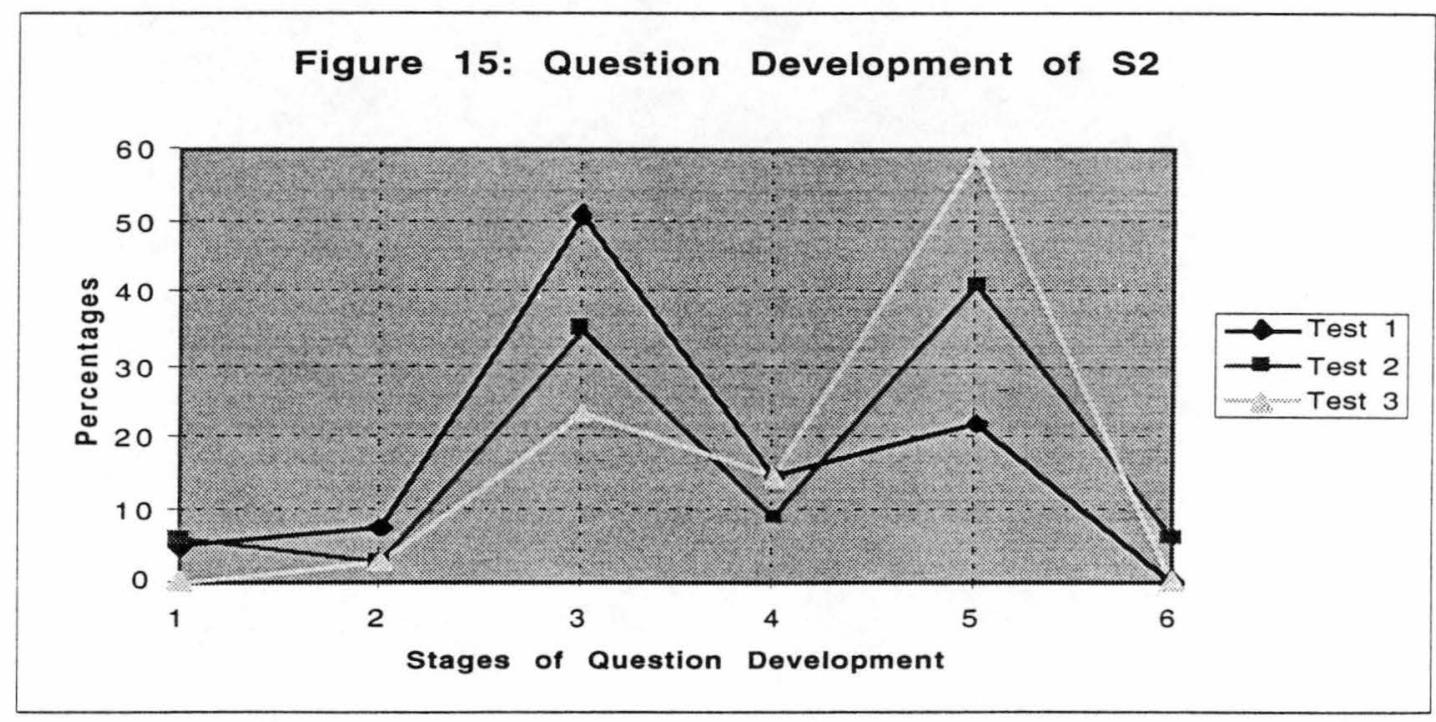

Test 1 indicated that $63 \%$ of his questions were incorrect, and only $37 \%$ questions were correct. The errors that he made were mostly in 'fronting', even though 'single word questions' and 'declarative word order questions' still occured ( $5 \%$ and $7 \%$ respectively). In test 1 , most of the errors were in the form of wh-fronting such as 'Where he wait her friends?', 'What the girl doing?', and 'How many the tree in the picture?'. There were three types of errors in the three examples given above. In the first example, the question word was followed by the declarative word order, no inversion was made. In the second example, the question word was followed by the declarative word order, but the verb in the declarative word order was in the -ing form. In the third example, the question word was followed by a non-verb 
sentence which was, as previously indicated, interference from the mother tongue, Indonesian.

In test 2, errors appeared in is-fronting such as 'Is she write the letter?, and 'What was they study at nine o'clock?'. These types of errors occured more in test 2 rather than the type of wh-fronting which occured in test 1 . Errors which occured in test 1 still appeared in test 2 but were fewer in number, since $\mathrm{S} 2$ was able to produce wh-questions more frequently.

The development of questions for $\mathrm{S} 2$ can be seen the decrease of fronting in test 2 and 3 compared to test 1, and the increase of yes-no questions and wh-questions. The increase of wh-questions was good, from $22 \%$ in test 1 , $35 \%$ in test 2 , to $59 \%$ in test 3 . S2 also began to use 'complex questions' in form of negative questions in test $2(6 \%)$.

\section{1) $\mathrm{S3}$}

S3 was a 20 year old male. He was an active student, although his performance in English was at a low level when he first entered the English class.

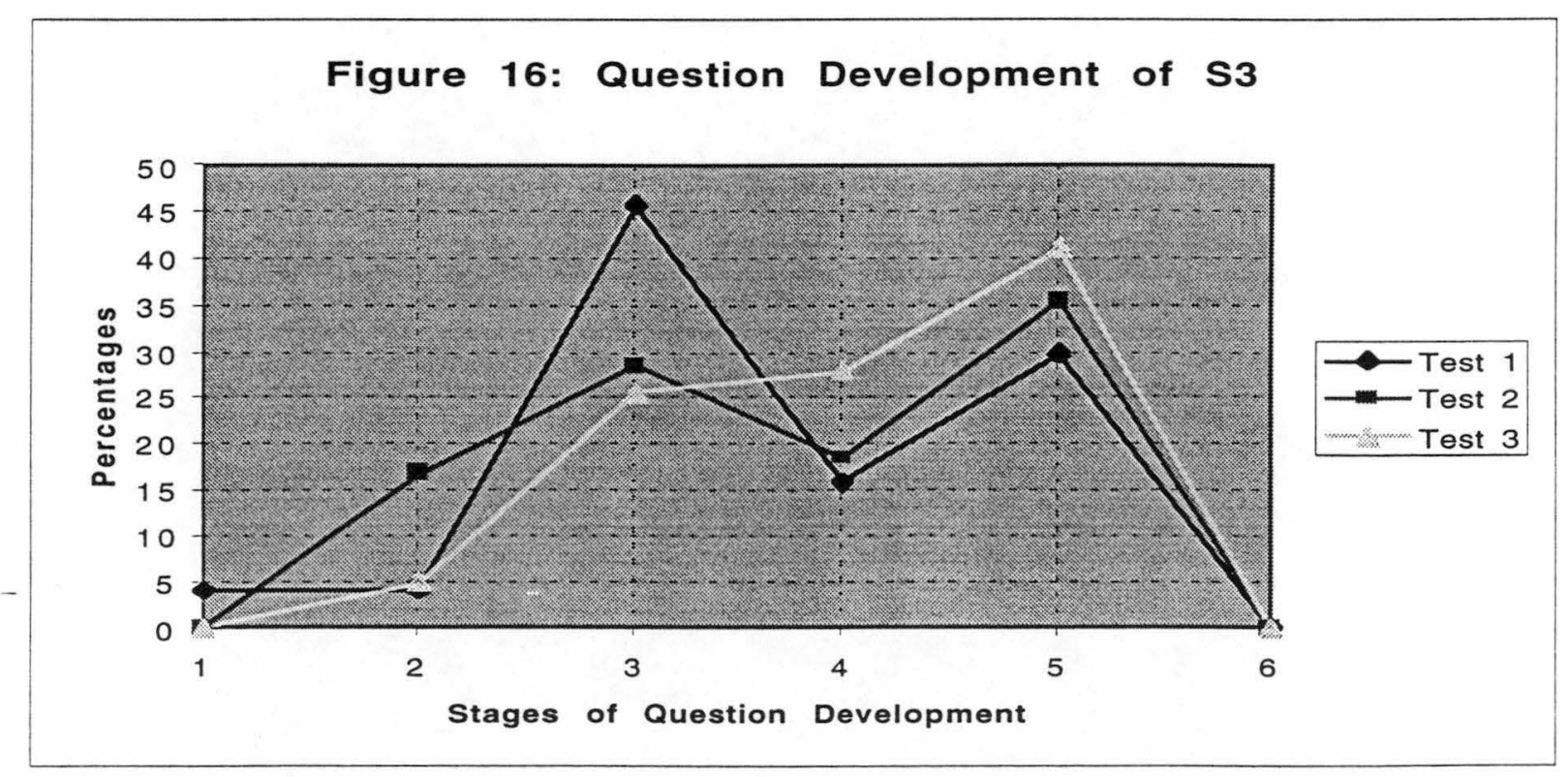


Test 1 indicated that $54 \%$ of his questions were incorrect, and only $46 \%$ were correct. The main problem he had in forming questions were in whfronting and wh + aux fronting. The types of wh-fronting were 'Whose it is assignment?', ' How many times you tell him?, and 'How many birds in the picture?'. The types of wh-fronting occured where a question word was followed by a declarative sentence, or a question word was followed by a non verb sentence. S3 also used 'yes-no questions in wh-question forms' such as 'What is they one family?', and and 'What they have a lot of friends?' to say 'Are they one family?' and 'Do they have a lot of friends?. The errors in wh + aux fronting were in the use of the verb to 'be' instead of other auxiliaries such as 'When was they do this recreation?' instead of 'When did they do this recreation?'. Errors also occured in overuse of auxiliaries such as 'Who did visit her father?' instead of 'Who visited her father?'.

In test 2, beside the two types of errors above, there were more questions in 'declarative word order' (17\%), while 'one word questions' did not appear anymore. There were also questions with is-fronting such as 'Are the robbers have moustache?'. In test 3 , although wh-fronting and wh + aux fronting errors occured the number was very small.

The question development of S3 can be seen in the decrease in fronting in tests 2 and 3 (from $46 \%$ in test 1, 29\% in test 2, to $26 \%$ in test 3 ), and the increase in 'yes-no-questions' and wh-questions (from 16\% and $30 \%$ in test 1 to $28 \%$ and $41 \%$ in test 3 respectively), as seen in figure 16 .

\section{2) 54}

S4 was a 20 year old male. He was a quiet learner, and he never asked questions in classroom interaction. However, in small group activities he was able to interact with other learners.

Test 1 indicated that only $33 \%$ of his questions were incorrect, while the other $67 \%$ were correct. The problems he had were in wh-fronting and wh + 
aux fronting. In wh-fronting, he made sentences such as 'How many children playing swing?', 'Where to face?, and 'How many birds on the hands?'. In these questions the question word was followed a declarative sentence, but the verb was in the -ing form or the infinitive or a non verb sentence was used. The errors in wh + aux fronting were in overuse of the modal auxiliary such as 'Who does have a large number of books?', and 'When did you have talk to him?'. In test 2 and test 3 , these types of questions still appeared, but less frequently.

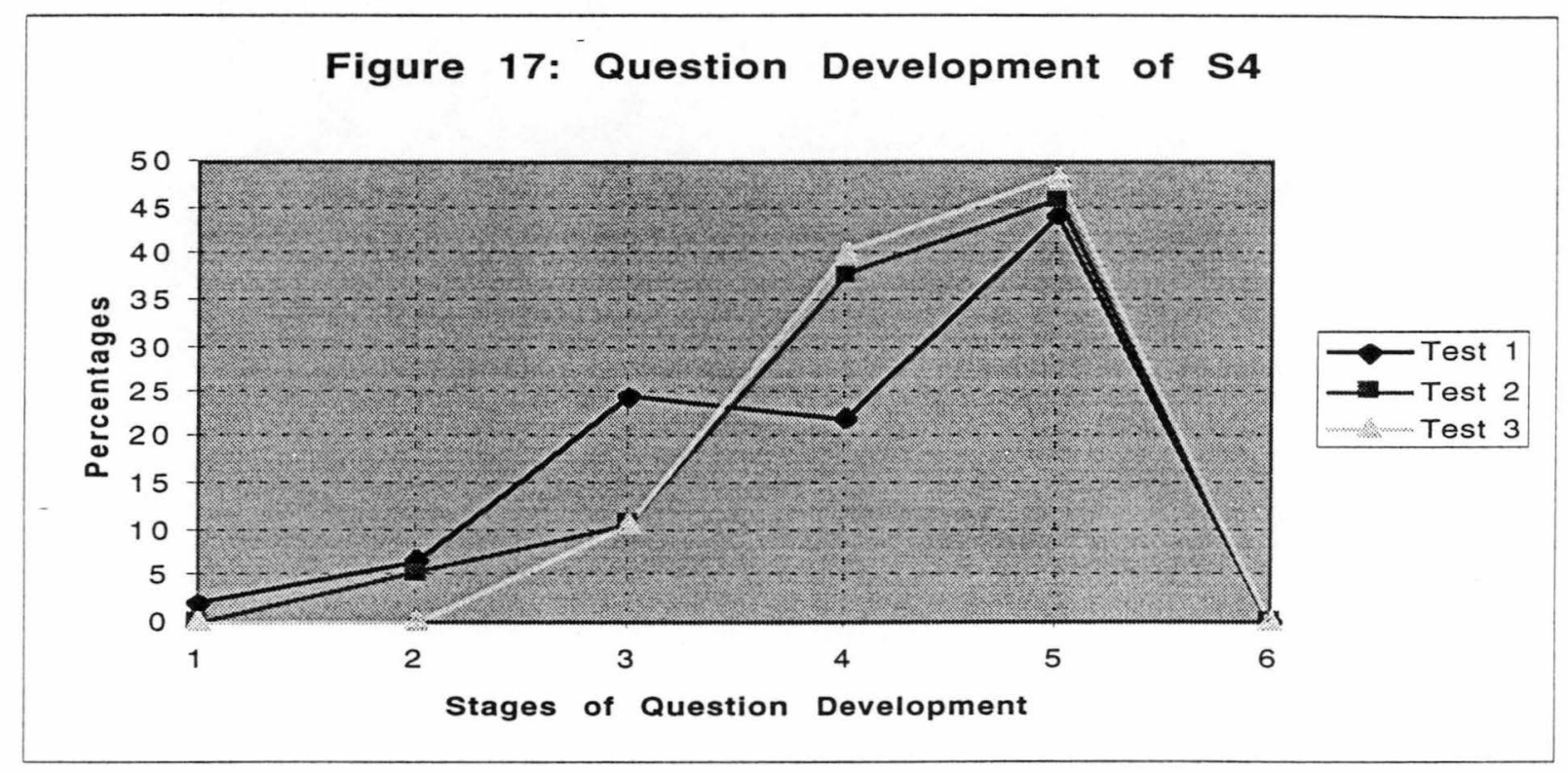

The question development of S4 is apparent in the decrease in fronting and the increase in yes-no questions and wh-questions. The increase in yes-no questions was dramatic from test 1 to test 2 (from $22 \%$ to $38 \%$ ), but only limited from test 2 to test 3 (from $38 \%$ to $41 \%$ ). The increase of whquestions was not as dramatic as yes-no questions (from $44 \%$ in test 1 , $46 \%$ in test 2 , to $49 \%$ in test 3 ).

\section{3) $\mathrm{S5}$}

S5 was an 18 year old female. She was not very active in class and only engaged in small group discussion. 


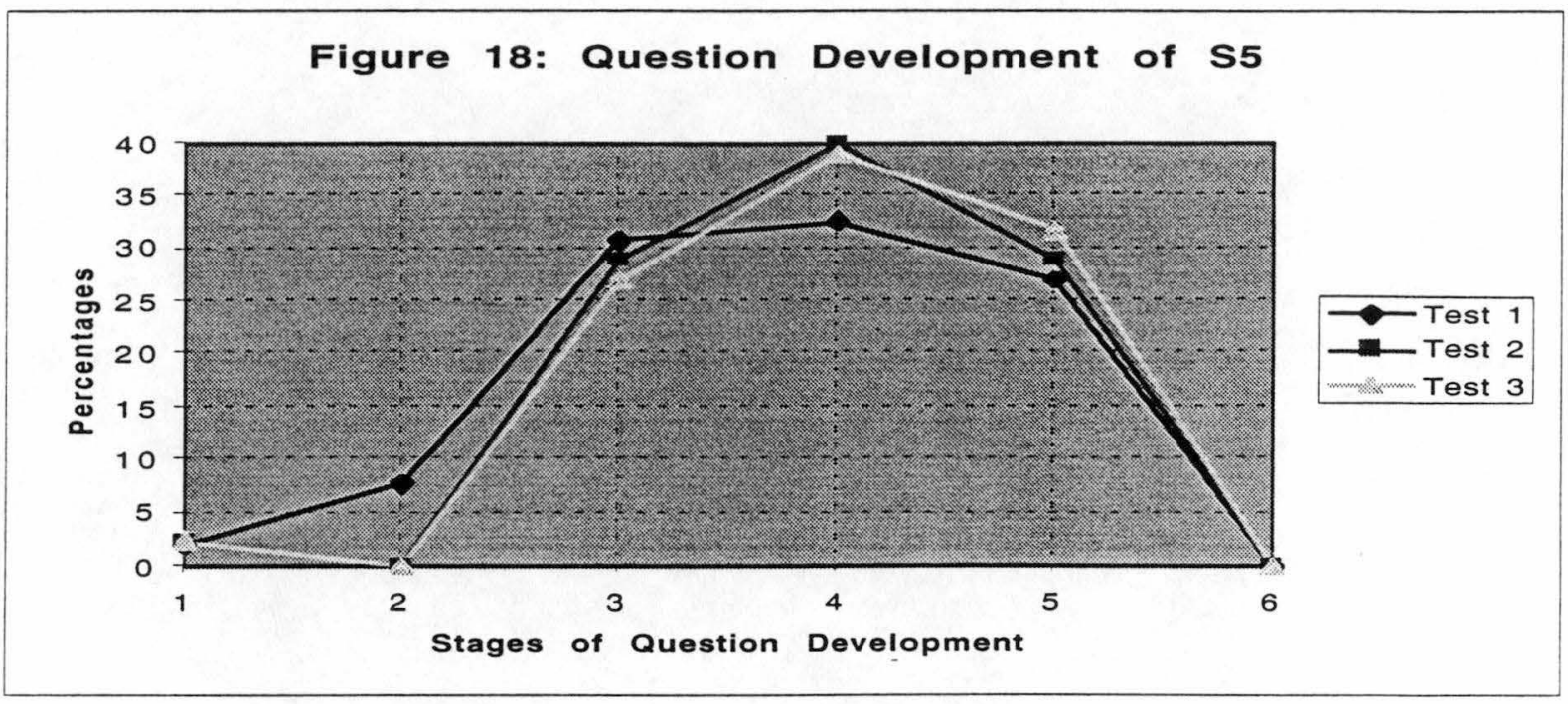

Test 1 indicated that $40 \%$ of questions S5 produced were incorrect, and of the others, $60 \%$, were correct. Questions in single word and declarative word orders occured in test 1 , and diminished in test 2 and test 3 . The most errors she made were in wh-fronting and $w h+$ aux fronting. The types of errors in wh-fronting were question words followed by a declarative sentence with the verb -ing form such as 'How many people wearing white dress?.' The question word could also be followed by a non-verb sentence such as 'How many children in your picture?'. Or the question word was followed by a word or phrase such as 'How much old people?", 'What about the bird?', and 'How about your picture?'. The errors in wh + aux fronting were in the form of overuse of the modal auxiliary such as 'Who does teach children in front of class?' or inappropriate use of the auxiliary such as 'What did they doing at nine o'clock?', 'Where is the mouse face in your picture?. These types of errors were still found in test 2 and test 3 .

Figure 18 shows that, S5 did not develop much in proficiency to form English questions, since the number of errors in fronting decreased only slightly (from $31 \%$ in test $1,29 \%$ in test 2 , and $27 \%$ in test 3 ). The increase in yes-no questions and wh-questions was only slight (from 33\% in test 1, to $39 \%$ in test 3 for 'yes-noquestion', and from $27 \%$ in test 1 to $32 \%$ in test 3 for wh-questions). 


\section{4) 56}

S6 was a 20 year old female. She was an active learner, because she often responded, asked questions, and commented in classroom interaction, although her English was at low level when she first entered the English department.

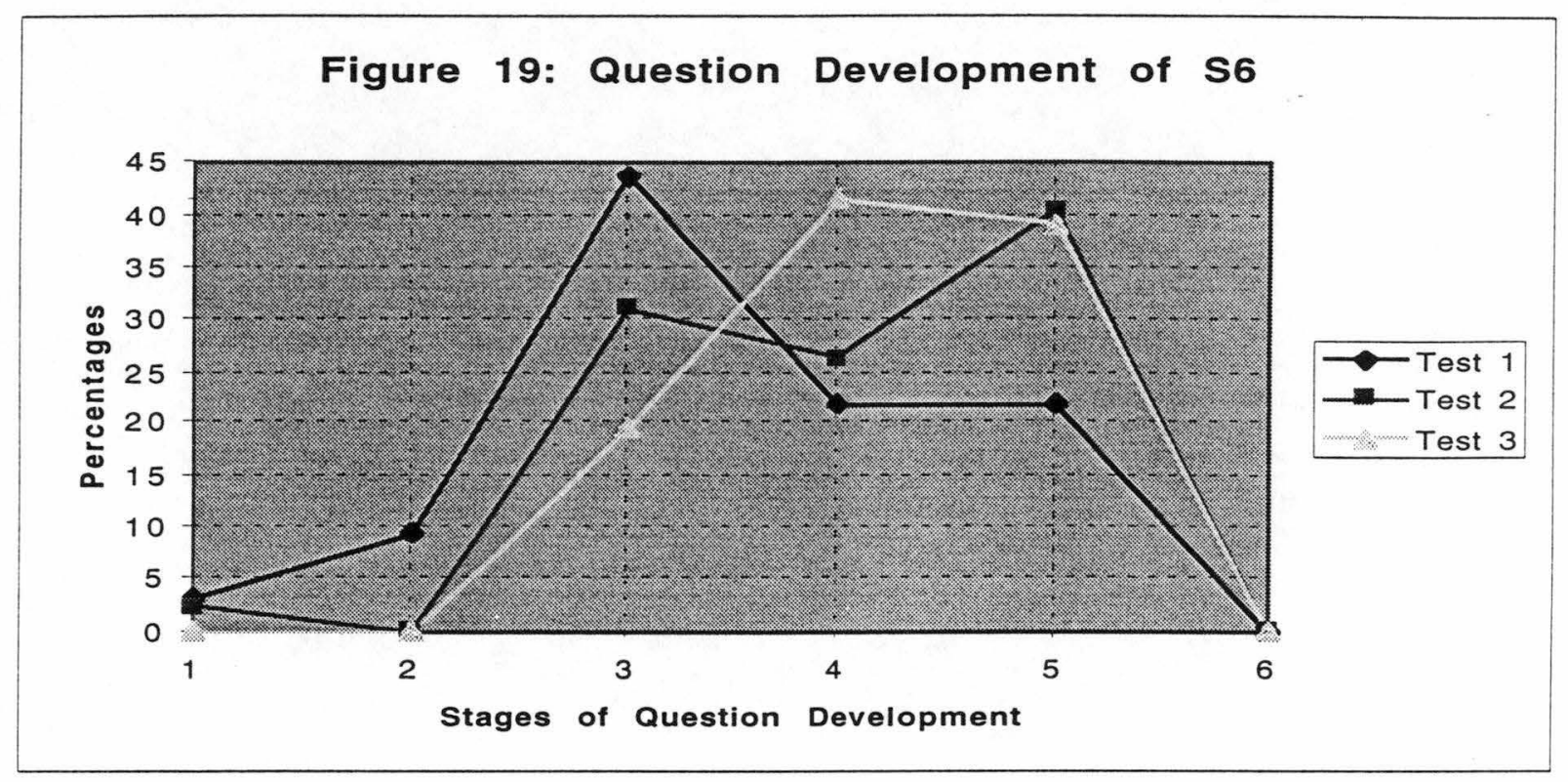

Test 1 indicated that $56 \%$ of her questions were incorrect, while the other $44 \%$ were correct. Errors appeared in wh-fronting, such as 'When they are going to beach?', in is-fronting, such as '/s she studies here every Tuesday?', or 'Was Paul arrived last week?, and in wh + aux fronting, such as 'Where is John study?. S6 also made errors in subject-verb agreement, such as 'What is the students doing?', or 'Was you in the city yesterday?', and errors in the use of question words such as 'Whose have this assignment?. In test 1 , S6 also made 'single word questions' and 'declarative word order questions'.

In test 2 and test 3, althoug these types of errors still appeared, the number decreased from $44 \%$ in test $1,31 \%$ in test 2 , to $20 \%$ in test 3. In contrast, the number of correct questions increased from $22 \%$ in test $1,26 \%$ 
in test 2 , to $41 \%$ in test 3 . While wh-questions fluctuated from $22 \%$ in test 1 , to $40 \%$ in test 2 , and down to $39 \%$ in test 3 .

\section{5) 57}

S7 was a 19 year old female. She was not very active in class, but she practised English well in small group activities.

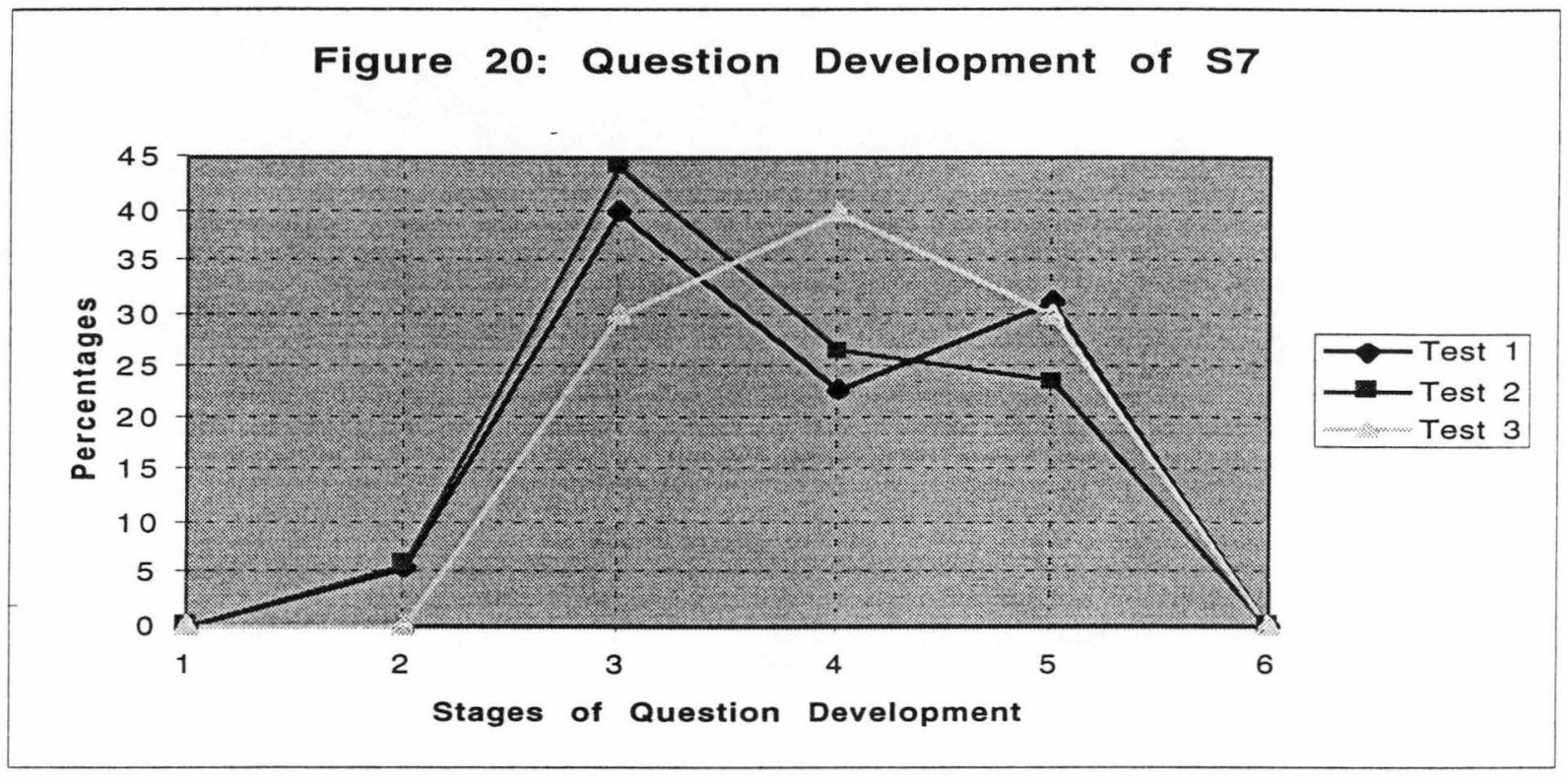

Test 1 indicated that $46 \%$ of her questions were incorrect and the other $54 \%$ were correct. The main problems she faced were wh-fronting, 'is fronting, and wh + aux fronting. The errors can be seen in the following examples; 'What colour the trees in your picture?' (wh-fronting), 'Is he bring a car?' (is fronting), and 'What is Mary have?', 'Who is stand beside the door?' (wh + aux fronting). In wh-fronting, S7 produced some sentences in the forms of 'What about...?', and 'How about....?', such as 'What about the animal number 3?' and 'How about your picture?'. The questions can be considered incomplete questions, since they should have been followed by another question, either a yes-no question or wh-question.

The question development of S7 can be seen in figure 20 which indicates that the number of 'declarative word order questions' and 'frontings' 
decreased and the number of yes-no questions and wh-questions increased. The main development of $L 7$ was in the dramatic increase in the use of 'yes-no question' forms (from $23 \%$ in test 1 to $40 \%$ in test 3 ).

\section{6) 58}

S8 was a 17 year old female. She was an active learner and always asked questions.

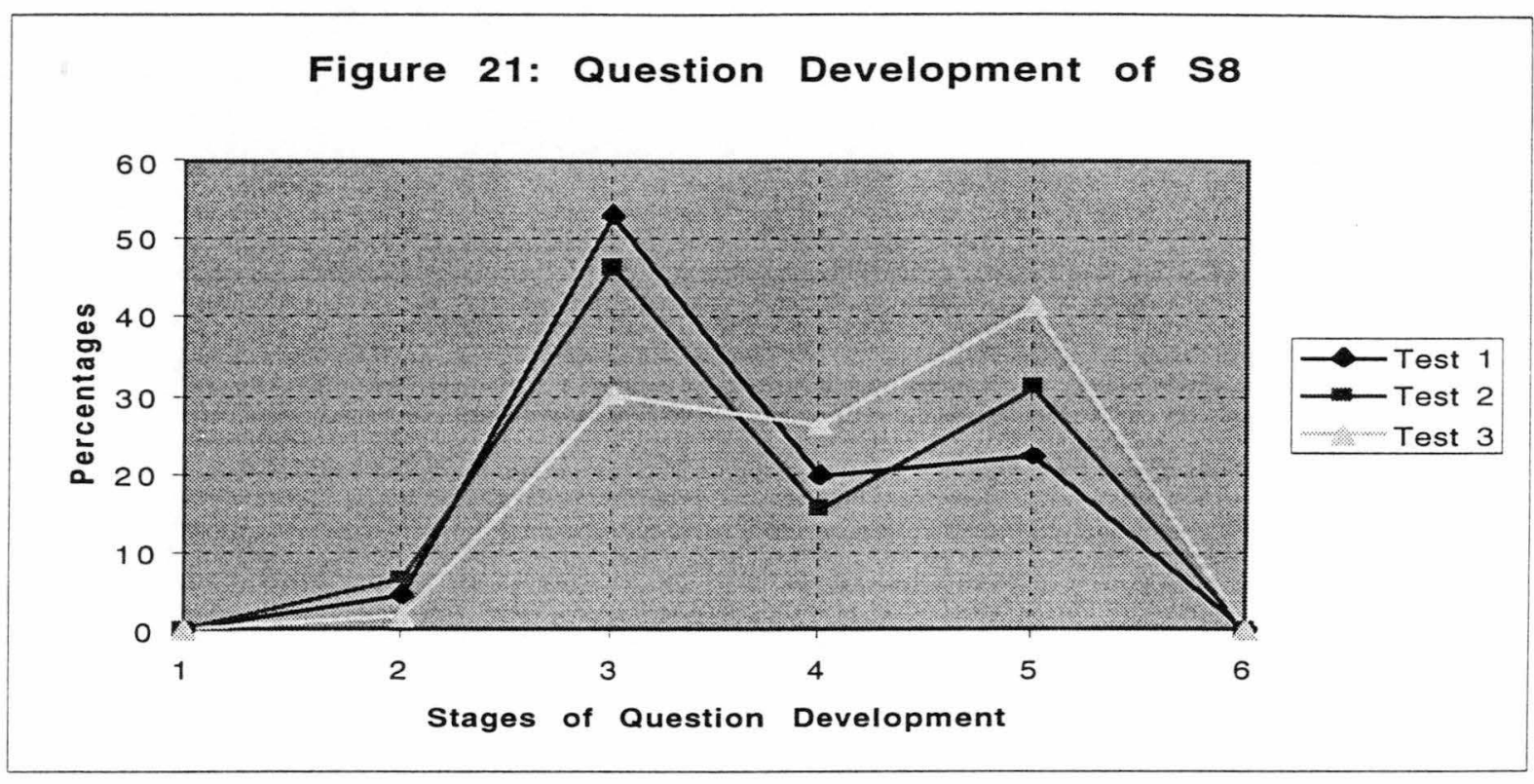

Test 1 indicated that $58 \%$ questions she produced were incorrect, and only $42 \%$ were correct. The main problems she faced were in wh-fronting, 'do fronting', is-fronting, and wh + aux fronting. Some questions also appeared in 'declarative word order' forms. Errors in 'wh-frontings' were in the use of a question word with a declarative sentence such as 'Where they watch TV?, 'Why they wearing hat?', a question word with a non-verb sentence such as 'Where Aminullah hungry?', a question word with words or phrase such as 'How many colours in your picture?'. Errors in 'do fronting' were in verb-tense agreement, such as 'Does Paul arrive last week?', 'Does she wearing white shoes?'. Errors in is-fronting occured in the use of 'be' instead of another auxiliary such as 'Is the woman wear new dress?', 'Are the students understand mean word?. Errors in wh + aux fronting were the 
same type as errors in is-fronting such as 'Where are the children play?', or' overuse of 'be' such as 'Who is sit beside a man wearing blue dress?. These types of errors still occured in test 2 , and test 3 , but the number decreased.

The question development of $S 8$ is apparent in the decrease in incorrect questions of 'declarative word order' (2), and 'fronting' (3), and the increase in yes-no questions (4), and wh-questions (5).

\subsubsection{The interpretation of the results in relation to a universal pattern of development of question forms}

The development of question forms considered here is the advancement of question forms toward grammatical and acceptable questions. It was found that the sixteen learners observed had progressed regarding the development of question forms. By comparing the result of tests given at the beginning, the middle, and the end of their study, it is apparent that the number of incorrect questions declined, while the number of correct questions increased. If at the beginning of the course, one word questions and declarative questions frequently appeared, by the end of the course, the number of these types of questions had decreased, and for some learners, were not used.

The universal pattern of question development begins with single word with rising intonation, then develops to declarative word order questions. Later, question words are used and are followed by the ability to make inversion in yes-no questions and wh-questions. Finally, complex questions such as question tags, negative questions, and embedded questions are applied (Littlewood, 1984; Ellis, 1985, Pienemann, Johnston, and Brindley, 1988; Lightbown \& Spada, 1993). The results in tables 12 and 13 (see pp. 133 and 134) above indicated that fronting (3), is the most frequently occuring question type but produces non-grammatical questions, and decreased in percentage of occurences in test 2 and test 3 . The decrease in frontings was followed an increase in the percentage of inversion in yes-no 
questions (4) and wh-questions (5), which are the correct forms of English questions. Stage 6 of question development (complex questions) had not been achieved by the learners yet, although two learners ( $L 4$ and S2) used a limited number of complex questions.

In conclusion, the data suggest that sequential stages of question development of Indonesian adult learners follow a universal pattern of development of question forms. More discussion about this will be presented in the next chapter.

\subsection{Summary}

The results in this chapter show that various types of questions were produced by Indonesian adult learners learning EFL in the classroom interaction. However, the analyses revealed that compared to the questions occurred in classroom interactions, a greater variation in types of questions occured in assessments, both written and oral assessments. The most frequently appearing form of questions in classroom interaction was yes-no questions with wh-questions the second most frequent. In terms of the hierarchical order of thinking, knowledge questions most frequently occurred, followed by comprehension questions. In other words, lower order questions dominated classroom interaction. In terms of the function of questions, more than $50 \%$ of questions were referential questions. The comparison of the two groups observed indicated that the more mature adult learners, group one, generated more questions in classroom interaction than the younger adult learners in group two.

The errors in forming questions were dominated by errors in frontings such as wh-fronting, do-fronting, is-fronting and $w h+$ aux fronting. This implies that most of the learners were in stage three of the six stages of question development. However, at the end of the study, their proficiency in forming questions had progressed to stages 4 and 5 , and learners were able to make inversion in yes-no questions and wh questions. 


\section{CHAPTER 6}

\section{DISCUSSION}

\subsection{Overview}

This chapter primarily examines the results described in Chapter 5 . The results are examined with respect to the literature review.and the research questions. The primary objective of this study was to investigate linguistic problems faced by Indonesian adult learners, and to analyse the relationship between these problems and the teaching strategies used by teachers in classroom interaction. Two main topics are discussed in the present chapter: the acquisition of -question forms in classroom interaction, including the conditions that enabled learners to acquire questions, and the actual questions which occurred in classroom interactions; and the question development of the 16 Indonesian adult learners.

\subsection{The acquisition of question forms in classroom interactions}

\subsubsection{The conditions that enable learners to acquire questions}

The acquisition of question forms in classroom interaction was examined to identify the conditions that might enable learners to acquire questions in classroom interaction, focusing particularly on the strategies used by the teachers in managing classroom interaction. In addition, the frequency of question occurrences was examined to determine which strategy was best suited to encouraging learners to ask and answer questions. Classroom conditions were examined to gain an understanding of the acquisition of question forms in classroom interactions. The classroom conditions, teaching strategies, frequency of questions from learners in the classroom, types of question forms produced in classroom interaction, types of errors made by 
learners, and types of teacher responses to the questions made by learners were studied. This examination was designed to enabled the identification of successful strategies which ensure effective question development of Indonesian adult learners of EFL.

Adults are considered to be learners who have the ability to process abstract concepts at the level which Piaget termed formal operational. They have the ability to set up and test hypotheses and to abstract common principles from concrete data or experiences (Collis \& Biggs, 1978). This is very important in language learning, since this ability enables adults to understand that words in one language may not have exact equivalence in another language. They will use sentences as a necessary element to test each hypothesis they construct, allowing them to consider all possibilities carefully. This ability is different from children who have to follow their stage of cognitive development to be able to think abstractly. That is why the development of language can be observed easily in children learning their first language. However, it does not mean that it is impossible to observe language development of adult learners learning a second or foreign language. Many studies have found that there are some similarities between first and second language development (Meisel, Clahsen \& Pienemann, 1981; Littlewood, 1984; Ellis, 1985; Pienemann \& Johnston, 1987; Lightbown \& Spada, 1990).

Whereas children acquire language, adult learners, in addition to acquiring the language, must utilise a second process to develop competencies in a second or foreign language; they must also learn the language. Acquisition is considered the subconscious process of gaining a language, while learning is a conscious process of acquiring language through a process of formal learning (Krashen, 1981; Gass \& Selinker, 1994; Zoble, 1995). Moreover, Krashen (1981) argues that the language teaching process must have these two components if it can create materials and context that provide meaningful communicative activities (intake). The use of the communicative approach in 
the teaching/learning process will enable adult learners to acquire and learn a second or foreign language.

Both English classes observed in this study used the communicative approach in managing classroom interaction as indicated by teachers in both classes observed. However, did they really conduct meaningful communicative activities in classroom so that the learners could acquire language while learning formal language? Observation of the classroom interaction revealed that the degree of meaningful communicative activities differed between the speaking class and the structure class. Task-oriented activities as the basis of teaching strategies in the speaking class created more meaningful communicative activities compared to the structure class which used practice based activities. In other words, in the structure class, practice-based activities created communicative activities based on the forms of language taught. This can be considered form-based communication because the communication activity is created around a language structure. In contrast, the speaking class used meaning based communication. However, in some activities observed, the structure class teachers also encouraged meaningful communication in small group work and pair work activities in addition to the practice based activities in classroom activities.

The distinction between practice-based communication and meaning-based communication is directly related to the roles of form and meaning in language. Form and meaning are two components of a language. Form here means linguistic forms such as sounds and words, while meaning is the intention brought by the sounds or words themselves. Pragmatically, one form can express a number of meanings, and one meaning can be expressed by a number of forms (Littlewood, 1981). To bridge these two differences, learners must be given opportunities to develop strategies for producing and interpreting language in actual use by applying meaningful communicative activities (Gass \& Madden, 1985; Nunan, 1989a; Scarcella, Anderson \& 
Krashen, 1990; Lynch, 1996). In these activities, learners are able to express an idea in the various forms of language they know. The use of this strategy will also encourage learners to interact with each other.

This investigation into classroom interaction found that differences in the strategies used seemed to affect directly the frequency of question occurrences. It found that learners became more involved in classroom interaction when meaningful communicative activities were employed rather than form based activities. Strategies used by teachers had more impact on the number of questions asked than the subject of study. More questions occurred in the structure class of Group 1 than the speaking class of Group 1 (mean scores 35 and 17 respectively). In contrast, more questions occurred in the speaking class of group two than the structure class of group two (mean scores 27 and 11 respectively). The class where more questions occurred was the class that employed various communicative activities such as small group work and pair work. This is consistent with studies by Long (1990b) and Lynch (1996) which found that learners interact more in small group activities than in class activities.

The reasons why small group activities had more impact on the numbers of questions asked by learners than class activity/formal lecture was also examined. It seems that in formal lectures, where teachers explained a lesson to a whole class, the learners tended to keep quiet although the teacher asked them questions, and also gave them time to ask questions themselves. This study found that there was a pressure on many learners to ask questions. Only a few students actively asked questions in classroom activities. Some learners in the interview said that:

"I am afraid to make mistake. I have something to ask but sometimes I feel shy because some of my friend are very good in English." (L7) 
"I rarely ask question. I am afraid that I make mistake because my vocabulary is very limited." (L3)

"The teachers have explained the lesson clearly, so I don't have any questions to ask anymore." (L5)

It is also possible that learners became satiated by the formal lecture and were not motivated to know more as indicated by L5 above. Therefore, communicative activities particularly those involving group work and pair work, are important teaching strategies. In these activities learners feel free to speak without anxiety, and they enable students to ask questions in class (Gass \& Madden, 1985; Nunan, 1989b; Long, 1990a).

The investigation into classroom interaction in this study indicated that creating activities that enabled students to interact with each other, especially in group work and pair work, increased the learners' self esteem in using English. It was the-interaction in group work and pair work that encouraged learners to ask and answer questions spontaneously using their own words. In small groups, learners had more opportunities to express their ideas in the language being learned, without feeling afraid of making mistakes (Long, 1990a).

The findings from the observation of group work and pair work were in line with the findings on quantitative and qualitative analysis of classroom conditions. The quantitative data from questionnaires indicated that in Group 1 learners were treated as adults and more activities were created to encourage students to speak English in class. Group 2 on the other hand encountered more opportunities that enhanced communicative ability. The qualitative data from interviews and observation showed that Group 1 was more active in clāssroom interaction than Group 2. Quantification of the frequency of questions of learners in both groups revealed that Group 1 produced more questions in classroom interaction (mean score 26) than Group 2 (mean score 
19). Therefore, it can be concluded, as Burns (1995) also found, that treating learners as adults for adult learners and creating activities that enable learners to speak English freely in class will ensure that more questions are produced by learners in classroom interaction.

\subsubsection{Questions in classroom interactions}

As indicated in Chapter 1 , the purpose of this study was to investigate questions produced by learners in classroom interaction. The previous section discussed classroom conditions that enabled learners to ask questions and the following section will examine questions produced by learners in classroom interactions. The examination will focus on the reasons for the learners asking questions in class, the types of questions produced by learners and the form of questions produced by learners in relation to question development.

The learners' reasons for asking questions in class varied. Some questions were about problems in grammar, pronunciation and vocabulary. This is similar to research by Abraham and Vann (1988) which indicated that learners in language classes tended to ask about the language problems they faced. Therefore, this investigation in the classroom interaction indicated that there is a group of learners' questions that can be categorised as questions concerning grammatical problems, pronunciation problems and vocabulary problems. Questions in grammar arose because the learners were unsure of using certain sentence patterns, eg. 'Can we use to be in that sentence?, 'We must change to be after subject?', 'Conjunction because is used to combine?, or the learners needed more explanation about grammatical usage, eg. 'What is the different between some and many?. Some questions by learners only practised the grammatical forms just learned, eg. 'What were you doing last night when the light went out?, or 'How much does that marker cost?'. These appeared in accordance with the context given by teachers, and these kinds 
of questions appeared frequently in class, especially in structure class which used form based communication.

Questions about pronunciation occurred since most learners had problems in pronouncing English words. Correct pronunciation is important for learners, because if a learner does not pronounce a word correctly, meaning can be misinterpreted. Questions in pronunciation frequently appeared in small group discussion and pair work, eg. 'How to pronounce orphan?', or 'How to pronounce great?'.

Questions about vocabulary mostly asked the equivalent of Indonesian words in English, eg. 'How do we say mengerikan in English?', 'Pusing in English, what is it?'. These appeared when learners were asked to form their own sentences or conversation. Sometimes, spontaneous questions in vocabulary also occurred to ask for an English word that the learners did not understand - in textbooks or an expression made by the teachers, eg. 'What does involve mean?', 'What is the meaning shake?", 'Look upset the same meaning worried?, no?', 'what do you mean by belittling?'

In addition, to questions about grammar, pronunciation and vocabulary, questions produced by learners practised grammatical forms just taught in conversation. These questions were also analysed because they were produced by learners in their own words, not just by reading from the text book.

In addition to the purpose of asking questions, the questions produced by learners were analysed in terms of types of questions. Types of questions were investigated in three ways: form of questions (Quirk, 1985), content of questions or hierarchical structure of thinking (Bloom, 1956), and function of questions (Long \& Sato, 1983). The forms of questions most frequently used in classroom interaction were yes-no questions (55\%), and wh-questions 
(43\%). Yes-no questions were used by learners to confirm what the teacher meant, eg. 'Can we use I am not sure?', 'We can use on the bank?'. Some questions occurred just to practise grammatical patterns in the topics given, eg. 'Did George eat in the restaurant?, and 'Did you enjoy your travel yesterday?. Wh-questions were used by learners to ask for information and clarification, eg. 'What is the different between we must pay at the bank, to the bank, and through the bank?', 'What different when and while?', 'Why did my answer reading is false?. This finding also reveals that the learners produced more closed questions than open questions (Huddleston, 1988). In addition, this finding reflects the stages of question development of learners where most learners were in a lower stage of question development.

From the content of questions or the hierarchical structure of thinking perspective (Bloom, 1956), the types of questions which most frequently occurred were knowledge (63\%) and comprehension (21\%). They requested a fact or explanation about a fact. The investigation of lower order and higher order questions of the hierarchical structure of thinking discovered that $88 \%$ of questions of learners were lower order questions, and only $12 \%$ were higher order questions.

In terms of the function of questions (Long \& Sato, 1983), the questions which most frequently occurred were referential (61\%), display (19\%), comprehension check (12\%), and clarification request (4\%). These findings reveal that meaningful communication occurred in the classroom interaction of both classes because not only epistemic questions (referential and display) but also echoic questions (confirmation checks and clarification requests) occurred. Echoic questions usually occur in natural communication. It was also found that more echoic questions occurred in the speaking class of both groups than the structure class (28\% in speaking Group 1, $16 \%$ in structure Group 1, 12\% in speaking Group 2 and $8 \%$ in structure Group 2), and more echoic questions occurred in Group 1 than Group 2. 
This study only focused on the acquisition of question forms of Indonesian adult EFL learners. In the following section therefore the forms of questions will be investigated in more detail. This investigation examined the stages of question development of learners in general. The examination of forms of questions produced by learners in classroom interaction will also discuss when these types of questions were used in classroom interaction.

The forms of questions which were used by learners in classroom interaction varied from (1) single word questions, (2) declarative word order questions, (3) fronting, (4) inversion in yes-no questions, (5) inversion in wh-questions to (6) complex questions. This reveals that the learners had various communicative competencies, ranging from producing mostly nongrammatical sentences to producing mostly grammatical sentences. It was found that only two types of questions were frequently used by learners in classroom interaction; wh-questions and yes-no questions. Within these types appeared various constructions ranging from non-grammatical sentences, which were usually fronting types, to the grammatically acceptable, particularly wh-questions and yes-no questions.

'Single word questions' or 'single phrase questions' were usually used by learners to ask for repetition of the utterances heard, eg. 'available?' or to confirm the information they heard before, eg. 'not all of the two syllable?', or 'six questions?'. The hearer recognised these expressions as questions from the rising intonation used by the speakers in uttering these words/phrases given. These expressions were recognised as yes-no questions. Single word questions were sometimes used to ask alternative questions by adding 'or' and another word/phrase as an alternative word/phrase, eg. 'get or getting?', 'handsomer or more handsome?, or 'Three o'clock in the morning or in the afternoon?'. These expressions were also used as a confirmation check of what they understood of the classroom interaction. 
'Declarative word order questions' were intended by the speaker to confirm information. The speakers needed a 'yes' or 'no' response from the hearer to questions eg. 'You don't understand that?', 'We write here?', or 'Many and much become more?'. The hearer recognised these utterances as questions because the speaker used a rising intonation at the end of the sentence. These questions are considered to be stage 2 of question development according to Pienemann, Johnston and Brindley (1988).

'Fronting' was considered a form of ungrammatical question used by learners because the learners did not apply the question formation rules appropriately. The learners used only one or two of the rules, such as the use of the question word only (wh-fronting) or the use of the auxiliary 'do' without considering the form of sentences (do fronting), and the use of 'is' for all types of sentences to make yes-no questions (is fronting). Wh-fronting was used by learners to ask for information, eg. 'Why we choose C?', 'Why the light making 's' here?', or 'Which one we want to give to her?'. 'Do fronting' and 'is fronting' were found in questions eg. 'Do you can describe about your father, your mother, and others?, and 's we answer in exercise book?' and used to provide confirmation to the listener. A more complex form of 'fronting' can be found in the form of 'wh + aux fronting' eg. 'Why did my answer is false?', 'What is shake means?', which were actually a combination of problems in wh-fronting and 'do fronting' or 'is fronting'. Question words were sometimes put at the end of sentences, eg. 'Was 'past tense', injures 'past tense', why?', or 'Two number after that, what about?'. Thus, fronting is an indication of learners' inability to appropriately apply the English question formation rules. These questions are considered to be stage 3 of question development.

In the next stage, the learners were able to invert the subject and auxiliary to form yes-no questions. They were able to use the auxiliary appropriately, eg. 'Can we use follow to learn?', 'Are you feeling hot?', 'Can you give example when to use rapidly?', or '/s it right?. In this way, yes-no questions were used 
by learners to ask for information, to ask for examples, and to confirm certain things. These types of questions are considered to be stage 4 of question development.

At stage 5, learners are able to form questions correctly, wh-questions used in classroom interaction mostly used the question words 'what', 'why', and 'how', eg. 'What is the meaning 'went out'?', 'What do you mean by belittling?', 'What is the different between lecture and lecturer?', 'Why do you use were?', How to pronoun great?, and 'How do we say 'mengerikan' in English?'. These questions asked about the meaning of words, the use of words in sentence and correct pronunciation. Most questions were about language use.

The highest stage of question development (stage 6) is complex questions. A limited number of complex questions was produced by the learners, and usually they were used to confirm information, eg. 'Why don't we choose reading?', 'Why don't the answer boring?', or 'Do you know what happened?'. Among the three possible complex questions in English in classroom interaction, only two forms occurred, negative questions, and embedded questions. Question tags did not appear in the learners' questions in classroom interaction.

The examination above showed that errors or non-grammatical questions were asked by students. However, these did not disturb classroom interaction, since the teachers could understand the intention of the learners. Therefore, if meaning is the main concern, the error in grammar was not noticed and communication continued unimpeded. Since most responses to the errors made by learners were given indirectly or by the way of expansion, they learnt indirectly that they had made an error, to try to correct it later on. This is consistent with what was suggested by Dulay, Burt and Krashen (1982) and Brown (1994) who claimed that expansion is more effective than correction 
since it permits the students to have uninterrupted time to rephrase their responses which results in improved performance.

Some errors found in questions made by learners indicate that some learners were eager to take risks and ask ungrammatical questions. It is the desire to take a risk that makes learners ask questions in class (Pica \& Doughty, 1985). Learners who avoid risks (risk avoiding) tend to be quiet in class. They do not ask questions even when the classroom environment encourages classroom interaction. One of the reasons learners did not ask questions was because of their difficulties in forming questions to coincide with English question formation rules. These rules are different from their own language question formation rules. The rules of agreement, tense, gender, and the use of auxiliary need to be considered in forming English questions. These rules are not found in forming questions in the learners' mother tongue, Indonesian. That is why errors in these rules occurred not only for beginners but also for advanced learners. This finding is consistent with Larsen-Freemen \& Long (1991) who claim that split and new language items in L2 are the two most difficult problems faced by second/foreign language learners producing utterances in their L2.

The investigation of the errors made by learners indicated that developmental errors dominated the types of errors made by learners $(86 \%)$. Interlingual errors accounted for only $9 \%$, and 'others' for $5 \%$. This finding is supported Dulay, Burt, and Krashen (1982) who argued that most errors made by second language learners were developmental errors. The present study also found that more types of errors were discovered in the assessment of the learners rather than questions in classroom interaction, and a greater variety of questions occurred in the assessment. This finding supports Larsen-Freemen and Long (1991) who claim that tests measure what the learner knows and does not know of the target language, while tasks only reveal what a learner knows. 
The type of error which most frequently occurred in learners' questions was fronting. Fronting comprised $68 \%$ of the errors made by the Indonesian adult learners. The investigation indicated that wh-fronting and 'wh + aux fronting' were the main fronting errors. It was found that $41 \%$ of errors were errors in wh-fronting, $18 \%$ were errors in 'wh + aux fronting', $67 \%$ were errors in 'is fronting', and $3 \%$ were errors in 'do fronting'. In interlingual errors, most errors were found in question word problems (4\%), and non-verb sentences $(2 \%)$, which were considered as interference of the learners' mother tongue. Yes-no questions in wh-question forms and word order problems were found to be $1 \%$ and $1 \%$ of errors respectively.

In terms of teacher responses to the questions made by learners, it was found that questions made by learners were responded to in different ways. Responses given by teachers not only answered questions from learners (cognitive feedback), but also directly or indirectly corrected the errors made by the learners (affective feedback). However, if correction is not carefully given, it may impose a pressure on the learners (Lynch, 1996). Speaking class teachers did not pay much attention to the errors made by the learners, while structure class teachers had a tendency to correct errors in grammar, but only the major errors made by learners. As discussed above, teachers in both classes also used expansion to respond to errors made by learners in forming questions.

Finally we can conclude that to encourage learners to feel free to ask questions in class, teachers should apply teaching strategies that enable learners to ask questions without imposing anxiety. Small group work was one strategy which was used by the teachers in this study to solve this problem. Responses from learners also indicated that they prefer working in pairs and small groups in which they can practise language freely without fear of making mistakes. 
The classroom conditions investigated above revealed that in addition to learning formal language, the learners were able to acquire question forms in classroom interaction. Both meaningful communicative activities and practice based communicative activities were employed for classroom interaction. More questions occurred in meaningful communicative activities than in practice-based communicative activities. Therefore, a communicative environment enables learners to develop their language in the classroom.

\subsection{The Development of Question forms of Indonesian Adult Learners}

This part of the study was based on the question development theory of Pienemann, Johnston, and Brindley (1988) who indicated that there are six stages of question development; single word, declarative word order, fronting, inversion in yes-no question, inversion in wh-questions, and complex questions.

The results of the written and oral assessments given to the 16 Indonesian adult learners, as explained in chapter 5 (section 5.5), revealed that the question development of learners observed was indicated by a decrease in producing stages 1,2 , and 3 of questions (single word questions, declarative word order questions, and fronting), and an increase in producing stages 4,5 , and 6 of questions (inversion in yes-no questions, inversion in wh-questions, and complex questions). Most of the learners observed followed this type of question development, but some learners did not. For those who did not follow the pattern, the use of question types fluctuated between the different stages. L3, L4, L5, L6, L7, and S8 were in this group. The other ten learners followed the pattern outlined above.

Most learners observed were in stage 3 of question development when they first entered English class. This is indicated by the highest percentage of 
questions in stage 3 of question development of test 1 . There were only two learners, L5 and S5, whose highest percentage in test 1 was not in stage 3 of question development, but stage 5 for L5, and stage 4 for S5. Some learners moved from stage 3 to stage 4 ( $L 4, L 8, S 6, S 7$ ) and others moved to stage 5 , $(\mathrm{L} 3, \mathrm{~L} 7, \mathrm{~S} 1, \mathrm{~S} 2, \mathrm{~S} 3, \mathrm{~S} 4, \mathrm{~S} 8$ ). Some learners remained in stage $3(\mathrm{~L} 1, \mathrm{~L} 2, \mathrm{~L} 6)$. One learner remained in stage 4 (S5), and one learner remained in stage 5 (L5).

Two of the learners who moved from stage 3 to stage 4 were active learners (L4 and S6). The other two learners were not active however they participate in group work activities. The learners who moved from stage 3 to stage 5 were mostly active learners $(L 3, S 1, S 3, S 8)$ while the other three learners $(L 7, S 2$, S4) were not active in class work but they participated actively in group work activities. Three learners (L1, L2, L6) who remained in stage 3 in test 3 were not active learners and did not participate a great deal in group activities as well. Their ability in forming questions in English did not improve. S5 also was not an active learner and she remained in stage 4 in test 3. Although L5 was an active learner, she still remained in stage 5 in test 3 . It takes a longer time to move from stage 5 to stage 6 of question development. This finding suggests there might be a direct explicit link between participation and stages of question development. It could be stated that those learners who are willing to participate in classroom activities are more likely to develop at a faster pace than those who do not.

The analysis of the errors made by the learners revealed that fronting was the most complicated stage of the six stages of question development. It can be argued that the occurrences of certain fronting in yes-no questions reflected certain types of fronting in wh + aux fronting. In other words, if a learner made an error in 'is fronting', he/she would also make an error in the form of wh + aux (be) fronting. Likewise, if a learner made an error in 'do fronting', he/she would also make an error in the form of wh + aux (do) fronting. Thus, if 
someone formed the sentence 's she study English every Tuesday?', he/she would also make the error 'What is she study? before he/she was able to form correct question forms. Likewise, if someone made the sentence 'Do you have told him several times?, he/she would also make errors like 'What do you have told him several times?'.

The question development of the study's Indonesian adult learners of EFL, then, is summarised in the following diagram.

The question development of Indonesian adult learners

1. single word questions

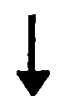

2. declarative word order questions

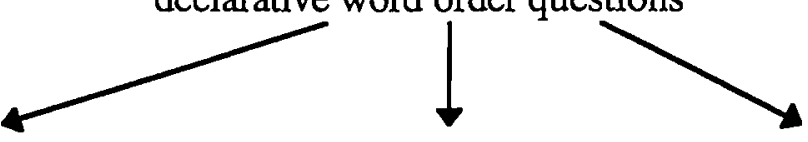

3.

4.

5.

6. is fronting wh-fronting
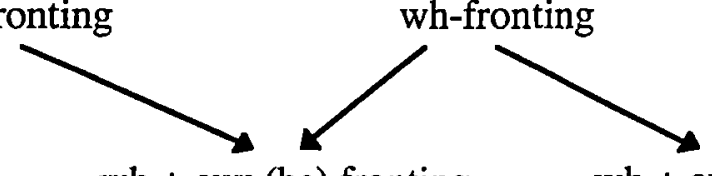

do fronting

wh + aux (be) fronting

wh + aux (do) fronting
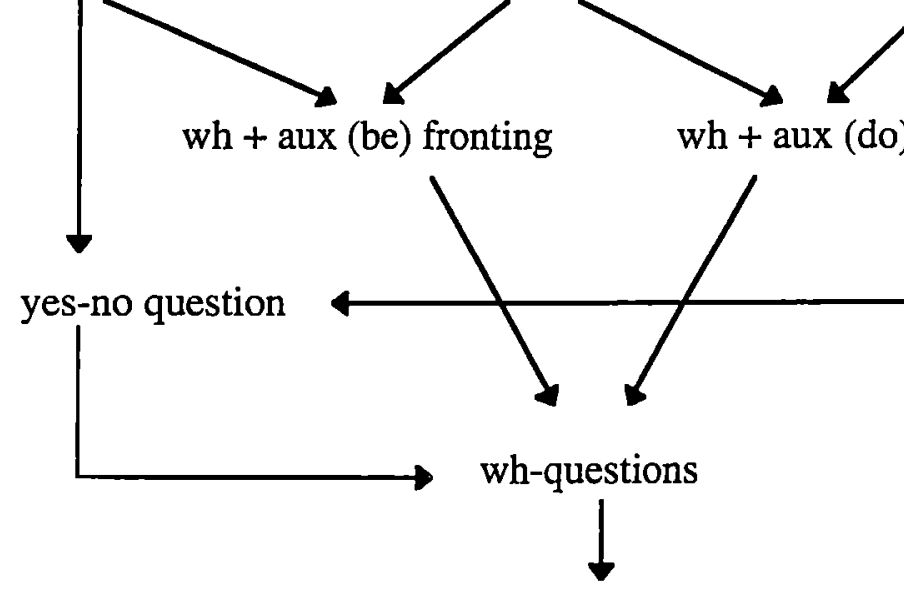

(

7.

complex questions

The diagram above shows that stages $3-6$ are considered to be the most complicated stages in the process of question development. Stages 5, 6 and 7 are the stages where the learners are considered to be able to form questions 
correctly, while stages 1 and 2 are the early stages of question development, and these stages are found in the language produced by beginners. But, in spoken language, these forms of questions are also frequently used by those who speak English fluently. Stage 3 and 4 are the forms of questions which are considered to be interlanguage in the proficiency to form English questions. These are the question forms which frequently occurred in the learners' utterances in this study.

To examine these question forms, it is necessary to examine the English question formation rules. There are three main characteristics of English question formation for differentiating questions from other forms of sentences; (1) intonation, (2) the use of question words, and (3) inversion of the auxiliary. To form a question in English, at least one of the characteristics above must be present.

At the earliest stage of question development, we know when someone is asking a question by the 'intonation' he uses, even if he uses a 'single word question' eg. 'Drink?' or a 'declarative word order question' eg. 'You drink?' . Hence, it is only intonation that differentiates whether a word or a declarative word order is a statement, a command, or a question.

At stage 3, learners try to apply another rule of English question formation; the use of question words such as what, where, when, etc. or the use of auxiliary verbs such as do, does, did, is, are, etc. At this stage, the speaker does not care about the form and the tense of the sentence he uses. The following examples are questions which were formed by the Indonesian adult learners in this stage.

\section{A. Wh-fronting -}

1. How many birds?

2. How many persons the old man in your picture?

3. What time you meet Mr. David in the restaurant?

4. Where he face? 
5. When they watch TV?

6. Why the man close the window?

B. Do-fronting

1. Do teacher show a picture of hand to her students?

2. Did Paul arrive next week?

3. Does Paul arrive last week?

4. Does she wearing white shoes?

5. Do you have told him several times?

6. Do she studies every Tuesday?

7. Do he is doing?

8. Do they are going to Medan?

9. Did he going to Jakarta?

10. Did they are married?

11. Do all of the books are here?

C. Is-fronting

1. Is it two person wearing a hat?

2. Are they lunch?

3. Are they have a lot of books here?

4. Is she studies here every Tuesday?

5. Is he open the door?

6. Are they robbed the bank?

7. Is the dog in your picture has many colour?

8. Was the woman and the boy surprise?

9. Are a lot of here?

10. Was the children said goodbye to her mother?

11 . was you in the city yesterday?

The attempts of learners to use wh-questions and the modal auxiliary to make yes-no questions above indicate that they are not sure what types of sentences followed question words, and what kinds of sentences can be used with auxiliary do, does, did, is, was, are, etc. The learners knew the rules when they learned English grammar in structure class, but they still made these errors. It is apparent that the learners of this stage still have problems with tenses and agreement in English.

At stage 4, the learners try to apply two question formation- rules simultaneously. In addition to intonation, they used question words and the modal auxiliary, but in an inappropriate manner. Since they still had problems 
with tense and agreement, the sentences they produced can be categorised as $w h+$ aux (be) fronting and $w h+$ aux (do) fronting.

A. Wh + aux (be) fronting

1. What is you like?

2. Who is Mary visited?

3. Where is John studies?

4. Who is has a large number of books?

5. Where was he waited you?

6. Who was Mary invited?

7. What was they study at nine o'clock?

8. What were two mans bring on their car?

9. What are they have a lot of friends? -

10 . What is they one family?

11. Who are stand beside the door?

12. Who are stand behind the tree?

B. Wh + aux (do) fronting

1. When did you left your house?

2. Where did he waited?

3. Who did visited her father?

4. How many times do you have told him?

5. Who does study in the library?

6. What does she doing?

7. Who does she visited father?

8. When does he hungry?

9. When did they are watching TV?

10. How many times did you have told him?

11 . Who do work in the library?

The learners here used wh + aux (do) and wh + aux (be) without considering the form of sentence they used. Therefore, problems in tense and agreement were still the main problems faced by the learners.

These findings reveal that learners who formed wh + aux (be) fronting were the ones who formed yes-no questions with is fronting, and learners who formed wh + aux (do) fronting were ones who formed yes-no questions with do fronting. The learners who formed both is fronting and do fronting produced both wh + aux (do) fronting and wh + do (be) fronting until they were able to recognise subject verb agreement and tense. 
At stage 5, the learners were able to differentiate when to be 'is, are, were, was, etc.' were to be used, and when auxiliary 'do, does, and did' were to be used as a result of the ability to recognise tense and agreement in English. The following sentences were produced by the learners who were at stage 5 of question development.

1 . Is she a nurse?

2. Is he going to Jakarta?

3. Are they holding the birds?

4. Are they on the street?

5. Can you describe that?

6 . Were you in the city yesterday?

7. Do you have a bottle on the table?

8. Does John study in the library?

9. Did the man open the door for woman?

10. Was she her mother?

At this stage learners were able to use 'be' and other auxiliaries appropriately.

At stage 6 , the learners were not only able to invert auxiliaries in an appropriate manner, but they were also able to use question words correctly. Some of the sentences produced by the learners who were at stage 6 of their question development are listed below.

1. Who is the woman holding glass?

2. Where did Ali wait you?

3. When did they watch TV?

4. Where is the flower?

5. How many persons sit down on the chair?

6. What are Jimmy and Mary doing?

7. Who are on the white car?

8. What about the trees, how many trees do you have?

9. What do they do on the carpet?

10. How about the other children, what are the parents of the children doing?

11. What does she do?

12. Where does John study every Tuesday? 
The sentences above show that the learners were able to form wh-questions correctly according to tense and agreement in English.

Finally, the learners were able to construct complex questions such as negative questions, question tags, and embedded questions. The following questions were produced by the Indonesian adult learners observed.

A. Negative Questions

1 . Weren't you in the city yesterday?

2. Weren't you together last night?

3. Don't you have a-more comfortable chair?

4. Why don't the answer 'boring'?

5. Why don't we choose 'reading'?

B. Question Tag

1. I am here, okay?

2. The people are cuddling, that's right?

C. Embedded Questions

1. Do you know what they are doing beside the table?

2. Do you understand what happened?

The sentences above showed that the learners tried to use complex questions although they were very rarely found in classroom communication. Question tags seemed to be difficult for learners to form correctly, since they only used the expressions 'okay' and 'that's right' to indicate 'tag questions' instead of 'aren't you' or 'aren't they'.

Among the seven stages of question development proposed above, all learners observed still had problems in fronting, even when they were able to produce stage 5,6 , and 7 of questions. It takes time to learn how to form questions correctly and appropriately for communication. The more the learners use the questions in communication, the more correct the question forms will be. 


\subsection{Summary}

By using meaningful communicative teaching strategies, teachers engaged both the acquisition and learning processes the adult learners of English as a foreign language. With the meaning based orientation in speaking class, and practice based orientation in structure class, both classes seemed to complement each other, ensuring the development of communicative competence and performance. The errors made by learners revealed that the question development of learners was good because the number of errors decreased, whereas the number of correct questions increased. This analysis also found that errors in certain types of questions in an earlier stage of question development will reflect the types of errors made in a later stage. 


\section{CHAPTER 7 \\ CONCLUSION}

Questions are a significant key to eliciting information. Questioning occurs in business, politics and education indicating that interaction is taking place between the addressor and addressee. The role English plays as an international language means that the skill of forming questions in English is necessary for people working in these fields. Moreover, rapid changes in technology and communications have meant that many people are communicating not only with people in their own country but also with foreigners. To fulfil this need, adult learners in non-English speaking countries are returning to study to enable them communicate in English.

The primary emphasis of this research was directed toward an investigation of Indonesian adult learners' acquisition of questions in English. The classroom environment was considered to be the place where skills in forming and asking questions were developed because questioning is an integral part of the culture of classroom interaction. In classroom interaction, questioning can be a teaching strategy, a learning strategy, a form of communication and a language skill. By focusing on questioning as a language skill, this study investigated the linguistic problems faced by Indonesian adult learners in forming English questions and identified their question development.

\subsection{The Research Study and Results}

This study was a process-product research which was directed toward the acquisition of questions by Indonesian adult learners of English as a foreign language. By using triangulation in data gathering, the researcher gained 
information of the process of classroom interaction in adult learner classes by a multi-person multi-method strategy. Cross-sectional and longitudinal studies were also undertaken by observing the learners for one semester, and assessing them to find the question forms produced by the learners and to identify the development of questions of the learners. Two groups of learners were observed. In each group, eight learners were chosen randomly. These 16 learners were observed and their question development recorded and analysed.

Analysis of the data from the questionnaires indicates that learners in Group 1 were treated more as adults and were given activities that enabled them to speak freely in class. As a result, more questions occurred in Group 1 than Group 2. It was also found that meaningful communicative activities encouraged learners to ask and answer questions in their own words. Although practice based communicative activities could elicit questions from learners, the number of questions produced were greater in meaningful communicative activities than practice based communicative activities.

In relation to meaningful and practice communicative based activities, the results indicated that learning in small groups and pair work was preferred by learners. In this learning type, learners had more opportunities to ask and answer questions, to practise the language being learned without a psychological burden. This finding strongly supports other recent studies that group work and pair work are important for creating authentic communication in the classroom. This finding challenges English teachers to create classroom activities that require learners to work in groups and pairs, not only in speaking lessons but also structure lessons.

The types of questions produced by learners in classroom interaction were mostly about linguistic problems faced by the learners, such as grammar, pronunciation and vocabulary. Questions were asked mostly in the forms of 
yes-no questions (55\%), and wh-questions (43\%). According to the hierarchical structure of thinking, the content of questions from learners most frequently were 'knowledge' (63\%) and 'comprehension' (21\%) requests. This indicated that most of the questions were lower order questions. In terms of the function of questions, it can be concluded that the learners mostly asked referential questions, that is requesting contextual information (61\%), while display questions occurred less frequently (19\%). These questions were considered to be epistemic questions. The occurrence of echoic questions (confirmation check and clarification request) in classroom interaction (17\%) revealed that meaningful communication occurred in classroom interaction, because these types of question functions usually occur in natural communication.

The investigation of the errors made by learners in forming English questions indicated that errors made by learners were mostly developmental errors, that is $86 \%$ of all the errors made by the learners, while interlingual errors accounted for only $9 \%$, and others for $5 \%$. The types of developmental errors were fronting, which were mostly in wh-fronting (41\%). The second most frequently occurring developmental error was wh + aux fronting (18\%), third was 'is fronting' (7\%), and fourth was 'do fronting' (3\%). Interlingual errors mostly occurred in 'problems in question words' (3\%) and 'non-verb sentences' $(2 \%)$. These were considered as interference of Indonesian language as the mother tongue. 'Yes-no questions in Wh-question form' also occurred as a result of interference of Indonesian language, that is as a result of a split language item in the L2 (Larsen-Freemen \& Long, 1991), when a single form in the $L 1$ becomes two in the $L 2(1 \%)$.

Responses to the questions by learners were not only given as cognitive feedback, that is answering the questions of learners, but also as affective feedback, that is correcting directly or indirectly the errors made by learners in forming questions in English. In addition to correction, the expansion type of 
affective feedback was also frequently given by the teachers. With expansion, teachers give more uninterrupted time for learners to rephrase their ideas. This is considered a valuable strategy for improving language performance.

With meaningful communicative strategies in managing the classroom and giving uninterrupted time for learners to rephrase their ideas, it was found that learners were able to acquire and develop skills in forming questions in classroom interaction. This study found that the question development of learners varied. There was a decrease in the non-grammatical questions of learners and an increase in the grammatical question forms, but the rate of increase and decrease varied for every learner. The comparison between test 1 and test 3 results indicated that four learners move from stage 3 to stage 4 of question development, and seven learners moved from stage 3 to stage 5 . Of the five learners who remained in the stage in which they entered English class, three learners remained in stage 3 , one learner in stage 4 , and one learner in stage 5 , although the number of their non-grammatical questions decreased and the number of their grammatical questions increased.

The triangulation on quantitative data (questionnaires and assessments) and qualitative data (observation and interview) indicates that active learners in classroom and group work activities improved much in their question development, and some learners who were active in group work, but not in classroom activity, also greatly improved in their question formation skills. Learners who were not active in classroom interaction and group work did not greatly improve in their question performance.

The investigation of the errors made by learners in forming questions in English found that the types of errors which occurred in the higher stage (wh + aux fronting) reflected the types of errors in previous stages (is-fronting or do fronting). In other words, learners who made errors in wh + aux (be) fronting were those who made errors in is fronting, and learners who made errors in 
wh + aux (do) fronting were those who made errors in do fronting. These errors were considered to be an overgeneralisation of English question formation rules by the learners.

\subsection{Limitations of the Study}

Some limitations existed within this study. The breadth of the field of questions in communication and the limited time for the longitudinal study were the two main limitations of this investigation.

The first limitation was in terms of the question itself. This study was limited to analysing the interrogative form of sentence which is marked by intonation, question word, and inversion of the subject-operator. However, in communication some of these forms are not questions, but directives or commands, eg. 'Would you like to open the window?', or 'Could you pass the salt?, which ask someone to do something. Some questions are formed as commands, eg. 'Tell me your name!', or 'Your address please!" instead of using the interrogative forms 'What is your name?', and 'What is your address?'. This study was limited to the analysis of only those sentences which were considered as questions with the three characteristics above.

The second limitation was the length of the time for conducting this research. Usually, longitudinal studies are undertaken over a longer period of time, such as one year, two years, or three years. But, this study was undertaken for only one semester, since one group of observed learners only had this period of time to study English in the language training centre. If they continued on to the next course, there would have been a wait of two or three months between courses. Thus, the lack of continuity of the program in this language centre restricted the researcher to a one semester period of study. 


\subsection{Recommendations}

If learners are impeded by problems in forming correct forms of questions in English, many will be reluctant to ask questions in class. Even when they have something to ask the teacher, they have a tendency to keep quiet in class. Meaningful communicative activities in small groups or pairs will help these learners to communicate in the language being learned without the fear of making mistakes. Teachers, not only those teaching speaking skills but also those teaching other language skills, should create classroom activities that require learners to work in groups or pairs. Teachers should give more time to learners to interact in these type of communicative activities, because it is students who must dominate classroom interaction, not teachers.

Although direct correction was needed by learners, as indicated by learners in interviews, indirect correction seems to be more effective for learning. Indirect correction avoids making learners feel uneasy. If corrections are given by teachers every time learners speak, the interruptions will disturb the fluency of the communication process. Expansion is recommended as the most effective strategy for correction.

This study found that most Indonesian adult learners had problems in fronting when forming questions in English. Focusing on this problem in the preparation of lessons could help learners solve this problem. Teachers may provide models of utterances that can make learners aware of fronting problems and then practise these forms in natural communication. This will be invaluable for learners in the process of acquiring English question forms. 'Do fronting' and 'is fronting' which occurred in learners' questions occurred because learners had problems with agreement and tenses. These types of errors reflect the tendency to make the same errors in wh + aux (be) fronting or $w h+$ aux (do) fronting. 
Meaningful communicative activities, the use of appropriate correction strategies and a focus on particular grammatical problems facing learners will lead to more effective classroom teaching and learning. It was also found that learners who participate in classroom interaction have greater improvement in question formation skills. The more the learners have the opportunity to interact, the greater the improvement in their language skills.

\subsection{Avenues for Further Research}

This study has indicated a relationship between the teaching strategies used by teachers and the development of question forms by EFL learners. Further research is needed however to establish the nature of the relationship between these two variables. Correlational and/or experimental studies may provide generalisibility of the results from the current context and may provide stronger evidence that certain teaching strategies are most appropriate for the development of question forms in EFL learners.

This study observed two groups of Indonesian adult learners in different age ranges. A replication of this research using the same range of ages in both groups may provide further support for the relationship between teaching strategies used by teacher and the development of questions by EFL learners. Further research may be needed to determine whether age differences will result in a different frequency of occurrences of questions in classroom interaction.

This study was conducted with intermediate EFL students in the process of acquiring English question forms. A replication of this research by observing beginner or advanced EFL learners would be useful as it may provide further support for the use of specific teaching strategies for developing EFL learners' ability to form English questions. 


\subsection{Summary}

A question is a tool for gaining information, and it requires a reply from the listener. Questioning on the other hand is a teaching and learning strategy which is important for gaining knowledge and skills effectively. Proficiency in forming and asking questions in English by Indonesian adult learners are important, but they cannot be achieved in a short time. Formal language learning in question formation is not enough to enable learners to form and questions correctly and appropriately. To achieve questioning skills, the learners need to listen, imitate, and use question in meaningful communication. Through risk taking, errors can be made in forming questions, so that learners will finally achieve the questioning skills. This study found that the acquisition of questions by Indonesian adult learners of English as a foreign language developed from single word questions to declarative word order questions, and fronting to the formation of correct yes-no questions, whquestions, and complex questions. 


\section{REFERENCES}

Abraham, R. G., \& Vann, R. J. (1988). Strategies of two language learners: A case study. In A. Wenden \& J. Rubin (Eds.), Learner strategy in language learning. Engglewood Cliffs, New Jersey: Prentice Hall, Inc.

Allen, D. E., \& Guy, R. F. (1978). Conversational analysis: The sociology of talk. Paris: Mouton \& Co.

Allen, J. P. B. (1980). The audio-lingual approach. In D. Byrne (Ed.), English teaching perspective. London: Longman.

Alwasilah, A. C. (1991). Cultural transfer in communication; A qualitative study of Indonesian students in US academic settings. (Unpublished Dissertation). Indiana University, Bloomington, Indiana USA.

Alwasilah, A. C. (1994). Gagal, bahasa Inggris di perguruan tinggi. Suara Karya, 10 March 1994, 5.

Andersen, E. S. (1990). Acquiring communicative competence: Knowledge of register variation. In R. C. Scarcella, E. S. Andersen, \& S. D. Krashen (Eds.), Developing communicative competence in a second language. (pp. 5-25). Boston: Heinle \& Heinle Publishers.

Arikunto, S. (1990). Manajemen penelitian. Jakarta: Rineka Cipta.

Asher, J. (1969). The total physical response approach to second language learning. Modern Language Journal, 53, 3-17.

Asher, J. W. (1976). Educational research and evaluation methods. Boston: Little, Brown and Company.

Biggs, J. B., \& Collis, K. F. (1982). Evaluating the quality of learning; The SOLO taxonomy (Structure of the Observed Learning Outcome). New York: Academic Press.

Bloom, B. S., \& Krathwohl, D. R. (1956). The taxonomy of educational objectives: The classification of educational goals. New York: D. McKay. 
Borg, W. R., \& Gall, M. D. (1983). Educational research: An introduction. New York: Longman Inc.

Brown, H. D. (1994). Principles of language learning and teaching. (3rd ed.). Englewood Cliffs, New Jersey: Prentice Hall, Inc.

Burns, P. C. \& Broman, B. L. (1983). The language arts in childhood education. Boston: Houghton Mifflin Company.

Burns, R. B. (1994), Introduction to research methods (2nd ed.), Melbourne: Longman.

Burns, R. (1995). The adult learner at work. Sydney: Business \& Professional Publishing.

Carlsen, W. S. (1991). Questioning in classrooms: A sociolinguistic perspective. Review of Educational Research, 61, 2, 157-178

Carrol, S., \& Swain, M. (1993). Explicit and implicit negative feedback: An emphirical study of the learning of linguistic generalisations. Studies in second Language Acquisitions, 15, 357-386.

Carrol, S., Swain, M., \& Roberge, Y. (1992). The role of feedback in adult second language acquisition: Error correction and morphological generalisations. Applied Psycholinguistics, 13, 173-198.

Cathcart, R \& Olsen, J. (1976). Teachers' and students' preferences for correction of classroom errors. In J. Fanselow \& R. Crymes (Eds.), On TESOL '76. Washington D.C.: TESOL

Chaudron, C. (1988). Second Language Classroom: Research on Teaching and Learning. New York: Longman.

Cazden, C. B. (1987). Relationship between talking and learning in classroom interaction. In B. K. Das (Ed.), Patterns of classroom interaction in Southeast Asia. Singapore: RELC SEAMEO.

Chomsky, N. (1965). Aspect of the theory of syntax. Cambridge, Mass.: MIT Press.

Clahsen, M. \& Pienemann, M. (1983). Deutsch als zweitsprache: Der spracherwerb auslandischer arbeiter. Tubingen: Narr. 
Cohen, L. \& Manion, L. (1994). Research methods in education (4th ed.). London: Routledge.

Collis, K. F. \& Biggs, J. B. (1978) Cognitive aspects in second language learning. In T. Le \& M. McCausland (Eds.), Working Papers in Language and Linguistics.. 7, 44-70.

Cook, V. (1991). Second language learning and language teaching. London: Edward Arnold.

Corder, S. P. (1973). Introducing applied linguistics. Harmondsworth, Middlesex: Penguin.

Corder, S. P. (1981). Error analysis and interlanguage. Oxford: Oxford University Press.

Crystal, D. (1991). A dictionary of linguistics and phonetics. Oxford: Basil Blackwell.

Day, E. M. \& Shapson, S. M. (1991). Integrating formal and functional approaches to language teaching in French immersion: An experimental study. Language Learning, 41, 1, 25-58.

Depdikbud. (1981). Teknologi instruksional. Jakarta: Dirjen Dikti.

Doughty, C., \& Pica, T. (1986). "Information gap" tasks: Do they facilitate second language acquisition?. TESOL Quarterly, 20, 2, 305-25

Dulay, H., Burt, M., \& Krashen, S. (1982). Language Two. Oxford: Oxford University Press.

Eckman, F. R., Moravcsik, E. A., \& Wirth, J. R. (1989). Implicational universals and interrogative structures in the interlanguage of ESL learners. Language Learning, 39 (2), 173-205.

Eggen, D. P. (1979). Strategies for teachers information processing models in the classroom. Englewood Cliffs, New Jersey: Prentice Hall.

Ellis, R. (1984). Classroom second language development. Oxford: Pergamon Press. 
Ellis, R. (1985). Understanding second language acquisition. Oxford: Oxford University Press.

Ellis, R. (1994). The study of second language acquisition. Oxford: Oxford University Press.

Faerch, C. \& Kasper, G. (1984). Strategies in interlanguage communication. New York: Longman.

Fotos, S. \& Ellis, R. (1991). Communicating about grammar: A task-based approach. TESOL Quarterly, 25, 4, 605-628.

Fromkin, V. (1984). An introduction to language. Sydney: Holt, Rinehart and Winston.

Garcia, G. E. (1994). Etnography and classroom communication: Teaching an 'emic' perspective. In K.G. Butler (Ed.),Cross-cultural perspectives in language assessment and intervention (pp. 28-53) Gaithersburg, Maryland: Aspen Publishers, Inc.

Gass, S. M. \& Madden, S. G. (1985). Input in second language acquisition. Boston, Massachusetts: Heinle \& Heinle Publishers.

Gass, S. M. \& Selinker, L. (1994). Second language acquisition: An introductory course. New Jersey: Lawrence Erlbaum Associates.

Gay, L. R. (1992). Educational research: Competencies for analysis and application. New York: Macmillan Publishing Company.

Gerlach, S. V. \& Ely, P. D. (1980). Teaching and media: A systematic approach. Englewood Cliffs, New Jersey: Prentice Hall.

Ghadessy, M. (1989). Selection of developmental errors by students with different L1 backgrounds. IRAL, 27 (1), 53-63.

Givon, T. (1979). From discourse to syntax: Grammar as a processing strategy. In T. Givon (Ed.), Syntax and semantics Vol. 12, New York: Academic Press.

Grow-Maienza, J. (1991). Question/response patterns in Indonesian classrooms. Paper presented at the annual meeting of the American Educational Research Association (Chicago, IL, 6 April 1991). 
Hammerly, H. (1987). The immersion approach: Litmus test of second language acquisition through classroom communication. Modern Language Journal, 71, 395-401.

Harmer, J. (1987). Teaching and learning grammar. London: Longman.

Hartman, R. R. K., \& Stork, F. C. (1973). Dictionary of language and linguistics. London: Applied Science Publishers, Ltd.

Hasan, R. (1991). Questions as a mode of learning in everyday talk. In T. Le \& M. McCausland (Eds.) Language education: Interaction \& development. (pp. 70-119). Proceeding of the International Conference in Vietnam. Launceston: University of Tasmania at Launceston.

Holley, F., \& King, J. (1971). Imitation and correction in foreign language learning. Modern language Journal, 55, 494-498.

Hopkins, D. (1993). A teacher's guide to classroom research (2nd ed.). Philadelphia: Open University Press.

Huddleston, R. (1988). English grammar: An outline. Cambridge: Cambridge University Press.

Hymes, D. (1972). On communicative competence. In J. B. Pride \& J. Holmes (Eds.), Sociolinguistics (pp. 269-293). Harmondsworth, Middx.: Penguin.

Joni, T. R. (1980). Strategi belajar mengajar. Malang: IKIP Malang

Kearsley, G. P. (1976). Questions and question-asking in verbal discourse: A cross-disciplinary review. Journal of Psycholinguistic Research, 5 (4), 355-375.

Krashen, S. D. (1981). Second language acquisition and second language learning. Oxford: Pergamon.

Krashen, S. D. (1982). Principles and practices in second language acquisition. Oxford: Pergamon Press.

Krashen, S. D. (1985). The input hypothesis: issues and implication. New York: Longman. 
Kwee, J. B. (1992). Indonesian: A complete course for beginner. London: Hodler \& Stoughton.

Larsen-Freeman, D. (1978). Evidence of the need fo a second language acquisition index of development. In W. Ritchie (Ed.), Second language acquisition research (pp. 127-136). New York: Academic Press.

Larsen-Freeman, D., \& Long, M. H. (1991). An introduction to second language acquisition research. London: Longman.

Laufer, B., \& Eliasson, S. (1993): What causes avoidance in L2 learning: L1-L2 difference, L1-L2 similarity, or L2 complexity?. Studies in second Language Acquisition, 15, 35-48.

Le, T., \& McCausland, M. (1986). The child as a communicative strategist. Australian Review of Applied Linguistics, 8, 1, 43-61.

Lightbown, P. M., \& Spada, N. (1990). Focus on form and corrective feedback in communicative language teaching: Effect on second language learning. Studies in Second Language Acquisitions, 12, 429-448.

Littlewood, W. (1981). Communicative language teaching: Introduction. Cambridge: Cambridge University Press.

Littlewood, W. (1984). Foreign and second language learning. Cambridge: Cambridge University Press.

Long, M. H. (1990a). Group work and communicative competence in the ESOL classroom. In R. C. Scarcella, E. S. Andersen, \& S. D. Krashen (Eds.), Developing Communicative Competence in a Second Language (pp. 303-315). Boston: Heinle \& Heinle Publishers.

Long, M. H. (1990b). The least a second language acquisition theory needs to explain. TESOL Quarterly, 24, 4, 649-666.

Long, M., Adams, L., Mclean, M., \& Castanos, F. (1976). Doing things with words: Verbal interaction in lockstep and small group classroom situations. In J. Fanselow \& R. Crymes (Eds.), On TESOL '76 (137-163). Washington D.C.: TESOL. 
Long, M. H. \& Sato, C. J. (1983). Classroom foreigner talk discourse: Forms and functions of teachers' questions. In $\mathrm{H}$. W. Seliger \& M. H. Long (Eds.), Classroom oriented research in second language acquisition. (pp. 268-285). Rowley. Massachusetts: Newbury House Publishers, Inc.

Lynch, T. (1991). Questioning roles in the classroom. ELT Journal, 45 (3), 201210.

Lynch, T. (1996). Communication in the language classroom. Oxford: Oxford University Press.

Mackey, A. (1994a). Targeting morpho-syntax in children's ESL: An empirical study of the use of interactive goal-based tasks. WPEL, 10, 1, 67-87.

Mackey, A. (1994b). Using communicative tasks to target grammatical structures. Sydney: The University of Sydney Language Acquisition Research Centre.

McLaughin, B. (1990). Concious versus unconcious. TESOL Quarterly, 24, 4, 617-634.

Meisel, J. M., Clahsen, H., \& Pienemann, M. (1981). On determining developmental stages in natural second language acquisition. Studies in Second Language Acquisition, 3, 2, 109-135.

Moeliono, A. M. (Ed.) (1988). Tata bahasa baku bahasa Indonesia. Jakarta: Perum Balai Pustaka.

Morgan, N. \& Saxton, J. (1991). Teaching, questioning and learning. London: Routledge

Newmark, L. (1971). A minimal language teaching program. In P. Pimsleur \& T. Quinn (Eds.), The psychology of second language learning. Cambridge: Cambridge University Press.

Nio, B. K. H. (1993). Pengajaran bahasa Inggris di SD; Permasalahan dan saran. Padang: FPBS IKIP Padang.

Nunan, D. (1989a). Designing tasks for the communicative classroom. Cambridge: Cambridge University Press. 
Nunan, D. (1989b). Understanding language classroom. New York: Prentice Hall.

Nunan, D. (1992). Research methods in language learning. Cambridge: Cambridge University Press.

Oxford, R., \& Croocall, D. (1988). Learning strategies. New Jersey: Prentice Hall.

Pica, T. (1983). Adult acquisition of English as a second language under different condition of expose. Language Learning, 33, 4, 465-97.

Pica, T (1994). Questions from the language classroom: Research perspective. TESOL Quarterly, 28 (1), 49-80.

Pica, T. \& Doughty, C. (1985). Input and interaction in the communicative language classroom: A comparison of teacher fronted and group activities. In, S. M. Gass \& C. Madden (Eds.), Input in Second Language Acquisition (pp. 115-132). Cambridge: Cambridge University Press,

Pienemann, M., \& Johnston, M. (1987). Factors influencing the development of language proficiency'. In D. Nunan (Ed.), Applying Second Language Acquisition Research (pp. 45-141). Adelaide: National Curriculum Resource Centre.

Pienemann, M., Johnston, M., \& Brindley, G. (1988). Constructing an acquisition-based procedure for second language assessment. Studies in Second Language Acquisition, 10, 217-243.

Quirk, R., \& Greenbaum, S. (1973). A university grammar of English. London: Longman.

Quirk, R., Greenbaum. S., Leech, G., and Startvik, J. (1985) A comprehensive grammar of the English language. London: Longman.

Ramirez, R. A. \& Stromquist, N. (1978). ESL methodology and students' language learning. TESOL Quarterly, 13, 2, 145-158.

Richard, J. C. (1974). Error analysis: Perspectives on second language acquisition. London: Longman. 
Richard, J. C., Platt, J., \& Weber, H. (1985). Longman dictionary of applied linguistics. London: Longman.

Ringbom, H. (1987). The role of first language in foreign language learning. Clevedon: Multilingual Matters Ltd.

Rivers, W. M. (1987). Interactive language teaching. Cambridge: Cambridge University Press.

Savignon, S. J. (1982). Communicative competence: Theory and classroom practice; Text and context in second language learning. Menlo Park, California: Addison-Wesley Publishing Company.

Scarcella, R. C., Andersen, E. S., \& Krashen, S. D. (1990). Developing communicative competence in a second language. Boston, Massachusetts: Heinle \& Heinle Publishers.

Schachter, J. (1983). Nutritional needs of language learners. In M. Clarke \& J. Handscombe (Eds.), On TESOL '82: Pacific Perspectives on Language Learning and Teaching (pp. 175-189). Washington D.C.: TESOL (17589).

Schuman, J. (1975). Affective factors and the problem of age in second language acquisition, Language Learning, 25, 209-235.

Schwartz, B. D. (1986). The epistemological status of second language acquisition. Second Language Research, 2, 120-159.

Schwartz, B. D. (1993). On explicit and negative data effecting and affecting competence and linguistic behaviour. Studies in Second language Acquisition, 15, 2, 147-165

Seliger, H. W. (1983). Learner Interaction in the classroom and its effect on language acquisition. In H.W. Seliger \& M.H. Long (Eds.), Classroom oriented research in second language acquisition (pp. 246-266). Rowley, Massachusetts: Newbury House Publishers, Inc.

Selinker, L. (1972). Interlanguage. International Review of Applied Linguistics in Language Teaching (IRAL), 10, 209-231. 
Shaw, P. A., \& Bailey, K. M. (1990). Cultural Differences in Academic Settings. In R.C. Scarcella, E.S. Andersen \& S.D. Krashen (Eds.), Developing communicative competence in a second language. (pp. 317-328). Boston, Massachusetts: Heinle \& Heinle Publishers.

Silverman, D. (1993). Interpreting qualitative data: Methods for analysing talk, text, and interaction. London: Sage Publications.

Sneddon, J. N. (1996). Indonesian reference grammar. St. Leonards, NSW: Allen \& Unwin.

Spada, N. (1986). The interaction between type of contact and type of instruction: Some effects on the L2 proficiency of adult learners. Studies in second language Acquisitions, 8, 181-200.

Spada, N. (1987). Relationship between instructional differences and learning outcomes: A process-product study of communicative language teaching. Applied Linguistics, 8, 12, 137-161.

Spada, N., \& Lightbown, P. M. (1993). Instruction and the development of questions in L2 classroom. Studies in Second language Acquisition, 15:205-224.

Stevens, F. (1984). Strategies for second-language acquisition. Montreal: Eden Press.

Tardif, R. (1989). The Penguin Macquire Dictionary of Australian Education. Victoria: Penguin Book.

Terrel, T. (1977). A natural approach to second language acquisition and learning. Modern Language Journal, LXI, 325-337.

Tomlinson, B. (1990). Managing change in indonesian high schools. ELT Journal, 44 (1), 25-37.

Towell, R. \& Hawkins, R. (1994). Approaches to second language acquisition. Clevedon: Multilingual Matters, Ltd.

Tyack, D. L. (1983). A child's acquisition of questions. In T. Le \& $M$. McCausland (Eds.), Working Papers in Language \& Linguistics. 16, December 1983, 26-40. 
Wagner-Gough, J. (1975). Comparative studies in second language learning. (Unpublished MA thesis), California: UCLA.

White, L. (1990). Implications of learnability theories for second language learning and teaching'. In M.A.K. Halliday, J. Gibbon, \& H. Nicholas (Eds.). Learning, keeping, and using language (pp. 271-286). Amsterdam: John Benjamins.

Wilkin, D. (1978). Notional syllabuses. Oxford: Oxford University Press.

Willing, K. (1988). Learning styles in adult migrant education. Adelaide: National Curriculum Resource Centre.

Yang, Y. (1988). An investigation of the relationship among learning styles, teaching methodology, learning strategies, and proficiency in second languages. (Unpublished Thesis). The University of Queensland.

Zaim, M. (1996). Second language acquisition in light of the basic SOLO model. Forum Pendidikan, 1, 21, 66-77.

Zobl, H. (1995). Converging evidence for the 'acquisition-learning' distinction. Applied Linguistics, 16 (1), 35-56 
APPENDICES 


\section{Appendix A:}

\section{Learners' Questionnaire (Kuesioner untuk Pembelajar Bahasa)}

The following are some questions about your English learning. There are no right or wrong answers. Please answer each of these questions as objectively as you can. Your answers will be treated strictly confidential. Thank you for your cooperation.

(Berikut ini akan diberikan beberapa pertanyaan tentang proses belajar bahasa Inggris yang saudara alami. Tidak ada jawaban yang benar atau salah, oleh karena itu jawablah masing-masing pertanyaan sesuai dengan kenyataan yang saudara alami. Jawaban saudara dijaga kerahasiaanya. Pencantuman data diri saudara hanyalah untuk keperluan pengolahan data penelitian ini saja. Terima kasih atas kerjasama saudara.)

\section{Section A : Biographical Data (Data Pribadi)}

1. Sex (Jenis Kelamin)

: Male(Laki-Laki)/ Female(Perempuan)

2. Age (Umur) years (tahun)

3. Mother tongue (Bahasa pertama) : a. Minangkabau (Bahasa Minang)

b. Javanese (Bahasa Jawa)

c. Bataknese (Bahasa Batak)

d.

4. Occupation (Pekerjaan)

: a. Lecturer (Dosen)

b. Official (Pegawai)

c. University Student (Mahasiswa)

d.

5. Total number of years learning English : years (tahun)

(Lama belajar bahasa Inggris) 


\section{Section B :}

Please indicate how well each statement describes your classroom learning by circling against (Nyatakan sejauh mana pernyataan-pernyataan di bawah ini sesuai dengan keadaan belajar saudara di kelas bahasa Inggris dengan melingkari):

Always if you always do or experience the activity

(Jika saudara selalu melakukan atau mengalami kegiatan tersebut)

Often if you often do or experience the activity

(Jika saudara sering melakukan atau mengalami kegiatan tersebut)

Sometimes if you sometimes do or experience the activity

(Jika saudara kadang-kadang melakukan atau mengalami kegiatan tersebut)

Rarely if you rarely do or experience the activity

(Jika saudara jarang melakukan atau mengalami kegiatan tersebut)

Never if you never do or experience the activity

(Jika saudara tidak pernah melakukan atau mengalami kegiatan tersebut)

\section{Classroom Learning Environment (Lingkungan Belajar di Kelas)}

1. The teachers treat me as an adult in English classes. (Guru memperlakukan saya sebagai orang dewasa di dalam kelas bahasa Inggris).

Always Often Sometimes Rarely Never

2. I feel free to speak English in English class. (Saya merasa bebas untuk berbicara bahasa Inggris di kelas bahasa Inggris saya).

Always Often Sometimes Rarely Never

3. The classroom environment enables me to practise my English in English classes.

(Lingkungan kelas bahasa Inggris memungkinkan saya untuk melatih bahasa Inggris)

Always Often Sometimes Rarely Never

4. The teachers are able to adjust their teaching strategies to suit my levels of English proficiency. (Guru dapat menyesuaikan strategi mengajarnya dengan tingkat kemampuan bahasa Inggris saya)

Always Often Sometimes Rarely Never

5. The teaching methods adopted by my teachers helps greatly in enhancing my level of English proficiency. (Metoda mengajar yang digunakan guru sangat menolong dalam meningkatkan kemampuan bahasa Inggris saya)

Always Often Sometimes Rarely Never 
6. The teachers spend most of the time in English classes explaining grammatical rules.

(Guru menggunakan banyak waktunya di kelas untuk menerangkan tatabahasa bahasa Inggris).

$$
\text { Always Often Sometimes Rarely Never }
$$

7. The teachers always use English in the classroom. (Guru selalu menggunakan bahasa Inggris di dalam kelas)

$$
\text { Always Often Sometimes Rarely Never }
$$

8. English is always used to explain grammatical rules. (Bahasa Inggris selalu digunakan untuk menerangkan aturan tatabahasa bahasa Inggris).

Always Often Sometimes Rarely Never

9.The classroom activity forces me to practice my English in the classroom. (Kegiatankegiatan dalam kelas bahasa Inggris mengharuskan saya untuk mempraktekkan Bahasa Inggris di dalam kelas).

Always Often Sometimes Rarely Never

10. I have a lot of activities in the classroom to practice my English. (Saya melakukan banyak kegiatan di dalam kelas untuk mempraktekkan bahasa Inggris saya.)

Always Often Sometimes Rarely Never

\section{Classroom Interaction}

11. I often ask questions in the English class. (Saya sering bertanya di dalam kelas bahasa Inggris)

Always Often Sometimes Rarely Never

12. I always ask questions in English. (Saya selalu bertanya dalam bahasa Inggris)
Always
Often
Sometimes
Rarely Never

13. I ask questions if I don't understand certain topics. (Saya suka bertanya kalau saya tidak memahami suatu topik)

Always Often Sometimes Rarely Never

14. I ask questions just to practise my English. (Saya bertanya hanya untuk mempraktekkan bahasa Inggris).
Always
Often
Sometimes
Rarely
Never

15. I generally ask the teacher to repeat a phrase that $\mathrm{I}$ don't understand. (Pada umumnya saya bertanya pada guru untuk mengulang ujaran yang tidak saya pahami)
Always
Often
Sometimes
Rarely
Never

16. If I don't know how to express an idea, I will ask for somebody in English. (Kalau saya ingin tahu tentang sesuatu, saya menanyakannya dengan menggunakan bahasa Inggris).

Always Often Sometimes Rarely Never 
17. Teachers always correct my mistakes in English grammar. (Guru selalu mengoreksi kesalahan saya dalam penggunaan tatabahasa bahasa Inggris)

Always Often Sometimes Rarely Never

18. Teachers always correct my mistakes in English pronunciation. (Guru selalu mengoreksi kesalahan ucapan (pronunciation) dalam bahasa Inggris)
Always
Often
Sometimes
Rarely Never

19. Teachers always correct my mistakes in English vocabulary. (Guru selalu mengoreksi kesalahan saya dalam penggunaan kosa-kata bahasa Inggris)
Always
Often
Sometimes
Rarely Never

20. Teachers always answer the questions asked by students. (Guru selalu menjawab pertanyaan-pertanyaan yang diajukan mahasiswa/peserta.)
Always
Often
Sometimes
Rarely Never

21. I like the teachers to correct my mistakes in grammar. (Saya sangat senang kalau guru memperbaiki kesalahan tatabahasa yang saya buat)

Always Often Sometimes Rarely Never

22. I like the teachers to correct my pronunciation. (Saya senang guru memperbaiki ucapan (pronunciation) saya).

Always Often Sometimes Rarely Never

23. I like the teachers to correct my vocabulary. (Saya senang guru mengoreksi kesalahan pemilihan kosa kata saya).

Always Often Sometimes Rarely Never


Appendix B:

\section{Teachers' Questionnaire}

The following are some questions about your English teaching. There is no right or wrong answers. Please answer each of these questions as objectively as you can. Your answers will be treated strictly confidential. Thank you for your cooperation.

\section{Section A : Biographical Data}

1. Sex

2. Subject taught

3. Class taught
: $\mathrm{M} / \mathrm{F}$

:

:

\section{Section B :}

Please indicate how well each statement describes your classroom learning by circling against:
Always if you always do or experience the activity
Often if you often do or experience the activity
Sometimes if you sometimes do or experience the activity
rarely if you rarely do or experience the activity
Never if you never do or experience the activity

\section{Classroom Teaching Environment}

1. I try to make situation that the students feel free to speak in the classroom.

Always Often Sometimes Rarely Never

2. I treat my students as adult learners in my English classes.
Always
Often
Sometimes
Rarely Never

3. I spend most of my time explaining and practising grammatical rules of English with the students.

$$
\text { Always Often Sometimes Rarely Never }
$$

4. I use a grammar-translation method as my main teaching strategy.

$$
\text { Always Often Sometimes Rarely Never }
$$

5. I use an audio-lingual method as my main teaching strategy.

Always Often Sometimes Rarely Never


6. I use a communicative method as my main teaching strategy.

Always Often Sometimes Rarely Never

7. I use English in English classroom interactions.

Always Often Sometimes Rarely Never

8. I force my students to use English in the English classroom.

Always Often Sometimes Rarely Never

9. I create some activities in the classroom to enable students to practice English.

Always Often Sometimes Rarely Never

10.The activities in the classroom forced my students to speak in English.

Always Often Sometimes Rarely Never

\section{Classroom Interaction}

11. My students rarely ask me questions during the learning process.

Always Often Sometimes Rarely Never

12. My students ask me questions if they do not understand certain topics.

Always Often Sometimes Rarely Never

13. My students ask me questions if I ask them to.

Always Often Sometimes Rarely Never

14. Students always use English to communicate with other students in the English classes.

Always Often Sometimes Rarely Never

15. Students spontaneously ask me questions if they get problems in the learning process in the English classroom.

Always Often Sometimes Rarely Never

16. Most of the students in my English class ask me questions in English.

Always Often Sometimes Rarely Never

17. I always correct students' mistakes in grammar.

Always Often Sometimes Rarely Never

18. I always correct students' mistakes in the vocabulary used

Always Often Sometimes Rarely Never

19. I always correct students' mistakes in pronunciation

Always Often Sometimes Rarely Never

20. I answer all questions asked by the students.

Always Often Sometimes Rarely Never 


\section{Appendix C:}

\section{English Test 1}

Time : 30 minutes

Name :

A. Write a suitable question based on the answer given!

\section{Example : Question:}

A: What

$\mathrm{B}$ : My name is Aminullah.

\section{Answer:}

A: What is your name?

B: My name is Aminullah.

1. A: Whose

$\mathrm{B}$ : This is my assignment.

2. A: What

B: I want a cup of coffee.

3. A: Which

B: I like this picture.

4. A: Who

B: Mary visited her father.

5. A: When

$\mathrm{B}$ : Aminullah was hungry at noon.

6. A: Where

B: He waited in the museum.

7. A:

B: They watched television at nine o'clock. 
8. A:

B: John studies in the library.

9. A:

B: Mary has a large number of books.

10. A:

B: I have told him several times.

11. A:

B: Yes, they have a lot of friends.

12.A:

$\mathrm{B}$ : No, he is not going to Jakarta.

13. A:

B: No, not all of the books are here.

14. A:

B: Yes, she studies here every Tuesday.

15. A:

B: Yes, Paul arrived last week. 
B. Based on the picture below, write WH QUESTIONS and YES/NO QUESTIONS. For Wh Questions, use the following question words: What, Who, Where, When, Why, How, and How many.

Example : 1. Who is the man wearing the red suit? (Wh Question)

2. Is he a teacher? (Yes/No Question)

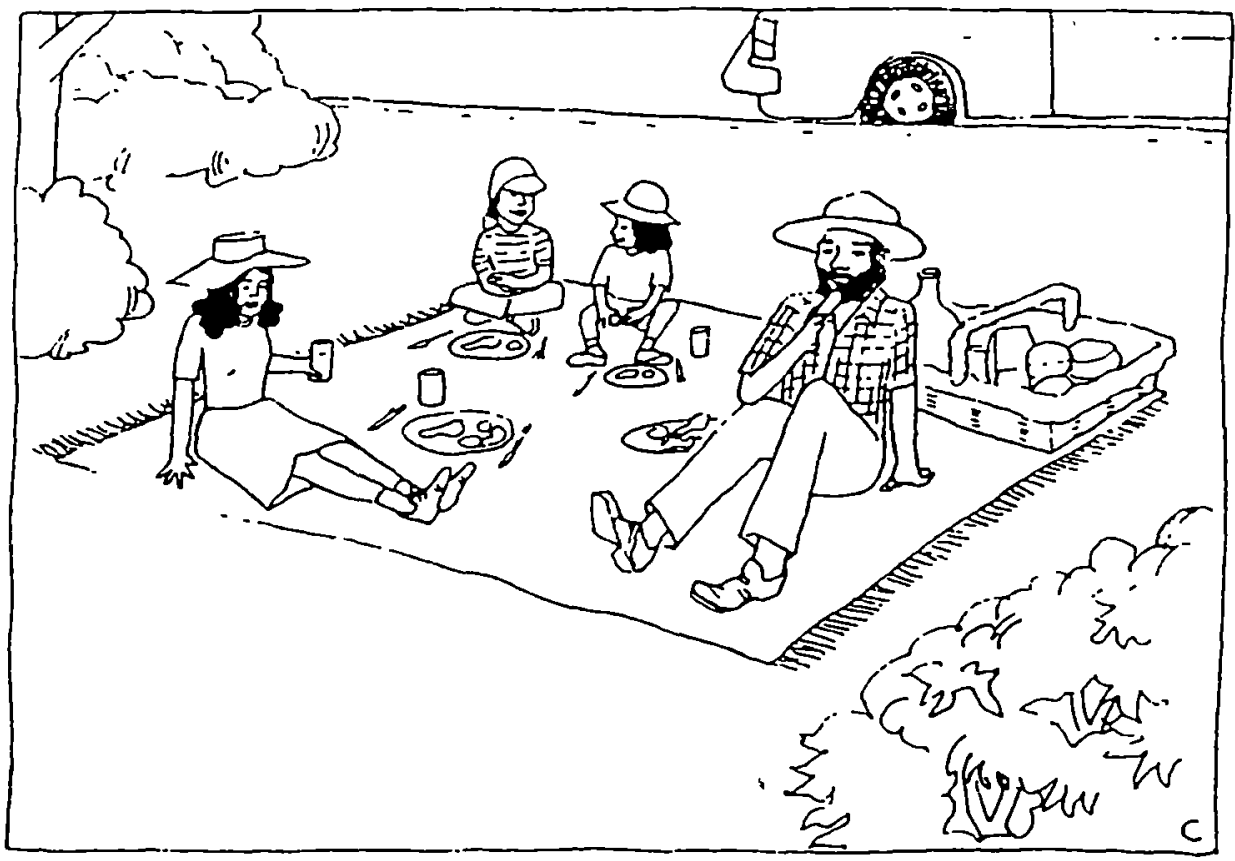

\section{Wh Questions:}

1.

2 .

3.

4.

5.

\section{Yes/No Questions:}

1.

2.

3.

4.

5 . 
Appendix D:

English Test 2

Time : 30 minutes

Name :

A. Complete the following conversation by inserting suitable questions in the blank.

Example : Question:

A:

B: I'm fine. Thank you..

Answer:

A: How are you?

B: I'm fine. Thank you..

Finn :

Mann : Yes. I was in the City yesterday.

Finn :

Mann : No. I was alone.

Finn :

Mann : I had lunch in Chinese Restaurant.

Finn :

Mann : I met him in the Restaurat.

Finn :

Mann : At 12 o'clock.

Finn :

Mann : Yes, we went shopping.

Finn :

Mann : No, we didn't. We studied in the afternoon.

Finn :

Mann : We studied in the library yesterday.

Finn :

Mann : We discussed reading assignment.

Finn :

Mann : I left my house at 10 o'clock. 
B. Based on the picture below, write WH QUESTIONS and YES/NO QUESTIONS. For Wh Questions, use the following question words: What, Who, Where, When, Why, How, and How many.

Example: 1. What is the policeman doing? (Wh Question) 2. Are they friends? (Yes/No Question)

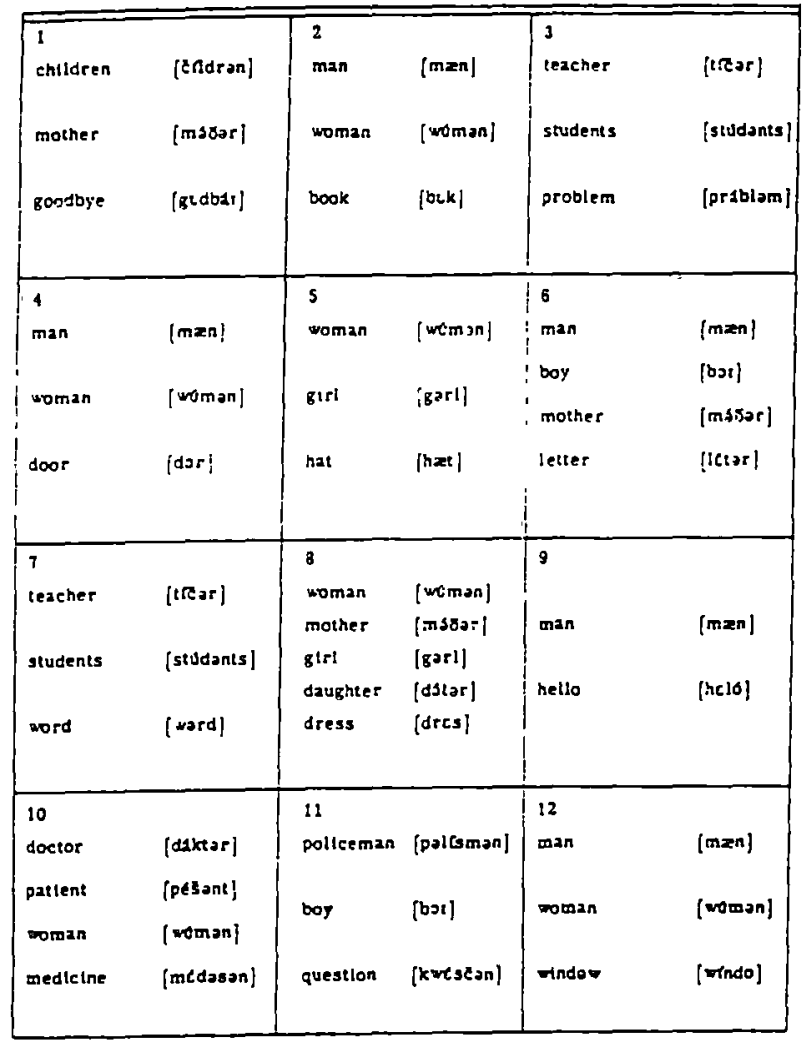

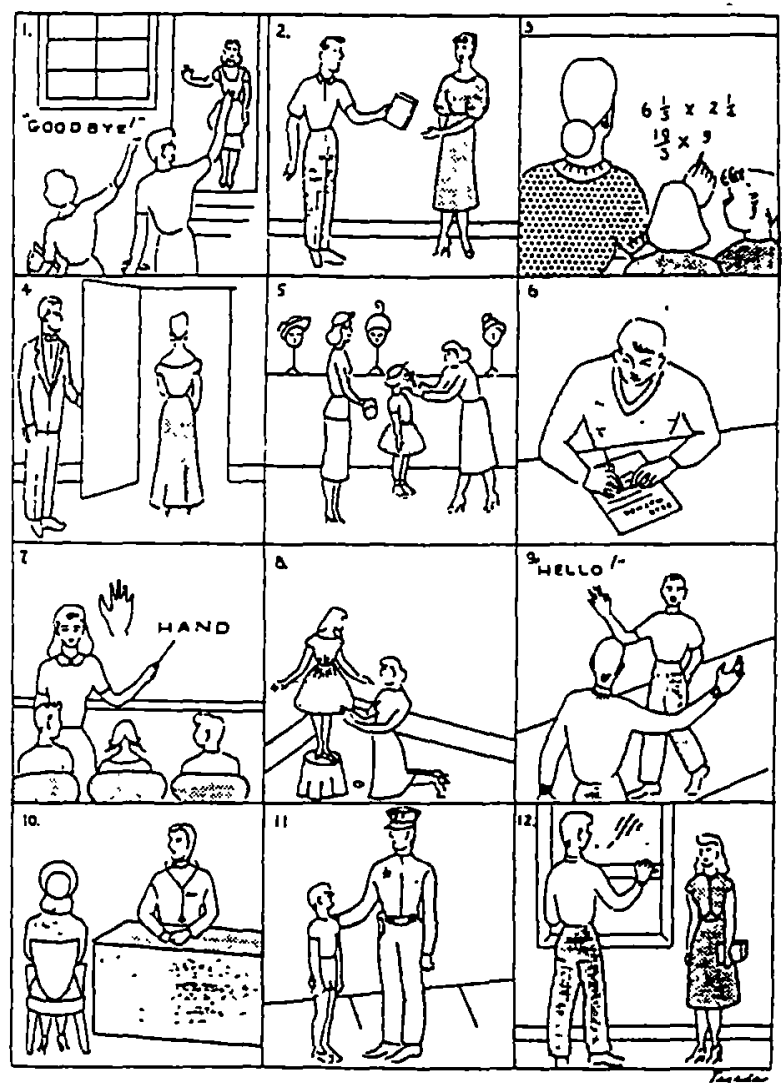

\section{Wh Questions:}

1.

2.

3.

4.

5.

\section{Yes/No Questions:}

1.

2.

3.

4.

5. 


\section{Appendix E:}

English Test 3

Time : 30 minutes

\section{Name :}

A. Write a suitable question based on the answer given!

\section{Example : Question:}

A: What

B: Her name is Zainab.

\section{Answer:}

A: What is her name?

B: Her name is Zainab.

1. A: Whose

$\mathrm{B}$ : That is my note book.

2. A: What

B: She wants a cup of tea.

3. A: Which

B: I like this shirt.

4. A: Who

B: Mary invited her friends.

5. A: When

B: Amarullah will be here at noon.

6. A: Where

B: He waited in the cafe.

7. A:

B: They studied Grammar at nine o'clock. 
8. A:

B: John works in the library.

9. A:

B: Mary has a lot of books.

10. A:

B: I have told him several times.

11. A:

B: Yes, they have a lot of friends.

12. A:

B: No, they are not going to Medan.

13. A:

B: No, not all of the students are here.

14. A:

B: Yes, she studies here every Tuesday.

15. A:

B: Yes, Paul arrived last week. 
B. Based on the picture below, write WH QUESTIONS and YES/NO QUESTIONS. For Wh Questions, use the following question words: What, Who, Where, When, Why, How, and How many.

Example : 1. Who is the man wearing the red suit? (Wh Question)

2. Is he a teacher? (Yes/No Question)

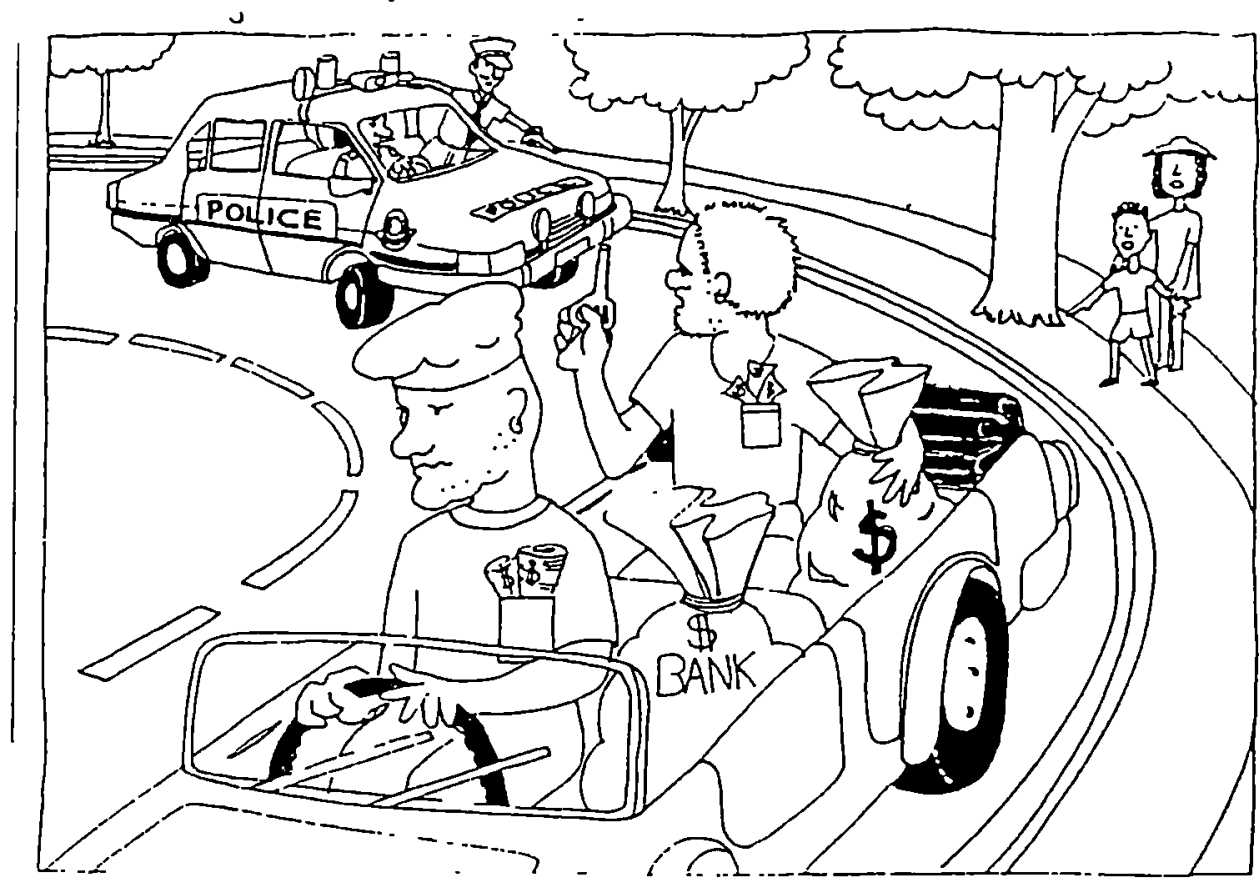

\section{Wh Questions:}

1.

2.

3.

4.

5.

\section{Yes/No Questions:}

1.

2.

3.

4.

5. 
Appendix F:

Oral Test 1

Time : 20 minutes

Name :

Level :

\section{Picture Differences}

We, both, have two pictures. They are not the same. Let's find the differences. We have to tell each other about our pictures. So, ask me questions to find out what the differences are.
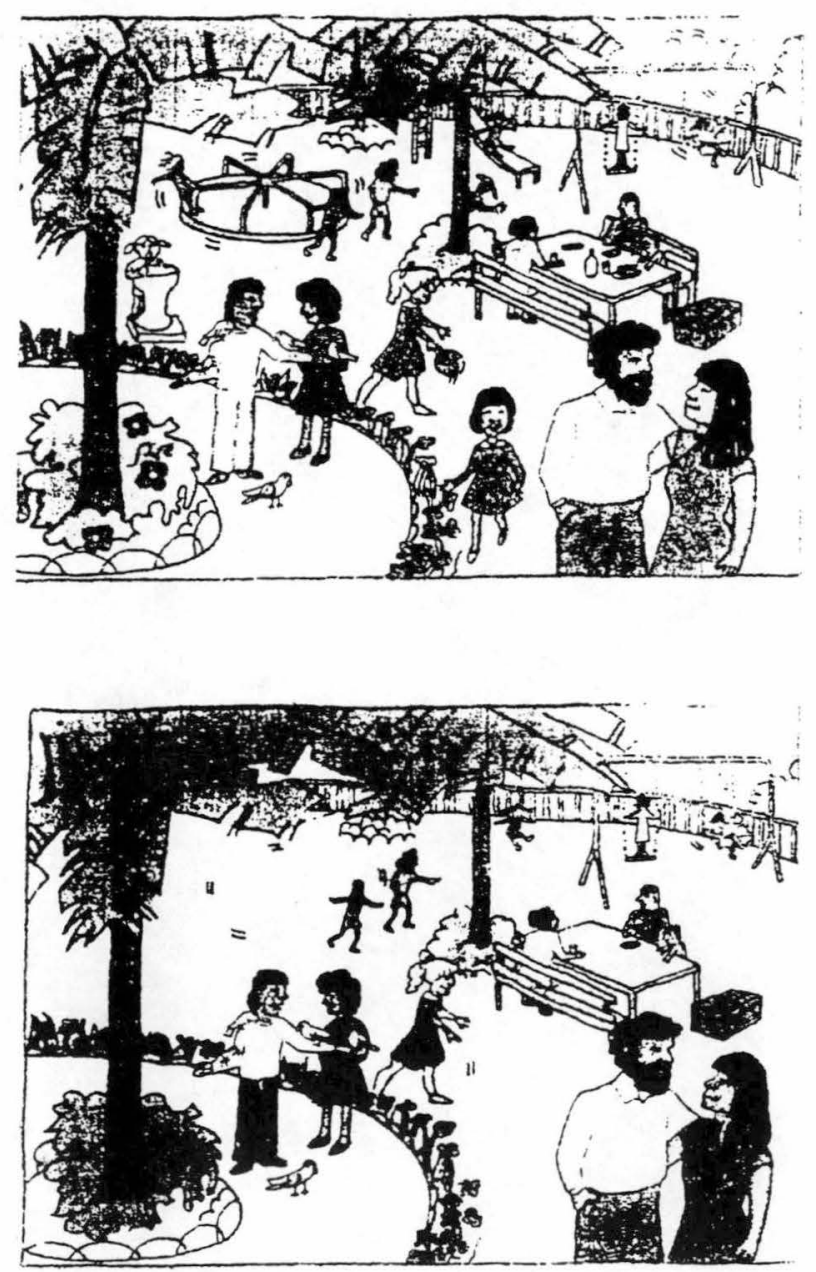


\section{Appendix G:}

Oral Test 2

Time : 20 minutes

Name:
Level :

\section{Picture Differences}

We, both, have two pictures. They are not the same. Let's find the differences. We have to tell each other about our pictures. So, ask me questions to find out what the differences are.
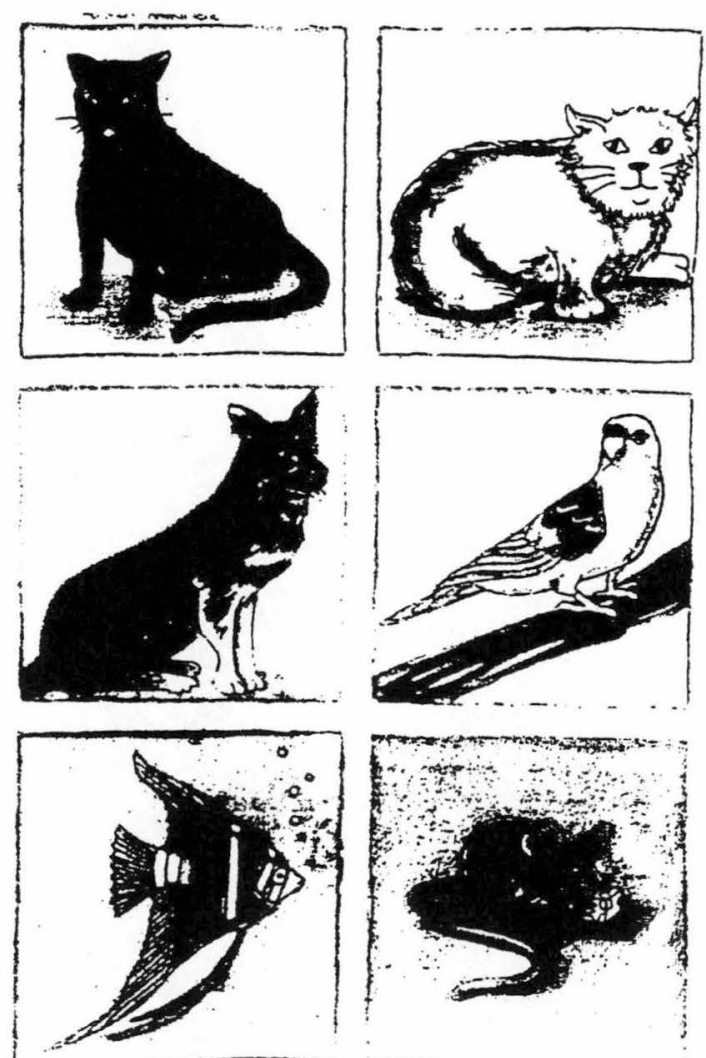
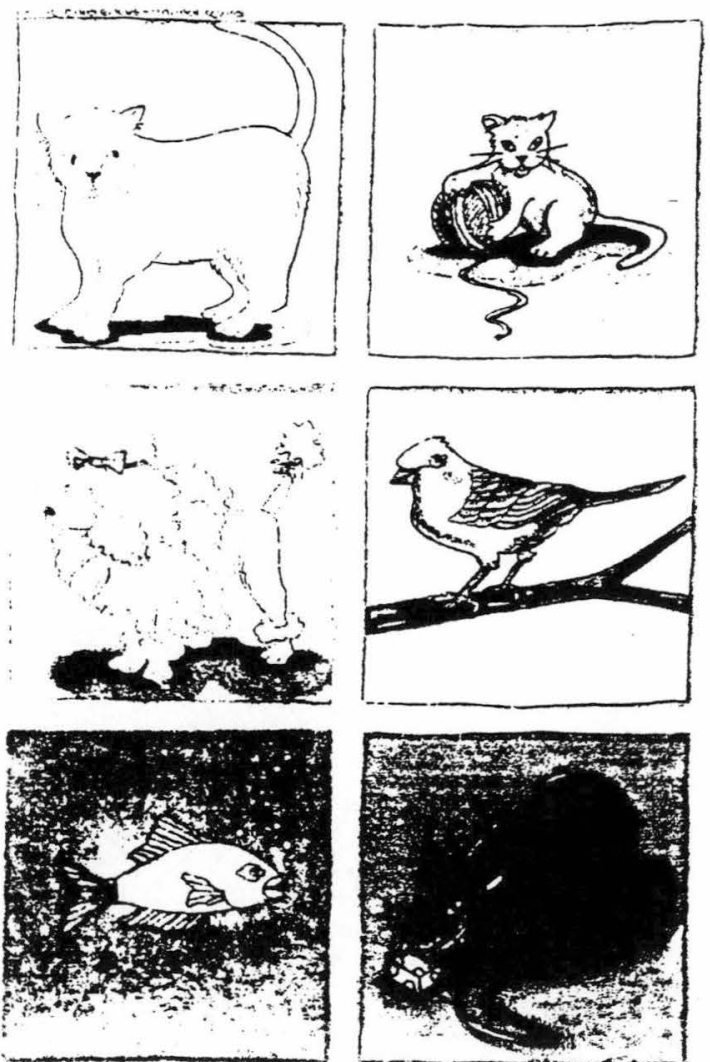
Appendix $\mathrm{H}$ :

Oral Test 3

Time : 20 minutes

Name :

\section{Picture Differences}

We, both, have two pictures. They are not the same. Let's find the differences. We have to tell each other about our pictures. So, ask me questions to find out what the differences are.
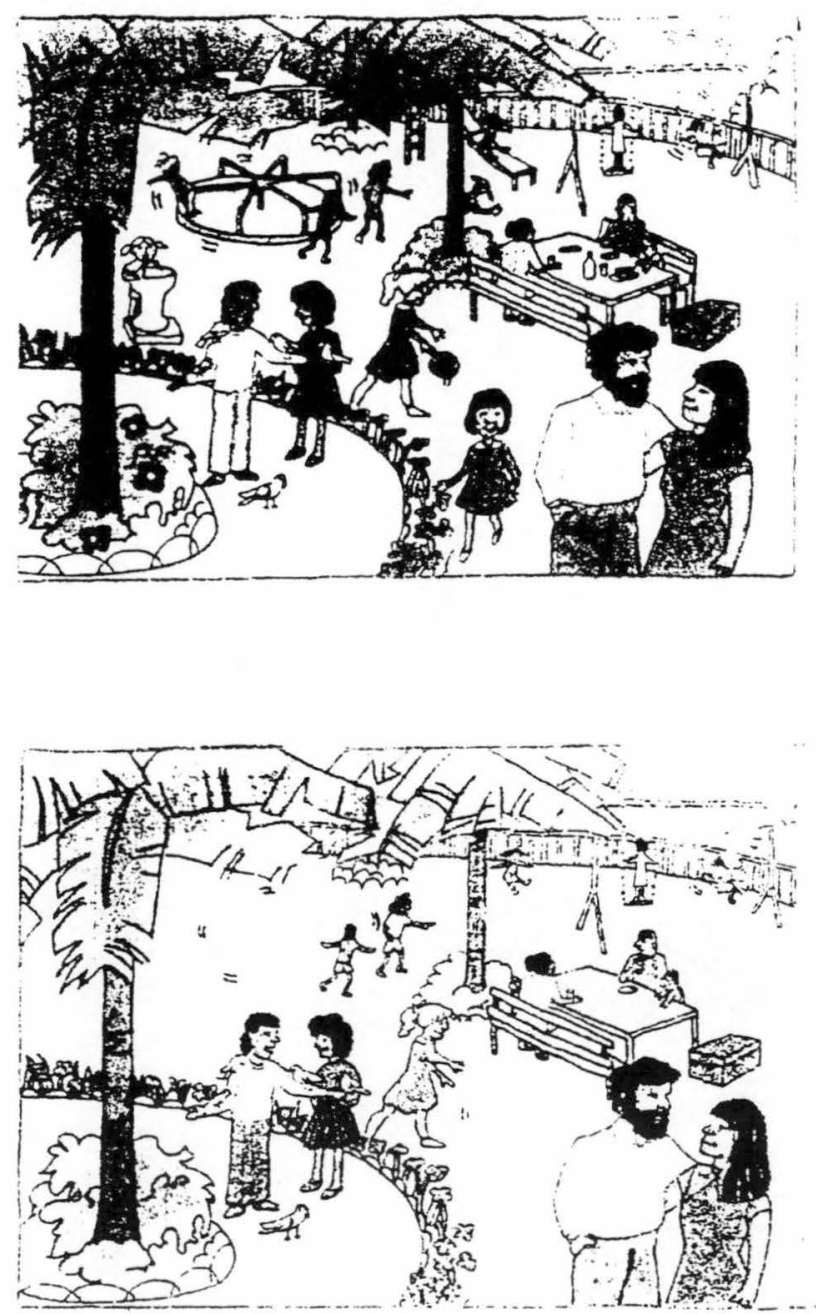


\section{Appendix I:}

\section{Guiding Questions for Interviewing Teachers}

Date of Interview

Place

\section{Demographic data}

Name

Sex

Subject taught

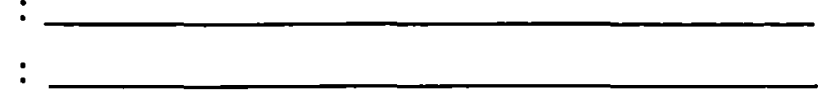

The following are some questions about your English teaching. There is no right or wrong answers. Please answer each of these questions as objectively as you can. Your answers will be treated strictly confidential. Thank you for your cooperation.

\section{Questions}

1. Are there any common problems faced by your students in asking questions?

2. How do you solve that problem?

3. Are there any common errors made by your students in asking questions?

4. Please rank the errors from the most serious to the least serious?

5 . How do you solve those problems?

6. How well do you understand the students' questions? Why?

7. How important is grammar teaching in EFL classes?

8. How do you treat your students if they make errors in spoken language?

9. Do you always correct each error made by your students?

10. Is there any main focus of your teaching, like grammar or communication?

11. How do you spend much of your time in teaching? Explaining grammatical rules or giving task to students to make language activities?

12. What initiative do you take to get students ask question in classroom interaction?

13. Is there any activity where students practice to ask questions in that activity?

14. Which activities are best suited to enable students to asking and to answer questions in the classroom?

15. Do you think that students have performed all their abilities in involving to the classroom activities?

16. How do you attempt to make them perform activity in class? 
Appendix J:

\section{Guiding Questions for Interviewing Students}

Date of Interview

Place

\section{Demographic data}

Name

Sex

Age

Mother tongue

Occupation

Highest degree obtained

Languages spoken

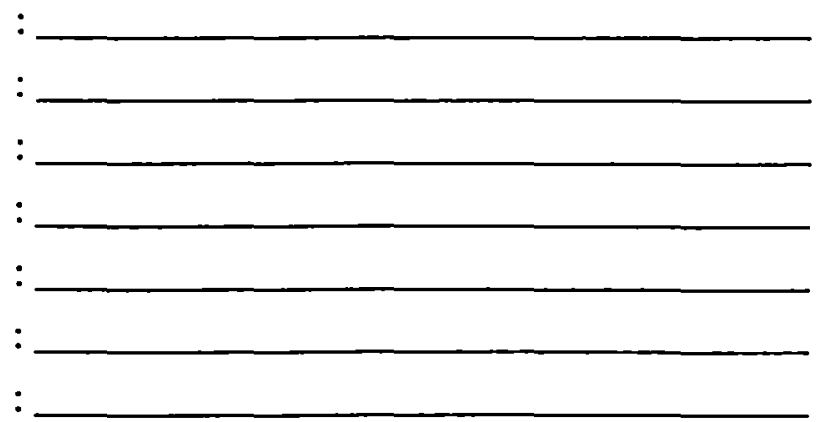

The following are some questions about your English tearning in 'Balai Bahasa IKIP Padang'. There is no right or wrong answers. Please answer each of these questions as objectively as you can. Your answers will be treated strictly confidential. Thank you for your cooperation.

\section{Questions}

1. How often do you ask questions in the classroom?

2. Are there any common problems you face in forming questions?

3. Why do you think you have those 'problems'?

4. Could you tell me how you solve these problems?

5. Do your grammar teachers explain about how to make questions in English?

6. Do your teachers correct each error you made?

7. Do your teachers correct your mistakes in pronunciation?

8. Do your teachers correct your mistakes in grammar?

9. Do your teachers correct your mistakes in vocabulary?

10. How do you feel about the teachers' correction?

11. Do you think grammar teaching is important to improve your English ability to communicate?

12. What do you think of the speaking class? Does it help you to increase your spoken language?

13. How do your teachers react to the questions you ask? 
14. What kinds of activities do you prefer in the classroom?

15. What activities are best suited to improve your ability in asking and answering questions correctly?

16. Do you have enough time to practise English in the classroom?

17. What do you think is the best thing your teachers can do to enable you practice English in the classroom?

18. Are you afraid of making mistakes in English?

19. What are your attempts to practice your English in the classroom?

20. What is the best thing you can do so far?

21 . What are your attempts to practice your English outside the classroom?

22. What is the best thing you can do so far? 